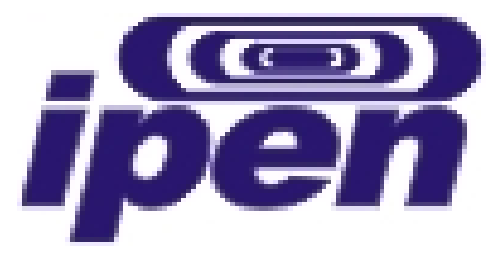

AUTARQUIA ASSOCIADA À UNIVERSIDADE DE SÃO PAULO

\title{
DEFINIÇÃO DO VOLUME DE PLANEJAMENTO DO ALVO (PTV) E SEU EFEITO NA RADIOTERAPIA
}

\author{
Maria Esmeralda Ramos Poli
}

Tese apresentada como parte dos requisitos para obtenção do Grau de Doutor em Ciências na Área de Tecnologia Nuclear - Aplicações.

Orientadora:

Dra. Letícia L. C. Rodrigues

SÃO PAULO 2007 
Dedico este trabalho às mulheres fortes $e$ sensíveis que fizeram parte da minha formação. Minhas avós Marí e Esmeralda, minha mãe Helena, e às queridas tia Márcia e Athemis que são minha inspiração e me fazem crer que tudo na vida é possível. 


\section{AGRADECIMENTOS}

Ao IPEN, na pessoa do Sr. Superintendente, Dr. Claúdio Rodrigues, pela oportunidade de executar este trabalho.

Aos Departamentos de Física Médica e Radioterapia e Oncologia da McGill University Health Centre (MUHC), em Montreal, onde a parte experimental deste trabalho foi realizada.

Ao Dr. Ervin B. Podgorsak pela grande oportunidade que me foi dada em seu Departamento, possibilitando minha participação não só no desenvolvimento do projeto de pesquisa mas também em atividades que tiveram um valor inestimável para meu desenvolvimento profissional, e por todo seu suporte durante meu treinamento na MUHC.

Ao William Parker que juntamente com o Dr. Podgorsak supervisionou minhas atividades provendo conhecimento técnico, tempo para verificar os métodos de medida, encorajamento e amizade.

Aos físicos Horacio Patrocínio, Michael Evans, e Russel Ruo pelo incentivo e por sempre estarem disponíveis para esclarecer minhas dúvidas.

À Dra. Letícia Lucente Campos Rodrigues, minha orientadora, pela atenção dispensada todos esses anos, incentivo e discussões.

À Soraya e lleana pela amizade e apoio especialmente no período do longo e tenebroso inverno canadense.

Ao Arthur e Erik meus queridos sobrinhos, por serem minha inspiração.

À Laura Furnari pela amizade e revisão deste trabalho.

À tia Márcia A. Poli pelo carinho e por ter cuidado da minha vida no Brasil durante o desenvolvimento deste trabalho no Canadá.

A todos os funcionários, estudantes de Física Médica e ao Departamento de Radioterapia e Oncologia da MUHC que fizeram com que minha estadia de 1 ano na MUHC fosse muito agradável.

A todos os funcionários, estudantes, e ao Departamento de Radioterapia e Física Médica do HCFMUSP que me receberam de volta ao trabalho no Brasil.

Ao Eduardo Netto pelo companheirismo, paciência e amor que foram essenciais durante a realização deste trabalho.

À CAPES (Coordenação de Aperfeiçoamento de Pessoal de Nível Superior), pelo apoio financeiro deste projeto. 


\title{
DEFINIÇÃO DO VOLUME DE PLANEJAMENTO DO ALVO (PTV) E SEU EFEITO NA RADIOTERAPIA
}

\author{
Maria Esmeralda Ramos Poli
}

\section{RESUMO}

Este trabalho visa estudar as margens necessárias para definir o volume de planejamento do alvo (PTV) requeridas para tratar adequadamente tumores móveis como os localizados na próstata ou tumores localizados em áreas com pouca mobilidade como os da região da cabeça e pescoço, na ausência de localização do alvo por imagem. Também tem como objetivo avaliar o impacto causado pelo PTV, em termos de dose, nas estruturas críticas ao seu redor e sua influência quando planejamento inverso é utilizado na radioterapia com modulação de feixe (IMRT). Dados de 387 pacientes de próstata foram analizados retrospectivamente. Todos os pacientes receberam localização pré-tratamento com ultra-som 2D resultando em 10.327 localizações, cada uma com deslocamento de isocentro em três direções: antero-posterior (AP), lateral direitaesquerda (DE), e superior-inferior (SI). O deslocamento médio e desvio padrão (SD) para cada direção foi estimado a partir dos dados de tratamento gravados diariamente. As incertezas (SD) na posição do alvo foram 4,4 mm (AP), 3,6 mm (DE), e 4,5 mm (SI).

O estudo das incertezas no posicionamento diário de 78 pacientes com tumores de cabeça e pescoço que utilizaram máscaras termoplásticas como imobilizadores, avaliados com equipamento de portal com imagem eletrônica (EPID), mostrou variações (SD) na posição do isocentro de tratamento de $3,1 \mathrm{~mm}$ (AP), $1,5 \mathrm{~mm}$ (DE), 4,5 mm (SI). Aplicando estes desvios num simulador antropomórfico estudou-se os histogramas de dose-volume resultantes do deslocamento do isocentro no tratamento diário.

Os resultados mostraram a importância de se colocar margens no volume clínico do alvo para garantir um tratamento adequado e também mostraram que a variação diária do isocentro de tratamento pode causar um aumento de dose maior que o nível de tolerância dos órgãos críticos. 


\title{
PLANNING TARGET VOLUME (PTV) DEFINITION AND ITS EFFECTS IN THE RADIOTHERAPY
}

\section{Maria Esmeralda Ramos Poli}

\begin{abstract}
This work intends to study the margins required to define a planning target volume (PTV) for adequate treatment of the mobile tumors such as prostate or those located in areas with less mobility as the ones in head and neck region, in the absence of daily localization imaging based. It is also intends to evaluate the impact caused by the PTV, in terms of dose, to the critical structures surrounding the PTV and its influence when inverse planning is used in the intensity-modulated radiation therapy (IMRT). Data from 387 prostate patients were analyzed retrospectively. Every patient in the study received daily pre-treatment localization with 2D ultrasound resulting in a total of 10,327 localizations, each comprising of an isocenter displacement in 3 directions: anterior-posterior (AP), right-left lateral $(\mathrm{RL})$, and superior-inferior $(\mathrm{SI})$. The mean displacement and standard deviation (SD) for each direction for each patient was computed from daily treatment records. The uncertainties (SD) in the target position were $4.4 \mathrm{~mm}(\mathrm{AP}), 3.6 \mathrm{~mm}$ $(\mathrm{RL})$, and $4.5 \mathrm{~mm}(\mathrm{SI})$.

A study of the uncertainties in the daily positioning of 78 head and neck patients who used thermoplastic mask to immobilize them, evaluated with electronic portal imaging device (EPID), showed variations (SD) in the isocenter treatment position of $3.1 \mathrm{~mm}(\mathrm{AP}), 1.5 \mathrm{~mm}(\mathrm{RL})$, and $4.5 \mathrm{~mm}(\mathrm{SI})$. By applying these shifts in an anthropomorphic phantom it was studied the dose-volume histograms resultant of the isocenter displacement in the daily treatment.

The result showed the importance of putting margins in the clinical target volume to assure an adequate treatment and also showed that isocenter daily variation can cause an increase to the dose greater than the tolerance level to the critical organs.
\end{abstract}




\section{SUMÁRIO}

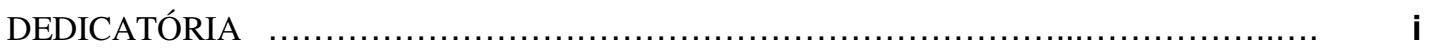

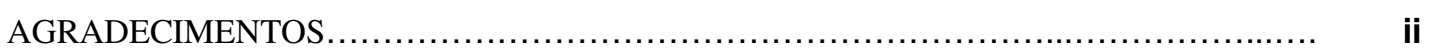

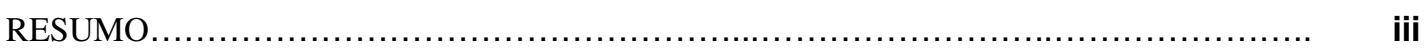

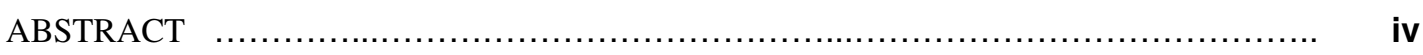

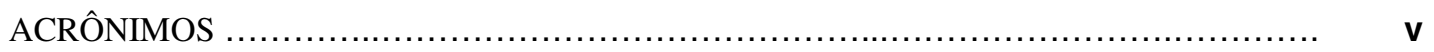

$\begin{array}{ll}\text { I INTRODUÇÃO } & 1\end{array}$

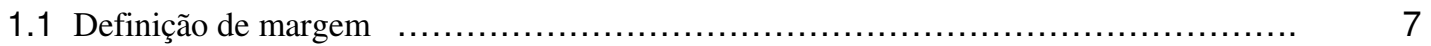

1.1.1 Importância da definição de margem e seus efeitos ...............................

1.1.2 Revisão da literatura para movimentos de órgãos …................................ 8

\begin{tabular}{lr} 
II OBJetivo & 13 \\
\hline
\end{tabular}

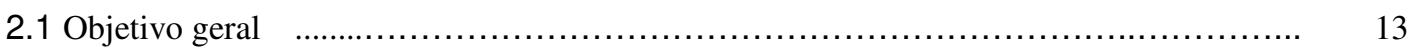

2.2 Objetivos específicos .................................................................. 13

III FUNDAMENTOS

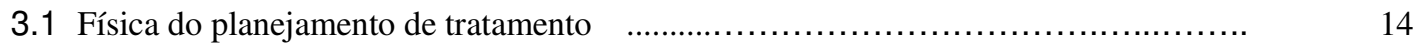

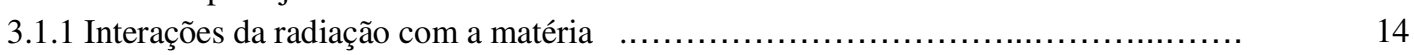

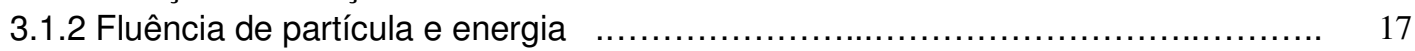

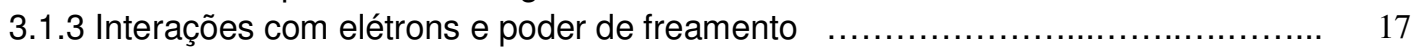

3.1.4 Conceito de KERMA, dose absorvida e equilíbrio eletrônico da partícula carregada (CPE) ...................................................................... 19

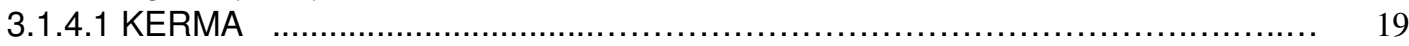

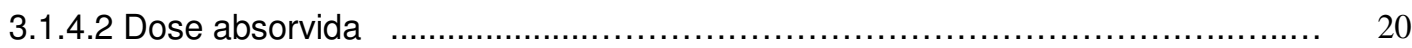

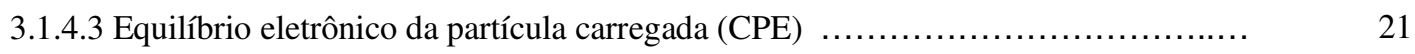

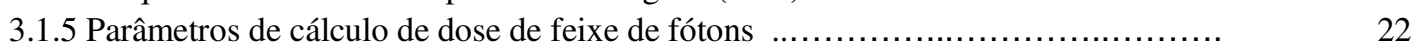

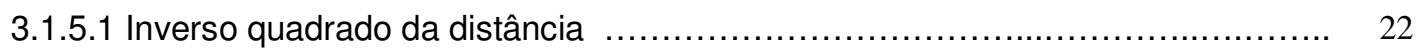

3.1.5.2 Formalismos dos parâmetros de localização: DFS e DFI ....................... 23

3.1.5.3 Fatores que relacionam dose na profundidade à dose no ponto de referência: porcentagem de dose profunda (PDP), razão tecido-ar (TAR), razão tecidosimulador (TPR) e razão tecido-máximo (TMR) f....................................... 23

3.1.5.4 Fatores que afetam a fluência do feixe: PSF, CF, SF, RDF e OCR ................ 25

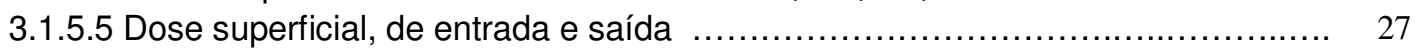

3.2 Processo de planejamento tridimensional ............................................. 29

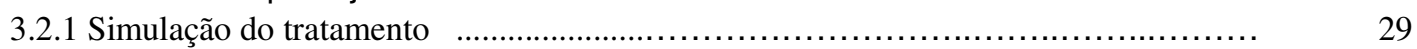

3.2.1.1 Posicionamento e imobilização do paciente $\quad$.......................................... 29

3.2.1.2 Aquisição de dados do paciente: tomografia computadorizada .......................... 32

3.2.1.3 Definição dos alvos e estruturas de interesse .......................................................

3.2.1.4 Definição do isocentro ....................................................................................

3.2.1.5 Transferência de imagem ..........................................................................

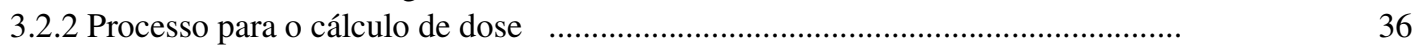

3.2.2.1 Algorítmos de planejamento de tratamento ......................................................... 37 
3.2.2.2 Métodos empíricos e tabelas de cálculo .............................................................

3.2.2.3 Integração Clarkson para campos irregulares .................................................. 38

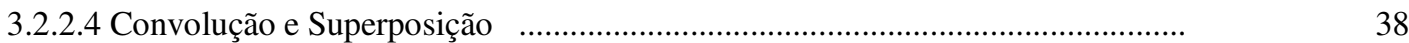

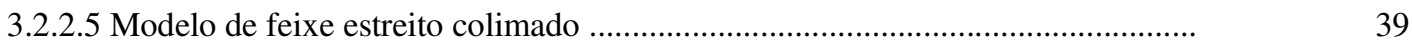

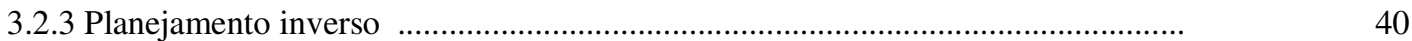

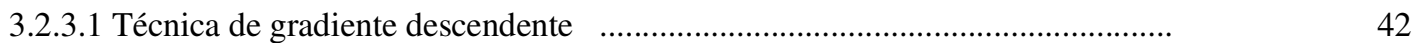

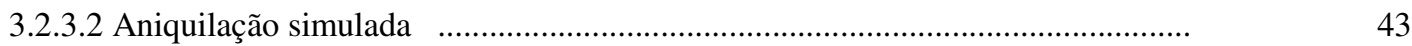

3.2.3.3 Otimização do planejamento com CORVUS ......................................................

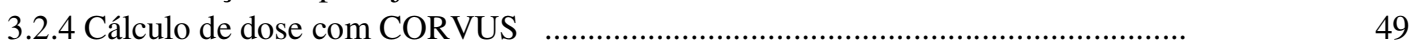

3.2.5 Avaliação do planejamento

3.2.6 Reconstrução radiográfica digital (DRR) ...........................................................

3.2.7 Sistema de gravação e verificação do planejamento ............................................

3.2.8 Exportação dos dados para a máquina de tratamento ...........................................

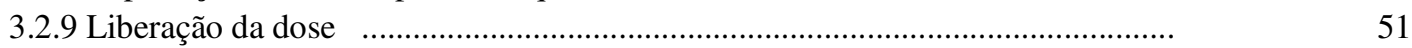

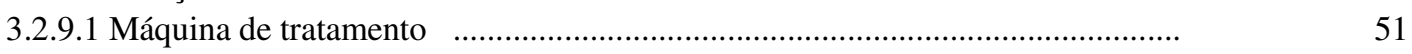

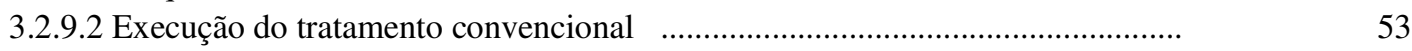

3.2.9.3 Execução do tratamento com IMRT dinâmico ...................................................

3.2.10 Controle de qualidade (CQ) …..................................................................

3.2.10.1 CQ pré-tratamento específico ao plano de tratamento - híbrido $\quad$......................

3.2.10.2 CQ pré-tratamento específico ao paciente - portais e ultra-som $\ldots . . . . . . . . . . . . . . . . . . \quad 55$

3.2.11 Comparação das técnicas de 3-DCRT e IMRT ..............................................

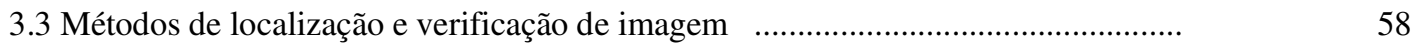

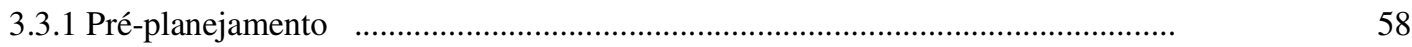

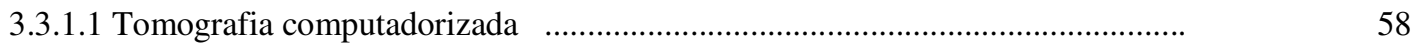

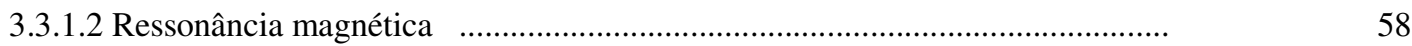

3.3.2 Pré-tratamento ............................................................................................

3.3.2.1 Imagem de portal e sementes de ouro

3.3.3 Durante o curso do tratamento ……................................................................

3.3.3.1 Equipamento de imagem de portal eletrônico (EPID) ……………………........

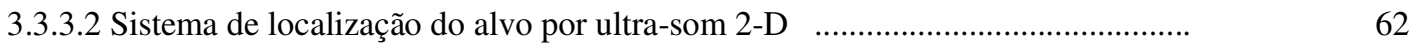

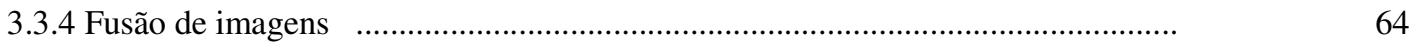

$\begin{array}{ll}\text { IV MATERIAIS E MÉTODOS } & 69\end{array}$

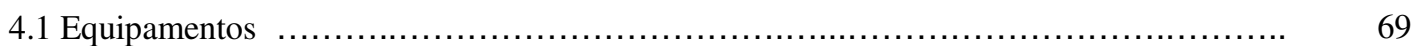

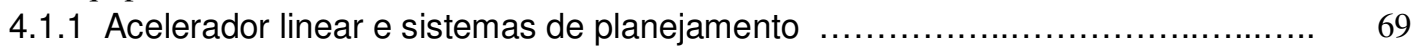

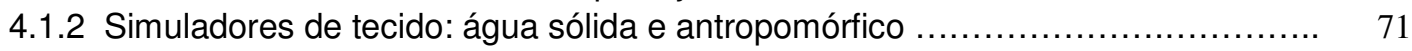

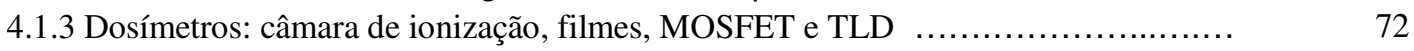

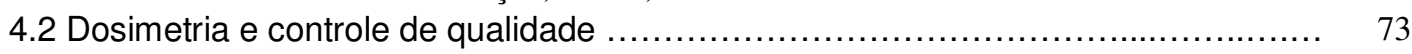

4.3 Imagem: tomografia computadorizada, ultra-som, equipamento de imagem de

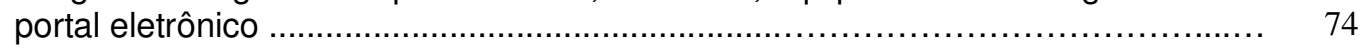

4.4 Calibração e testes de desempenho dos dosímetros ............................. 75

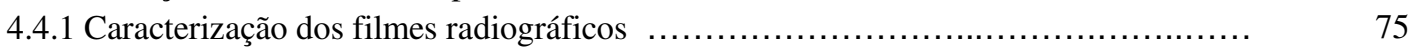

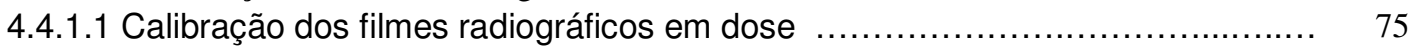

4.4.1.2 Filmes radiográficos na verificação da distribuição de dose do IMRT ........... 75

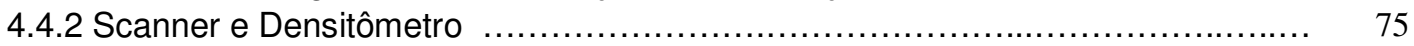

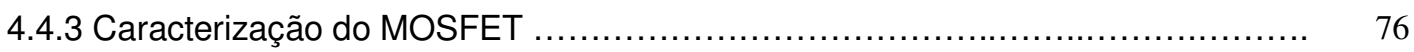

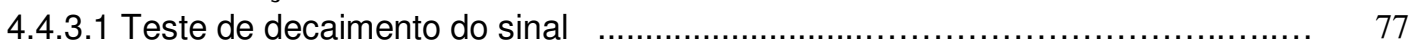

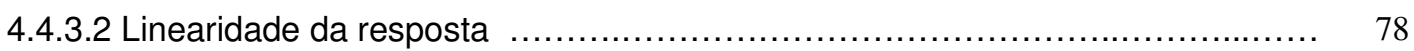

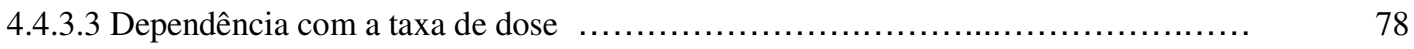




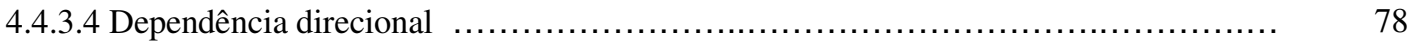

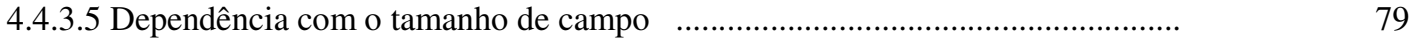

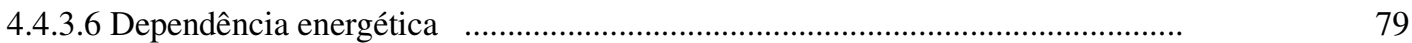

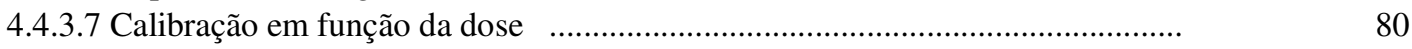

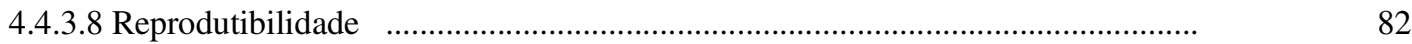

4.4.3.9 Emprego do MOSFET na dosimetria do IMRT ……......................................

4.4.4 Caracterização do TLD........................................................................................

4.5 Técnicas experimentais para avaliação dos erros e incertezas associadas ao PTV e o seu

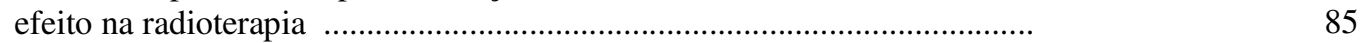

4.5.1 Incertezas relacionadas à localização do paciente: casos de cabeça e pescoço....

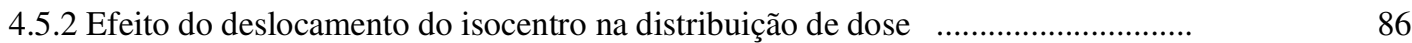

4.5.3 Efeito do tamanho do PTV nas estruturas críticas vizinhas ....................................

4.5.4 Efeito da margem dada ao volume alvo para formar o PTV em relação à dose na superfície quando se utiliza planejamento inverso para IMRT no tratamento de câncer de cabeça e pescoço

4.5.5 Efeito de margens do PTV na dose periférica para tratamentos planejados com IMRT

4.5.6 Incertezas relacionadas ao movimento do órgão entre frações do tratamento: casos de próstata

4.5.6.1 Modelo matemático para englobar erros sistemáticos e randômicos para definir o PTV

4.5.7 Efeito do movimento do isocentro através das novas coordenadas geradas pela localização com ultra-som na dose no alvo

5.1 Calibração e testes de desempenho dos dosímetros ........................................... 96

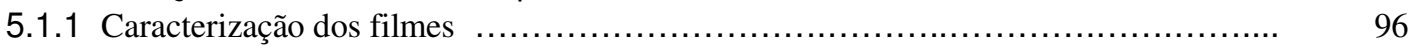

5.1.1.1 Calibração dos filmes radiográficos em função da dose............................. 96

5.1.1.2 Filmes radiográficos na verificação da distribuição de dose do IMRT ............... 97

5.1 .2 Caracterização do MOSFET .............................................................. 99

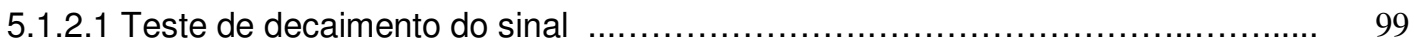

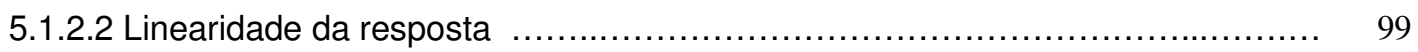

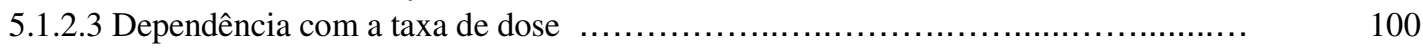

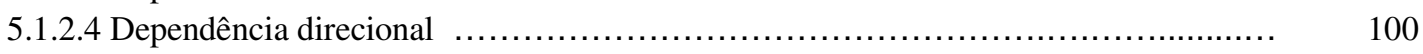

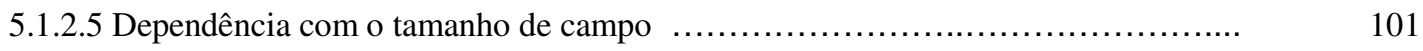

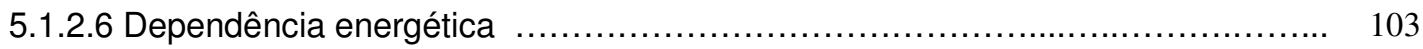

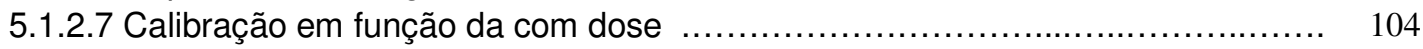

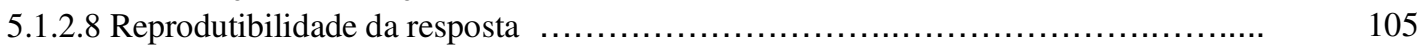

5.1.2.9 Emprego do MOSFET na dosimetria do IMRT ................................... 105

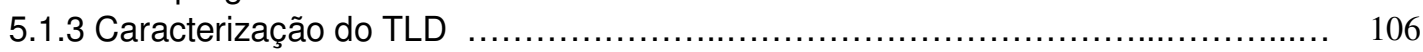

5.2 Técnicas experimentais para avaliação dos erros e incertezas associadas ao PTV e ao seu efeito na radioterapia ........................................................ 107

5.2.1 Incertezas relacionadas à localização do paciente: casos ENT ......................... 107

5.2.2 Efeito do deslocamento do isocentro na distribuição de dose e efeito do tamanho do PTV nas doses geradas em suas estruturas críticas vizinhas

5.2.3 Efeito da margem dada ao volume alvo para formar o PTV em relação à dose na superfície quando se utiliza planejamento inverso para IMRT no tratamento de câncer de cabeça e pescoço

5.2.4 Efeito de margens do PTV nas doses das regiões periféricas ao tratamento ....... 116

5.2.5 Incertezas relacionadas ao movimento do órgão entre frações do tratamento: casos de tumor na próstata 
5.2.5.1 Modelo matemático para englobar erros sistemáticos e randômicos para definir PTV

5.2.5.2 Efeito na dose devido ao movimento do isocentro através das novas coordenadas geradas pela localização do alvo com ultra-som.

5.2.5.3 Guia prático: como eleger o paciente à certas restrições de dose

VI CONCLUSÕES

APÊNDICE A

140

APÊNDICE B

152

APÊNDICE C

156

REFERÊNCIAS 


\section{INTRODUÇÃO}

A radioterapia é uma técnica de tratamento que utiliza a radiação ionizante para destruir células não sadias tais como as cancerígenas, com o objetivo principal de tratar pacientes portadores de câncer. Até a década de 80 a distribuição da radiação pelo corpo do paciente era realizada basicamente através de cálculos manuais. A partir da década de 90 , os computadores começaram a ser introduzidos na radioterapia e hoje o seu uso é fundamental para que o tratamento seja realizado de forma a causar o menor dano possível aos tecidos sadios e, ao mesmo tempo, garantir que o alvo receba a dose de tratamento desejada. Para que isso ocorra, a radioterapia deve ser planejada e o processo do planejamento do tratamento consiste de vários passos que incluem a aquisição de dados do paciente, definição do alvo, simulação, cálculo de dose e avaliação do plano de tratamento ${ }^{2-4}$, conforme explicado a seguir:

- Aquisição dos dados do paciente: é o primeiro passo no planejamento do tratamento. As suas informações anatômicas podem ser obtidas através de imagens radiográficas ou fluoroscópicas. Para ambas imagens, há necessidade de se fazer o contorno do paciente de forma a se obter uma representação bidimensional da forma do seu corpo na região de interesse para o tratamento. Existem vários métodos para se determinar o contorno, sendo o mais comum o uso de fios de chumbo de solda para delinear a superfície do paciente. Este método de aquisição de dados, embora tenha sido muito usado, é um método pouco eficaz na localização do tumor uma vez que as imagens de raios- $X$ ou fluoroscopia não produzem bom contraste em tecidos moles. Para vencer estes obstáculos a tomografia computadorizada (CT) se tornou muito frequente para se obter informações tridimensionais (3-D) do paciente, assim como oferecer informações mais precisas da localização do tumor por causa do contraste em tecidos moles.

- Definição do alvo: a fim de se delinear os volumes alvos e órgãos sensíveis, alguns métodos de exames são necessários para localizar estas estruturas dentro do paciente. Em alguns casos a identificação do volume alvo pode ser feita por palpação clínica ou exame visual. No entanto, é mais frequente a necessidade do uso de imagens radiológicas tais como filmes radiográficos, tomografia 
computadorizada (CT), imagem por ressonância magnética (MRI) e tomografia por emissão de pósitron (PET). Estas modalidades de imagens podem ser usadas individualmente ou combinadas de forma a se obter a melhor localização do tecido cancerígeno no paciente. Os volumes de tratamento são geralmente definidos de acordo com as publicações da Comissão Internacional de Unidades e Medidas de Radiação (ICRU) números $50^{5}$ e $62^{6}$. O volume de tumor visível, conhecido como GTV (do inglês gross tumor volume), é definido como a massa palpável ou extensão visível do crescimento tumoral. O volume contendo o GTV e doença microscópia maligna possível é denominado volume clínico do alvo, conhecido pelo acrônimo em inglês CTV (clinical target volume). É muito importante que este volume seja tratado adequadamente a fim de se alcançar o objetivo da terapia, seja ela paliativa ou curativa. O volume de planejamento do alvo (PTV, do inglês planning target volume) é uma definição de volume que leva em conta o efeito de todas as variações geométricas tais como: movimento de órgãos ou incerteza da sua posição com a finalidade de assegurar que a dose prescrita seja realmente absorvida no CTV. Os órgãos de risco (OAR, organ at risk) podem ser delineados e incluídos no planejamento do tratamento em uma tentativa de diminuir as complicações em tecido normal através da verificação de que a dose nos tecidos sadios não ultrapasse a sua dose de tolerância. Assim como para o CTV, também foi definido para o OAR um volume de planejamento que leva em conta sua movimentação e posição dentro do paciente denominado PORV (do inglês planning organs at risk volume). O ICRU $62^{6}$ ainda descreve mais dois volumes que podem ser usados para definir o volume planejado que recebeu efetivamente a dose prescrita, TV (do inglês treatment volume) e IV (irradiated volume) que pode ser descrito como o volume irradiado com uma dose que seja importante ser reportada para o tipo de paciente em questão, não havendo uma dose mínima para se relatar, pois dependerá de cada situação. Uma representação destas definições de volumes alvos pode ser vista na FIGURA 1.1. 


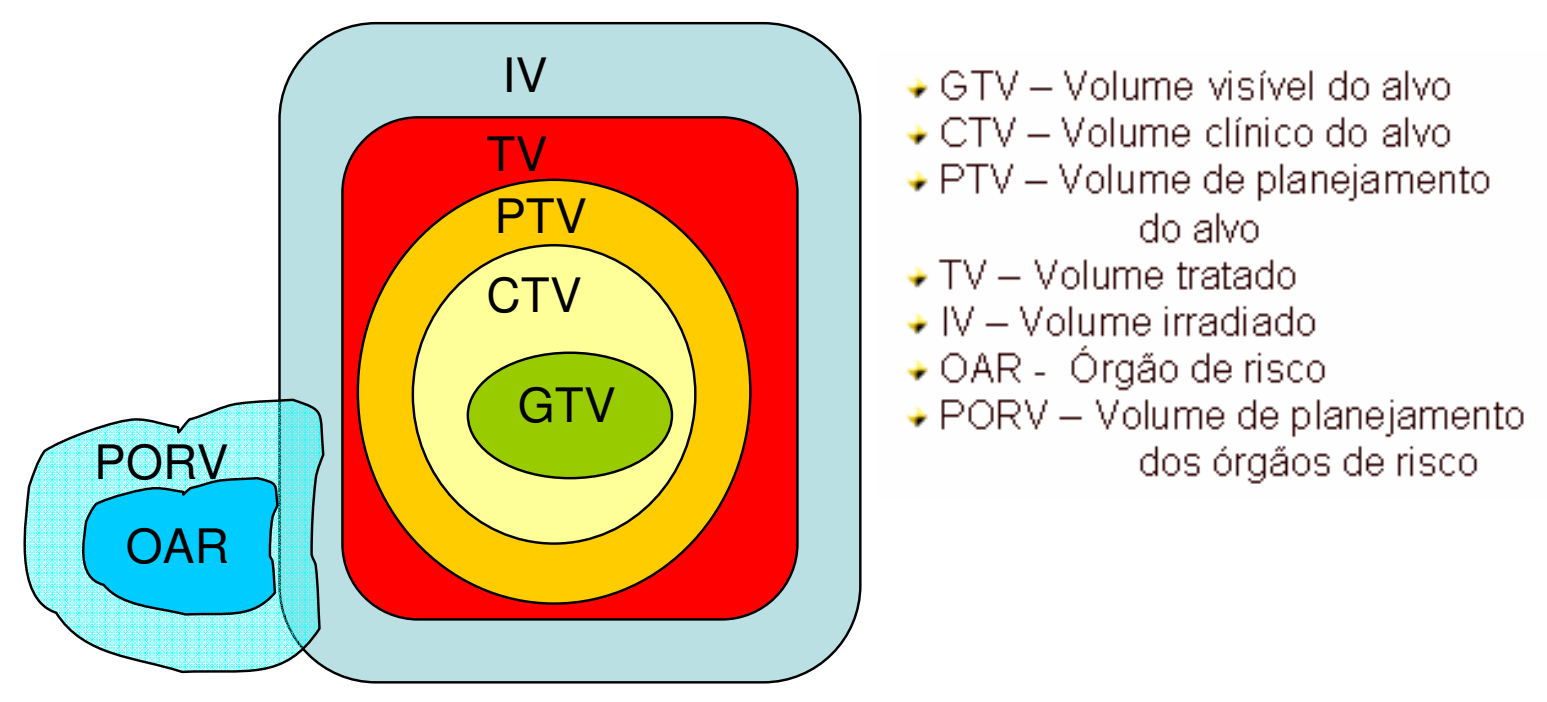

FIGURA 1.1 - Definições de volumes alvos e órgãos de risco.

- Simulação: uma vez que os dados do paciente foram adquiridos e os alvos localizados, podem ser determinados os parâmetros do feixe necessários para tratar o paciente. Se a geometria do feixe for determinada usando métodos de fluoroscopia ou radiografia convencional então os limites dos campos de tratamento devem ser determinados usando estruturas ósseas como referência. Um outro método é a simulação virtual que, a partir de dados de imagens de CT pode se obter radiografias planas reconstruídas digitalmente (conhecida como $\mathrm{DRR}$, digitally recontructed radiograph), nas quais podem ser sobrepostas as delineações dos campos de tratamento. Esta imagem digital que inclui informações do campo de tratamento é chamada de projeção da visão do olho do feixe e o acrônimo usado é BEV, do inglês beam's eye view. A simulação virtual do plano permite que os feixes de radiação sejam determinados relativamente às estruturas de tecido mole delineadas nas imagens de CT.

- Cálculo de dose: após selecionar propriamente os campos, pode ser realizado um cálculo de dose para os alvos e os órgãos de risco. No caso de campos simples, com formato regular como um quadrado, retângulo ou esfera, em meio homogêneo, as tabelas com dados dosimétricos dos feixes podem ser usadas para cálculo manual ${ }^{3}$. Para campos com formato irregular, a dose resultante pode ser estimada através de técnicas como o método de integração de Clarkson ${ }^{7}$. Nos casos de distribuições em meio heterogêneo, algorítmos de cálculo de dose podem incluir formas de correção de tecidos hetereogêneos dentro do paciente 
como é o caso dos algorítmos de convolução e superposição ${ }^{8}$, algorítmos de feixes estreitos (pencil beam) $)^{9}$ e os baseados em Monte Carlo podem ser usados. Em um planejamento convencional, o planejador seleciona os parâmetros do feixe por tentativa e erro de acordo com o contorno do paciente. Uma distribuição de dose é então calculada e avaliada. Este processo é repetido até que um plano de tratamento aceitável seja encontrado. Por outro lado, o planejamento inverso faz uso de métodos de otimização computadorizada para gerar um plano de tratamento adequado. Neste caso, as doses de prescrição desejadas e as constrições dose-volume para os órgãos de risco são introduzidas primeiramente pelo planejador do tratamento, e os parâmetros do feixe são então determinados com a otimização de uma função custo definida para estes objetivos e limitações. Os algorítmos de planejamento inverso geralmente produzem intensidades de feixes complexas que requerem um sistema de liberação do tratamento avançado, tais como os realizados com radioterapia com modulação da intensidade (acrônimo conhecido IMRT que em inglês é intensity-modulated radiation therapy). A radioterapia com modulação da intensidade do feixe (IMRT) é um método de liberação de um tratamento tri-dimensional conformado que permite a modulação da forma e intensidade dos feixes de radiação. Uma dose pode ser dada a um alvo de formato irregular enquanto os tecidos vizinhos adjacentes são poupados. Existem várias formas de IMRT envolvendo compensadores físicos simples, feixes escaneados, feixe modulado em forma de leque (tomoterapia), ou colimadores multi-lâminas (MLC) que podem ser usados para modular o feixe ${ }^{10-12}$. Devido à complexidade requerida na liberação dos feixes, o IMRT é usada frequentemente com sistemas de planejamento inverso do tratamento tais como 0 sistema CORVUS (Nomos Corporation, Cranberry, PA) ${ }^{13,14}$.

Neste trabalho foi utilizado o IMRT com planejamento inverso e o sistema de liberação dos feixes com um colimador de multi-lâminas (MLC) para alcançar a forma do campo e modulação de feixe desejadas. Os colimadores multi-lâminas consistem de 20 a 60 pares opostos e adjacentes de lâminas finas de tungstênio montadas no cabeçote do acelerador linear. A espessura de cada lâmina é tal que a espessura de sua projeção no isocentro da máquina de tratamento varia entre $0,5 \mathrm{~cm}$ e $1 \mathrm{~cm}$. Cada lâmina é controlada por motores independentes tal que possa ser movido em configurações diferentes para conformar o volume de tratamento. Atualmente são disponíveis dois modos de liberação dos feixes com 
MLC para uso clínico, o modo estático (step and shoot) e o modo dinâmico. No modo estático, o tratamento é liberado através de uma série de sub-feixes com intensidades variadas. Cada sub-feixe tem uma configuração específica das lâminas do MLC e tempo de feixe. A combinação dos sub-feixes produz a distribuição de dose desejada. No modo dinâmico, o método de liberação do feixe implementado é o chamado "sliding-window". Neste caso a abertura do MLC é movida através do feixe enquanto o acelerador linear está com o feixe ligado. A forma da abertura e da velocidade é modulada conforme necessário para se obter a distribuição desejada. O método de liberação dinâmica permite um tratamento mais acurado porque o número de sub-campos não é limitado como no modo estático e o tempo de tratamento total pode ser reduzido consideravelmente.

- Avaliação do plano do tratamento: pode ser em natureza quantitativa ou qualitativa. $O$ fato de que os planos de tratamento raramente satisfazem completamente o critério inicial de planejamento sem comprometer estruturas sadias implica na necessidade de uma avaliação subjetiva do plano. Qualitativamente, várias ferramentas são disponíveis para avaliação do plano de tratamento. Isto inclui distribuições de isodoses em todos os cortes axiais da tomografia assim como nas imagens reconstruídas nos planos sagital, coronal e oblíquo. As superfícies de isodoses podem ser mostradas em reconstruções 3-D a partir dos dados do CT, ou projetadas nas imagens DRR e BEV.

Para acessar quantitativamente a qualidade do plano de tratamento são utilizadas informações sobre as distribuições de isodoses, estatísticas de dose, e histogramas dose-volume (DVH), ver APÊNDICE A. O DVH é uma representação gráfica da distribuição de frequência de doses dentro de um dado volume, seja ele o alvo ou órgão de risco. Pode ser usado na forma direta (diferencial) ou integral (cumulativa). O DVH direto possibilita determinar o volume de tecido que recebe uma dose dentro de um certo valor incremental enquanto o DVH cumulativo calcula volumes que recebem no mínimo uma certa dose. Um problema do DVH é a falta de informação sobre a distribuição espacial da dose. Um exemplo de um DVH cumulativo típico e ideal para um alvo e órgão de risco pode ser visto na FIG. 1.2. 


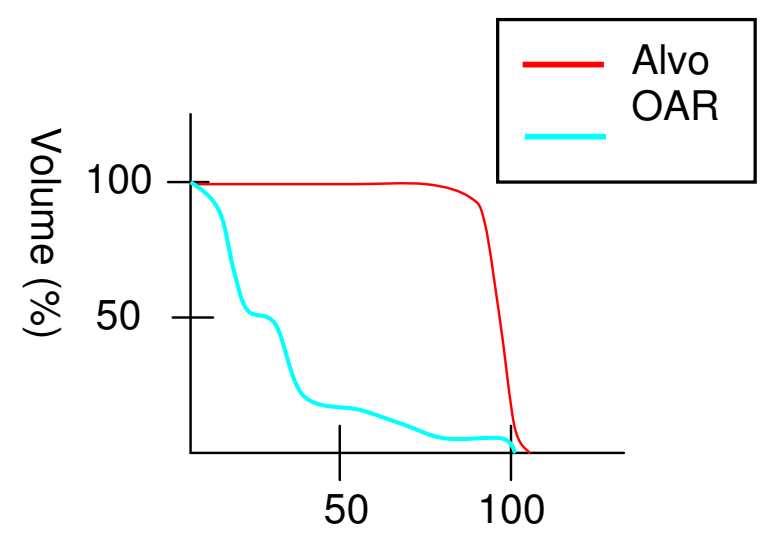

Dose (\%)

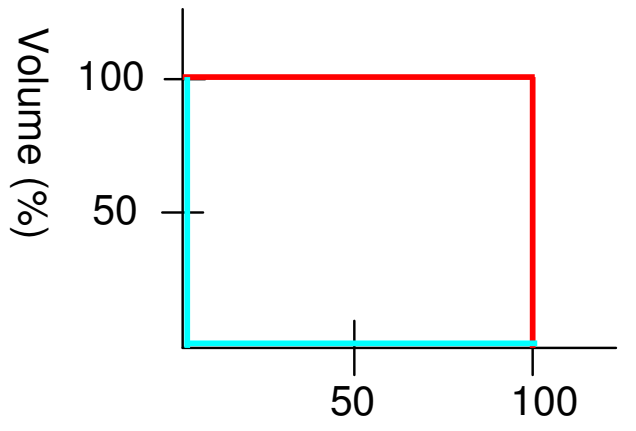

Dose (\%)

FIGURA 1.2 - Histogramas de dose-volume para um plano de tratamento típico (esquerda) e ideal (direita).

A avaliação do plano deve incluir fatores importantes tais como uniformidade de dose e limites de dose aos órgãos críticos. Para radioterapia convencional, o ICRU $50^{5}$ recomenda que a dose em todos os pontos dentro do alvo não deve exceder $7 \%$ e não deve ser inferior a $5 \%$ da dose no isocentro se $100 \%$ da dose é prescrita neste ponto. No entanto, nos tratamentos com IMRT estas constrições de uniformidade de dose podem não ser alcançadas se as distribuições de dose têm formas côncavas ou gradientes grandes de dose perto de órgãos críticos ${ }^{15}$. Consequentemente, a prescrição e o relato de doses para tratamentos com IMRT diferem das recomendações do ICRU ${ }^{5,6}$. Os limites de dose impostos na radioterapia são geralmente devido às doses de tolerância nos órgãos sadios. Muitas pesquisas têm sido realizadas para avaliar a tolerância à radiação em tecidos, e muitas instituições de tratamento clínico aderem a valores sugeridos em uma compilação de dados realizados por Emami et al. ${ }^{16}$.

Recentemente, índices biológicos têm sido usados para avaliar planos de tratamento. Modelos biológicos são usados para avaliar o efeito de uma distribuição de dose calculada em estruturas irradiadas. Dois destes índices são a probabilidade de controle tumoral (TCP) e probabilidade de complicação em tecido normal (NTCP), que são funções do tamanho da fração, gradiente de dose dentro da estrutura, e uma resposta da dose modelada biologicamente ${ }^{17}$. A dose biologicamente eficaz (BED) é uma grandeza que relaciona o tamanho da fração da dose à dose, e é uma função dos parâmetros $\alpha$ e $\beta$ ajustados 
radiobiologicamente $^{18}$. A dose equivalente uniforme $(E U D)^{19}$ é definida como a dose liberada ao órgão inteiro requerida para produzir o mesmo efeito biológico que uma irradiação parcial para uma outra dose liberada ao mesmo órgão estudado.

\subsection{DEFINIÇÃO DE MARGEM}

Como discutido anteriormente, a definição de volumes e margens para radioterapia foi realizada pela primeira vez pela publicação No. 50 (ICRU 50) ${ }^{5}$, em 1993 e posteriormente atualizado pela publicação No. 62 (ICRU 62) ${ }^{6}$ em 1999. Os ICRU 50 e 62 definem o volume de tumor visível em imagens diagnósticas como sendo o GTV; o volume clínico, CTV, é o volume acrescentado ao GTV para incluir doença sub-clínica; o PTV é o volume de planejamento que deverá ser acrescentado ao CTV para garantir que este seja tratado com a dose prescrita; OAR é o acrônimo usado para órgãos de risco, ou seja, os órgãos que são vizinhos ao volume que será tratado e PORV é o PTV para os órgãos de risco. $O$ CTV é definido clinicamente e o PTV deve ser a margem que leva em conta variações devidas ao posicionamento diário do paciente (setup), movimentação do órgão, erros associados ao equipamento (como incerteza na posição da estativa rotatória, mesa, colimador, etc.), mudança na geometria do paciente (ganho ou perda de peso, por exemplo) e outros erros associados ao tratamento.

\subsubsection{A IMPORTÂNCIA DA DEFINIÇÃO DE MARGEM E SEUS EFEITOS}

A radioterapia com planejamento tridimensional conformado ao alvo assume que a localização do alvo é bem conhecida e que as variações na sua posição devido às incertezas de localização são levadas em conta no PTV.

Erros associados ao posicionamento e localização do alvo em radioterapia vêm sendo estudados para vários sítios de tratamento há 5 anos, mas ainda não há nenhum trabalho descrevendo a metodologia da sua análise ou abordando os aspectos diferentes da implicação da margem no tratamento conformacionado.

Com o uso crescente de novas tecnologias tal como a modulação da intensidade do feixe (IMRT), a margem que deve ser dada ao alvo está se tornando objeto de investigação, uma vez que o seu tamanho pode afetar órgãos de risco gerando 
doses muito acima do limite de tolerância ${ }^{16}$ ou, dependendo da sua localização, o uso de planejamento inverso pode afetar a otimização de dose gerando doses excessivas em estruturas sadias que, muitas vezes, não podem ser avaliadas precisamente pelo sistema de planejamento como é o caso da pele.

Para lembrar de quão importante é o tamanho da margem em termos volumétricos, basta verificar a mudança fracional no volume como uma função do seu diâmetro, que é justamente seu diferencial, e um pode ser dividido pelo outro, o que significa que ${ }^{20}$ :

Se o volume da esfera $=4 / 3 \pi r^{3}=\pi d^{3} / 6$, onde r é o raio da esfera e d seu diâmetro

$$
\Delta V=\left(\pi d^{2} / 2\right) \Delta d
$$

então

$$
\Delta V / V=\left\{\left(\pi d^{2} / 2\right) \Delta d\right\} /\left\{\pi d^{3} / 6\right\}
$$

ou

$$
\Delta \mathrm{V} / \mathrm{V}=3 \Delta \mathrm{d} / \mathrm{d}
$$

Portanto, ao se adicionar $1 \mathrm{~mm}$ de margem a um alvo com $6 \mathrm{~mm}$ de diâmetro isto acrescentará $100 \%$ no volume como mostrado a seguir.

$$
\begin{gathered}
\Delta \mathrm{V} / \mathrm{V}=3 \Delta \mathrm{d} / \mathrm{d}=3 \times 2 \times 1 \mathrm{~mm} / 6 \mathrm{~mm} \\
\Delta \mathrm{V} / \mathrm{V}=1,0 \text { ou } 100 \%
\end{gathered}
$$

Por isso a margem dada ao volume clínico para formar o PTV deve ser muito bem estudada e discutida com o radioterapêuta a fim de se chegar em um consenso para que a dose seja liberada no alvo, sem que tantos tecidos sadios sejam sacrificados.

\subsubsection{Revisão da literatura para movimento de órgãos}

A revisão bibliográfica para o movimento de algumas regiões de interesse na radioterapia, como o pulmão, diafragma, e a região da cabeça e pescoço, são apresentadas nas TABELAS 1.1, 1.2 e 1.3, respectivamente. 
TABELA 1.1 - Resumo da literatura reportando movimento do alvo intra-torácico durante a respiração entre frações do tratamento.

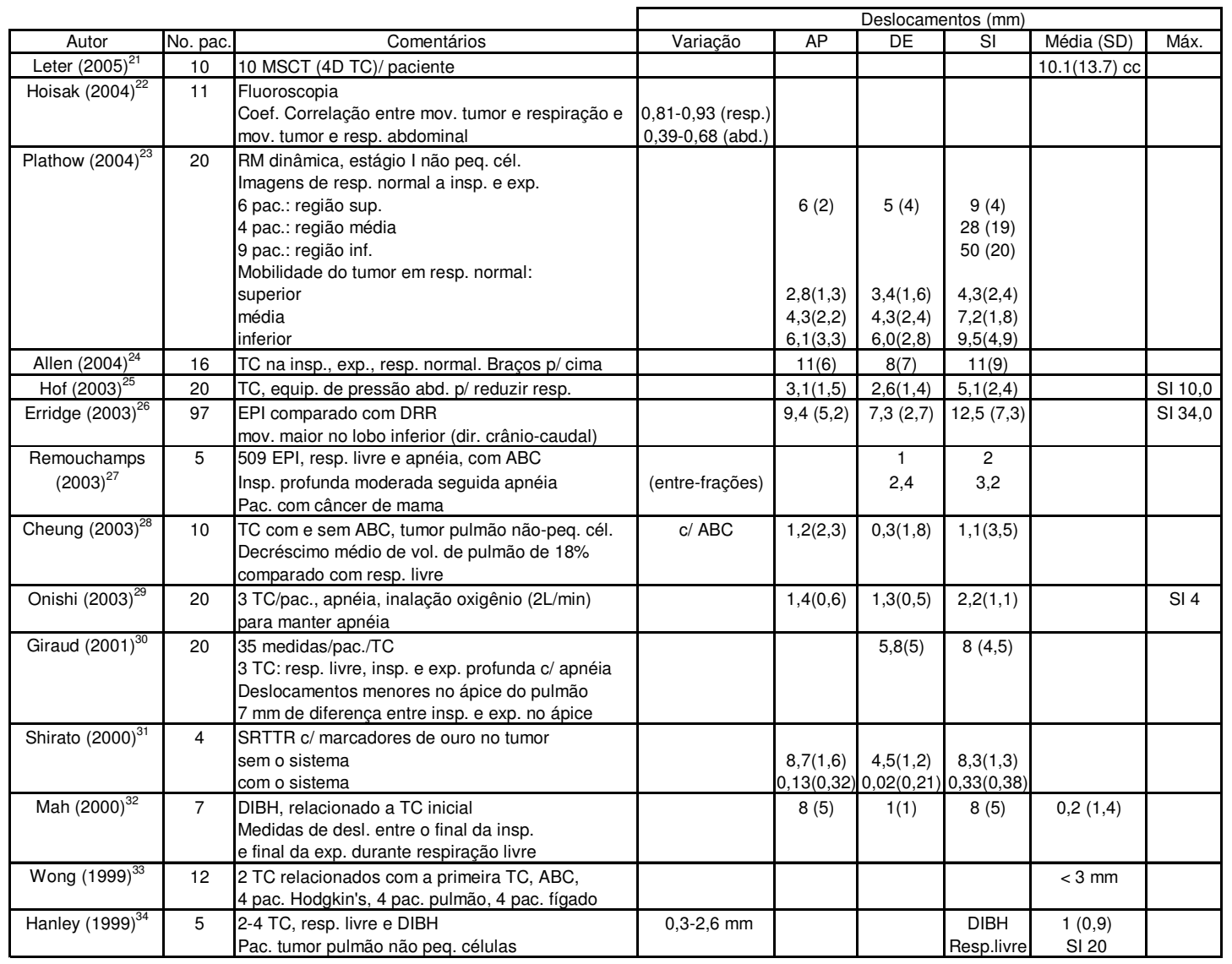

Abreviações: MSTC = tomografia computadorizada multi-slice espiral 4-D; eq.= equipamento; $A B C$ = active breathing control (ou controle ativo da respiração); resp.= respiração; RM = ressonância magnética; insp. = inspiração; exp.= expiração; SRTTR = sistema de rastreamento do tumor em tempo real; DIBH = deep inspiration breath-hold (ou inspiração profunda seguida de apnéia); EPI = imagem com portal eletrônico.

Pode-se resumir os dados da literatura da seguinte forma: se há controle da respiração durante o tratamento então os desvios padrões (SD), relacionados aos movimentos do alvo dentro do pulmão, podem variar de 2 a $5 \mathrm{~mm}$; no caso de respiração livre os SD variam de 2 a $9 \mathrm{~mm}$. Os maiores deslocamentos ocorreram nas regiões medial e inferior na direção crânio-caudal: SD de 4 a $20 \mathrm{~mm}$ para respiração variando de normal a profunda.

As margens sugeridas por Plathow et al. ${ }^{23}$ foram de 3,4 mm para alvo localizado no ápice do pulmão, 4,5 mm para a região medial, e 7,2 $\mathrm{mm}$ para a região inferior. O trabalho do Van Sornsen de Koste et al. $^{35}$, por analisar o pulmão em partes, não consta da TAB. 1.1. O autor ${ }^{35}$ considera o movimento do alvo por região 
anatômica dentro do pulmão onde os movimentos são similares. Os resultados deste trabalho são apresentados na FIGURA 1.3 onde $\mathrm{X}$ representa movimento latero-lateral em $\mathrm{mm}$, Y para crânio-caudal $(\mathrm{mm})$ e $Z$ para antero-posterior $(\mathrm{mm})$, 3-D vector é o vetor resultante das 3 direções.

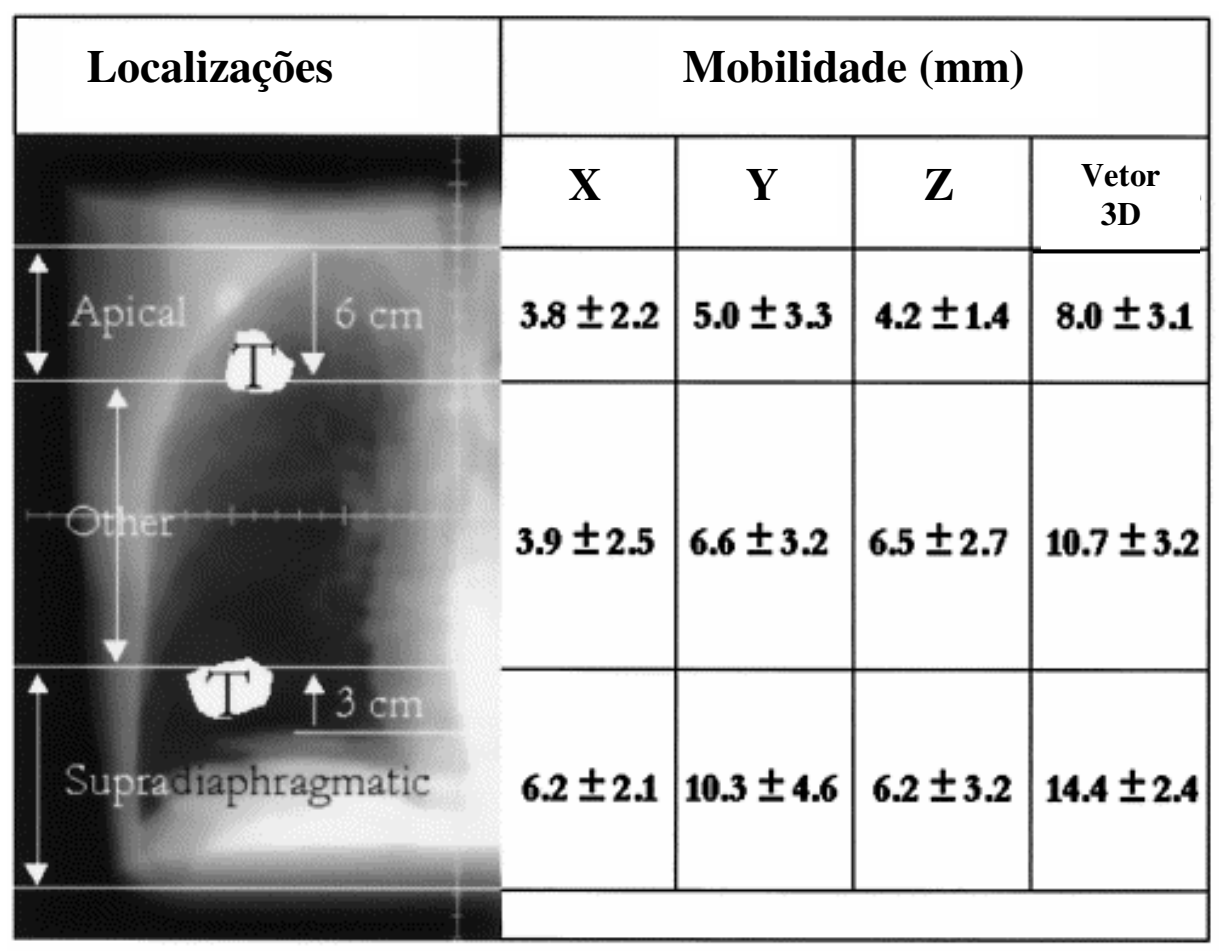

FIGURA 1.3 - Região anatômica de estudo com os respectivos deslocamentos do alvo nas direções $\mathrm{X}, \mathrm{Y}, \mathrm{Z}$ e o vetor $3-\mathrm{D}^{35}$. 
TABELA 1.2 - Resumo da literatura reportando movimento do diafragma em pacientes com câncer de pulmão.

\begin{tabular}{|c|c|c|c|c|c|c|c|c|}
\hline Autor & No. pac. & Comentários & \multicolumn{6}{|c|}{ Deslocamentos e desvio padrão (SD) em mm } \\
\hline $\begin{array}{l}\text { Plathow } \\
(2004)^{23}\end{array}$ & 20 & $\begin{array}{l}\text { RM dinâmica, estágio I pulmão não peq. células } \\
\text { imagens adquiridas desde normal à profunda insp. e exp. }\end{array}$ & & & & $60(20)$ & & \\
\hline $\begin{array}{c}\text { Lee } \\
(2004)^{36}\end{array}$ & 10 & $\begin{array}{l}\text { TC, fluoroscopia, respiração normal e máxima } \\
\text { decúbito dorsal } \\
\text { decúbito ventral }\end{array}$ & & & & & $\begin{array}{l}16(1,9) \\
12(1,9) \\
\end{array}$ & \\
\hline $\begin{array}{l}\text { Kimura } \\
(2004)^{37}\end{array}$ & 5 & $\begin{array}{l}\text { Voluntários saudáveis, respiração presa no final da fase de } \\
\text { expiração e da inspiração com espirômetro } \\
\text { TC monitorada } 2 \text { x/ fase, relacionada à referências ósseas }\end{array}$ & $\begin{array}{l}\text { inspiração } \\
\text { expiração } \\
10,0-22,6 \\
\end{array}$ & $\begin{array}{l}(1,5) \\
(1,1)\end{array}$ & $\begin{array}{l}(1,6) \\
(1,2)\end{array}$ & $\begin{array}{l}(1,9) \\
(1,6)\end{array}$ & $\begin{array}{c}\text { Respiração livre } \\
15,8(5,6) \\
\end{array}$ & \\
\hline $\begin{array}{l}\text { Wagman } \\
(2003)^{38}\end{array}$ & 10 & $\begin{array}{l}\text { Monitor de posição em tempo real (RPM), sistema de } \\
\text { controle da expiração a inspiração }\end{array}$ & \begin{tabular}{c|} 
Diafragma dir. \\
Diafragma esq.
\end{tabular} & \begin{tabular}{|c|}
$8,09(1,54)$ \\
$34,21(17,29)$ \\
\end{tabular} & $\begin{array}{r}4,05(4,97) \\
5,58(6,1) \\
\end{array}$ & $\begin{array}{c}11,5(4,81) \\
21,35(12,52) \\
\end{array}$ & & \\
\hline $\begin{array}{l}\text { Ford } \\
(2002)^{39}\end{array}$ & $\begin{array}{c}8 \\
4 \text { (pulmão) } \\
4(\text { fígado) } \\
\end{array}$ & $\begin{array}{l}\text { Planejamento com scan sincronizado à respiração } \\
\text { Com sistema de controle de resp. (gate): } \\
\text { Sem sistema de controle de resp. (gate): }\end{array}$ & & & & & $\begin{array}{c}2,8(1,0) \\
6,9(2,1) \\
\end{array}$ & \\
\hline $\begin{array}{l}\text { Giraud } \\
(2001)^{30}\end{array}$ & 20 & $\begin{array}{l}35 \text { medidas/paciente/ aquisição } \\
3 \text { TC: resp. livre, resp. profunda c/apnéia na insp. e exp. }\end{array}$ & & & & & $34,25(20,4)$ & $67,8 \mathrm{~mm}$ \\
\hline $\begin{array}{l}\text { Dawson } \\
(2001)^{40}\end{array}$ & 8 & $\begin{array}{l}2 \text { TC, fluoroscopia, } 262 \text { radiografias, ABC } \\
\text { Mov. do diafragma em relação ao esqueleto }\end{array}$ & $3,0-6,1$ & & & & SI 4,4 & \\
\hline $\begin{array}{l}\text { Hanley } \\
(1999)^{34}\end{array}$ & 5 & Fluoroscopia, resp. livre, decúbito dorsal & $18,8-38,2$ & & & & 26,4 & \\
\hline
\end{tabular}

Da TABELA 1.2 pode ser observado que o movimento diafragmático do lado direito não é similar ao do lado esquerdo como sugerido por Wagman et al. ${ }^{38}$. Como também pode ser notado que os deslocamentos encontrados variam de um modo geral de 1,1 a 6,1 mm com sistema de controle de respiração (gate). Sem controle da respiração, nota-se variações de 7 a $38,2 \mathrm{~mm}$ para pacientes com respiração normal ou tranquila. Já para os pacientes avaliados nas fases de inspiração e expiração profunda, a variação máxima encontrada foi de $67,8 \mathrm{~mm}$ no diafragma. Os maiores deslocamentos se deram nas direções antero-posterior e superior-inferior ou crânio-caudal. 
TABELA 1.3 - Resumo da literatura reportando variações de posição e alvo na região da cabeça e pescoço, onde rg. vl/ dia é a regressão do volume alvo por dia, estrut. são as estruturas avaliadas e máx. é o deslocamento máximo.

\begin{tabular}{|c|c|c|c|c|c|c|c|c|}
\hline \multirow{2}{*}{$\begin{array}{l}\text { Autor } \\
\text { (ano) }\end{array}$} & \multirow{2}{*}{$\begin{array}{l}\text { No. } \\
\text { Pac }\end{array}$} & \multirow[t]{2}{*}{ Comentário } & \multirow[t]{2}{*}{ Estrut. } & \multirow{2}{*}{$\begin{array}{c}\text { rg. } \\
\text { vl./dia } \\
\text { (\%/dia) }\end{array}$} & \multicolumn{3}{|c|}{$\begin{array}{l}\text { Deslocamento } \\
(\mathrm{mm})\end{array}$} & \multirow{2}{*}{$\begin{array}{l}\text { Máx. } \\
\text { (mm) }\end{array}$} \\
\hline & & & & & $A / P$ & $\mathrm{D} / \mathrm{E}$ & $\mathrm{S} / \mathrm{I}$ & \\
\hline \multirow{2}{*}{$\begin{array}{c}\text { Barker } \\
(2004)^{43}\end{array}$} & \multirow{2}{*}{14} & \multirow{2}{*}{$\begin{array}{c}\text { Taxa de regressão do volume } \\
\text { durante o trat. em relação ao } \\
\text { vol. inicial do CT }\end{array}$} & GTV & 1,8 & & & & 3,1 \\
\hline & & & Parótidas & 0,6 & & & & \\
\hline $\begin{array}{c}\text { Gross } \\
(2003)^{44}\end{array}$ & 40 & $\begin{array}{l}\text { Desl. dos isocentros em relação } \\
\text { às coord. estereotáxicas em } \\
\text { pac. com tumor ENT. } \\
\text { Desl. espacial médio de } \\
5,06 \mathrm{~mm} \text {. }\end{array}$ & & & 2,54 & 2,15 & 2,69 & \\
\hline
\end{tabular}

Existem poucos trabalhos na literatura sobre as variações da região da cabeça e pescoço. Embora não hajam grandes variações de órgãos internos nesta região, existe uma variação significante do volume na região de tratamento como mostra o estudo de Barker et al. ${ }^{43}$ e mesmo para os casos de pacientes com máscara de imobilização estereotáxica, os deslocamentos da posição do isocentro de uma fração a outra do tratamento também não podem ser desprezados, como mostra o trabalho de Gross et al. ${ }^{44}$ ( deslocamentos do isocentro da ordem de $2 \mathrm{~mm}$ ). 


\section{OBJETIVOS}

\subsection{OBJETIVO GERAL}

Definir métodos para avaliar margens dada ao volume clínico do alvo (CTV) para gerar volume de planejamento do alvo (PTV) em pacientes submetidos à terapia com radiação e verificar como a margem dada ao PTV pode afetar em termos de dose o planejamento tridimensional com e sem a utilização de planejamento inverso.

\subsection{OBJETIVOS ESPECÍFICOS}

- Caracterizar os dosímetros usados nas técnicas: radioterapia tridimensional conformada (3DCRT ou 3-D convencional) e a radioterapia com modulação de feixe (IMRT);

- Determinar técnicas experimentais para avaliação dos erros e incertezas associadas ao PTV e o seu efeito na radioterapia, por meio do:

- Estudo das incertezas relacionadas à localização do paciente para os casos de radioterapia da região da cabeça e pescoço;

- Efeito do deslocamento do isocentro na distribuição de dose e do tamanho do PTV nas doses geradas nas estruturas críticas vizinhas à ele;

- Efeito da margem dada ao volume alvo para formar o PTV em relação à dose na superfície para IMRT com planejamento inverso;

- Estudo de como o PTV afeta a distribuição de dose fora do campo de radiação;

- Estudo para avaliar incertezas relacionadas ao movimento de órgãos entre frações de tratamento para o caso da próstrata;

- Efeito na dose devido ao movimento do isocentro através das novas coordenadas geradas pela localização do alvo com ultra-som 2D;

- Definir margens para gerar o volume de planejamento do alvo. 


\section{FUNDAMENTOS}

Este capítulo destina-se à física geral aplicada ao tratamento radioterápico. Será apresentado um resumo das interações da radiação com a matéria, distribuição de dose bem como alguns formalismos usados na radioterapia.

\subsection{FÍSICA DO PLANEJAMENTO DE TRATAMENTO}

\subsubsection{Interações da radiação com a matéria ${ }^{3-5}$}

Existem quatro tipos básicos de radiação ionizante: partículas alfa (núcleo de hélio), partículas beta (elétrons e pósitrons), fótons e nêutrons. Na radioterapia, os fótons são o tipo de radiação mais utilizado.

Os fótons são ondas eletromagnéticas que carregam energia e depositam dose na matéria através de um processo com duas etapas. Na primeira etapa a energia dos fótons é transferida para partículas carregadas e na segunda etapa as partículas carregadas interagem com outras partículas carregadas depositando energia e causando dano no meio. Devido a esse processo é que os fótons são conhecidos como radiações indiretamente ionizantes e partículas carregadas são radiações diretamente ionizantes.

Os fótons podem perder energia para elétrons e pósitrons em um meio através de vários tipos de interações. A Tabela 3.1 resume os tipos mais comuns de interações da radiação com a matéria.

A probabilidade da interação depende da energia do fóton, $h v$, e do número atômico do material atenuador, $Z$. A intensidade $I(x)$ de um feixe de fótons ao passar por um meio de espessura $x$ pode ser representado por

$$
I(x)=I(0) e^{-\mu(h v, Z) x},
$$

onde o coeficiente de atenuação linear, $\mu$, descreve a probabilidade de um evento de transferência de energia de fótons monoenergéticos primários por unidade de espessura de um material, que depende da energia da radiação incidente, $h_{v}$, do número atômico do material, $z$, e do meio absorvedor. Um fóton pode transferir toda ou parte de sua energia através de vários tipos diferentes de interação que podem resultar em ionização do átomo, excitação, ou produção de um par elétron- 
pósitron. A energia pode aparecer como energia cinética $(K E)$ de partículas carregadas, assim como na formação de energia de repouso $\left(m_{e} c^{2}\right)$ das partículas carregadas.

Tabela 3.1. Resumo das principais características de algumas interações da radiação com a matéria ${ }^{3}$.

\begin{tabular}{|c|c|c|c|c|c|}
\hline & $\begin{array}{c}\text { Efeito } \\
\text { Fotoelétrico }\end{array}$ & $\begin{array}{l}\text { Espalha- } \\
\text { mento } \\
\text { Rayleigh }\end{array}$ & $\begin{array}{c}\text { Efeito } \\
\text { Compton }\end{array}$ & $\begin{array}{c}\text { Produção de } \\
\text { Pares }\end{array}$ & $\begin{array}{c}\text { Produção de } \\
\text { Tripleto }\end{array}$ \\
\hline $\begin{array}{l}\text { Alcance típico da } \\
\text { energia de fótons }\end{array}$ & $0-0,5 \mathrm{MeV}$ & $<1 \mathrm{MeV}$ & Aprox. $1 \mathrm{MeV}$ & $>1,022 \mathrm{MeV}$ & $>2,044 \mathrm{MeV}$ \\
\hline $\begin{array}{l}\text { Interação dos } \\
\text { fótons com }\end{array}$ & átomos & $\begin{array}{l}\text { elétrons } \\
\text { ligados }\end{array}$ & elétrons livres & $\begin{array}{c}\text { campo } \\
\text { Coulombiano } \\
\text { do núcleo }\end{array}$ & $\begin{array}{c}\text { campo } \\
\text { Coulombiano } \\
\text { de elétrons }\end{array}$ \\
\hline $\begin{array}{l}\text { Energia transferida } \\
\text { às part. } \\
\text { carregadas }\end{array}$ & $h v-P_{k} \omega_{k} h \bar{v}_{k}$ & 0 & $\bar{E}_{t r}^{\sigma}$ & $h v-2 m_{e} c^{2}$ & $h v-4 m_{e} c^{2}$ \\
\hline $\begin{array}{l}\text { Dependência } \\
\text { energética }\end{array}$ & $\frac{1}{(h v)^{3}}$ & $\frac{1}{(h v)^{2}}$ & $\begin{array}{l}\text { decresce } \\
\text { com } h v\end{array}$ & $\begin{array}{c}\text { aumenta com } \\
h v\end{array}$ & $\begin{array}{c}\text { aumenta com } \\
h v\end{array}$ \\
\hline $\begin{array}{l}\text { Dependência } \\
\text { atômica com } Z\end{array}$ & $Z^{4}$ & $Z^{2}$ & $Z$ & $Z^{2}$ & $\begin{array}{c}\text { aumenta com } \\
Z\end{array}$ \\
\hline
\end{tabular}

Quando um fóton interage com um átomo através de um elétron fracamente ligado, ele pode ser defletido em ângulos pequenos e não transferir praticamente nenhuma energia por um processo chamado espalhamento Rayleigh, também conhecido como espalhamento coerente ou elástico.

No efeito fotoelétrico o fóton também interage com um elétron fracamente ligado e toda a energia do fóton é transferida ao elétron que é ejetado do átomo. O fóton é totalmente absorvido e o elétron ejetado com energia cinética KE é chamado de fotoelétron. A energia inicial do fóton $h v$ deve ser maior que a energia de ligação, $B_{e}$. A energia cinética do elétron ejetado é dada por $h v-B_{e}$. A lacuna no átomo pode então ser preenchida por um elétron de uma camada mais externa com a emissão de um raio-X característico ou um elétron Auger.

O efeito Compton, também denominado espalhamento incoerente, é a interação de um fóton com um elétron orbital fracamente ligado. $\mathrm{O}$ fóton com energia inicial 
$h v$ transfere parte de sua energia ao elétron que em seguida é ejetado do átomo em um ângulo $\Phi$ e com energia cinética $K E$. $O$ fóton original é espalhado com energia $h v$ 'e ângulo de espalhamento $\theta$.

No processo de produção de pares um fóton ao passar na vizinhança de um campo nuclear pode desaparecer dando origem a um par de elétron e pósitron se a energia do fóton estiver acima da energia limiar de $2 m_{e} c^{2}$, onde $m_{e}$ é a massa do elétron. Se o fóton estiver dentro do campo de um elétron orbital poderá ocorrer produção de tripleto. Neste processo o fóton nas proximidades do núcleo se transforma em um elétron e um pósitron que compartilham a energia cinética remanescente com o elétron orbital. A energia limiar para ocorrer produção de tripletos é $4 m_{e} c^{2}$. Após a produção de par ou tripleto, o pósitron pode se combinar com um elétron em uma interação de aniquilação e dois fótons de $511 \mathrm{keV}$ são emitidos em direções opostas.

Os fótons com energias altas também podem interagir diretamente com o núcleo do átomo e ser absorvido. Nas reações fotonucleares, um nêutron ou próton é emitido após a interação do fóton com o núcleo do átomo resultando em uma transformação nuclear do átomo em um isótopo radioativo.

A probabilidade de interação do fóton com um meio é dependente da energia do fóton e do número atômico do material absorvedor como foi visto na TAB. 3.1 que mostra a relação do efeito fotoelétrico, o efeito Compton e a produção de pares como uma função destes dois parâmetros. Na radioterapia a energia média do feixe de tratamento está entre 1 e $10 \mathrm{MeV}$, o tecido tem $Z_{\text {efetivo }} \sim 7$, isto faz do efeito Compton a interação do fóton predominante nesta área ${ }^{45}$.

Conforme as interações dos fótons com a matéria ocorrem, o feixe de fótons primários vai sendo atenuado. $O$ coeficiente de atenuação linear total $\mu$ será então a soma de todos os coeficientes de atenuação de todos os processos descritos e representado por:

$$
\mu=\sigma_{R}+\sigma_{C}+\kappa+\tau,
$$

onde $\sigma_{R}, \sigma_{C}, \kappa$,e $\tau$ são os coeficientes de atenuação devido ao espalhamento Rayleigh, espalhamento Compton, produção de pares e tripletos, e efeito fotoelétrico, respectivamente. O coeficiente de atenuação de massa que também é comumente usado na física das radiações é definido como o coeficiente de atenuação linear do material dividido por sua densidade, $\mu / \rho$. 


\subsubsection{Fluência de partícula e energia ${ }^{3-5}$}

Quando partículas monoenergéticas atravessam um meio elas adquirem um espectro de energia devido à natureza randômica da interação de partículas e transferência de energia. Isto é referido como energia de difusão e aplica-se a partículas incidentes e subsequentes. Se estas partículas forem fótons então o alcance de difusão é usado para descrever a variação em taxa de perda de energia de elétrons orbitais liberados. A energia e alcance de difusão bem como $o$ espalhamento múltiplo de elétrons torna difícil o conhecimento absoluto das características do feixe de radiação na profundidade. Duas grandezas dosimétricas descrevem um feixe de radiação em um ponto: o espectro de fluência da partícula, $\Phi$, e o espectro de fluência de energia, $\psi$. Elas são características da geometria através do qual as partículas passam. $O$ espectro de fluência da partícula é dada por:

$$
\left.\Phi=\int_{0}^{E_{\max }} \frac{d \Phi(T)}{d T} d T \text { [partículas } / \mathrm{m}^{2}\right],
$$

e a fluência de energia é dada por:

$$
\Psi=\int_{0}^{E_{\max }} \frac{d \Psi(T)}{d T} d T\left[\mathrm{~J} / \mathrm{m}^{2}\right],
$$

ou em termos de espectro de fluência da partícula:

$$
\Psi=\int_{0}^{E_{\max }} \frac{T \cdot d \Phi(T)}{d T} d T
$$

onde $T$ é a energia cinética da partícula. Se a partícula for um fóton então é usada a energia do fóton.

\subsubsection{Interações com elétrons e poder de freamento}

As partículas carregadas perdem energia por meio de métodos diferentes e distintos dos ocorridos com partículas não carregadas. Enquanto os fótons podem passar através da matéria sofrendo um número pequeno de interações, perdendo pouca energia, ou participando de um número limitado de eventos catastróficos, as partículas carregadas, envoltas pelo campo coulombiano, interagem com o núcleo dos átomos e elétrons orbitais, ao longo de sua trajetória. Por causa 
destas interações múltiplas as partículas carregadas leves são espalhadas muitas vezes e, portanto, viajam em distâncias finitas antes de parar completamente ${ }^{46,47}$. Estes eventos podem ser descritos por colisões elásticas, onde o elétron é espalhado em uma direção diferente sem perda de energia, ou por colisões inelásticas, onde o elétron transfere parte da sua energia cinética a um elétron orbital ou a energia é perdida através de interações de bremsstrahlung, onde ela é emitida na forma de fótons como resultado de uma desaceleração de uma partícula carregada.

A energia cinética do elétron perdida por unidade de comprimento de trajetória no meio absorvedor é definida como o poder de freamento de energia de massa e definido na equação 3.6.

$$
\left(\frac{S}{\rho}\right)_{\text {total }}=\frac{1}{\rho} \frac{d T}{d x}\left[\mathrm{MeV} \cdot \mathrm{cm}^{2} / \mathrm{g}\right]
$$

onde $\rho$ é a densidade do material atenuador e $T$ a energia cinética do elétron. Esta grandeza pode ser decomposta em dois componentes distintos: no poder de freamento de colisão de massa, devido às interações com elétrons do orbital, e no poder de freamento radioativo de massa, devido às interações com o núcleo ${ }^{46}$. Então tem-se que:

$$
\left(\frac{S}{\rho}\right)_{\text {total }}=\left(\frac{S}{\rho}\right)_{\mathrm{col}}+\left(\frac{S}{\rho}\right)_{\mathrm{rad}} .
$$

O poder de freamento de colisão mássico para elétrons é dado por ${ }^{46}$ :

$$
\left(\frac{S_{c o l}}{\rho}\right)=c \frac{1}{\beta^{2}} \frac{Z}{A}\left[\ln \left(\frac{T}{I}\right)^{2}+\ln (1+\tau / 2)+F^{ \pm}(\tau)-\delta-C / Z\right]
$$

onde

C é uma constante;

$\beta \quad$ é a velocidade da partícula incidente normalizada para a velocidade da luz $v / c$;

$Z \quad$ é o número atômico do material;

A é o número de massa do material;

I é o potencial de ionização e excitação médio dos átomos do material;

$\tau \quad$ é a energia cinética da partícula incidente normalizada para a energia de repouso $T / m_{e} c^{2}$; 
$\delta \quad$ é a correção de polarização;

$F^{ \pm}(\tau)$ é uma notação estenográfica para funções auxiliares das energias cinéticas do pósitron e elétron; e

C/Z é a correção da camada que é uma função do meio e da velocidade da partícula carregada.

A expressão para poder de freamento radioativo é aplicável a elétrons e pósitrons porque eles podem gerar uma quantidade significante de bremsstrahlung. $O$ poder de freamento não restrito é dado por:

$$
\left(\frac{S_{r a d}}{\rho}\right)=c \frac{Z^{2}}{A}\left(T+m_{e} c^{2}\right) \bar{B}_{r}
$$

em que

$\bar{B}_{r}$ é uma função que varia lentamente com a energia da partícula incidente com valores entre 16/3 e 15 para feixe de fótons de alta energia.

O poder de freamento das equações 3.6 a 3.9 dependem da partícula incidente (energia cinética) e do meio absorvedor $(Z, A, l$ e $\delta)$.

\subsubsection{Conceito de KERMA, dose absorvida e equilíbrio da partícula carregada}

\subsubsection{KERMA ${ }^{3,48,49}$}

A energia cinética liberada por unidade de massa é chamada KERMA. Esta grandeza representa a quantidade média de energia transferida de partículas não carregadas tais como fótons a partículas carregadas como elétrons e pósitrons e pode ser indicada por:

$$
K=\frac{d \bar{E}_{t r}}{d m}
$$

A unidade para KERMA é joule por kilograma $(\mathrm{J} / \mathrm{kg})$. Esta grandeza pode ser separada em dois componentes, o KERMA de colisão, $\mathrm{K}_{\mathrm{col}}$, e o KERMA radioativo, $\mathrm{K}_{\text {rad, }}$, onde

$$
K=K_{c o l}+K_{\text {rad }} \text {. }
$$

O KERMA de colisão representa a quantidade de energia transferida para partículas carregadas por meio de interações de colisão e o KERMA radioativo representa a quantidade de energia transferida através de interações radioativas, 
tais como bremsstrahlung e aniquilação elétron-pósitron. O KERMA total pode ser relacionado ao KERMA de colisão pela fração de bremsstrahlung $g$, tal como mostrado na equação 3.12 :

$$
K_{c o l}=K(1-g)
$$

O KERMA total em um ponto no absorvedor também pode ser relacionado à fluência de energia do fóton, $\psi$, que é a energia incidente radiante em uma esfera com área de seção de choque $d A$, por

$$
K=\psi\left(\frac{\mu_{t r}}{\rho}\right) .
$$

\subsubsection{Dose absorvida ${ }^{3,48-51}$}

O termo dose absorvida refere-se à energia transferida de partículas carregadas ao meio e que é absorvida localmente perto do sítio de interação. A energia liberada neste processo ocorre randômicamente em eventos discretos e por isso é descrita por uma função de probabilidade. A dose absorvida é definida em um ponto ainda que a energia liberada seja definida sobre um volume. A probabilidade de ocorrer um evento em um único ponto é zero porque a seção de choque de área de um ponto no qual as partículas podem colidir é zero. Portanto, dose é uma grandeza não estocástica derivada de um valor esperado da energia liberada:

$$
D=\frac{d \bar{\varepsilon}}{d m},
$$

onde $\bar{\varepsilon}$ é a energia média liberada por partículas carregadas em um volume de massa $\mathrm{m}$. A unidade de dose absorvida é o Gray (Gy) e $1 \mathrm{~Gy}=1 \mathrm{~J} / \mathrm{kg}$.

$A$ dose $D$ em um meio está relacionada ao poder de freamento de colisão de massa por meio da expressão:

$$
D=\phi\left(\frac{S}{\rho}\right)_{c o l},
$$

onde $\phi$ é a fluência do elétron no meio. 


\subsubsection{Equilíbrio eletrônico da partícula carregada (CPE)}

O equilíbrio (ou equilíbrio eletrônico) da partícula carregada (CPE) é um estado obtido dentro da matéria irradiada quando existe um equilíbrio entre as partículas que estão entrando e as que estão saindo de uma dada região. Para um feixe de fótons incidente em um dado atenuador o KERMA de colisão será maior na superfície do meio e decrescerá exponencialmente de acordo com o coeficiente de atenuação, já que o KERMA é dependente da fluência de energia do fóton. A dose absorvida é proporcional à fluência de elétrons, e elétrons são gerados a partir das interações dos fótons então, assumindo que um feixe de fótons é livre de elétrons, a dose será menor na superfície e aumentará continuamente (região de buildup) até que o equilíbrio entre as partículas carregadas (CPE) seja alcançado. Neste ponto a dose absorvida e o KERMA de colisão são iguais, resultando na relação $3.16^{3,49,52}$.

$$
D=K_{c o l}=K(1-g) .
$$

Após a condição de equilíbrio eletrônico ser alcançada a dose se torna um pouco menor que o KERMA de colisão. Isto ocorre porque os elétrons secundários (elétrons nos quais os fótons transferiram suas energias) somente depositarão esta energia após o ponto de transferência de energia inicial do fóton. Em geral, a dose é relacionada ao KERMA de colisão por uma constante de proporcionalidade $\beta$ dada pela relação abaixo

$$
D=\beta K_{\text {col }},
$$

onde $\beta<1$ na região de buildup (antes do CPE), $\beta=1$ no CPE e $\beta>1$ no equilíbrio transiente da partícula carregada (TCPE). O TCPE ocorre após o CPE, pois a fluência dos fótons é reduzida devido a atenuação na matéria e, portanto, é gerado um número menor de elétrons secundários. Esta relação é ilustrada na FIG. 3.1. 


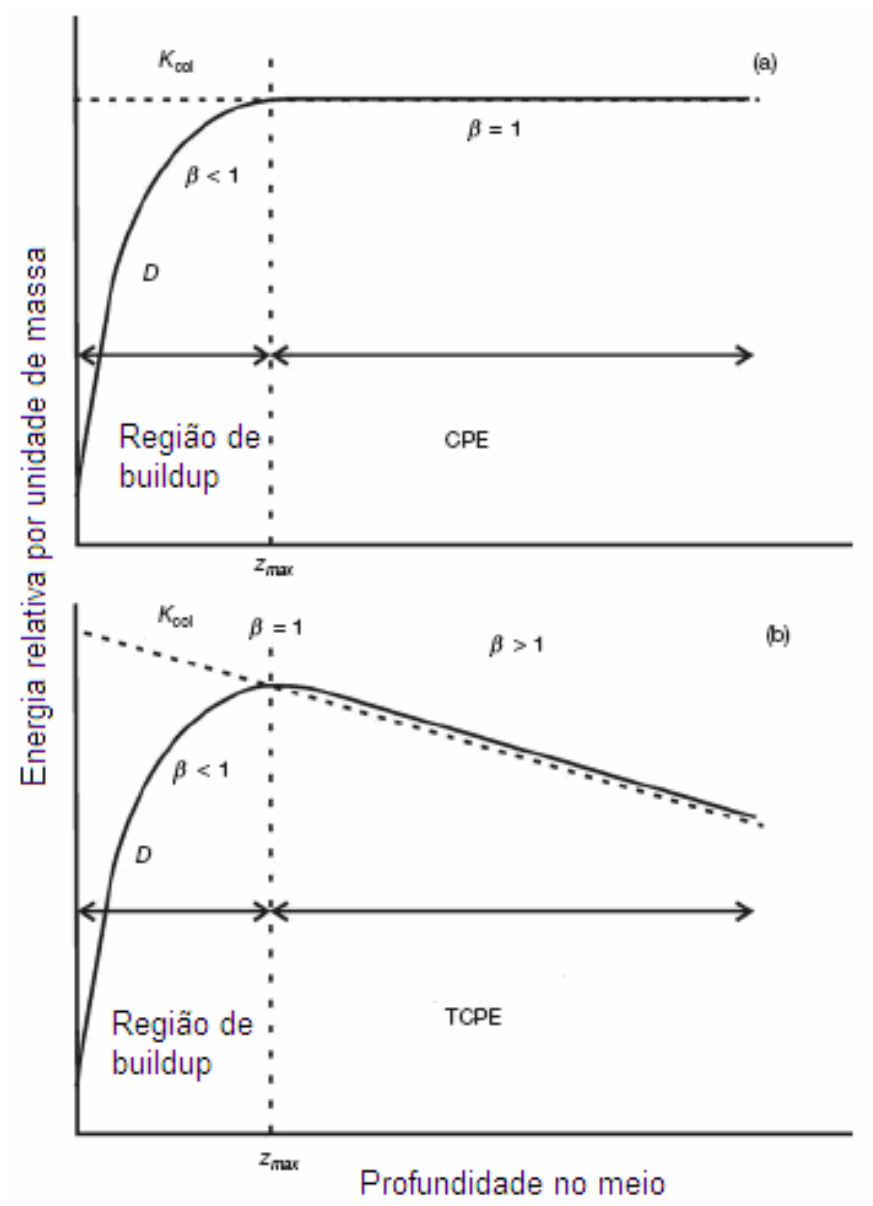

FIGURA 3.1 - Dose absorvida e KERMA de colisão como uma função da profundidade no meio irradiado por um feixe de fótons de alta energia para: (a) o caso hipotético sem atenuação do fóton ou espalhamento; e para (b) o caso realista ${ }^{3}$.

\subsubsection{Parâmetros de cálculo de dose de feixe de fótons}

\subsubsection{Inverso do quadrado da distância}

$\mathrm{Na}$ radioterapia com feixe de fótons externo, o feixe de tratamento pode vir tanto de uma fonte radioativa como de um alvo de raios-X. Como o feixe de fótons se propaga no ar, ele irradia isotrópicamente de um ponto e a fluência de fótons $\psi$ (número de fótons por unidade de área) decresce com a distância $f$ como é mostrado na equação 3.18 .

$$
\left(\frac{\psi_{1}}{\psi_{2}}\right)=\left(\frac{f_{2}}{f_{1}}\right)^{2},
$$


em que os sub-escritos 1 e 2 referem-se a duas distâncias arbitrárias da fonte pontual do feixe de fótons. Como o KERMA no ar é proporcional à fluência de fótons e a dose em uma massa pequena de ar, então pode-se dizer que a dose $D^{\prime}$ em uma profundidade $d$, em uma área $A$, com uma distância $f$ da fonte e energia $h v$ pode ser relacionada à dose em outra distância por ${ }^{3}$ :

$$
\left[\frac{D^{\prime}\left(d, A_{1}, f_{1}, h v\right)}{D^{\prime}\left(d, A_{2}, f_{2}, h v\right)}\right] \propto\left(\frac{f_{2}}{f_{1}}\right)^{2} .
$$

Este conceito conhecido na radioterapia como a lei do inverso do quadrado da distância diz, basicamente, que a dose é inversamente proporcional ao quadrado da distância da fonte.

\subsubsection{Formalismos dos parâmetros de localização: DFS e DFI}

Em radioterapia, existem dois formalismos usados para definir os parâmetros do tratamento de acordo com as condições estabelecidas para o posicionamento do paciente (termo conhecido como setup). Um dos formalismos é a técnica da distância da fonte à superfície (DFS), que utiliza a distância da fonte de radiação à superfície do paciente ou simulador de tecido e, o outro, é a técnica da distância da fonte ao eixo central (DFI) que utiliza a distância da fonte ao ponto do isocentro do paciente.

A técnica DFI é escolhida frequentemente para tratamentos que incluem vários campos ao redor do alvo, enquanto a DFS é usada geralmente para os casos de lesão superficial.

\subsubsection{Fatores que relacionam dose na profundidade à dose no ponto de referência: porcentagem de dose profunda (PDP), razão tecido-ar (TAR), razão tecido-simulador (TPR) e razão tecido-máximo (TMR) ${ }^{3,49}$}

A realização de medições do rendimento do feixe em todas as profundidades e posições é uma tarefa muito trabalhosa. Geralmente, os rendimentos dos feixes são obtidos na profundidade de referência e relacionados a outros pontos no simulador de tecido através de fatores dependentes da profundidade. $O$ parâmetro mais usado na radioterapia é a porcentagem de dose profunda (PDP). A PDP em um meio é definida como a razão da dose num ponto no eixo central 
do feixe à dose na profundidade de dose máxima, $d_{\max }$, e é definido na equação 3.20 .

$$
P D P(d, A, f, h v)=100 \frac{D_{Q}}{D_{P}},
$$

onde $D_{Q}$ é a dose na profundidade $d$ em um simulador de tecido e $D_{P}$ é a dose no ponto $P\left(\mathrm{~d}_{\max }\right)$ no eixo central do feixe. A PDP é dependente da profundidade $d$ no simulador de tecido, do tamanho de campo $A$ na superfície do simulador de tecido, da distância fonte superfície (DFS) fe da energia $h v$ do feixe de fótons.

Nos casos em que são necessários vários feixes para o tratamento radioterápico, é mais prático liberar o tratamento usando um isocentro ou distância da fonte ao eixo central constante (DFI). O paciente deve ser posicionado no isocentro da máquina de tratamento, para que a estativa rotatória possa girar ao redor deste ponto para liberar cada um dos feixes sem a necessidade de movimentar 0 paciente durante o tratamento. Na maioria dos casos, a distância fonte ao isocentro, ponto $Q$, é fixada em $100 \mathrm{~cm}$. Uma nova série de parâmetros dosimétricos usando este formalismo deve ser definida. A relação tecido-ar (TAR) é a primeira desta série e é dada por:

$$
\operatorname{TAR}\left(d, A_{Q}, h v\right)=\frac{D_{Q}}{D_{Q}^{\prime}},
$$

em que $D_{Q}$ é a dose no simulador de tecido no isocentro e $D_{Q}^{\prime}$ é a dose no ar em um meio com massa pequena no isocentro. Na técnica DFI o tamanho de campo é definido no isocentro.

Em virtude da fluência inadequada de partículas carregadas durante a realização de medidas no ar para feixes com energias superiores a $1 \mathrm{MeV}$ são utilizadas as razões tecido-simulador, TPR, e razão tecido-máximo, TMR. De forma similar ao TAR, o TPR é dado por:

$$
\operatorname{TPR}\left(d, A_{Q}, h v\right)=\frac{D_{Q}}{D_{Q r e f}},
$$

em que $D_{\text {Qref }}$ é a dose no simulador na profundidade de referência no eixo central do feixe de radiação e $D_{Q}$ é a dose a um dado ponto no simulador no eixo central. $\mathrm{Na}$ FIG. 3.2 é mostrado este conceito. Alternativamente, a profundidade de referência pode ser escolhida como a profundidade de dose máxima. Neste caso, 
o fator que relaciona a dose neste ponto à dose no ponto arbitrário é denominada razão tecido-máxima (TMR) e é dada por:

$$
\operatorname{TMR}\left(d, A_{Q}, h v\right)=\frac{D_{Q}}{D_{Q \max }} .
$$

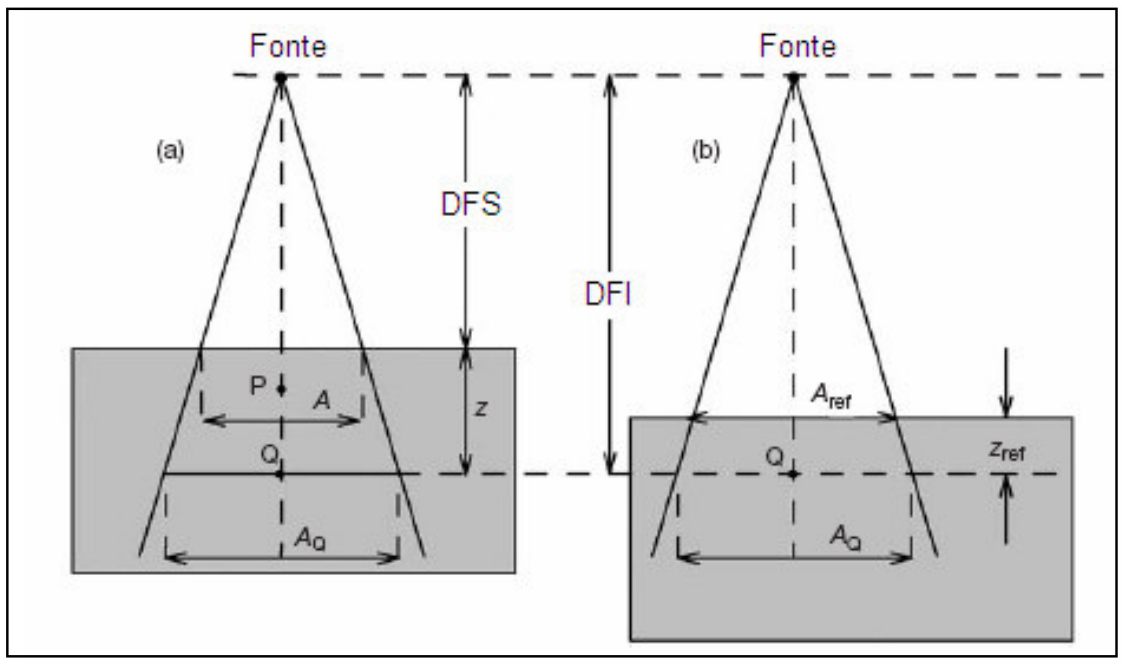

FIGURA 3.2 - Geometria usada para medida de TPR (d, $A_{Q}, h v$ ). (a) Geometria para medida de $D_{Q}$ na profundidade $z$ no simulador; (b) geometria para medida de $D_{\text {Qref }}$ na profundidade $z_{\text {ref }}$ no simulador. A distância entre a fonte e o ponto de medida, assim como o tamanho de campo no ponto de interesse, é a mesma para (a) e (b) ${ }^{3}$.

A principal vantagem em se utilizar os parâmetros TAR, TPR e TMR na radioterapia é que eles são independentes da distância fonte-superfície (DFS) e são, portanto, condizentes aos tratamentos com DFI fixas.

\subsubsection{Fatores que afetam a fluência do feixe: PSF, CF, SF, RDF e OCR ${ }^{3,49}$}

Uma vez que a dose na profundidade de referência é conhecida vários parâmetros são utilizados para caracterizar o rendimento da máquina em relação ao tamanho de campo. Nominalmente, o fator de pico espalhamento (PSF), o fator colimador (CF), o fator espalhamento (SF) e o fator de dose relativa (RDF) são utilizados na radioterapia. 
O fator de pico espalhamento (PSF) é definido como a dose no ponto $P$ no simulador em relação a dose no ponto $P$ no ar, $\frac{D_{P}}{D_{P}^{\prime}}$, em um meio de massa pequena o suficiente para alcançar CPE. Este fator leva em conta o aumento de espalhamento devido à presença do simulador irradiado. O PSF é independente do tamanho de campo e da energia do feixe.

$$
\operatorname{PSF}(A, h v)=\frac{D_{P}}{D_{P}^{\prime}} .
$$

O fator colimador (CF) leva em conta o aumento no espalhamento do colimador que ocorre devido a uma área grande do material do colimador ficar exposto ao feixe quando o tamanho de campo é aumentado. O CF é definido como a dose dada a uma massa pequena no ar no ponto $P$ para um dado tamanho de campo $A$ em relação à dose em uma massa pequena no ponto $P$ para um tamanho de campo de $10 \times 10 \mathrm{~cm}^{2}$.

$$
C F(A, h v)=\frac{D_{P}(A, h v)}{D_{P}(10, h v)}
$$

O fator de espalhamento (SF) é o PSF para um dado tamanho de campo $A$ normalizado ao PSF para o tamanho de campo de referência de $10 \times 10 \mathrm{~cm}^{2}$, representado por:

$$
S F(A, h v)=\frac{P S F(A, h v)}{P S F(10, h v)} .
$$

O fator de dose relativo (RDF) é a razão da dose no ponto $P$ para um dado tamanho de campo para a dose no ponto $P$ para um tamanho de campo de $10 \times 10 \mathrm{~cm}^{2}$. Com um pouco de manipulação algébrica, mostrado na equação 3.27 , pode-se verificar que o RDF é um produto simples do fator colimador e o fator espalhamento:

$$
R D F(A, h v)=\frac{D_{P}(A, h v)}{D_{P}(10, h v)}=S F(A, h v) C F(A, h v)
$$

Como todos os parâmetros apresentados anteriormente referem-se à dose no eixo central do feixe, faz-se então necessário relacionar a dose em pontos fora do eixo central com a dose no eixo central. A razão de dose fora do eixo central (OCR) é definida como a razão entre a dose em um ponto no eixo central na profundidade $d$ e a dose num ponto fora do eixo central, para uma mesma profundidade. A equação resultante é: 


$$
\operatorname{OCR}(d, x)=\frac{D(d, x)}{D(d, x=0)},
$$

em que $x$ é a distância lateral do eixo central.

\subsubsection{Dose superficial, dose de entrada e dose de saída}

A medição direta da distribuição de dose no interior do paciente é praticamente impossível ainda que seja necessário o conhecimento da distribuição de dose no volume irradiado com precisão e acurácia para que se obtenha um tratamento bem sucedido. Isto pode ser alcançado através do uso de várias funções que relacionam a dose em qualquer ponto arbitrário dentro do paciente a uma dose conhecida no ponto de calibração do feixe (ou referência) no simulador ${ }^{3,49}$. As funções são medidas com detectores de radiação em simuladores equivalentes ao tecido ou água e a dose no ponto de referência é determinada para água em condições de referência específicas tais como profundidade, distância fontesuperfície, como discutido na Seção 3.1.5.4.

Uma distribuição de dose típica de um feixe de fótons de megavoltagem quando atinge o paciente é mostrado na FIG. 3.3. O feixe penetra o paciente na superfície onde libera uma certa dose superficial $D_{s}$. Após a superfície a dose aumenta rapidamente alcançando um valor máximo na profundidade $Z_{\max }$ e então decresce quase que exponencialmente até um valor $D_{e x}$ no ponto onde o feixe sai do paciente.

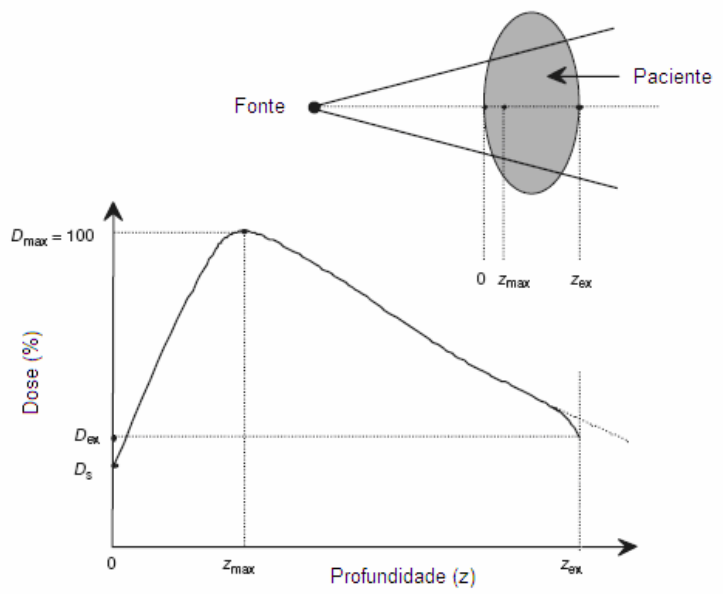

FIGURA 3.3 - Deposição de dose de um feixe de fótons de megavoltagem em um paciente. $D_{s}$ é a dose na superfície no lado de entrada do feixe, $D_{e x}$ é a dose na superfície no lado de saída do feixe, $D_{\max }$ é a dose máxima normalizada a 100. A região entre $z=0$ e $z=z_{\max }$ é denominada região de buildup ${ }^{3}$. 
Para feixe de fótons de megavoltagem a dose na superfície é muito menor que a dose máxima e depende da energia do feixe e do tamanho de campo. Quanto maior for a energia do feixe, menor será a dose de superfície. A dose na superfície para um feixe com tamanho de campo $10 \times 10 \mathrm{~cm}^{2}$ será aproximadamente $30 \%$ no caso de feixe de cobalto e $15 \%$ para um feixe de raios-X de $6 \mathrm{MV}$. A dose na superfície, quando é comparada à dose máxima, se refere ao efeito de poupar a pele, que representa uma vantagem importante dos feixes de megavoltagem sobre os antigos feixes de ortovoltagem e feixes superficiais no tratamento de tumores profundos.

A dose superficial representa a contribuição da dose proveniente de: a) fótons espalhados dos colimadores, filtro achatador, e ar; b) fótons retro-espalhados do paciente e c) elétrons de alta energia produzidos pela interação de fótons no ar e em qualquer estrutura de blindagem, ou de proteção, perto do paciente ${ }^{3}$.

$\mathrm{Na}$ região que fica imediatamente após a superfície do paciente a condição de CPE não é alcançada e portanto, a dose absorvida é bem menor que o KERMA de colisão. A dose de entrada geralmente se encontra em qualquer ponto nesta região e depende da profundidade em que se encontra o ponto efetivo de medida do detector de radiação. Na prática, a medida da dose de superfície é muito difícil de ser realizada, principalmente por causa da incerteza na geometria feixedetector e por isso, ela geralmente é realizada na profundidade do ponto efetivo de medida do detector e pode ser estimada através de simulações que utilizam cálculos de Monte Carlo. Quando a dose é realizada em algum ponto entre a região $z=0$ e $z=z_{\max }$, então ela será conhecida como dose de entrada. Com 0 aumento da profundidade o CPE é alcançado. Nesta profundidade, $z=z_{\max }$ que é aproximadamente igual ao alcance das partículas secundárias carregadas, e a dose se torna comparável ao KERMA de colisão. Após a profundidade de $Z_{\max }$ tanto a dose quanto o KERMA de colisão decrescem devido à atenuação dos fótons no paciente.

A dose liberada no paciente no ponto de saída do feixe é denominada dose de saída. Como representado na FIG. 3.3, perto do ponto de saída do feixe a curva de distribuição de dose apresenta uma inclinação para baixo em relação à curva de distribuição de dose extrapolada. Este efeito relativamente pequeno é atribuído à perda de espalhamento no ponto de saída do feixe devido à falta de tecido além deste ponto. 


\subsection{PROCESSO DE PLANEJAMENTO TRIDIMENSIONAL}

Este item destina-se ao processo de planejamento tridimensional aplicado na radioterapia. Será apresentado um resumo das técnicas de posicionamento, aquisição de imagens, transferência de dados, algorítmos de cálculo de dose e controle de qualidade pré e pós-tratamento.

\subsubsection{Simulação do tratamento ${ }^{2-4}$}

A simulação do tratamento foi desenvolvida para assegurar que os feixes escolhidos para o tratamento do paciente são adequados para englobar o alvo. Hoje em dia, a simulação consiste em: determinar a posição de tratamento; adquirir os dados do paciente para o planejamento do tratamento; identificar os volumes alvos e os órgãos de risco; determinar e verificar a geometria dos campos de tratamento; e gerar radiografias de simulação para cada feixe de tratamento para comparação com os portais, que são filmes realizados com o feixe de tratamento.

\subsubsection{Posicionamento e imobilização do paciente ${ }^{2-4}$}

A primeira fase da simulação é o posicionamento do paciente na mesa de simulação, que geralmente é igual à mesa de tratamento. $O$ paciente é normalmente posicionado em decúbito dorsal. A posição em decúbito ventral é utilizada quando o paciente não é capaz de se manter imóvel em decúbito dorsal, ou quando o tumor se extende até próximo ou na superfície posterior do corpo.

Alguns pacientes podem ou não requerer algum tipo de imobilização externa para o seu tratamento, isto irá depender da posição do tratamento ou da precisão necessária para sua reprodutibilidade.

A imobilização do tratamento tem duas características importantes: uma é a imobilização do paciente durante 0 tratamento e a outra é permitir a reprodutibilidade da posição do paciente desde a simulação até o tratamento, bem como de um tratamento a outro.

Uma imobilização simples inclui fita crepe e cinto de velcro. Os acessórios básicos utilizados na radioterapia são os apoios para cabeça, que possuem vários formatos para se ajustar adequadamente a qualquer anatomia, e as bases, que 
incluem apoio para os ombros. A FIG. 3.4 mostra alguns apoios para a cabeça. Este tipo de apoio é necessário para tratamentos que incluem regiões como cabeça, pescoço e tórax.

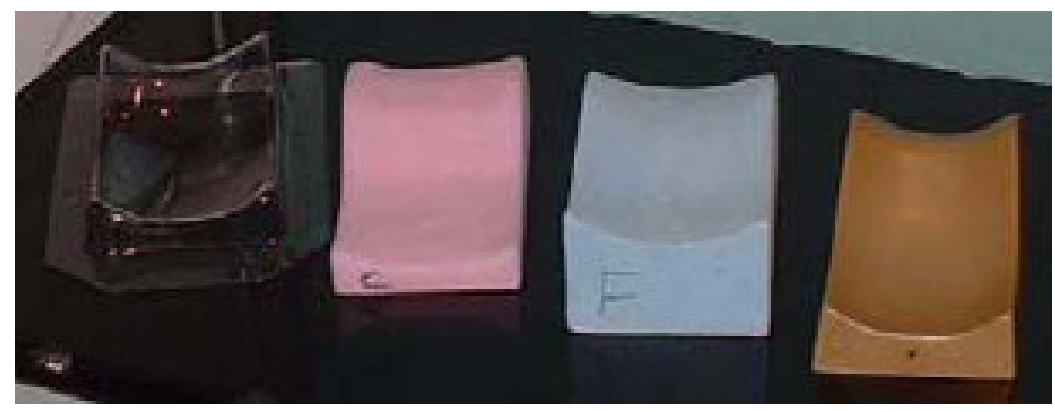

FIGURA 3.4 - Apoios para cabeça usados na radioterapia com feixes externos ${ }^{3}$.

Os pacientes tratados nas regiões da cabeça e do pescoço geralmente usam máscaras termoplásticas para sua imobilização. Estas máscaras, quando aquecidas, podem ser moldadas ao corpo do paciente. A máscara pode ser fixada diretamente na mesa de tratamento ou em uma base plástica, como é mostrado na FIG. 3.5. Uma outra máscara, mais moderna, é mostrada na FIG. 3.6 e sua principal vantagem sobre as outras é a imobilização dos ombros, por possuir um sistema de retração para os ombros no sentido do pé. A base que fixa a máscara também fixa sua porção inferior que cobre os ombros do paciente, o que não era possível de se fazer com as máscaras representadas pela FIG. 3.5. A máscara mostrada na FIG. 3.6 é principalmente utilizada em tratamentos com modulação de feixe, onde o posicionamento dos ombros é crucial para a reprodutibilidade da distribuição de dose.

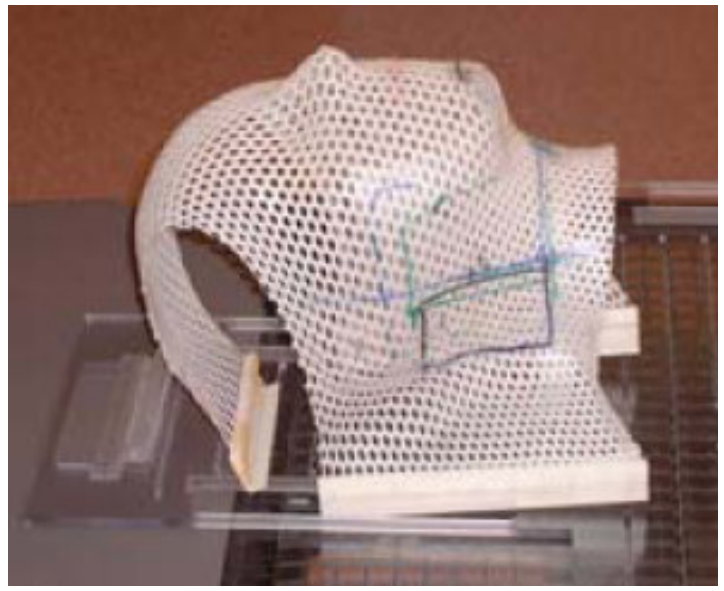

FIGURA 3.5 - Máscara termoplástica utilizada para imobilização de pacientes de cabeça e pescoço e cérebro ${ }^{3}$. 


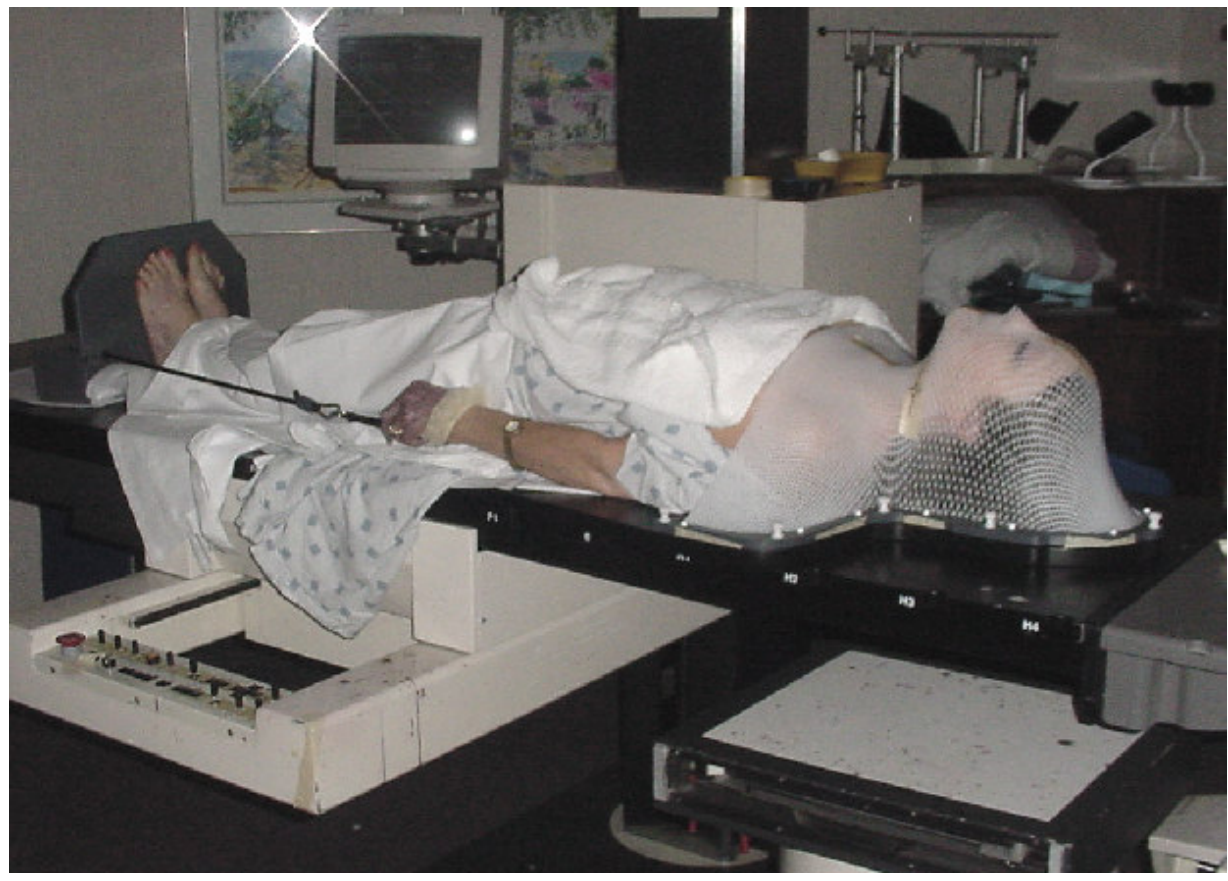

FIGURA 3.6 - Máscara termoplástica utilizada para pacientes em tratamento de cabeça e pescoço.

Para o tratamento da região da mama pode ser usada uma rampa de mama que contém um apoio para cabeça, apoios laterais para os braços e pode ser angulada de forma a deixar o tórax da paciente paralelo à mesa de tratamento.

Os pacientes com doença em região pélvica podem utilizar imobilizadores a vácuo que são reutilizáveis como os colchões à vácuo, Alpha-cradle ou Vac-fix. Estes colchões são dispostos sob o paciente e quando o vácuo é alcançado, através de uma bomba de sucção, o colchão toma a forma do corpo do paciente.

Para os pacientes com câncer da próstata analisados neste trabalho foi utilizado um imobilizador simples, que consiste de um pequeno isopor quadrado com marcas dos laseres da sala de tratamento, que era colocado entre os pés do paciente, garantindo assim uma separação fixa entre as pernas do paciente e também ajudava a manter a rotação das cabeças de fêmur na mesma posição no decorrer do tratamento. Este acessório é ilustrado na FIG. 3.7. 


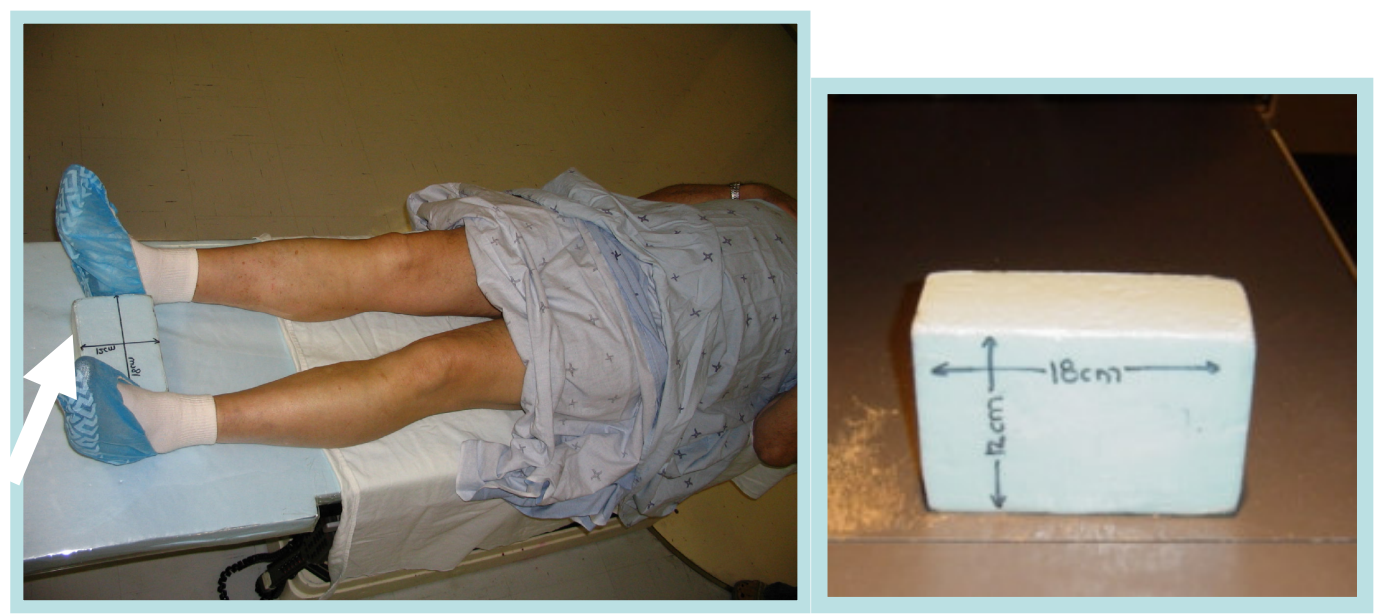

FIGURA 3.7 - Acessório utilizado na McGill University Health Centre para reprodutibilidade de pacientes em tratamento da região pélvica.

Outras técnicas de tratamento como radiocirurgia, que requerem um alto grau de precisão no posicionamento, utilizam equipamentos especiais que não serão descritos neste trabalho.

\subsubsection{Aquisição de dados do paciente: tomografia computadorizada}

Após o posicionamento e imobilização do paciente, as informações sobre sua anatomia e localização do alvo devem ser adquiridas. Se o planejamento for 2-D, é necessário somente um contorno transversal da pele do paciente na região de interesse, que pode ser feito manualmente utilizando um fio de chumbo ou gaze para gesso na hora da simulação.

No caso do planejamento tridimensional (3-D), o paciente é submetido à tomografia computadorizada (CT) para simulação do tratamento, onde marcadores fiduciais são colocados nele para estabelecer um sistema de coordenadas de referência que deve ser usado tanto no sistema de planejamento de tratamento quanto no primeiro dia do tratamento ${ }^{2-4,20}$.

Os dados do paciente, que devem ser adquiridos para alimentar um sistema de planejamento tridimensional devem incluir: a) a forma externa do corpo do paciente, que deve ser desenhado na imagem de CT em todas as áreas onde os feixes de tratamento entram e saem, assim como nas áreas adjacentes para que a radiação espalhada seja levada em conta no cálculo; b) os desenhos (ou contornos) das estruturas internas, as quais se deseja conhecer a dose, e os 
alvos para se determinar sua forma e volume para o cálculo de dose; c) as densidades eletrônicas para cada elemento de volume na matriz de cálculo de dose, quando uma correção para heterogeneidades for utilizada no cálculo; e d) as características da atenuação de cada elemento de volume para que a imagem seja processada adequadamente.

A tomografia computadorizada (CT) contém todas as informações necessárias para um planejamento de tratamento complexo, e deve ser tomada como a imagem de base em uma simulação em que são utilizadas outras modalidades de imagem como, por exemplo, a ressonância magnética.

Através de um procedimento chamado fusão de imagem, disponível no sistema de planejamento computadorizado, é possível sobrepor imagens adquiridas da CT com outras modalidades de imagens como ressonância magnética, ultra-som, angiografia e PET, que podem ser utilizadas para auxiliar no desenho dos alvos, especialmente nos casos de tumores cerebrais em que a densidade do tumor é praticamente igual à do tecido cerebral, dificultando sua visualização na imagem de $C T^{52}$.

\subsubsection{Definição dos alvos e estruturas de interesse}

Como descrito em 3.2.1.2, todos os alvos e estruturas de interesse (OAR) $)^{5,6}$ devem ser desenhados nas imagens provenientes da CT que foram transferidas ao sistema de planejamento computadorizado (TPS). A integração dos desenhos realizados em cada corte do CT dará origem aos volumes tumorais visíveis conhecidos como GTV e aos volumes correspondentes às estruturas sadias de interesse. A partir do GTV é que é definido o volume de tratamento clínico (CTV), que inclui o ou os GTVs mais uma área delimitada clinicamente como extensão de doença não visível por imagens. Na FIG. 3.8 são mostrados os desenhos de GTV e CTVs para um caso de tumor de cabeça e pescoço. Já o volume de planejamento do tratamento, denominado PTV, e o volume de planejamento dos órgãos de risco, $\mathrm{PORV}^{6}$, devem ser determinados através do conhecimento das incertezas geométricas que estão embutidas tanto na posição quanto no desenho dos volumes de CTV e OAR ${ }^{6}$. Portanto, tanto o PTV quanto o PORV ${ }^{6}$ dependem dos parâmetros de localização e imobilização do paciente e devem ser definidos no sistema de planejamento (TPS) ${ }^{5,6}$. 


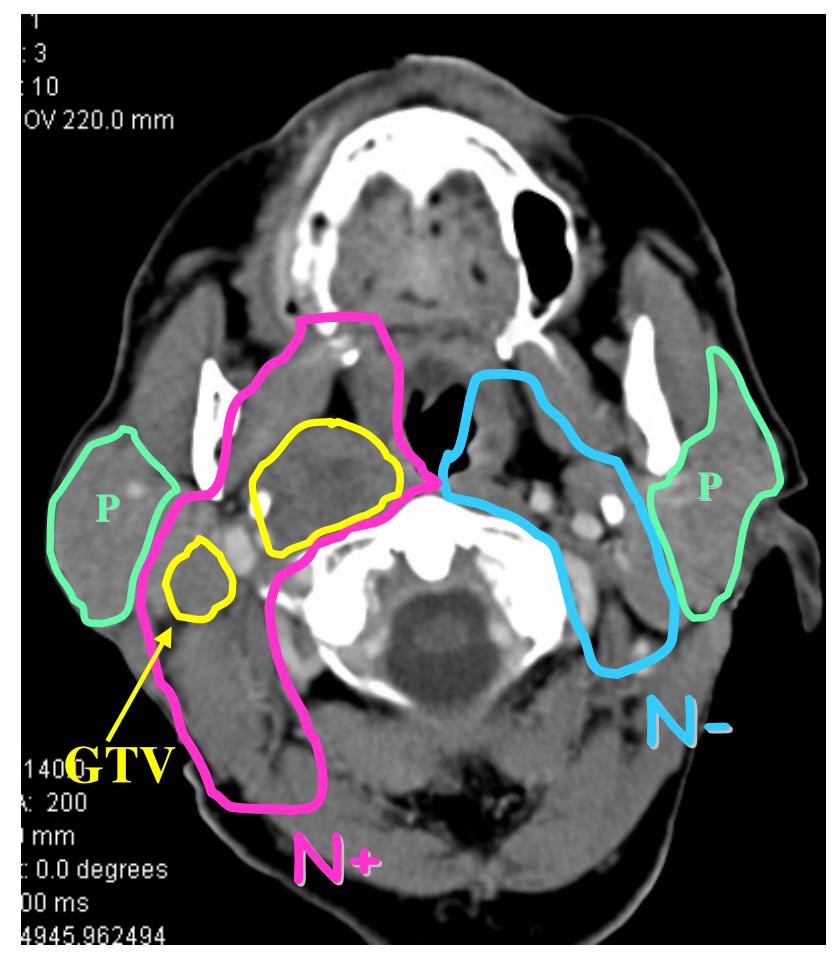

FIGURA 3.8 - Alvos e estruturas de interesse de dose para um paciente de cabeça e pescoço. GTV, em amarelo, são os tumores visíveis, CTV1 é a margem clínica para a região com envolvimento nodal $\left(\mathrm{N}_{+}\right), \mathrm{CTV} 2$, em azul, é o desenho com margem clínica para a região sem envolvimento nodal (N-) e as regiões em verde são as parótidas $(\mathrm{P})$ direita e esquerda. $\mathrm{O}$ contorno das estruturas no $\mathrm{CT}$ está de acordo com o RTOG ${ }^{53}$.

\subsubsection{Definição do isocentro}

$\mathrm{O}$ isocentro de tratamento é geralmente definido no centro geométrico do PTV, e suas coordenadas são definidas com relação ao isocentro de referência, que foi marcado com tinta fucsina na pele do paciente ao término da simulação do tratamento ${ }^{5,6}$.

Para que o paciente seja posicionado no dia de tratamento da mesma forma como foi planejado no TPS faz-se necessário relacionar o sistema de coordenadas do paciente ao sistema de coordenadas da sala de tratamento. Isto se dá através da marcação dos lasers de referência da sala de simulação na pele do paciente no dia da simulação. Estas marcas ou pontos de referência podem ser externos ou internos (como os marcadores de sementes de ouro implantados no alvo). Quando se opta por marcas externas, os lasers da sala de simulação são usados 
para fazer marcas sagital, coronal e axial na pele do paciente afim de alinhá-lo à máquina de tratamento.

O alinhamento do paciente e a reprodutibilidade do tratamento dependem de um ajuste perfeito entre o sistema de coordenadas de referência obtido na simulação de tratamento, o sistema de coordenadas do isocentro de tratamento planejado e por fim o sistema de coordenadas relacionado à sala de tratamento que deverá coincidir com o sistema de coordenadas do isocentro, obtido no TPS. Na FIG. 3.9 são mostrados estes três sistemas de coordenadas.

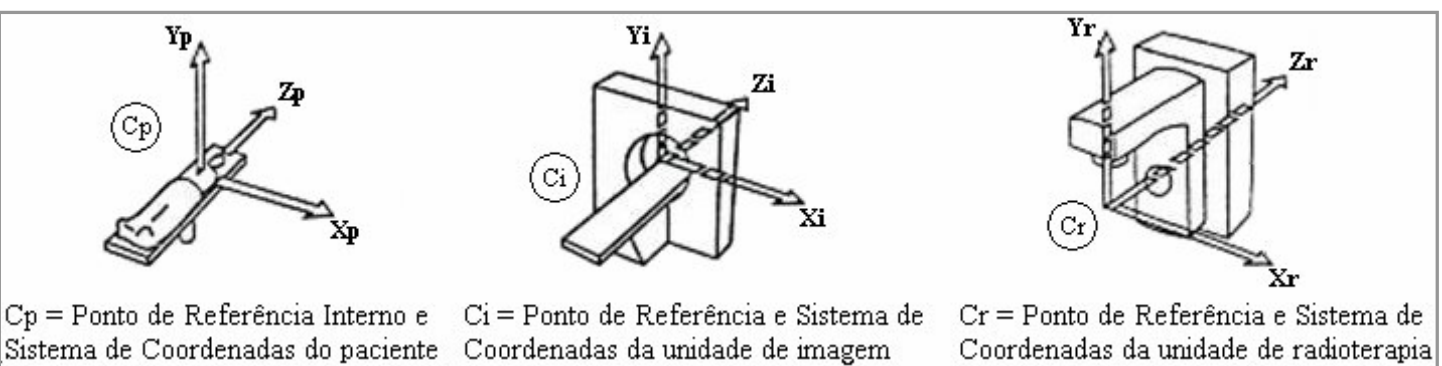

FIGURA 3.9 - Sistemas de coordenadas relacionadas ao paciente no dia da simulação, $C_{p}$, durante a aquisição de dados na unidade de imagem, $C_{i}$, e o sistema de coordenadas da sala de tratamento, $\mathrm{C}_{\mathrm{r}}{ }^{6}$.

\subsubsection{Transferência de imagem}

Uma vez que os desenhos dos volumes alvos e estruturas de interesse de dose são realizados, as imagens de CT e os desenhos devem ser enviados ao sistema de planejamento de tratamento (TPS). Estes dados podem ser gravados em uma mídia removível (como CD e DVD) ou podem ser transferidos via DICOM-RT. A última opção é a mais apropriada para manter os dados à salvo de eventuais danos.

DICOM (Digital Imaging Communications in Medicine) é um programa que foi criado com a finalidade de se padronizar as imagens diagnósticas como tomografias, ressonância magnética, radiografias, ultra-sonografia e etc ${ }^{54}$. 0 padrão DICOM é uma série de regras que permite que imagens médicas e informações associadas sejam trocadas entre equipamento de imagem, computadores e hospitais. O padrão estabelece uma linguagem comum entre equipamentos de marcas diferentes, que geralmente não são compatíveis ${ }^{54}$. 0 padrão adotado na radioterapia é o sistema DICOM-RT que permite, além da 
transferência de imagens, a transferência de dados específicos da área de radioterapia, tais como os desenhos dos volumes dos alvos, etc. Os dados do paciente, imagens de CT e desenhos, são transferidos do sistema de simulação computadorizado, AcQsim, para o sistema de planejamento, CORVUS, via DICOM-RT. Neste caso o sistema DICOM-RT faz parte de um software de gerenciamento de dados de paciente da radioterapia chamado VARiS (da empresa Varian Medical Systems).

\subsubsection{Processo para o cálculo de dose}

Uma vez que imagens e desenhos são enviados ao sistema de planejamento, o processo de planejamento do tratamento é então iniciado.

No planejamento 3-D convencional, a geometria do feixe (orientação do feixe, forma, modificadores, peso de cada feixe, etc) é definida primeiramente, e a seguir o cálculo da distribuição de dose é realizado pelo TPS através de algorítmos de cálculo de dose que serão descritos na próxima seção. A prescrição de dose é então realizada. Após a revisão qualitativa da distribuição de dose por um planejador do tratamento e/ou radioterapêuta, o plano pode ser melhorado através da modificação dos parâmetros geométricos iniciais do feixe para que a distribuição de dose cubra o alvo mais adequadamente e/ou a dose nos órgãos de risco sejam minimizadas. Este processo é repetido até que um plano satisfatório seja alcançado.

Já no caso em que a técnica escolhida é a técnica de conformação do alvo com modulação da intensidade do feixe (IMRT), que foi a técnica utilizada neste trabalho para os estudos de cabeça e pescoço, o processo de planejamento se torna mais complexo. Para um melhor entendimento deste processo, podemos dividí-lo em três etapas: a) seleção da técnica, b) computação da distribuição de dose e c) otimização computadorizada.

\section{a) Seleção da técnica}

A seleção da técnica consiste em especificar no TPS a proposta de liberação de dose no alvo (Gy/fração), especificar todas as restrições de dose às estruturas críticas e colocar todos os parâmetros geométricos dos feixes de tratamento necessários para a liberação da dose, que consistem em definir as posições do colimador de multi-lâminas (MLC), estativa rotatória, colimador e mesa, assim como a energia do feixe de tratamento. 


\section{b) Computação da distribuição de dose}

Nesta etapa o software irá calcular a dose seguindo várias etapas, com a finalidade de conseguir gerar um número de sub-feixes (beamlets) para cada posição da estativa rotatória de forma a distribuir a dose prescrita adequadamente no alvo e, ao mesmo tempo, obedecer às restrições de dose nos volumes referentes aos órgãos de risco.

\section{c) Otimização computadorizada}

Para a utilização da técnica de IMRT é indispensável o uso de um método de construção de perfis de intensidade do feixe não-uniformemente otimizados. Este método para construção de planos é denominado planejamento inverso e é bem distinto do modo interativo do planejamento 3-D convencional.

\subsubsection{Algorítmos de planejamento de tratamento}

As medidas de dose para se obter os parâmetros básicos do feixe geralmente são realizadas em um simulador de tecido com água, superfície plana, para campos quadrados e retangulares. No entanto, para tratamentos de paciente normalmente são utilizadas colimações individuais a fim de que a distribuição de dose a um dado alvo seja conformada a ele. Estas colimações podem ser montadas no equipamento de tratamento ou são feitas com o uso do colimador de multilâminas. Para que a dose seja calculada a partir dos dados do feixe obtidos através de medidas, há necessidade de correções. As correções devem ser realizadas para ajustar os parâmetros do feixe obtidos através do simulador de água com a condição real de tratamento do paciente: superfície irregular, volume heterogêneo, uso de colimações e outros. Nas seções seguintes serão descritos alguns métodos comuns e algorítmos usados para calcular a dose sob condições clínicas.

\subsubsection{Métodos empíricos e tabelas de cálculo}

Um dos métodos mais simples para estabelecer a dose em um ponto é através da medida direta. Uma vez que o plano de tratamento é escolhido, uma medida da dose pode ser realizada em um ponto escolhido dentro de um simulador de água através do uso de detetores como câmara de ionização ${ }^{55}$, filmes ou dosímetros termoluminescentes (TLD). Se a geometria do plano de tratamento e o rendimento são normalmente usados na radioterapia, então tabelas podem ser criadas tais 
que as medidas de dose não precisam ser repetidas para cada novo tratamento, e as doses em outros pontos no paciente podem ser interpoladas ou extrapoladas dos dados da tabela. Estas tabelas frequentemente incluem PDPs ou TMRs para energias diferentes e tamanhos de campos variados que combinados com OCR (razão de dose fora do eixo central) podem ser usados para acessar a dose em qualquer ponto no paciente nas situações em que são usadas geometrias simples de tratamento.

\subsubsection{Integração Clarkson para campos irregulares}

Devido ao formato irregular de tumores e a necessidade de colimação de tecidos sadios, os feixes usados na radioterapia possuem frequentemente um formato irregular. Os parâmetros definidos anteriormente como PDPs, TMRs e outros, são definidos para campos quadrados ou campos circulares equivalentes ao quadrado. Um dos métodos utilizados para converter os parâmetros de campos irregulares em regulares é denominado integração segmental de Clarkson ${ }^{3,7}$. Este método se baseia no fato de que o componente de espalhamento da dose, dependente do tamanho de campo e da forma, pode ser calculado separadamente da dose devido ao componente do feixe primário que independe do tamanho de campo e sua forma. Ele basicamente consiste de dividir o campo em setores múltiplos a partir de um centro e somar a contribuição de cada setor com raio $r_{i}$. Então para $\mathrm{N}$ setores teremos:

$$
F(d, \text { campoirreg }, f, h v)=\frac{1}{N} \sum_{i=1}^{N} F\left(d, r_{i}, f, h v\right),
$$

em que $N$ é o número de setores cobrindo o campo em 360 graus, $F$ é a função de planejamento de tratamento tal como PDP. A profundidade é $d$, a distância fonte-superfície é $f$ e $h v$ é a energia do feixe para campos circulares com raio $r_{i}$.

\subsubsection{Convolução e Superposição}

No método convolução e superposição, uma dose de expansão kernel, que é uma função que dá a distribuição espacial média da energia em torno da iteração de um fóton primário, em geral é calculada usando Monte Carlo ${ }^{8,56}$. Ela é usada para descrever a deposição da energia por um feixe estreito (pencil beam) que interage em um único ponto no meio. A dose no ponto $D(r)$ inclui as contribuições das partículas secundárias criadas no ponto da interação primária, r'. Assumindo- 
se que as partículas incidentes são paralelas ao eixo central do feixe, a dose pode ser simplesmente calculada por uma operação de convolução como:

$$
D(r)=\int_{V} T\left(r^{\prime}\right) A\left(r-r^{\prime}\right) d^{3} r^{\prime},
$$

em que $T\left(r^{\prime}\right)$ é a energia total liberada pelas interações dos fótons primários por unidade de massa e $A\left(r-r^{\prime}\right)$ é a dose kernel expandida, que descreve a fração média da energia depositada por unidade de volume em $r$ por fóton interagindo em $r$.

No feixe divergente, as direções dos feixes incidentes não são todas paralelas em todos os pontos do meio, e os kernels deveriam ser alinhados conforme a direção dos fótons que estiverem interagindo no meio. A dose $D_{T}\left(r^{\prime}\right)$ leva em conta um ajuste do eixo kernel para alinhá-lo com o feixe incidente e pode ser calculada com uma superposição como: ${ }^{104}$

$$
D_{T}\left(r^{\prime}\right)=\int_{V} T\left(r^{\prime}\right) A_{T}\left(r-r^{\prime} ; r^{\prime}\right) d^{3} r^{\prime}
$$

em que $A_{T}\left(r-r^{\prime} ; r^{\prime}\right)$ é a dose kernel expandida e ajustada para estar alinhada com $r$.

\subsubsection{Modelo de feixe estreito colimado ${ }^{9,10,57}$}

O modelo de feixe estreitamente colimado de tamanho finito ( em inglês finite-size pencil beam, FSPB) é um algorítmo de cálculo de dose 3-D cujo princípio se baseia no uso de feixes quadrados estreitamente colimados com tamanho finito para calcular a dose proveniente de campos de qualquer forma e padrão de distribuição de intensidade. O volume integral do campo pode ser coberto por uma superposição de um número de feixes estreitos tal que cada feixe pequeno diverge e se confina na sua vizinhança. Se a dose devido a um único feixe estreito for conhecida, então a distribuição de dose para um campo irregular pode ser calculada através da sobreposição das distribuições de dose de cada um dos feixes estreitos necessários para reproduzir o campo irregular. Na forma de equação tem-se que ${ }^{9,10}$ :

$$
D^{P}=\sum_{I J=0}^{n m} D_{I J}^{P} W_{I J},
$$


em que $D_{I J}^{P}$ é a dose em $P$ proveniente do feixe estreito $I J$ e $W_{I J}$ é um fator de ponderação dado por ${ }^{9}$ :

$$
W_{I J}=\Phi_{I J} I S L,
$$

em que $\Phi_{I J}$ é a fluência do feixe para o pencil beam IJ e ISL é a correção da lei do inverso do quadrado da distância necessária para considerar a divergência do feixe.

\subsubsection{Planejamento inverso}

O método de distribuição de dose por IMRT requer uma construção otimizada do perfil de intensidade do feixe não-uniforme que é uma tarefa na qual a otimização por computador é indispensável. Este método de construção do plano com IMRT é descrito como planejamento inverso para distinguí-lo do processo interativo direto usado no planejamento convencional 3-D ${ }^{10,15}$.

O processo de planejamento inverso pode ser separado em dois componentes: a) especificação do critério de otimização (função objetiva e restrições) e b) o algorítmo de otimização utilizado.

\section{a) Função objetiva e restrições ${ }^{10,11,13,14,58}$}

Para o planejamento inverso com IMRT, os objetivos clínicos são especificados matematicamente na forma de uma função objetiva (também chamada função custo). As técnicas de otimização computacional serão então usadas para determinar os parâmetros do feixe (geralmente limitadas à ponderação dos subfeixes ou beamlets) que irão alcançar ou se aproximar muito da solução desejada. O valor (custo ou pontuação) da função objetiva é o índice de quão bom ficou o planejamento do tratamento. Portanto, o objetivo da otimização é minimizar (ou maximizar, dependendo da escolha da função objetiva) a pontuação (ou custo).

A maioria dos sistemas de otimização com IMRT usam critérios baseados em dose ou dose-volume ${ }^{10}$. Um método normalmente utilizado para criar as funções objetivas dose-volume ou baseadas em dose é a que minimiza a variância da dose em relação à dose prescrita ou ao limite de dose. Uma função típica é a soma dos termos da variância (ver APÊNDICE A), representando cada estrutura anatômica multiplicada pelo fator de penalização (isto é, fatores de importância). Se o médico conhece a relação dose-volume que são desejadas para os órgãos 
de interesse, então as funções objetivas baseadas em dose-volume devem produzir planos mais apropriados que o critério baseado em dose. As otimizações baseadas nos histogramas de dose-volume (DVHs) deveriam levar em consideração as respostas diferentes de dose nos órgãos e no tumor. A função custo no sistema de otimização do TPS Corvus é definido por ${ }^{13,14}$ :

$$
f=\alpha_{0} \sum_{x \in t}\left(D(x)-D_{0}\right)^{2}+\sum_{i} \alpha_{i} \sum_{x \in C_{i}}\left(D(x)-D_{i}\right)^{2},
$$

$\alpha_{i}=0$, para $D(x)<D_{i}$,

em que $D(x)$ é a dose no ponto $x . D_{0}$ e $D_{i}$ são as doses de tolerância para o tumor e $i$ órgãos críticos, $\alpha_{0}$ e $\alpha_{i}$ são as ponderações que são comuns à todos os pontos no tumor e órgãos críticos separadamente, respectivamente. A restrição $\alpha_{i}=0$ para $D(x)<D_{i}$ somente reflete o fato que não há penalização se a dose for abaixo do limite superior para as estruturas sensíveis. O valor da função custo é uma quantidade relativa.

O processo de planejamento se inicia, então, através de uma seleção manual das energias dos feixes e ângulos de incidência baseada na experiência do pessoal envolvido. Uma intensidade uniforme para cada feixe $j$ é então aplicada para calcular a distribuição de dose $D_{j}(x)$ em qualquer localização espacial $x$ tal que a dose liberada no ponto de referência escolhido é 100 unidades de dose. A seguir, é atribuída uma variável de ponderação $w_{j m}$ para cada pencil beam $(\mathrm{j}, \mathrm{m})$ de forma que a dose total em qualquer ponto $\mathrm{x}$ é dado por:

$$
D(x)=\sum D_{j}(x) w_{j m},
$$

O nível de intensidade pode ser considerado como a divisão da ponderação máxima para um dado mapa de fluência do feixe. Uma vez que $w_{j m}$ não é limitado por cima, a ponderação por unidade de nível de intensidade não é conhecida préviamente.

\section{b) Algorítmos de otimização ${ }^{10,58-60}$}

O planejamento de tratamento com IMRT se baseia em satisfazer um conjunto de requisitos complexos de dose-volume tanto para a cobertura do alvo quanto para poupar órgãos críticos. Estes requisitos podem ser descritos por uma função objetiva, que como dito em a), é uma representação matemática de cada restrição 
de dose-volume e sua importância em achar uma solução para o problema de planejamento do tratamento ${ }^{10}$.

Os algorítmos de otimização ${ }^{58,59}$ são confeccionados para pesquisar interativamente um conjunto de variáveis independentes que resultam na minimização ou maximização da função objetiva. Para um plano de tratamento típico, um método de otimização incluiria em princípio um palpite inicial dos perfis de feixes necessários para alcançar o objetivo. Este perfil seria modificado e a dose recalculada. Este plano novo seria então reavaliado e comparado com os objetivos e restrições pré-definidos e este procedimento seria repetido até que um plano aceitável fosse encontrado. Os métodos de otimização usados em IMRT podem ser determinísticos, como nas técnicas de gradiente descendente (downhill) e aniquilação simulada, ou estocásticos, como na técnica de Monte Carlo.

\subsubsection{Técnica de gradiente descendente ${ }^{58,61}$}

Um dos métodos de otimização determinísticos mais comuns é a técnica de gradiente descendente (conhecida como downhill) com gradientes descendentes íngremes. Suponha-se uma função objetiva $f(x)$ representando uma função dependente do critério dose-volume cujo plano se deseja otimizar. O gradiente da função no ponto inicial $x_{0}$ é dado por ${ }^{58}$ :

$$
\left|\vec{\nabla} f\left(x_{0}\right)\right|=\left.\frac{d f(x)}{d x}\right|_{x=x_{0}}
$$

em que $x$ e $x_{0}$ podem representar, por exemplo, uma dada distribuição de pesos dos sub-feixes (beamlets ).

A variável $x$ é então movida para baixo (downhill) na curva por uma quantidade proporcional à $-\vec{\nabla} f(x)$. Em outras palavras, quanto mais íngreme for a curva, maior será a modificação da posição prévia da variável. Uma vez que a variável alcança um mínimo ou o vale, o gradiente se torna zero e o processo pára. Esta técnica utilizada comumente no IMRT é geralmente rápida, pois não requer mais que 100 interações para otimizar a função ${ }^{58}$. 
Um dos problemas associados a este método é sua dependência com a localização do parâmetro $x_{0}$ que representa o estado inicial. Se a função consiste de vários mínimos então a solução pode ficar armadilhada em um mínimo local, se tornando impossível alcançar o mínimo absoluto da função. As funções objetivas complexas contendo informações de dose-volume têm se apresentado com vários mínimos locais ${ }^{62} \mathrm{e}$, portanto, requerem um método de otimização mais adequado. Uma representação esquemática do conceito por trás da técnica de otimização de gradiente downhill é mostrado na FIG. 3.10.

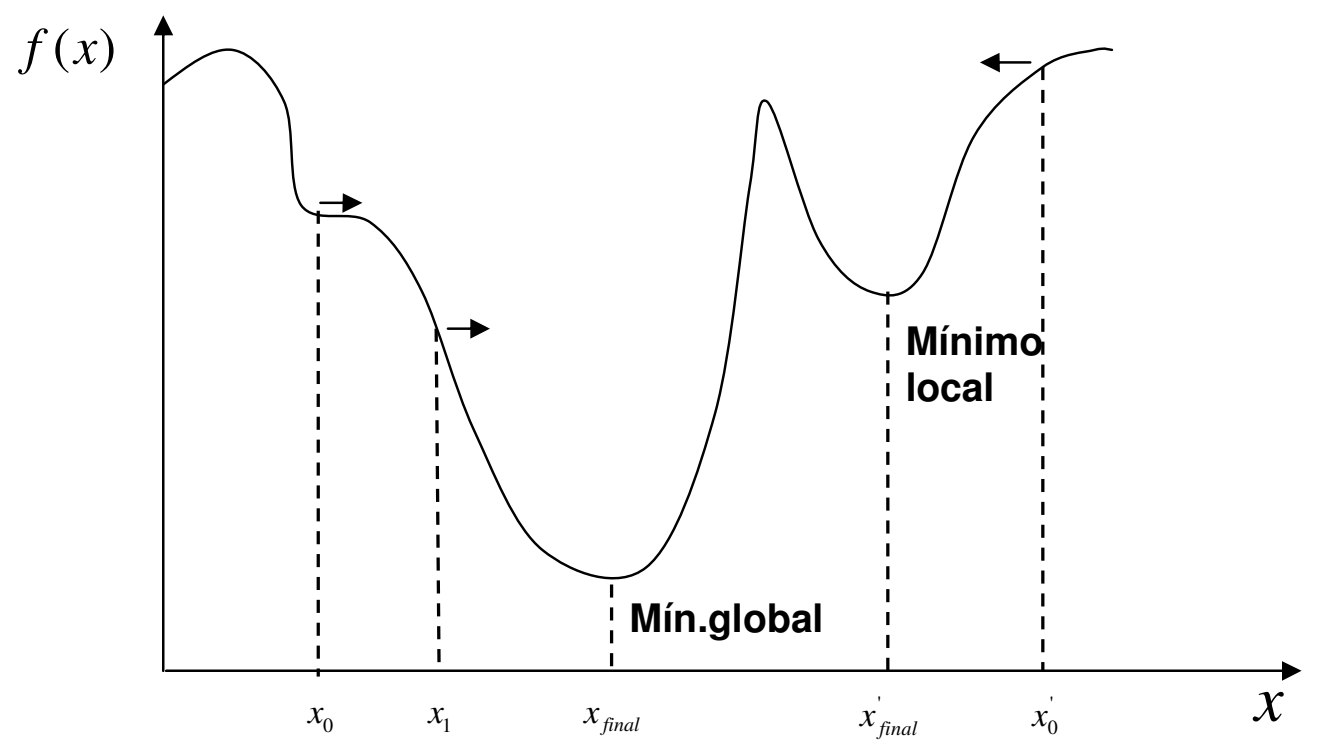

FIGURA 3.10 - Técnica de otimização de gradiente descendente íngreme (downhill). Uma condição inicial $\mathrm{x}_{0}$ é escolhida e movida ao longo de uma função de planejamento objetiva $f(x)$ por um valor proporcional ao gradiente ou inclinação da curva naquele ponto. $O$ processo é repetido até um mínimo ser alcançado.

\subsubsection{Aniquilação simulada}

A aniquilação é um processo pelo qual um sólido é resfriado lentamente de uma temperatura e estado de energia altos até um estado de energia baixo ser alcançado. A aniquilação simulada é um processo de otimização matemático baseado no conceito similar ao se encontrar um mínimo global de uma dada função. Ele foi usado pela primeira vez por Kirkpatrick et al. ${ }^{63}$ para otimizar a colocação dos componentes de computador e, mais tarde, foi aplicado em vários campos para solucionar problemas no processamento de imagem, astronomia, modelagem financeira, medicina nuclear e radioterapia. Este processo, 
diferentemente do anterior, pode evitar as armadilhas de mínimos locais uma vez que o seu processo de otimização é estatístico, possibilita a passagem através de barreiras de energia e assim o escape de um mínimo local. No entanto, a técnica de aniquilação simulada não garante que a solução seja encontrada num período de tempo razoável ${ }^{63-66}$.

Uma iteração de aniquilação simulada consiste basicamente de três componentes: a função geradora; a função de aceitação e a função de atualização ${ }^{59}$. A função geradora produz uma configuração nova a partir da configuração atual de variáveis de otimização. Ela usa uma distribuição de probabilidades tal como Gaussiana ou Lorentziana para encontrar uma região de pesquisa ao redor de uma solução particular e então move a solução em uma determinada direção. A função de aceitação utiliza a mudança da função custo para avaliar se a nova configuração deveria ser aceita ou rejeitada mesmo que o custo seja mais alto. A nova configuração é sempre aceita quando o custo é reduzido. Se o custo for aumentado, a nova configuração só será aceita randomicamente com uma função de probabilidade similar à distribuição de probabilidade de Boltzmann. Finalmente, a função de atualização renovará os parâmetros relacionados ao tamanho do passo e ao grau de subida da curva. A convergência da aniquilação simulada em mínimo global depende da maneira como os parâmetros são atualizados. Um diagrama representando os componentes da aniquilação simulada é mostrado na FIG. 3.11. 


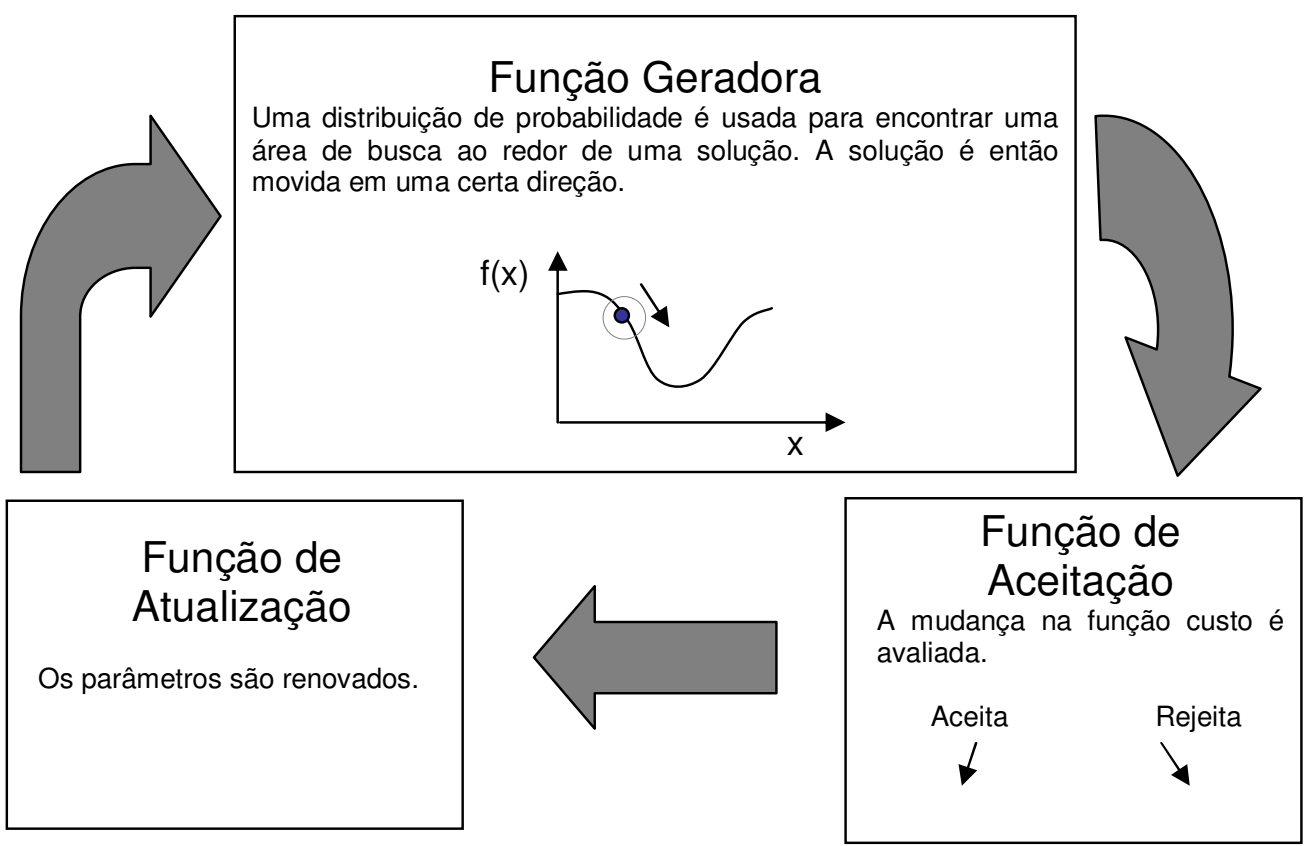

FIGURA 3.11 - Diagrama de bloco da técnica de aniquilação simulada para otimização.

\subsubsection{Otimização do planejamento com CORVUS}

O sistema de planejamento de tratamento CORVUS (Nomos Corporation, Cranberry, $\mathrm{PA})^{13,14}$ é feito para criar planos de tratamento conformacionados 3-D com IMRT de acordo com os dados das imagens tomográficas do paciente e da prescrição do médico. Ele utiliza um modelo de dose baseado nos dados de dose de feixe estreito (FSPB) derivado dos dados de dose adquiridos através de medidas com feixes clínicos em um simulador de água ${ }^{9,57}$. O primeiro passo no planejamento do tratamento com CORVUS é a criação dos volumes de planejamento do tratamento (PTVs) e de estruturas críticas nas imagens de CT. Os volumes são definidos e os erros devidos à localização e à imobilização são levados em conta. O planejador seleciona o número de feixes e a geometria do feixe apropriada, como os ângulos de entrada. Então, um conjunto de FSPB é determinado para cada feixe para que o volume de tratamento seja adequadamente coberto. Basicamente, cada feixe é dividido em uma grade de resolução pré-determinada. Cada elemento dentro da grade terá sua própria FSPB (ver FIG. 3.12). Neste ponto é que as correções de heterogeneidades em tecidos podem ser aplicadas. Uma otimização é realizada para determinar a intensidade de cada feixe estreito a fim de alcançar os objetivos da prescrição. $O$ 
processo de otimização no CORVUS tem dois componentes: a fase de construção dose-volume e a fase de aniquilação. $O$ primeiro processo escolhe um conjunto de pontos de amostra no volume de dose criado com uma octtree ${ }^{14}$, que é uma estrutura de dados hierárquica que representa e aloca informações características agregadas dentro de uma região cúbica do espaço (ver FIG. 3.13). Isto é simplesmente a sub-divisão repetida do volume de dose integral dentro de voxels (elementos de volume) até que uma grade seja criada. O tamanho do voxel é uma função da dose e do gradiente de dose tal que um número maior de voxels serão encontrados no alvo e nas regiões de rápida queda de dose. Depois que esta divisão é feita e a informação é guardada na memória do computador, a fase de otimização (aniquilação) começa. Um diagrama de blocos do processo de aniquilação simulada usado pelo CORVUS é mostrado na FIG. 3.14. Valores diferentes de transmissão do FSPB são tentados a cada nova interação. A função custo é calculada e comparada ao custo anterior, e o processo é repetido até que a função custo seja minimizada. No CORVUS, a função custo é baseada nas relações de dose-volume extraídas do DVH (histograma de dose-volume) calculada nos planejamentos tentados préviamente ${ }^{13,14}$.

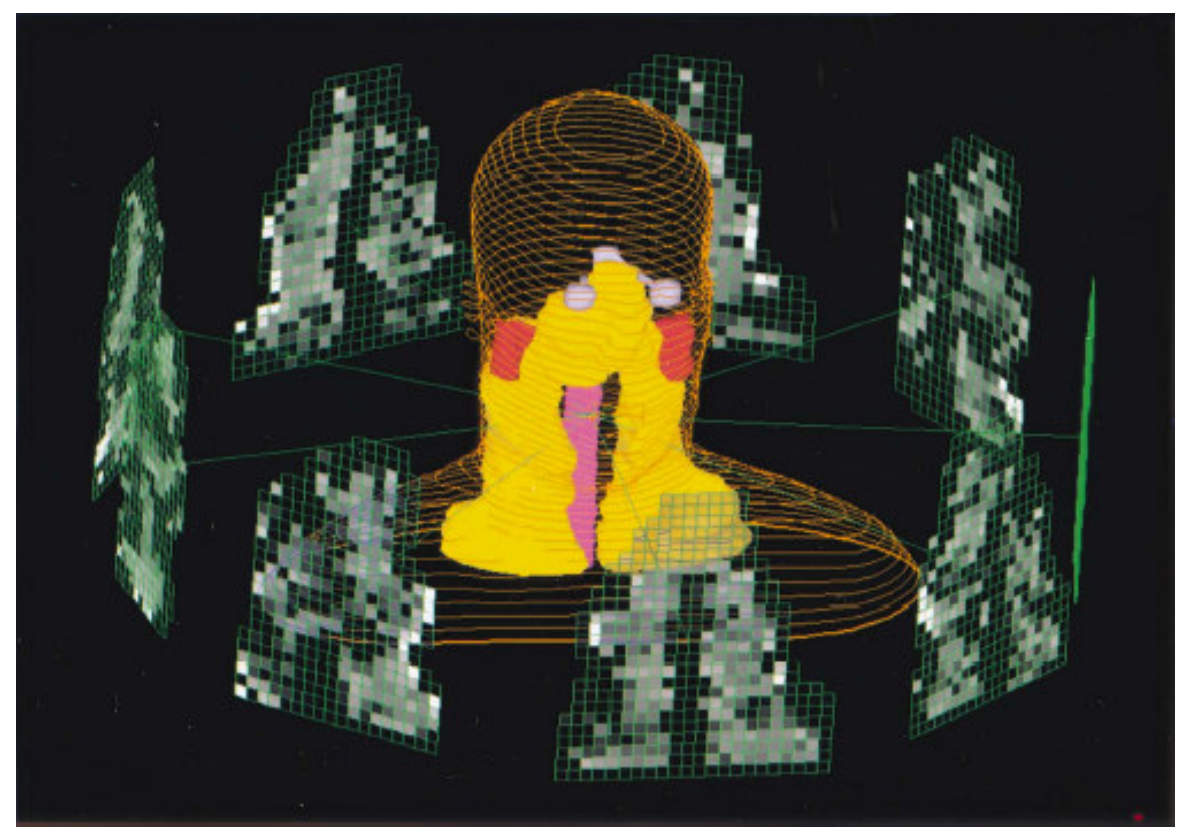

FIGURA 3.12 - Visão 3-D do paciente com 9 feixes com intensidades moduladas usados para gerar a distribuição de dose final. Os níveis de cinza dentro dos feixes representam o valor de intensidade. Figura extraída do CWG, $2001^{10}$. 


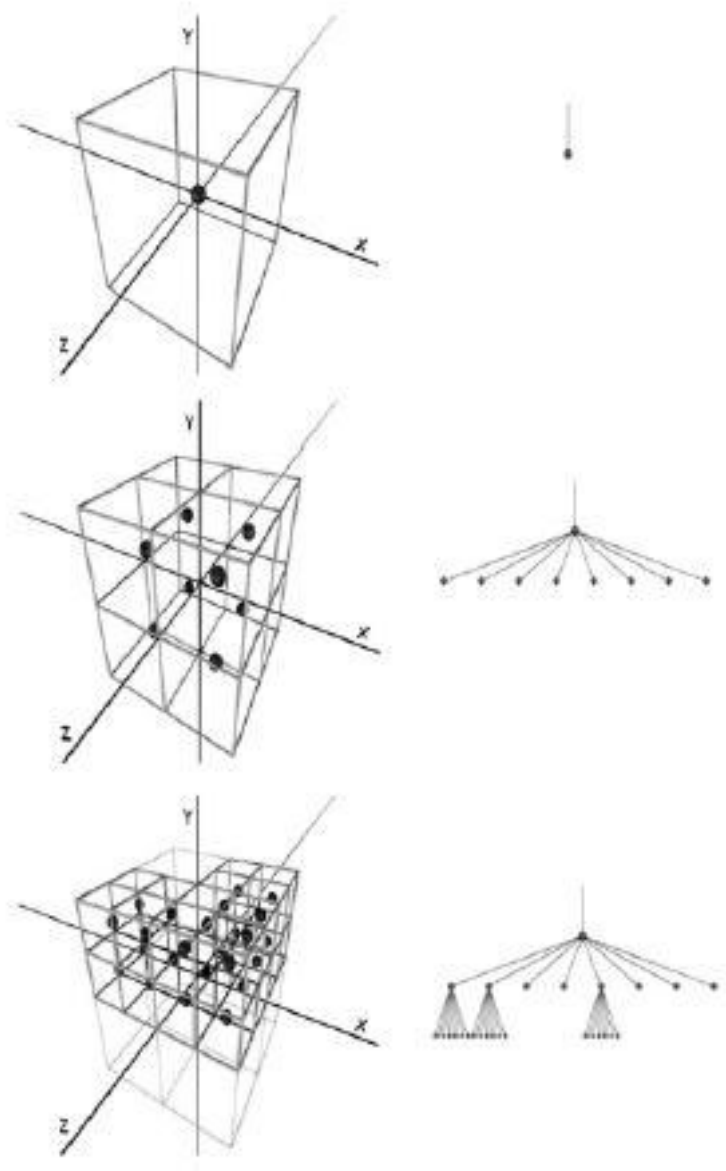

FIGURA 3.13 - Três níveis de análise de uma decomposição espacial octtree. A coluna da esquerda mostra o espaço examinado do primeiro ao terceiro nível de análise. Todas as propriedades são consideradas provenientes dos pontos de agregação nos centros dos cubos. A coluna da direita mostra as octtrees correspondentes que contem as informações sobre as propriedades emitidas dos pontos de agregação ${ }^{67}$. 


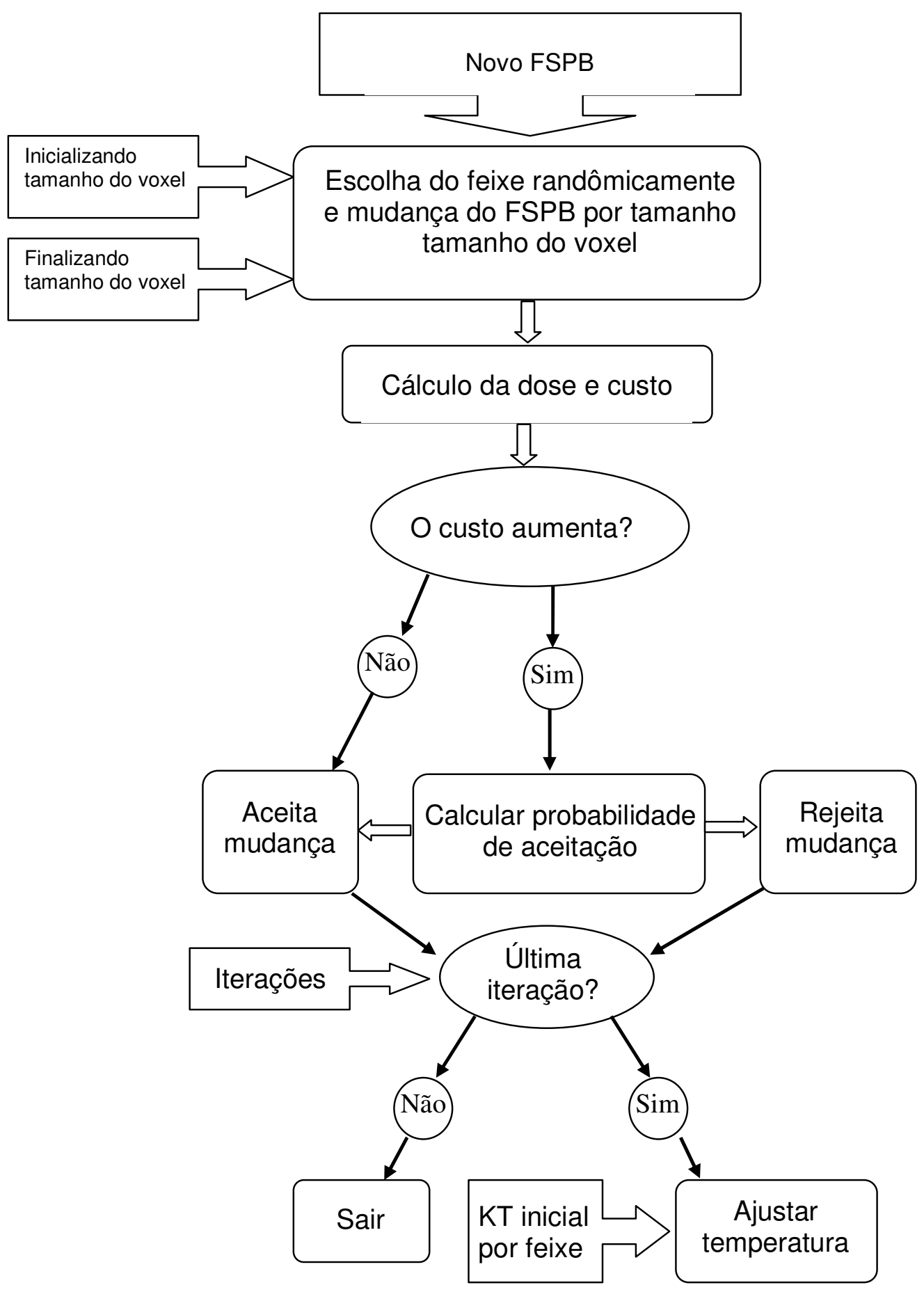

FIGURA 3.14 - Técnica de Aniquilação Simulada utilizada no CORVUS. 


\subsubsection{Cálculo de dose com CORVUS}

No sistema de planejamento de tratamento CORVUS ${ }^{81,82}$ o conjunto de dados de dose do feixe largo (convencional) proveniente de medidas realizadas com o feixe clínico é usado para calcular o feixe estreito (FSPB) através da integração de setores. Após a otimização ser completada é realizado um cálculo de dose completo com a resolução selecionada pelo usuário na prescrição. $O$ volume de dose total é a soma da dose de todos os feixes estreitos (FSPB).

A dose total absorvida em um ponto do paciente $\overrightarrow{R_{p}}=\left(x_{p}, y_{p}, z_{p}\right)$ é a soma de doses liberada por múltiplos feixes no plano ${ }^{14}$ :

$$
D\left(\overrightarrow{R_{p}}\right)=\sum_{n=1}^{N B} W_{n} \cdot D_{n}\left(\overrightarrow{R_{p}}\right),
$$

em que $N B$ é o número de feixes e $W_{n}$ é o peso relativo de cada feixe.

O modelo de dose FSPB simplificado, D, é representado no CORVUS como:

$$
D(d, x, y)=M U \sum_{j-1}^{n j} F\left(x_{j}, y_{j}\right) T\left(x_{j}, y_{j}\right) F S P B\left(d, x-x_{j}, y-y_{j}\right),
$$

em que $M U$ é o número de unidades monitoras liberada, d é profundidade no meio, $F\left(x_{j}, y_{j}\right)$ é uma função que descreve a distribuição da fluência incidente, e $T\left(x_{j}, y_{j}\right)$ descreve a transmissão através de qualquer modificador do feixe (filtros e compensadores). $\mathrm{O}$ deslocamento $\left(x-x_{j}, y-y_{j}\right)$ representa a distância lateral do ponto de interesse em relação ao ponto central do $\operatorname{FSPB}\left(x_{j}, y_{j}\right)$ em uma geometria não divergente.

\subsubsection{Avaliação do planejamento}

Após o cálculo de dose, o radioterapeuta avalia o plano de tratamento. Esta avaliação consiste da verificação de portais e da distribuição de dose para um determinado tratamento.

Os portais de tratamento são imagens radiográficas realizadas com o feixe da máquina de tratamento ou são reconstruções radiográficas digitais feitas no sistema de planejamento computadorizado a partir da reconstrução 3-D das imagens anatômicas (geralmente CT) do paciente.

A distribuição de dose do plano pode ser obtida através de alguns poucos pontos significativos dentro do volume alvo; a partir de uma matriz de pontos em um 
desenho ou imagem, bidimensional; ou de uma matriz de pontos que cobrem a anatomia do paciente tridimensionalmente.

Algumas ferramentas como as curvas de isodose, planos ortogonais, superfícies de isodose, estatísticas de distribuição de dose (dose mínima, máxima e média ao volume; dose em pelo menos $95 \%$ do volume e volume irradiado com pelo menos 95\% da dose prescrita), histogramas de dose-volume diferencial e cumulativo, podem ser usadas na avaliação da distribuição de dose planejada ${ }^{3}$. O APÊNDICE A fornece uma explicação mais detalhada sobre as estatísticas da distribuição de dose, incluindo histogramas de dose-volume.

\subsubsection{Reconstrução radiográfica digital (DRR)}

Uma vez que o plano de tratamento é aprovado, são realizados DRRs para cada paciente, com a finalidade de gravar o isocentro de tratamento na forma de imagens do paciente. A reconstrução radiográfica digital é feita a partir das imagens tomográficas de cada paciente. Após o plano de tratamento ser finalizado, faz-se imagens antero-posterior (AP) e látero-lateral (LL) no sistema de planejamento com um campo padrão, geralmente $10 \times 10 \mathrm{~cm}^{2}$, no isocentro de tratamento. Estas imagens são gravadas no planejamento do paciente e também impressas na forma de filmes radiográficos. Este procedimento permite que 0 pessoal envolvido no tratamento do paciente possa verificar qualquer deslocamento na posição do isocentro durante os tratamentos.

\subsubsection{Sistema de gravação e verificação do planejamento}

O sistema de gravação e verificação é um sistema computadorizado que transfere os dados do planejamento do tratamento realizado no TPS para a máquina de tratamento, assim como os compara com os dados de entrada nela. A identificação do paciente, parâmetros da máquina e dados de prescrição da dose são gravados primeiramente em um computador. Na hora do tratamento estes parâmetros são identificados na máquina de tratamento e se não houver diferença o tratamento pode ser inicializado. Quando há discrepâncias, elas são indicadas e os parâmetros que não coincidem com o planejado são realçados na tela do sistema de gravação e verificação. Após o tratamento, todos os dados de parâmetros da máquina, como posição dos colimadores de multi-lâminas, são gravados. Isto permite que se possa verificar a qualidade dos tratamentos 
realizados no departamento, assim como acompanhar o desempenho de tratamentos com modulação de intensidade do feixe dinâmico.

Normalmente as tolerâncias para verificação dos parâmetros da máquina são fornecidas pelo fabricante, e as tabelas de tolerância clínica devem ser definidas no departamento para cada série de técnicas a fim de levar em conta variações diárias nas localizações de pacientes.

Um sistema de comunicação entre o sistema de planejamento de tratamento e o acelerador pode evitar erros associados à transferência manual de informações impressas do TPS para o acelerador e pode ajudar no tratamento de casos complexos envolvendo colimadores assimétricos e com multi-lâminas, o que otimiza o tempo de tratamento.

\subsubsection{Exportação dos dados para a máquina de tratamento}

Todas as informações pertinentes ao tratamento do paciente, além de serem transferidas digitalmente, via DICOM, do TPS para a máquina de tratamento, são impressas ou escritas manualmente no prontuário do paciente, que é usado diariamente para que o técnico operador da máquina de tratamento verifique se os dados impressos correspondem aos dados entrados no acelerador.

\subsubsection{Liberação da dose}

A dose pode ser liberada no paciente pelo método convencional, item 3.2.9.2, ou conformada com ou sem o uso de IMRT, item 3.2.9.3. A mesma máquina de tratamento pode executar ambos os métodos de liberação da dose.

\subsubsection{Máquina de tratamento}

$\mathrm{Na}$ área de radioterapia existem vários métodos para liberar uma certa quantidade de radiação ao tumor. Um desses métodos é o uso de feixes de radiação externos produzidos por um acelerador linear, como representado na FIG. 3.15. Esta técnica tem sido usada há muitas décadas e desde então muitos avanços em software e hardware de computador tem levado ao desenvolvimento de técnicas sofisticadas de radioterapia para tratar melhor a doença e poupar tecidos sadios.

Após 1980, com o desenvolvimento de computadores, o planejamento de tratamento 3-D emergiu como um método viável para melhorar a liberação da radiação. Este método permite a visualização tridimensional (3-D) do tumor e dos 
tecidos sadios através da integração de imagens 3-D como as de tomografia computadorizada (CT). Esta técnica permite que os médicos realizem simulação virtual de um feixe de radiação que atinge o alvo visto de qualquer ângulo no espaço, chamado de visão do olho do feixe (BEV, do inglês beam's eye view). Neste tipo de terapia em que os campos são baseados em projeções do BEV pode-se obter o cálculo volumétrico de dose e se utilizar ferramentas de análise de dose volumétricas como histogramas de dose-volume (DVH).

Ambos os planejamentos de tratamentos 2-D e 3-D usavam métodos de tentativa e erro em que os computadores calculavam a dose de radiação a partir de feixes colocados arbitrariamente pelos médicos, físicos ou dosimetristas. Este método de planejamento direto consumia muito tempo e oferecia um número limitado de feixes. Este tipo de planejamento 3-D alcançou um avanço maior com a invenção dos colimadores multi-lâminas (MLC), como mostrado na FIG. 4.1. Esta invenção substituiu o uso de blocos de proteção feitos com uma liga de metais pesados (cerrobend) para proteger estruturas normais. O médico desenha a forma da proteção no computador do sistema de planejamento e esta forma é transferida à máquina de tratamento, na forma de arquivo de computador, que a reproduz automaticamente, portanto cada feixe é conformado como planejado no sistema de planejamento (TPS) ${ }^{2,3}$. 


\section{fonte primária}

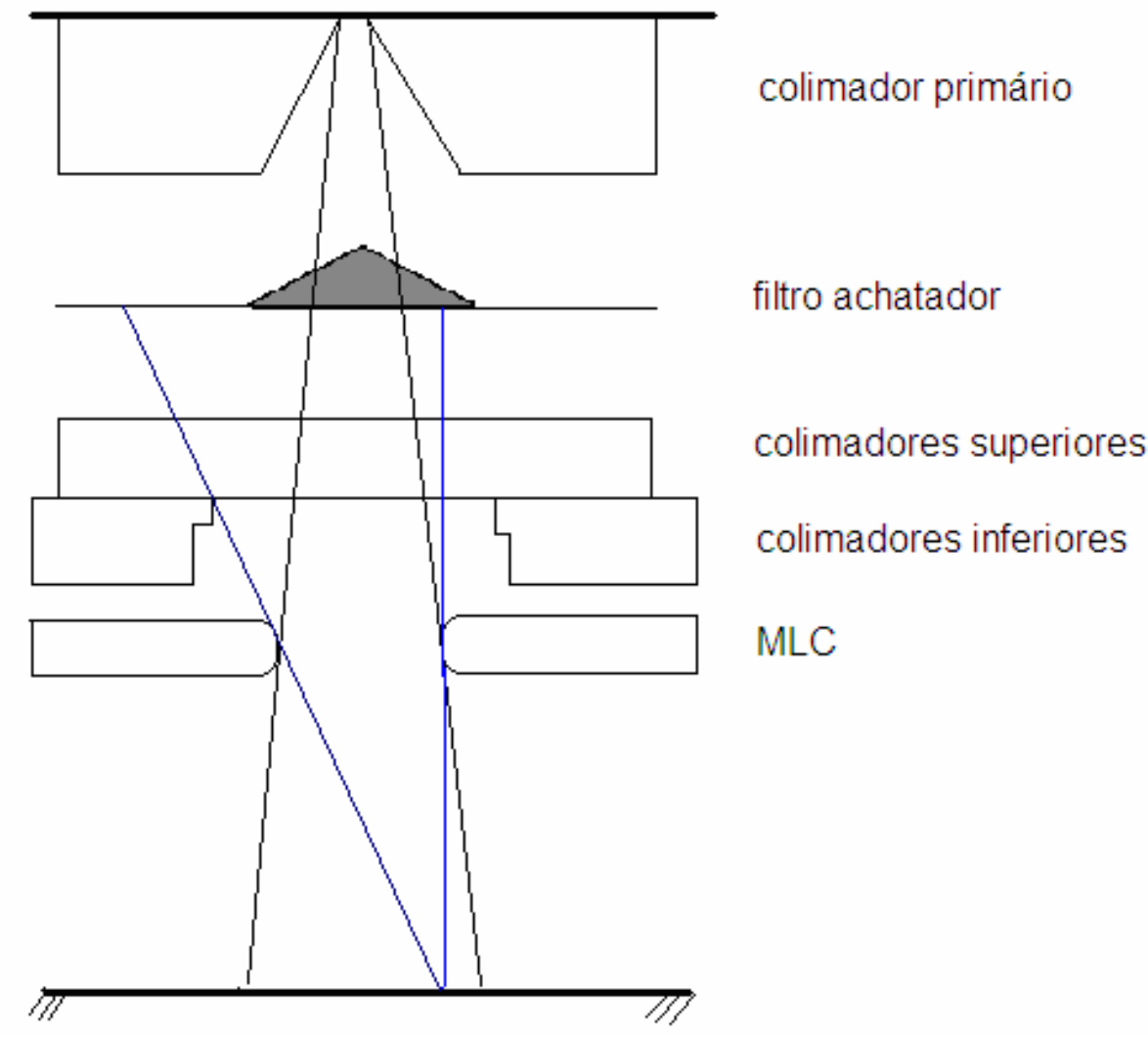

FIGURA 3.15 - Representação esquemática da cabeça de tratamento para um acelerador linear Varian. As linhas azuis ilustram a dose espalhada na cabeça proveniente da "fonte extra-focal" num dado ponto no campo. Consequentemente, as posições dos colimadores pode afetar o fator rendimento (output) dos campos colimados com MLC. Portanto, para cada projeto de acelerador deve-se esperar uma dose espalhada diferente.

\subsubsection{Execução do tratamento convencional}

Se a localização do tratamento for confirmada, seja através de marcadores externos e/ou imagem, a dose é então liberada no paciente. No tratamento 3-D convencional o técnico que opera o acelerador entra com os dados do paciente e com os parâmetros de cada feixe que compõem o seu tratamento na máquina de tratamento. A forma do campo pode ser determinada pelos colimadores multilâminas ou por blocos de proteção confeccionados para modelar cada feixe. Se necessário, podem ser colocados acessórios na saída do feixe tais como filtros, 
compensadores ou material substituto de tecido, o bólus. O número de unidades monitoras é colocado no console de controle e o paciente é então tratado.

Em termos de controle de qualidade, o técnico da radioterapia pode observar cada parâmetro do feixe e confirmar se são consistentes com o planejado.

\subsubsection{Execução do tratamento com IMRT dinâmico ${ }^{10,58,68}$}

No caso do tratamento 3-D com IMRT dinâmico, o tratamento deve envolver movimento dos colimadores com multi-lâminas enquanto o feixe está ligado e, dependendo da técnica, enquanto a estativa rotatória está se movendo também.

Para uma posição fixa da estativa rotatória, a abertura formada por cada par oposto de colimadores multi-lâminas é movido através do feixe sob o controle de computador, enquanto o feixe está ligado produzindo os perfis de fluência desejados para tratar o volume alvo. $O$ arranjo dos pares de lâminas e a velocidade de cada par de MLC são determinados por uma técnica introduzida por Convery e Rosenbloom ${ }^{10}$ e desenvolvida por Bortfeld et a ${ }^{58}$. Esta técnica de IMRT é conhecida por colimadores multi-lâminas de janelas deslizantes (sliding window) ou MLC dinâmico e foi implementada pela primeira vez no Memorial SloanKettering Cancer Center em Nova lorque. O Grupo de Trabalho Colaborativo em IMRT, $(C W G)^{10}$, recomenda o termo IMRT dinâmico quando a forma do colimador muda durante a irradiação.

Esta técnica de liberação da dose torna o controle de qualidade muito mais complexo e praticamente impossível de ser realizado visualmente pelo técnico em radioterapia.

\subsubsection{Controle de qualidade (CQ $)^{12,69-71}$}

Os planejamentos com IMRT envolvem muitos passos como arranjo dos MLCs e parâmetros da máquina de tratamento, por isso os dados do computador de planejamento são transferidos para a máquina de tratamento eletronicamente, via DICOM ou DICOM-RT. No entanto a integridade dos dados transferidos deve ser verificada rotineiramente, senão para cada plano produzido.

O controle de qualidade (CQ) para IMRT consiste de dois componentes principais. Primeiramente, o controle de qualidade da máquina de tratamento deve ser realizado como parte do processo de comissionamento e então revisado continuamente. Segundo, um controle de qualidade específico ao paciente deve 
ser realizado para verificar os campos com modulação da intensidade para cada paciente. Isto pode ser feito de diversas formas pré-tratamento. Uma delas é realizar um controle de qualidade em um simulador híbrido.

\subsubsection{CQ pré-tratamento específico ao plano de tratamento - híbrido}

Neste método de $C Q$, a distribuição de dose é recalculada para um simulador cúbico usando todos os parâmetros do tratamento que foram determinados no plano do paciente. Este planejamento é chamado de híbrido porque ao transferir o planejamento do paciente para o simulador no TPS, ele não muda as fluências respectivas a cada campo, o sistema somente recalcula a dose para o simulador, pois ele é geométricamente diferente do paciente.

Os dados usados no planejamento do paciente são transferidos para a máquina de tratamento e o planejamento pode ser liberado no simulador que deverá conter dosímetros apropriados (filmes ${ }^{11,72,73}$, mosfets $^{74}$ e câmara de ionização ${ }^{55}$ ) para uma avaliação do tratamento. As medidas resultantes da dose liberada no simulador podem ser comparadas diretamente aos cálculos realizados no simulador. Este procedimento testa o processo de tratamento como um todo.

\subsubsection{CQ pré-tratamento específico ao paciente - portais e ultra-som}

O controle de qualidade pré-tratamento específico ao paciente consiste em utilizar métodos para verificar a posição do alvo em relação ao feixe antes de cada fração do tratamento.

É óbvio que a posição do paciente que foi usada durante a aquisição da imagem para o planejamento radioterápico deve ser reproduzida no momento do tratamento para cada paciente em cada fração do tratamento, e isto é um dos maiores desafios no tratamento radioterápico. Pacientes que não têm muita mobilidade ou que são pouco flexíveis tendem a mudar sua forma diariamente. Isto resulta em uma incerteza considerável em localizar o feixe no alvo e evitar a irradiação em tecido normal. Esta incerteza tem sido considerada quando uma margem é deixada ao redor da região que receberá a dose prescrita usando o conceito de PTV. No entanto, se o tamanho da margem pode ser reduzido, uma quantidade menor de tecido normal é irradiado. Existem vários métodos viáveis para verificar o posicionamento do paciente. O mais convencional é o uso do alinhamento do paciente através de três lasers que coincidem no plano do 
isocentro da máquina de tratamento ${ }^{6}$. Os lasers devem coincidir com marcas à tinta ou tatuagens feitas na pele do paciente. Este método não se aplica a tumores internos ou movimento de órgãos. Por isso, um outro nível de localização foi implementado na radioterapia, que é o uso de imagem portal, que pode ser realizada com filme ou eletronicamente, para alinhar o feixe em relação à anatomia óssea. Por esta razão alguns tumores usam marcadores radiopacos como sementes metálicas para alinhar verdadeiramente o alvo com o feixe. Um outro método é utilizar um equipamento de ultra-som que tem suas coordenadas relacionadas com as da máquina de tratamento para localizar a próstata do paciente quando esta for o alvo e reposicionar o isocentro da máquina de tratamento para a nova posição do alvo. Neste trabalho foram utilizados os seguintes métodos: imagem com portal eletrônico (EPID) e ultra-som, para confirmação da posição do alvo ${ }^{75,76}$. 


\subsubsection{Comparação das técnicas de 3-D CRT e IMRT}

Para um melhor entendimento pode-se resumir este capítulo comparando a técnica de planejamento tridimensional convencional, 3-D CRT, com a técnica de modulação do feixe, IMRT, conforme a FIG. 3.16.

3-D CRT

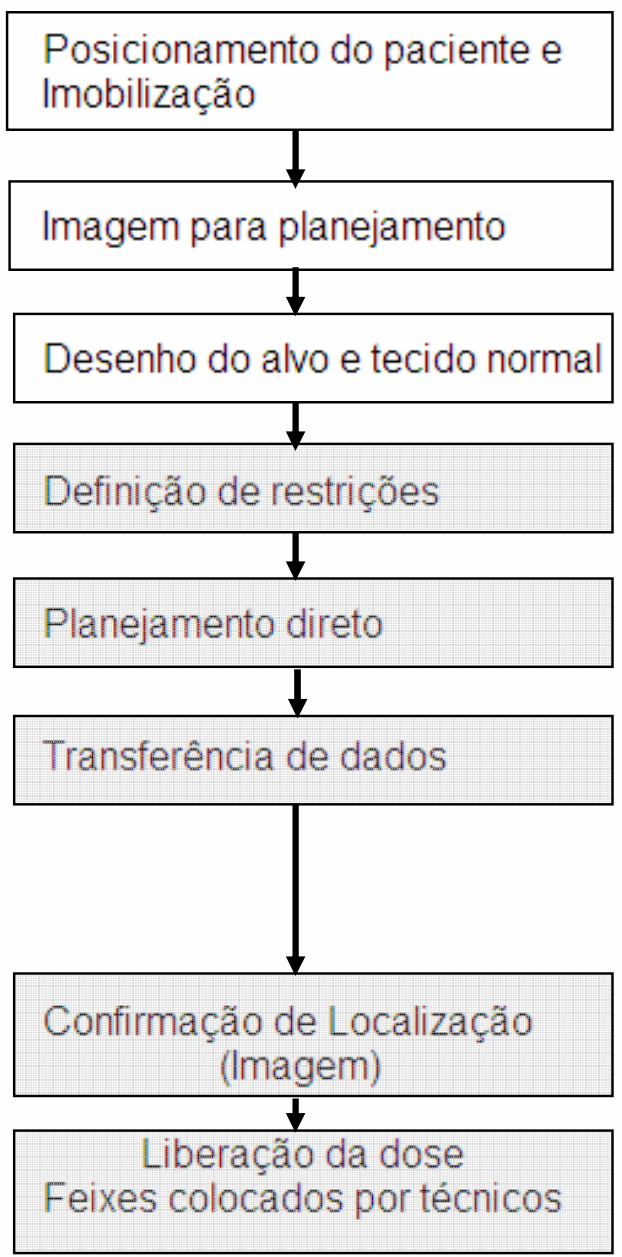

IMRT

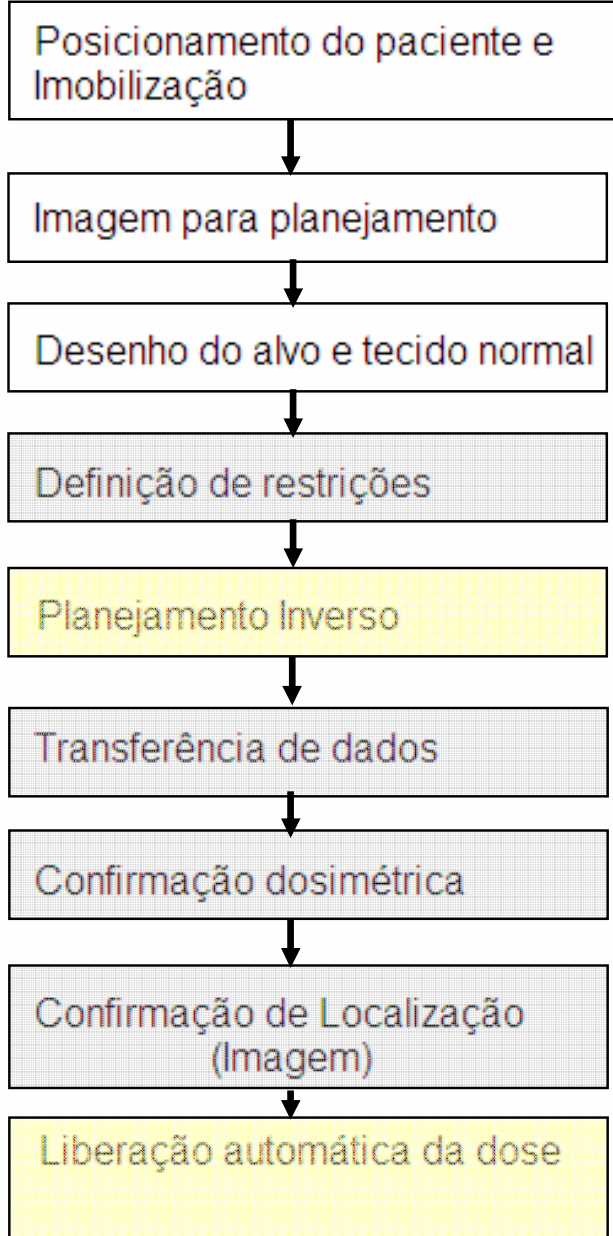

FIGURA 3.16 - Comparação dos passos no procedimento do planejamento do tratamento e liberação da dose para 3-D CRT e IMRT. As caixas em cinza indicam que há diferença entre 3-D CRT e IMRT, e as caixas em amarelo enfatizam as etapas que acontecem automaticamente e que do ponto de vista do usuário se comporta como uma "caixa preta" 2 . 


\subsection{MÉTODOS DE LOCALIZAÇÃO E VERIFICAÇÃO DE IMAGEM}

Este item apresenta os métodos de localização e verificação do posicionamento e do alvo através da imagem, descrevendo os tipos de imagens utilizadas préplanejamento, pré-tratamento e durante o curso da radioterapia.

\subsubsection{Pré-planejamento}

As imagens adquiridas pré-planejamento são as imagens que irão fornecer dados anatômicos do paciente para serem usadas no planejamento do tratamento. As imagens provenientes do tomógrafo computadorizado e as da ressonância magnética possibilitam a reconstrução tridimensional do paciente no sistema de planejamento computadorizado.

\subsubsection{Tomografia computadorizada}

A tomografia computadorizada (CT) contém todas as informações necessárias para um planejamento de tratamento complexo e deve ser tomada como a imagem de base em uma simulação em que são utilizadas outras modalidades de imagem como, por exemplo, a ressonância magnética ${ }^{77}$.

\subsubsection{Ressonância magnética}

Por meio de um procedimento chamado fusão de imagem disponível no sistema de planejamento computadorizado, é possível sobrepor imagens adquiridas da CT com outras modalidades de imagens como tais como ressonância magnética, ultra-som, angiografia e PET que podem ser utilizadas para auxiliar no desenho dos alvos, especialmente nos casos de tumores cerebrais em que a densidade do tumor é praticamente igual à do tecido cerebral, dificultando assim a sua visualização na imagem de $\mathrm{CT}{ }^{78,79}$.

\subsubsection{Pré-tratamento}

As imagens adquiridas antes do paciente iniciar o tratamento são aquelas que fornecerão dados sobre o posicionamento do paciente e o isocento de tratamento. 


\subsubsection{Imagem de portal e sementes de ouro}

A imagem portal como descrito a seguir (FIGURA 3.17) fornece uma informação anatômica importante do posicionamento do paciente no momento do tratamento, mas não possibilita a visualização de tumores com densidade próxima a do tecido. Essa é uma das razões pela qual o emprego de marcadores radiopacos no alvo de tratamento vem sendo cada vez mais usado na radioterapia conformada, em que a precisão na localização do alvo é muito importante para que as margens do tratamento possam ser cada vez mais reduzidas. Um dos marcadores utilizados é a semente de ouro, mais usada nos casos de tratamento da próstata, como mostrado na FIGURA 3.18. Neste caso, as sementes são implantadas na próstata e, quando o portal do paciente é realizado, pode-se visualizar as sementes e, assim, corrigir a posição do alvo no momento do tratamento comparando-a com o dia da simulação ${ }^{4}$.

\subsubsection{Durante o curso do tratamento}

Durante a radioterapia alguns equipamentos possibilitam a aquisição de imagens durante a liberação do feixe de radiação. Os mais conhecidos e que foram utilizados neste trabalho são o equipamento de imagem de portal eletrônico e sistema de localização do alvo por ultra-som 2-D.

\subsubsection{Equipamento de imagem de portal eletrônico (EPID)}

Sistemas de imagem portal eletrônico consistem de um conjunto de detectores de radiação, geralmente montados em um braço manual ou semi-robótico do acelerador, e são capazes de transferir as informações dos detectores para um computador que as processarão e irão convertê-las em imagem. Estes sistemas utilizam uma variedade de detectores, todos produzem imagens em computador com uma variedade de graus de qualidade. Os sistemas atuais incluem: detectores fluoroscópicos; detectores com câmaras de ionização e detectores silício amorfo (a-Si). A imagem de portal eletrônico utilizada neste trabalho foi produzida a partir de detectores silício amorfo ${ }^{76}$.

Este sistema tem as seguintes características: a) possue um aparato de detector de estado sólido consistindo de foto-diodos de silício amorfo e transistores de efeito de campo dispostos em uma matriz retangular grande; b) usa uma tela de fósforo fluorescente combinada com uma placa de metal como no sistema 
fluoroscópico. A placa de metal converte raios-X incidentes em elétrons e a tela fluorescente converte elétrons em fótons de luz. Os fótons de luz produzem pares de elétrons-lacunas nos foto-diodos. A quantidade dos pares elétrons-lacunas é proporcional à intensidade permitindo assim a formação de uma imagem; c) ele produz uma imagem com melhor resolução e contraste que os outros sistemas. Sua imagem pode ser vista na FIG. 3.17.

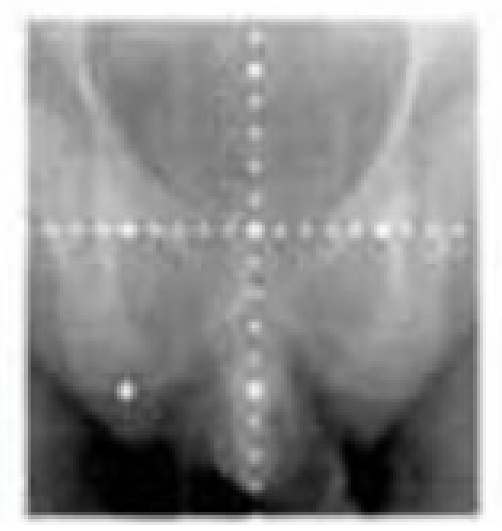

FIGURA 3.17 - Imagem sagital da região pélvica produzida por um sistema de imagem de portal eletrônico produzido com o sistema que utiliza os detectores silício amorfo.
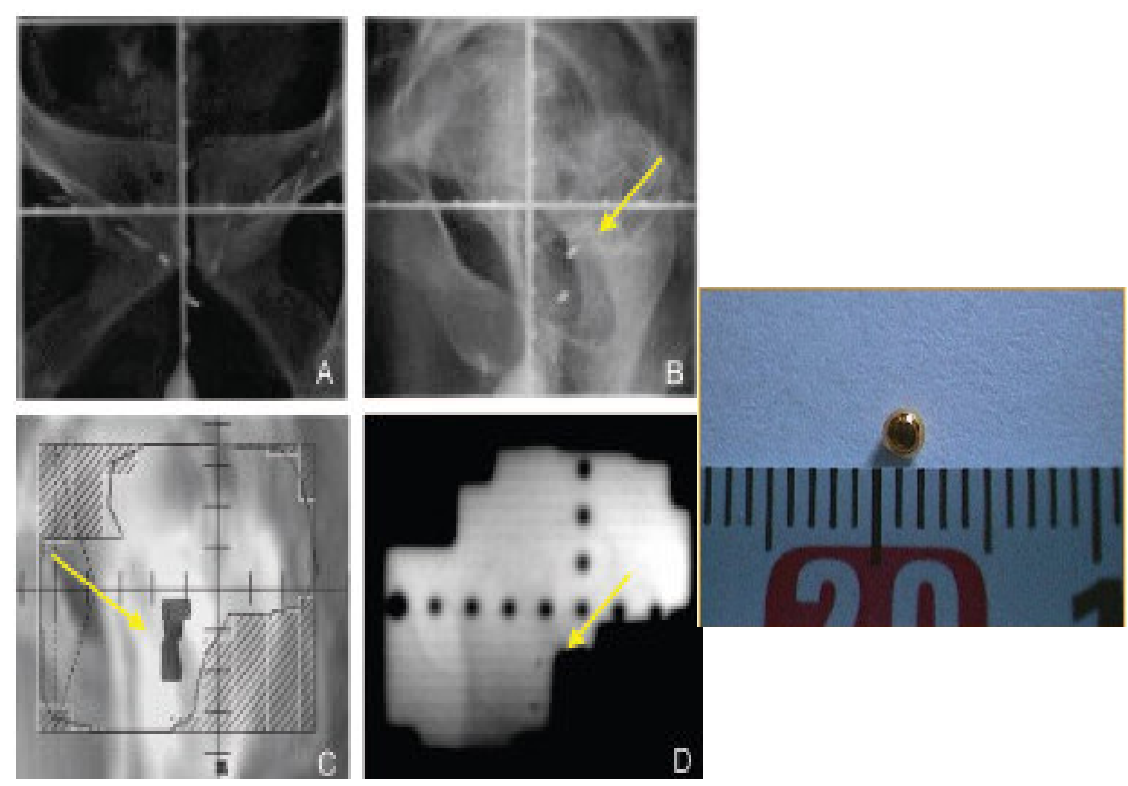

FIGURA 3.18 - Imagem de portal eletrônico com as setas mostrando os marcadores internos e sementes de ouro implantadas no alvo. Em destaque uma semente de ouro sobre uma escala métrica ${ }^{4}$. 
A imagem com portal eletrônico é usada para verificar o posicionamento do paciente em relação ao feixe de radiação na primeira fração do tratamento e é repetido se os campos são modificados e, algumas vezes, durante o curso do tratamento para fins de controle de qualidade.

A proposta da imagem de portal é: verificar a localização do campo de tratamento caracterizado pelo isocentro ou outro ponto de referência relativo à estruturas anatômicas do paciente durante o tratamento real; verificar se a abertura do feixe produzida por blocos ou colimadores multi-lâminas foi produzida e registrada adequadamente.

As imagens portais são comparadas com imagens de referência que podem ser imagens de simulador (ortogonais), radiografias reconstruídas digitalmente (DRR) no TPS ou a primeira imagem portal feita durante uma série de tratamentos. Um exemplo é mostrado na FIG. 3.19, na qual DRRs dos campos de tratamento pélvico anterior e lateral e DRRs dos campos abertos com intensidade usada no EPID são mostradas para comparação com as imagens obtidas com um EPID ${ }^{3}$.

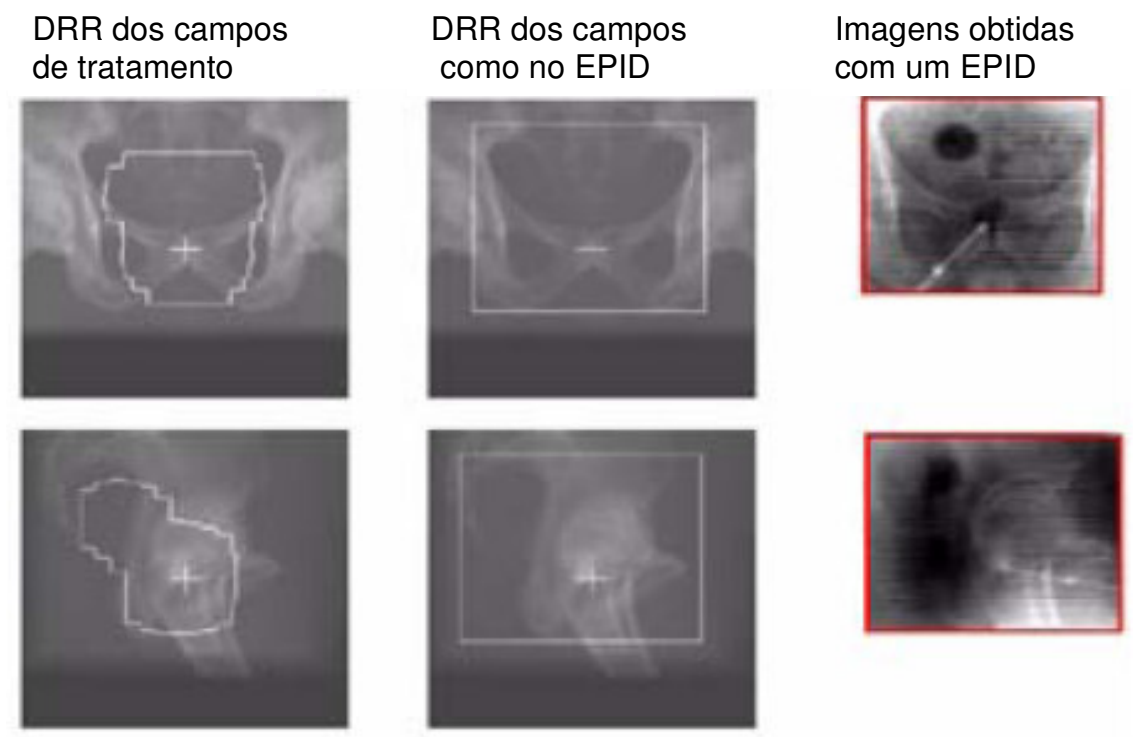

FIGURA 3.19 - DRRs dos campos de tratamento e dos campos abertos para verificar a posição do isocentro e dos campos obtidos com EPID correspondentes ${ }^{3}$. 
Uma série de imagens portais para um mesmo paciente adquirida em várias frações no decorrer do tratamento pode fornecer dados sobre as variações diárias no posicionamento (setup) do paciente e pode dar informações sobre mudanças ocorridas no decorrer do tratamento. Se uma série de imagens for adquirida durante o tratamento pode-se obter informações sobre movimento de órgãos como o pulmão p.ex. durante a irradiação. Se a imagem for adquirida no início de cada fração do tratamento pode-se verificar as mudanças anatômicas do paciente com relação ao seu posicionamento na imagem usada para planejamento e, assim, fazer ajustes para que o paciente seja tratado em uma posição semelhante à do seu planejamento.

\subsubsection{Sistema de localização do alvo por ultra-som 2-D}

O sistema de localização do alvo, nos casos de próstata, utilizado neste trabalho foi fabricado pela Nomos, sistema BAT (B-mode Acquisition and Targeting) ${ }^{80}$. Este sistema consiste de um carro onde está disposta uma unidade de ultra-som posicionado próximo à mesa de tratamento do acelerador e é usado pelo técnico da radioterapia para adquirir a imagem do alvo antes de cada fração do tratamento. A relação do volume alvo a um ponto de referência, geralmente 0 isocentro do acelerador, é determinado interativamente com o usuário e comparada com o volume alvo original desenhado nas imagens de CT. O sistema faz sugestões com relação à translação do paciente para que o alvo seja movido na mesma posição relativa ao isocentro conforme planejado. O técnico pode mover a mesa de tratamento e consequentemente o paciente, baseado nestas informações, para obter uma melhor acurácia do tratamento.

No sistema BAT, os desenhos axiais e sagitais de estruturas de interesse visíveis ao ultra-som são armazenadas em seu sistema com as coordenadas relacionadas ao isocentro de tratamento do paciente. Uma vez enviadas as reconstruções axial e sagital dos desenhos do CTV (próstata), bexiga e reto, realizados no sistema de planejamento tridimensional com as imagens provenientes da tomografia computadorizada, posiciona-se o paciente na mesa de tratamento do acelerador de modo que suas marcas externas do isocentro coincidam com os lasers da sala de tratamento e, então, realiza-se o seu ultra-som pélvico. As imagens axiais e sagitais formadas com o ultra-som são mostradas na tela do monitor do BAT e pode-se considerar que o novo isocentro do CTV adquirido com o ultra-som é o 
real pois o BAT tem suas coordenadas relacionadas às do acelerador. O técnico do equipamento move manualmente (com ajuda das setas no console do BAT) as novas imagens adquiridas com o BAT sobre as imagens axial e sagital dos desenhos do CTV feitos no TPS e então este deslocamento representa o movimento do CTV do dia do planejamento para o dia do tratamento. O dado do deslocamento para cada fração do tratamento é então gravado no sistema individualmente e foi usado neste trabalho para avaliar o deslocamento da próstata durante o tratamento radioterápico. A decisão de movimentar o isocentro de tratamento de acordo com a sugestão do BAT é tomada no departamento. Se o deslocamento da próstata for maior que a margem dada a ela para tratamento (PTV), então o isocentro é deslocado para a nova posição do órgão.

A utilização diária deste sistema na rotina clínica integra uma das muitas modalidades utilizadas no que é conhecido hoje por Radioterapia Guiada por Imagem (IGRT). Na FIG. 3.20 é mostrado o sistema de ultra-som BAT e as imagens axial e sagital adquiridas dele comparadas com os contornos realizados no sistema planejamento e transferidos para o BAT para comparação do isocentro de tratamento. 


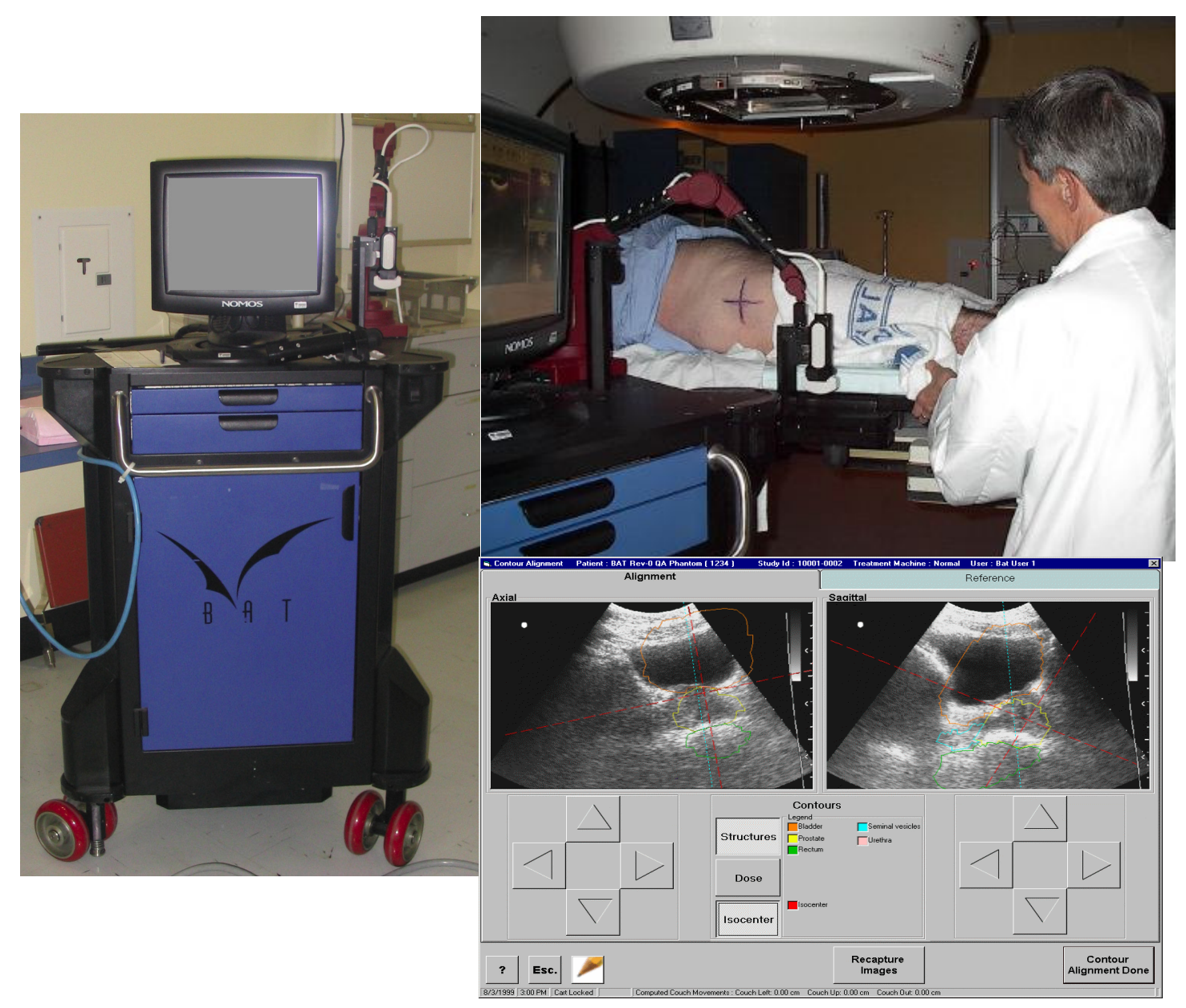

FIGURA 3.20 - Sistema de ultra-som BAT, utilizado na McGill University Health Centre, em destaque à esquerda. Técnico da radioterapia localizando o alvo e as imagens obtidas sobrepostas aos contornos provenientes do CT.

\subsubsection{Fusão de imagens ${ }^{81-83}$}

Por causa do uso crescente de modalidades múltiplas de imagens há necessidade de que softwares que compõem o TPS correlacionem e registrem estas imagens de tal forma que elas possam ser comparadas rotineiramente. A maioria dos softwares de simulação virtual já possuem esta modalidade, eles permitem a importação de imagens provenientes de fontes diferentes para comparação direta usando técnicas de registro/fusão de imagens. Além disso pode-se usar esta técnica em combinar imagens para verificação do tratamento radioterápico. Para este fim é necessário o registro da imagem comparando a imagem do posicionamento (setup) do paciente no dia do tratamento com a do 
planejamento. Neste trabalho foram utilizados dois métodos de fusão de imagens, um foi o descrito no ítem 3.3.3.2, que consiste do sistema de ultra-som BAT, onde as imagens do ultra-som são registradas e correlacionadas com os desenhos axiais e sagitais adquiridos no TPS e o outro método é a fusão de imagens obtidas por reconstrução radiográfica digital (DRR) com as provenientes do EPID obtidas diariamente no acelerador para verificação de posicionamento (setup) do paciente. Neste último método, o paciente é posicionado no isocentro de tratamento e imagens ortogonais são adquiridas com o EPID e transferida via DICOM-RT para um sistema como o VARIS/VISION, onde elas podem ser comparadas e correlacionadas como mostra o exemplo na FIGURA 3.21. Esta correlação pode ser feita pixel a pixel escolhendo manualmente pontos de referência anatômicos em ambas as imagens para que o sistema os reconheça como similares para que então efetue a fusão ou, automaticamente, a partir das coordenadas DICOM ou por densidade eletrônica.
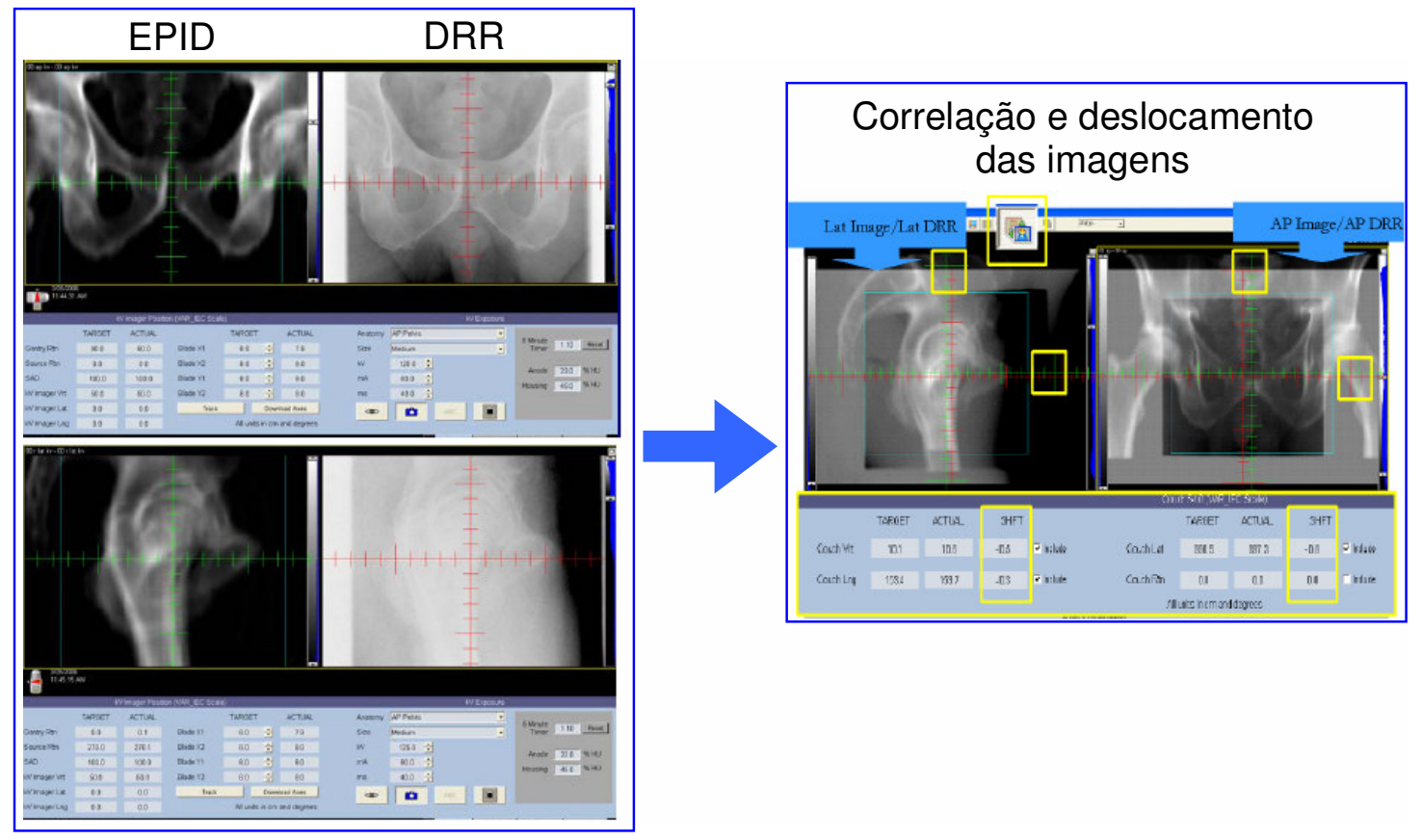

FIGURA 3.21 - Registro e correlação de imagens antero-posterior (AP) e laterais (LAT) provenientes de EPID e DRR ${ }^{69}$. 
O processo de fusão pode ser descrito basicamente como um problema de transformação de coordenadas de um sistema de referência a outro, como descrito por Bouza ${ }^{81}$. Ele pode se apresentar como uma transformação homogênea, entre dois sistemas de referência $S 1$ na modalidade $M 1$ e $S 2$ na modalidade $M 2^{81}$ :

$$
\begin{aligned}
& x=t_{11} u+t_{12} v+t_{13} w+t_{14} \\
& y=t_{21} u+t_{22} v+t_{23} w+t_{24} \\
& z=t_{31} u+t_{32} v+t_{33} w+t_{34} \\
& 1=t_{41} u+t_{42} v+t_{43} w+t_{44}
\end{aligned}
$$

onde $(\mathrm{x}, \mathrm{y}, \mathrm{z})$ representam as coordenadas de um ponto do espaço no sistema de referência $S 1$ e $(\mathrm{u}, \mathrm{v}, \mathrm{w})$ as coordenadas do mesmo ponto do espaço medidas no sistema de referência $S 2$. Os elementos da transformação $\left(t_{11}, t_{12}, t_{13}, t_{14}, t_{21}\right.$, $\left.t_{22}, \ldots, t_{44}\right)$, serão tratados daqui em diante como elementos de uma matriz $T$ na forma $t[i, j]$.

Uma matriz da forma anterior pode descrever transformações que introduzem rotação, translação, magnificação, especulação e deformações de vários tipos.

Para o presente estudo, foi restringida a matriz de modo a admitir apenas rotações e translações. Com esta restrição foi introduzida a condição de fusão de corpos rígidos, pois não foram admitidas deformações em nenhum deles.

$$
\begin{aligned}
& \Sigma\left(\mathrm{t}[\mathrm{i}, \mathrm{k}]{ }^{*} \mathrm{t}[\mathrm{j}, \mathrm{k}]\right)=0 \text {, se } \mathrm{i} \neq \mathrm{j} \text { (somando por } \mathrm{k} \text { de } 1 \text { a } 3 \text { ) } \\
& \Sigma\left(\mathrm{t}[\mathrm{i}, \mathrm{k}]^{*} \mathrm{t}[\mathrm{j}, \mathrm{k}]\right)=1 \text {, se } \mathrm{i}=\mathrm{j} \text { (somando por } \mathrm{k} \text { de } 1 \text { a } 3 \text { ) }
\end{aligned}
$$

As condições descritas nas equações 3.30 e 3.31 , representam a condição de ortogonalidade e normalidade da submatriz pertencente à matriz $T$.

O problema central do alinhamento (registration) consiste em encontrar os elementos da matriz da transformação T[i,j] . Achar os T[i,j] é obter a solução do problema .

Classificação dos algoritmos para encontrar T[i,j] são baseados em: marco estereotáxico, pontos de referência (intrínsecos ou extrínsecos), superfícies delimitadas, e voxel, com grau de similaridade medida por uma transformação pontual.

Solução baseada em pontos de referência: para calcular os elementos t[i,j] da matriz $T$, é necessário conhecer, pelo menos, quatro pontos equivalentes em 
ambas as técnicas. Estes pontos são chamados de marcadores referenciais. De modo que:

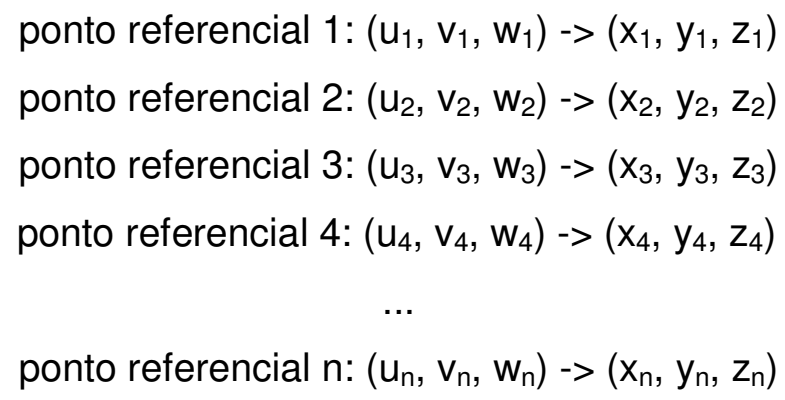

Os programas MNPS (para planejamento de neurocirurgia estereotáxica e radiocirurgia) e CAT3D (para planejamento de radioterapia 3-D) dispõem de um módulo para fusão multimodal de imagens. Um dos métodos é baseado em pontos de referência, com o uso de referenciais intrínsecos, ou seja, referências anatômicas.

Para que um detalhe anatômico constitua um bom referencial, é recomendado ${ }^{81}$ que ele tenha características como:

1. ser facilmente observado nas duas modalidades de imagens a serem fundidas;

2. ser pequeno, para minimizar a incerteza do observador ou exibir alguma simetria que ajude a eliminar incerteza;

3. estar presente no conjunto de imagens adquiridas por ambas modalidades;

4. não estar contido em algum plano capaz de passar muito perto de todos os pontos referenciais;

5. não estar dentro ou na periferia de elementos que introduzam artefatos em alguma das modalidades.

Esta recomendação apresenta um conjunto de pontos anatômicos que o autor ${ }^{81}$ tem utilizado com sucesso no planejamento de um grande número de procedimentos de radiocirurgia estereotáxica, e que podem ser utilizados no planejamento de radioterapia 3-D em localizações encefálicas. Esta recomendação tem caráter geral. Não existe garantia de que algum destes referenciais seja útil em qualquer caso real.

Qualquer um dos referenciais mencionados pode ter sido escondido por artefatos gerados por próteses, marcos de estereotaxia, ou outros objetos. Alguns destes 
referenciais também podem ser de pouca utilidade por patologias que deformam a anatomia, tais como hidrocefalias, hematomas, tumores, etc.

A quantidade mínima de referenciais que os programas exigem é quatro. Os autores $^{81-83}$ recomendam utilizar o maior número possível de referenciais, pois o erro (considerando só erros acidentais e não sistemáticos) é proporcional ao inverso da raiz quadrada do número de referenciais $(N)$ ou seja o Erro $\sim 1 / N^{1 / 2}$. 


\section{MATERIAIS E MÉTODOS}

Neste capítulo apresentam-se os materiais e métodos utilizados para realizar os experimentos necessários para definir o volume de tratamento planejado e avaliar os seus efeitos no planejamento radioterápico. As primeiras seções deste capítulo dão uma descrição dos equipamentos utilizados para realizar o planejamento e realizar as medições e também cita todos os equipamentos disponíveis na McGill University Health Centre utilizados neste trabalho. Nas seções seguintes são descritos os métodos experimentais usados para avaliar as variações dos alvos. Descreve-se também a avaliação dessas variações através da análise da reprodutibilidade do tratamento, do estudo da alteração da posição do alvo entre frações do tratamento, e da avaliação dos efeitos que as margens de tratamento causam na dose periférica ao alvo assim como nas estruturas críticas circunvizinhas.

\subsection{EQUIPAMENTOS}

\subsubsection{ACELERADOR LINEAR E SISTEMAS DE PLANEJAMENTO}

Os aceleradores lineares e sistemas de planejamento disponíveis no Departamento de Radioterapia e no Departamento de Física Médica da McGill University Health Centre (MUHC) utilizadas para o desenvolvimento deste trabalho foram:

- 1 acelerador linear Clinac-21 EX Varian (6 e 18 MV fótons; 4-20 MeV elétrons) com MLC (120 lâminas) e equipamento de imagem de portal eletrônico (EPID) de silício amorfo, integrado ao acelerador;

- 1 acelerador linear Clinac-21 EX Varian (6 e $18 \mathrm{MV}$ fótons; 6-20 MeV elétrons) com MLC (120 lâminas) e EPID de câmara de ionização líquida;

- 1 acelerador linear Clinac-2300 C/D Varian (6 e $18 \mathrm{MV}$ fótons; 6-22 MeV elétrons) com MLC (52 laminas), microMLC (Brainlab) e EPID câmara de ionização líquida;

- 2 aceleradores lineares Clinac 6 EX (6 MV fótons) com MLC (120 lâminas) e EPID câmara de ionização líquida;

- 7 estações de simulação virtual Picker AcQsim, Philips, Cleveland, OH; 
- 5 estações de planejamento de tratamento CadPlan, Varian, Palo Alto, CA;

- 2 estações de planejamento de tratamento Eclipse, Varian Palo Alto, CA;

- 1 sistema de planejamento inverso: Helios, Varian, Palo Alto, CA;

- 1 sistema de planejamento inverso: Corvus, NOMOS, Pittsburgh, PA;

- 1 sistema de planejamento com Monte Carlo: Peregrine, NOMOS, Pittsburgh, PA.

Um estudo para entender melhor como os 2 sistemas de planejamentos, Eclipse e CORVUS, funcionam é mostrado no APÊNDICE B.

O colimador de multi-lâminas do acelerador Varian modelo 2100 usado neste trabalho é construído como parte da estativa rotatória (conhecida pelo termo em inglês gantry) de tratamento e localizado abaixo dos colimadores inferiores como mostra a FIG. 4.1.

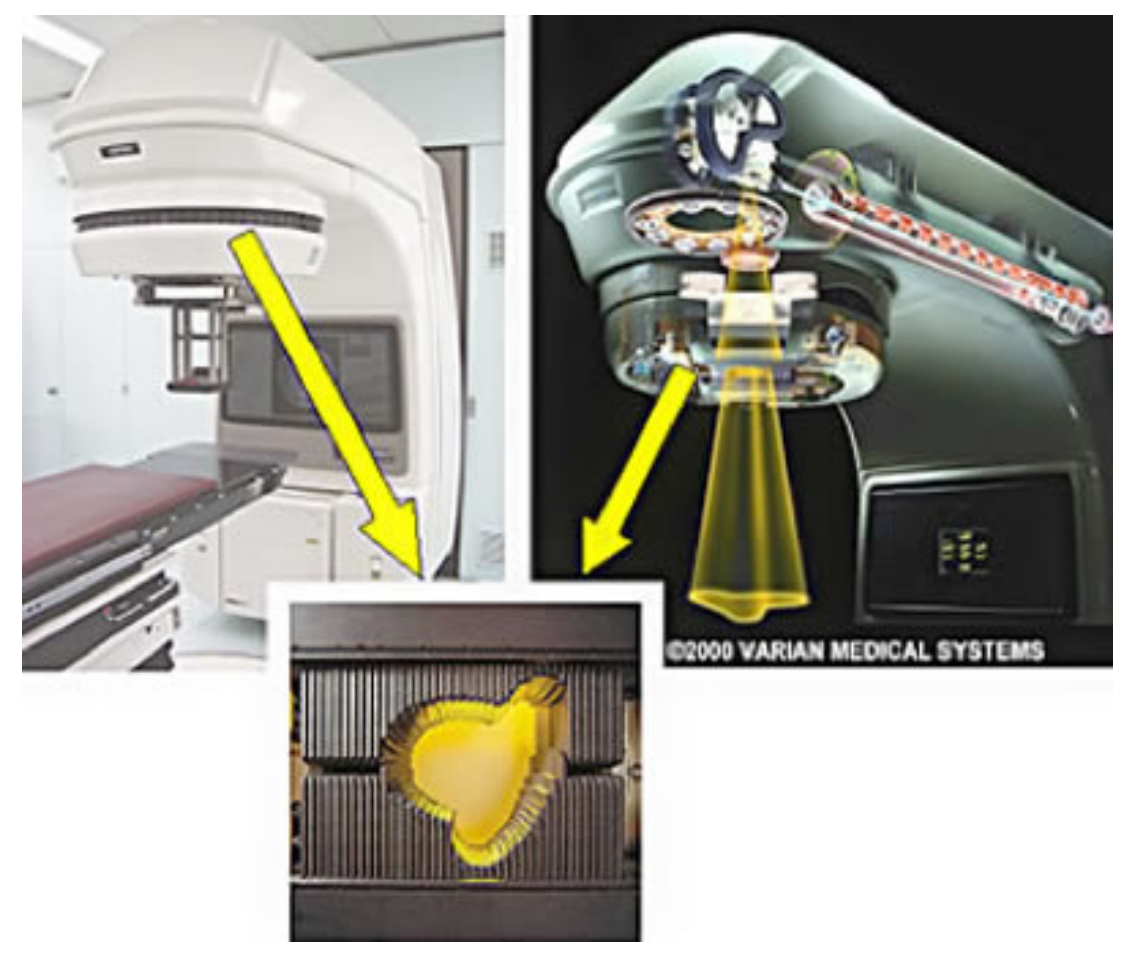

FIGURA 4.1 - Acelerador linear Varian com colimadores multi-lâminas (MLC) em destaque na caixa menor ${ }^{84}$.

Parte dos planejamentos realizados neste trabalho utilizou a técnica de intensidade modulada (IMRT) para liberar o tratamento. Esta técnica utiliza algoritmos de sequência de lâmina para traduzir os padrões de intensidades produzidos no sistema de planejamento em instruções sobre como a máquina de 
tratamento deve mover as lâminas. A técnica para liberar o IMRT foi a técnica de janelas deslizantes ou dinâmica. Para uma posição fixa do gantry, a abertura formada por cada par oposto de colimadores de multi-lâminas é alterada através de controle computadorizado, com o feixe de radiação ligado, para produzir os perfis de fluência desejado. Nesta técnica de colimadores com multilâminas dinâmica (dMLC) cada par de lâminas no MLC define uma separação (gap) que se move unidirecionalmente, com uma velocidade independente como uma função do tempo, de tal forma que as posições das lâminas, suas velocidades, a liberação das UMs, e as taxas de dose interajam entre si.

\subsubsection{Simuladores de tecido: água sólida e antropomórfico}

Os simuladores utilizados na MUHC foram:

- Simulador antropomórfico RANDO fabricado por The Phantom Laboratory, Salem, NY, USA;

- Simuladores de água sólida da Gammex modelo RMI-457, Middleton, WI, EUA.

Os simuladores de água sólida utilizados foram os fabricados pela Gammex, com o nome de RMI-457, apresentados na FIG. 4.2. Eles possuem a densidade eletrônica equivalente a água (certificado de calibração com diferenças de até $0,5 \%$ em relação a água). As placas possuem espessuras variadas de $0,2 \mathrm{~cm}$ a $6 \mathrm{~cm}$ e tamanhos de $30 \mathrm{~cm} \times 30 \mathrm{~cm}$. Este tipo de simulador tem a vantagem de não acumular carga e não ser afetado por mudanças na temperatura e umidade. Sua composição é mostrada na Tabela 4.1.

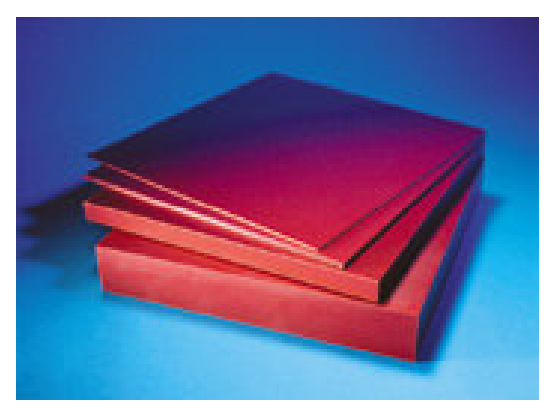

FIGURA 4.2 - Simulador de tecido de material equivalente a água, conhecido como simulador de água sólida, da Gammex. 
TABELA 4.1 - Composição elementar (fração por peso), densidade nominal e número atômico médio do simulador de tecido de água sólida e da água ${ }^{51}$.

\begin{tabular}{|c|c|c|}
\hline $\begin{array}{c}\text { Composição elementar do } \\
\text { simulador }\end{array}$ & $\begin{array}{c}\text { Água sólida RMI-457 } \\
\text { (GAMMEX) }\end{array}$ & Água líquida \\
\hline $\mathrm{H}$ & 0,0809 & 0,1119 \\
\hline $\mathrm{C}$ & 0,6722 & \\
\hline $\mathrm{N}$ & 0,0240 & 0,8881 \\
\hline $\mathrm{O}$ & 0,1984 & \\
\hline $\mathrm{Cl}$ & 0,0013 & 1,000 \\
\hline $\mathrm{Ca}$ & 0,0232 & 6,6 \\
\hline Número atômico médio $(\bar{Z})$ & 1,030 & \\
\hline
\end{tabular}

O simulador antropomórfico RANDO, FIG. 4.3, representa uma figura masculina de $175 \mathrm{~cm}$ de altura e $73,5 \mathrm{~kg}$, e é composto de um esqueleto humano natural recoberto com material de densidade $0,985 \mathrm{~g} / \mathrm{cm}^{3}$ e número atômico efetivo 7,3 (conforme ICRP, 1975, medidas do homem padrão) ${ }^{85}$. Os pulmões moldados na situação expandida de ar, têm o mesmo número atomico mas densidade de $0,32 \mathrm{~g} / \mathrm{cm}^{3}$. Está dividido em 36 fatias de $2,5 \mathrm{~cm}$ de espessura cada. Cada fatia possui orifícios distribuídos a cada $3 \mathrm{~cm}$ ou $1,5 \mathrm{~cm}$ onde podem ser acomodados os TLDs.

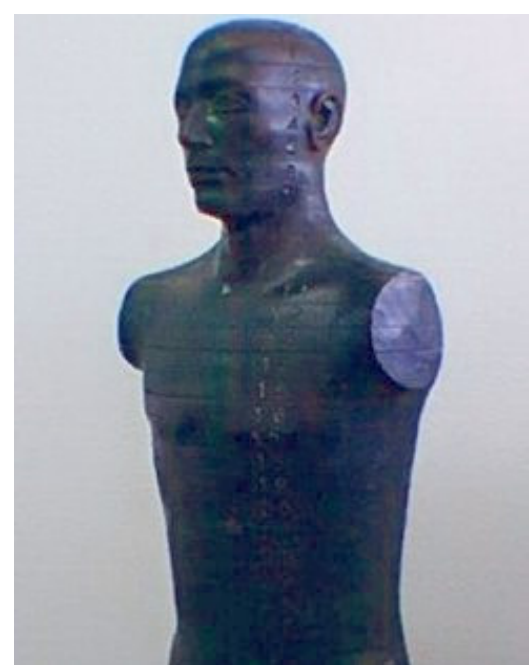

FIGURA 4.3 - Simulador antropomórfico RANDO.

\subsubsection{Dosímetros: câmara de ionização, filmes, MOSFET e TLD}

O APÊNDICE $\mathrm{C}$ apresenta os fundamentos teóricos da física dos dosímetros utilizados neste trabalho, que são citados a seguir. 
- Câmaras de ionização cilíndrica $0,6 \mathrm{~cm}^{3}$ tipo Farmer modelo NE 2571 da Nuclear Enterprises, Inglaterra;

- Eletrômetro Keithley modelo 35617, Cleveland, Ohio, EUA;

- Filmes radiográficos X-Omat V e EDR-2 fabricados pela Kodak, Rochester, NY, EUA;

- Scanner Vidar VXR-12 e OmniPro software para dosimetria com filme, Scanditronix, Alemanha;

- Densitômetro Victoreen modelo 37-443 da Nuclear Associates, Hicksville, NY, EUA;

- Sistema de dosimetria termoluminescente Harshaw QS 3500 com software WinREMS, Thermo Electron Corporation, Waltham, MA;

- Forno PTW-TLDO;

- Dosímetros termoluminescentes MTS 100, LiF:Mg,Ti, TLD Poland, Cracóvia, Polônia;

- Sistema de dosimetria MOSFET 20 modelo TN-RD-50, Thomson and Nielsen Electronics Ltda, CA, EUA.

\subsection{Dosimetria e controle de qualidade}

A dosimetria e controle de qualidade dos feixes de fótons utilizados foram realizados como descrito a seguir.

- Calibração de feixes de fótons e elétrons: de acordo com o protocolo americano para determinação de rendimento do feixe, AAPM TG- $51^{50}$, onde é determinada a taxa de dose em um ponto $\mathrm{P}$ numa profundidade de referência $z_{\text {ref }}$ na água para uma distância nominal da fonte DFS ou DFI e um tamanho de campo de referência determinado na superfície do simulador de água ou no isocentro. Os fatores de calibração adquiridos em água são convertidos para um simulador de água sólida, onde uma câmara de ionização cilíndrica é posicionada no $z_{\text {ref }}$ para cada tipo e energia do feixe. Este procedimento simplifica o processo de verificação do rendimento e é usado nos testes de verificação de rendimentos executados periódicamente nas máquinas de tratamento.

- Verificação de parâmetros dosimétricos de feixes de fótons e elétrons: verificação da energia do feixe, porcentagem de dose profunda (PDP) como função da profundidade na água, planura, simetria e avaliação de dose fora do 
eixo central e perfis de dose para filtro dinâmico verificados com diodos fazem parte da dosimetria completa em feixe de fótons ${ }^{3,49}$.

- Verificação de dose: no ponto de máximo e na profundidade para diferentes tamanhos e formas dos blocos de proteção confeccionados individualmente nos tratamentos com elétrons.

- Garantia de qualidade no tratamento com IMRT: alinhamento dos colimadores de multi-lâminas (MLCs), verificação da velocidade da lâmina através da repetição do mesmo teste com um mapa de fluência definido e analisando a liberação do tratamento gravado no software VARiS ${ }^{10,12}$.

A câmara de ionização cilíndrica de $0,6 \mathrm{~cm}^{3}$ tipo Farmer modelo NE 2571 foi usada como dosimetro de referência para a calibração e caracterização dos filmes e MOSFETs.

\subsection{Imagem: tomografia computadorizada, ultra-som, equipamento de imagem de portal eletrônico}

Sistema de imagem pré-planejamento:

- 2 CT simuladores: PQ-5000 AcQsim e AcQsim-CT, Philips, OH (todos os pacientes no MUHC são submetidos ao CT simulador pré-tratamento). Para a realização deste trabalho todos os desenhos dos alvos e estruturas de interesse foram feitos no sistema AcQsim da Phillips.

Sistema de localização do alvo pré-tratamento:

- sistema de ultra-som 2-D baseado em localização de alvo BAT, NOMOS Corporation, Cranberry Township, PA.

Sistema de avaliação de tratamento:

- equipamento de imagem de portal eletrônica (EPID) Varian, Palo Alto, CA. 


\subsection{CALIBRAÇÃO E TESTES DE DESEMPENHO DOS DOSÍMETROS}

\subsubsection{Caracterização dos filmes radiográficos}

Os filmes X-Omat V e o EDR-2 foram calibrados e testados para IMRT.

\subsubsection{Calibração dos filmes radiográficos em dose}

Os filmes radiográficos utilizados foram o X-Omat $\mathrm{V}$ e o EDR-2. Para estes filmes foram utilizados o scanner Vidar VXR-12 e o software OmniPro para análise dosimétrica do filme.

O filme $\mathrm{X}$-Omat $\mathrm{V}$ é um filme de baixa velocidade projetado para verificar a variação da intensidade do feixe e dar uma dose aproximada nos pacientes submetidos à radioterapia. Este filme apresenta resposta linear em relação a dose entre 5 e 100 cGy e saturação em 300 cGy. O filme radiográfico EDR-2 é um filme de velocidade muito baixa com grãos finos de tamanho aproximado de $0,05 \mu \mathrm{m}^{2}$. As suas camadas de emulsão dupla são cobertas por uma base de $0,18 \mathrm{~mm}$ para permitir que o filme seja processado de modo convencional. Possui resposta linear de dose entre 25 e 400 cGy e saturação em 700 cGy ${ }^{73}$.

\subsubsection{Filmes radiográficos na verificação da distribuição de dose do IMRT}

Os filmes X-Omat $\mathrm{V}$ e EDR-2 foram testados e usados para verificar a distribuição de dose nos planejamentos com IMRT. Ambos os filmes foram irradiados com uma dose de 1 Gy em um feixe de fótons de $6 \mathrm{MV}$ a $8,5 \mathrm{~cm}$ de profundidade, no simulador de água sólida Gammex. O planejamento foi feito no TPS CORVUS para dar uma distribuição de dose homogênea em cinco regiões da parte central do volume irradiado. A distribuição de dose resultante, normalizada para a dose máxima em cada filme é apresentada na FIG. 5.2.

Para calibrar os filmes foram realizadas medições entre 0 e 3 Gy, num simulador de água sólida e na profundidade de máxima dose para o feixe de fótons de $6 \mathrm{MV}$.

\subsubsection{Scanner e Densitômetro}

Os filmes foram processados convencionalmente numa processadora rápida e depois de revelados foram submetidos ao scanner Vidar VXR-12 que possui uma lâmpada fluorescente da Philips modelo F17T8/TL841 e então analisados com o software OmniPro. O scanner tem uma velocidade de aquisição de imagens ou 
digitalização de $20 \mathrm{~ms} /$ linha e uma resolução de 75 dpi (ou 3 dpmm), ou seja resolve pontos espaçados por volta de $350 \mu \mathrm{m}$.

$\mathrm{O}$ densitômetro Victoreen foi usado como referência para se obter as curvas sensitômétricas dos fimes X-Omat $V$ e EDR-2 e então alimentar o software OmniPro.

\subsubsection{Caracterização do MOSFET ${ }^{86}$}

O transistor de efeito de campo metal-óxido-silício, conhecido como MOSFET, é um tipo de interruptor (switch) semicondutor (ligado-desligado) em que uma membrana de óxido é disposta entre o metal e o silício, recebendo o nome de MOS. O suprimento de tensão foi ajustado para alta sensibilidade que significa aproximadamente $3 \mathrm{mV} / \mathrm{cGy}$.

Os dosímetros MOSFETs foram utilizados neste trabalho para verficar a dose proveniente do tratamento com IMRT. Como sua resposta para IMRT ainda não era conhecida foi feito um estudo para caracterizá-lo e testá-lo para este fim.

Os dosímetros foram testados quanto ao:

a) Decaimento do sinal (fading);

b) Linearidade da resposta;

c) Dependência da resposta com a taxa de dose;

d) Dependência direcional;

e) Dependência com o tamanho de campo;

f) Dependência energética;

g) Curva resposta com dose;

h) Reprodutibilidade da resposta.

O conjunto dosimétrico de referência utilizado neste estudo foi a câmara de ionização cilíndrica NE 2571 SN 2665 e o eletrômetro Keithley modelo 35617. As medidas sob o feixe de fótons de $6 \mathrm{MV}$ do Clinac 600 foram realizadas com a câmara de ionização e então repetida com os dosímetros MOSFET sob as mesmas condições. Para cada dosímetro MOSFET foi obtida a média das leituras e o resultado dividido pela dose determinada préviamente com a câmara de ionização para determinar o fator calibração em $\mathrm{mV} / \mathrm{cGy}$. Todos os testes foram feitos com os dosímetros na profundidade de dose máxima sob feixe de fótons de $6 \mathrm{MV}$ e DFS de $100 \mathrm{~cm}$, que será chamado de condição de referência. 


\subsubsection{Teste de decaimento do sinal}

O decaimento é uma mudança que ocorre ao longo do tempo na leitura de tensão do MOSFET após a irradiação. Ele é atribuído a mudanças nas densidades de cargas armadilhadas no óxido, induzidas pela radiação $\left(\Delta \mathrm{N}_{\mathrm{ot}}\right)$ e nas armadilhas da interface $\left(\Delta \mathrm{N}_{\mathrm{ot}}\right)$ após a irradiação. Estas densidades são dependentes das condições do bias pré e pós irradiação ${ }^{87}$.

Os dosímetros foram irradiados com feixe de fótons de $6 \mathrm{MV}$, DFS de $100 \mathrm{~cm}$, $75 \mathrm{UM}$ e taxa de dose de $400 \mathrm{UM} / \mathrm{min}$. O arranjo geométrico deste teste é mostrado nas FIGURAS 4.4 e 4.5.

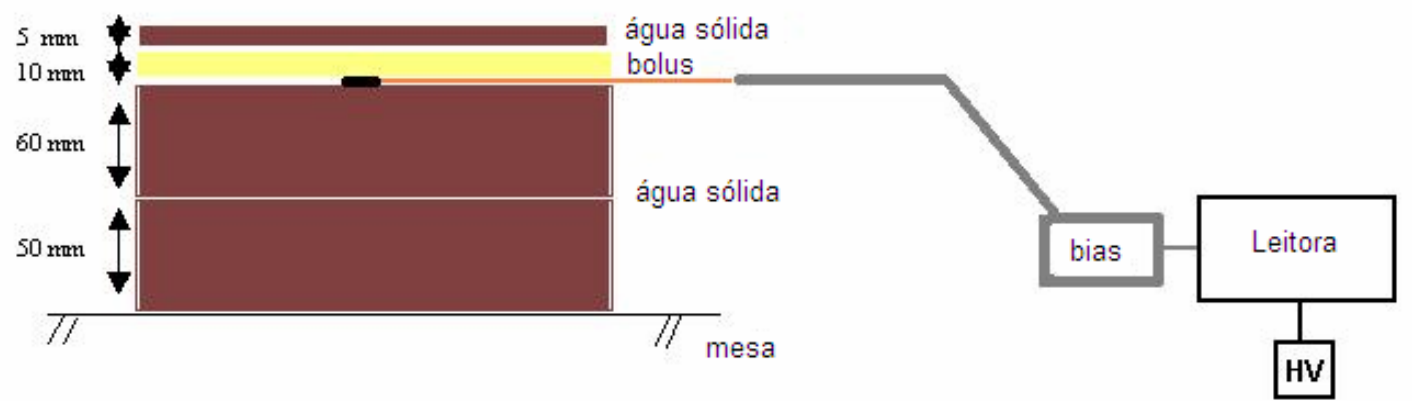

FIGURA 4.4 - Visão lateral do arranjo geométrico do sistema de dosimetria MOSFET na água sólida.

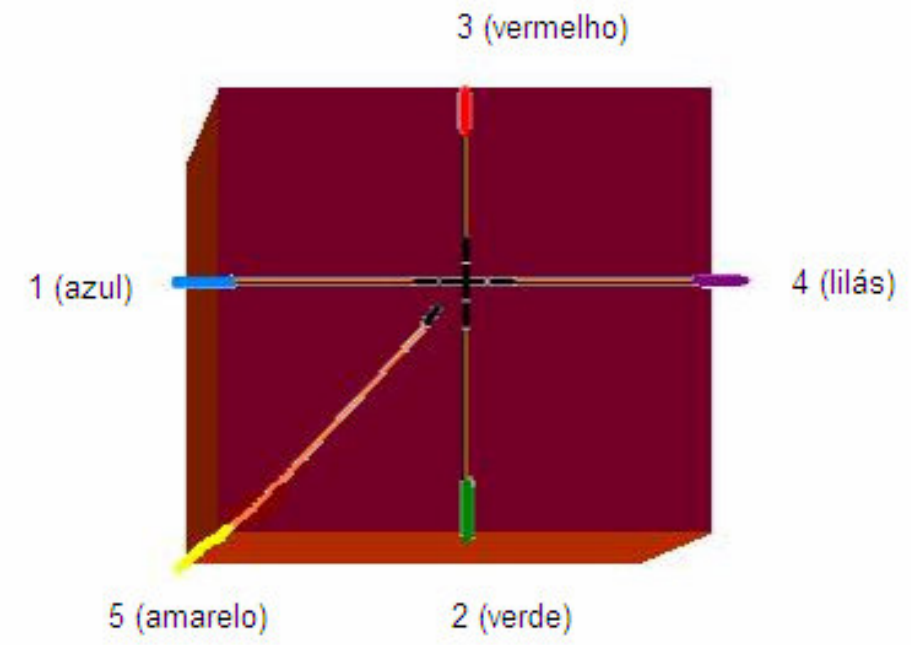

FIGURA 4.5 - Visão anterior do posicionamento dos cinco MOSFETs avaliados. 
A leitura dos dosímetros foi obtida antes da irradiação, 1 minuto após a irradiação $\left(x_{0}\right)$ e 15 minutos após a irradiação $\left(x_{15}\right)$. $O$ decaimento do sinal é dado pela equação 4.1 .

$$
|F|=\frac{\left|x_{15}-x_{0}\right|}{x_{0}} \times 100 \%
$$

\subsubsection{Linearidade da resposta}

Como a vida útil do MOSFET é $20.000 \mathrm{mV}$, somente alguns deles foram selecionados para os testes a seguir. Um único dosímetro MOSFET foi testado com relação a linearidade. $O$ dosímetro foi irradiado sob o feixe de fótons de $6 \mathrm{MV}$, tamanho de campo $10 \mathrm{~cm} \times 10 \mathrm{~cm}$, DFS de $100 \mathrm{~cm}$, taxa de dose de $400 \mathrm{UM} / \mathrm{min}$ e as medições foram tomadas entre 0 e 300 cGy.

\subsubsection{Dependência com a taxa de dose}

Para este teste um MOSFET foi submetido às condições de referência e foram realizadas medições entre 200 e $500 \mathrm{UM} / \mathrm{min}$. O dosímetro foi irradiado com 30 UM por medida.

\subsubsection{Dependência direcional}

Para este experimento foi construído um simulador de tecido cilíndrico de poliestireno com $10 \mathrm{~cm}$ de raio e encaixe central para colocação do MOSFET, como mostrado na FIG. 4.6. Neste teste o dosímetro MOSFET foi irradiado nas condições de referência com tamanho de campo $6 \mathrm{~cm} \times 6 \mathrm{~cm}$ e 30 UM por medida. As medições foram tomadas num primeiro momento girando o gantry a cada 45 graus e depois girando o próprio dosímetro a cada 45 graus, num intervalo de 0 a 315 graus. 


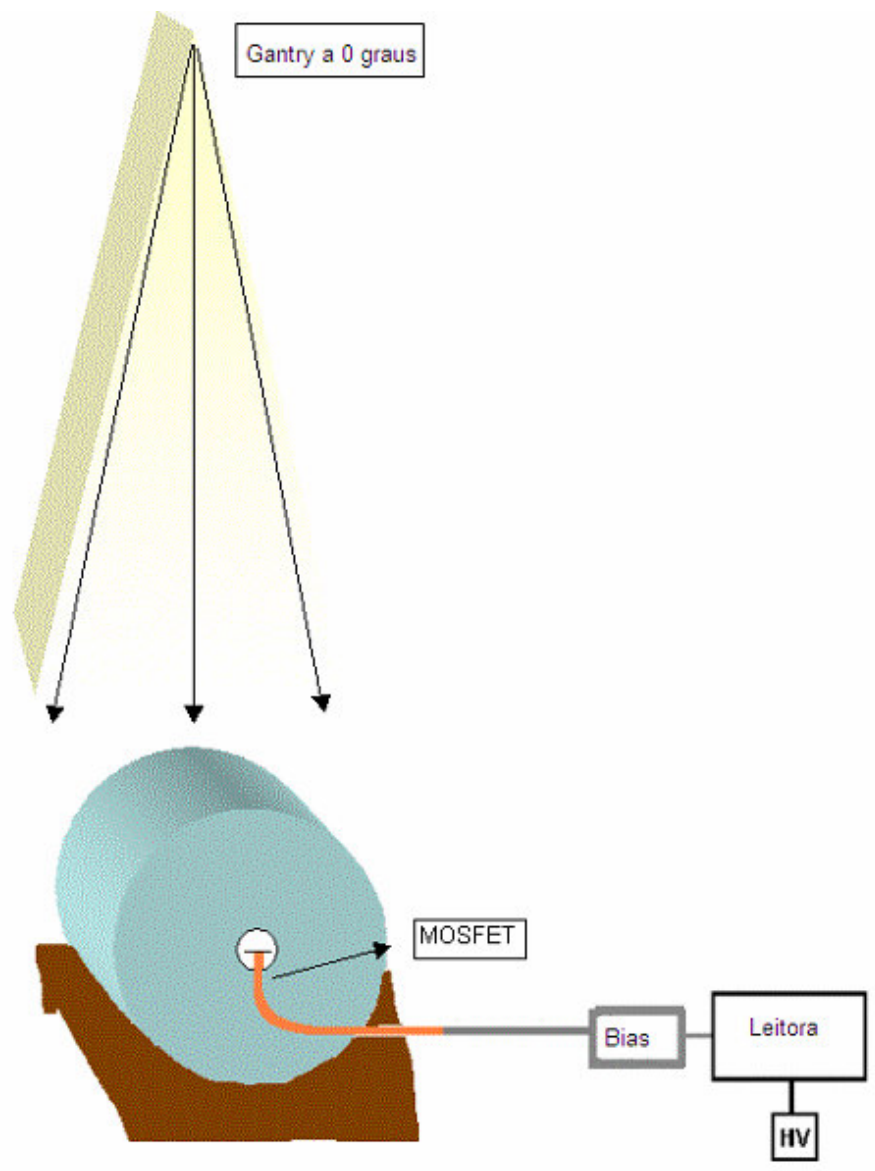

FIGURA 4.6 - Procedimento experimental para avaliar a dependência direcional da resposta do MOSFET utilizando um simulador cilíndrico com o MOSFET posicionado no seu centro.

\subsubsection{Dependência com o tamanho de campo}

Para fazer esta avaliação com os dosímetros MOSFET foram utilizados filmes EDR-2 e a câmara de ionização Farmer de $0,6 \mathrm{~cm}^{3}$. As medições foram realizadas com os dosímetros MOSFET e repetidas com os filmes e a câmara de ionização para as mesmas condições de referência: fótons $6 \mathrm{MV}$, taxa de dose de $400 \mathrm{UM} / \mathrm{min}$, DFS de $100 \mathrm{~cm}$, profundidade de $1,5 \mathrm{~cm}$ e simulador de tecido de água sólida. As medidas foram tomadas para os tamanhos de campos entre $5 \mathrm{e}$ $260 \mathrm{~mm}$ com todos os detectores.

\subsubsection{Dependência energética}

A resposta de um sistema de dosimetria geralmente é função da qualidade do feixe de radiação. Como os sistemas de dosimetria são calibrados em uma 
qualidade de feixe de radiação e usados num alcance muito maior de energia, a variação da resposta do sistema dosimétrico com a qualidade de radiação (denominado dependência da energia) deveria ser levado em conta ${ }^{51}$.

Para avaliar esta dependência 3 dosímetros MOSFET foram irradiados com feixe de fótons de 6 e 18 MV do CLINAC 2100 sob as mesmas condições de referência: tamanho de campo $10 \mathrm{~cm} \times 10 \mathrm{~cm}$, DFS de $100 \mathrm{~cm}, 100 \mathrm{UM}$ por medida. $\mathrm{O}$ arranjo experimental é mostrado na FIG. 4.7.

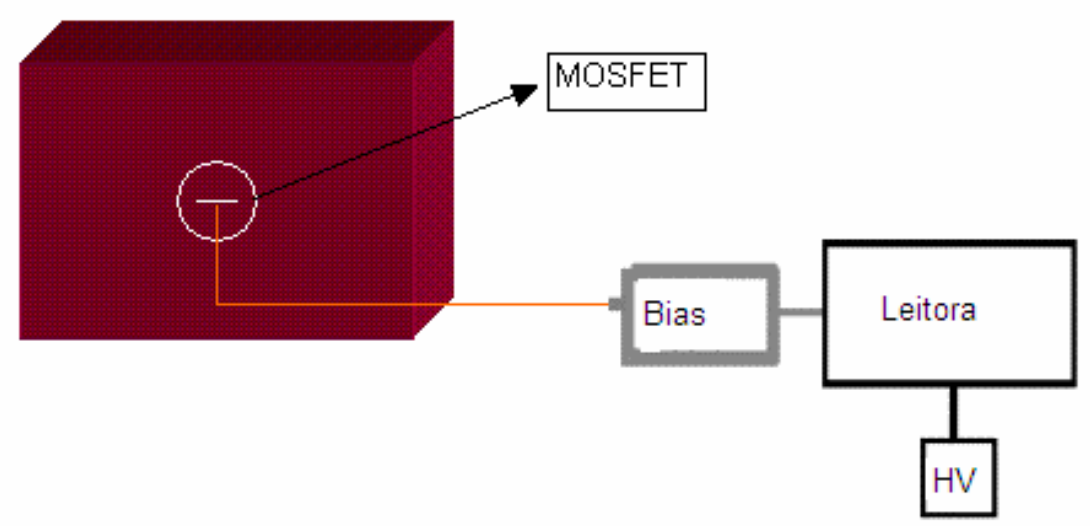

FIGURA 4.7 - Arranjo experimental do sistema de dosimetria do MOSFET no simulador de tecido de água sólida.

\subsubsection{Calibração em função da dose}

O fator de calibração para os dosímetros MOSFET foi obtido através da irradiação com um feixe de $6 \mathrm{MV}$ de fótons, $100 \mathrm{UM}$ por irradiação, DFS de $100 \mathrm{~cm}$ e em duas profundidades diferentes de medida: a $1,5 \mathrm{~cm}$ e $10 \mathrm{~cm}$. Os dosímetros foram colocados num simulador de tecido de água sólida como mostrado na FIG. 4.7. Uma câmara de ionização tipo Farmer de $0,6 \mathrm{~cm}^{3}$ calibrada no laboratório secundário foi irradiada nas mesmas condições do MOSFET e então utilizada como referência para obtenção do fator calibração, cGy/mV, para cada dosímetro MOSFET. 
Os procedimentos para calibração dos dosímetros MOSFET são relacionados a seguir.

1. Colocar a câmara de ionização de $0,6 \mathrm{~cm}^{3}$ na profundidade de máxima dose (Dmax) na água sólida, irradiada com fótons de $6 \mathrm{MV}$, campo $10 \times 10 \mathrm{~cm}^{2}$, 100 cGy e DFS de $100 \mathrm{~cm}$.

2. Conectar os MOSFET à fonte de tensão pelo menos com uma noite de antecedência ao seu uso para sua estabilidade. Uma vez que os MOSFET são conectados à fonte de tensão, eles devem permanecer permanentemente conectados até o fim da sua vida útil.

3. Escolher o modo de operação da fonte de tensão; o padrão é $3 \mathrm{mV} / \mathrm{cGy}$, mas para os casos de medida em dose de entrada e dose fora do campo de radiação é melhor uma sensibilidade mais alta ( $9 \mathrm{mV} / \mathrm{cGy}$ ).

4. Zerar os dosímetros.

5. Desconectar a fonte de tensão da leitora, mas os dosímetros devem continuar conectados nele para a irradiação.

6. Fixar os dosímetros no objeto simulador de água sólida, nas mesmas profundidades e nas mesmas condições do passo 1.

7. Irradiar os dosímetros com fótons de $6 \mathrm{MV}, 10 \times 10 \mathrm{~cm}^{2}$, e 100 cGy.

8. Reconectar à leitora a fonte de tensão conectada aos dosímetros.

9. Pressionar o botão "Read" da leitora uma única vez para cada dosímetro para obter as respectivas tensões $(\mathrm{mV})$.

10. Irradiar cada MOSFET pelo menos 3 vezes.

11. Determinar o fator de calibração: a média das leituras obtidas para cada MOSFET dividida pela dose previamente obtida com a câmara de ionização nas mesmas condições de radiação (passo 1) fornece o fator calibração em mV/cGy. Portanto,

$$
\text { Dose (cGy) = Tensão no MOSFET (mV) / FC (mV/cGy) }
$$

em que:

FC é o fator de calibração obtido para cada MOSFET e pode variar de $0,1 \mathrm{mV} / \mathrm{cGy}$ a $99,99 \mathrm{mV} / \mathrm{cGy}$.

Desta forma foram obtidos os fatores de calibração para 4 dos 5 dosímetros utilizados neste trabalho apresentado na TABELA 5.4. 


\subsubsection{Reprodutibilidade}

A reprodutibilidade das leituras dos MOSFET foi obtida submetendo os dosímetros à repetidas exposições de 67 cGy utilizando um arranjo geométrico conforme o apresentado na FIG. 4.7.

\subsubsection{Emprego do MOSFET na dosimetria do IMRT}

O MOSFET foi testado para verificar a dose nos planejamentos com IMRT. Os dosímetros foram irradiados com feixe de fótons de $6 \mathrm{MV}$, no simulador de água sólida Gammex, a 8,5 cm de profundidade e dose de 1 Gy. O planejamento foi feito no TPS CORVUS para dar uma distribuição de dose homogênea em cinco regiões da parte central do volume irradiado. Os MOSFETs foram distribuídos de forma a coincidirem com os pontos de dose de 80 cGy, 8 cGy e 4 cGy calculados no TPS. Os valores de dose obtidos são apresentados no capítulo 5.

\subsubsection{Caracterização do TLD}

Na FIG. 4.8 são apresentados os dosímetros termoluminescentes utilizados neste trabalho: cristais de LiF:Mg, Ti, tipo MTS 100, comumente denominados TLD-100. Estes dosímetros possuem o formato quadrado com dimensão de $3,2 \mathrm{~mm} \times$ $3,2 \mathrm{~mm} \times 0,25 \mathrm{~mm}$, número atômico efetivo de 8,1 e densidade de $2,64 \mathrm{~g} / \mathrm{cm}^{3}$.

A sensibilidade é maior que 0,2 $\mathrm{G}$ y, a linearidade entre $100 \mu \mathrm{Gy}$ e 10 Gy é menor que 1\% (FIG. 5.10). A emissão máxima de luz TL é diretamente proporcional à taxa de aquecimento da leitora para uma dose constante. A eficiência intrínseca ao TL é a quantidade de luz do TL emitida por unidade de massa dividida pela dose absorvida e para o TLD-100 de LiF é 0,039\% ${ }^{88}$.

O tratamento térmico de reutilização foi feito aquecendo os dosímetros por $1 \mathrm{~h}$ à $400^{\circ} \mathrm{C}$ e em seguida mantendo-os por $2 \mathrm{~h}$ à $100^{\circ} \mathrm{C}$ no forno PTW-TLDO. O resfriamento foi realizado à temperatura ambiente de $31^{\circ} \mathrm{C}$. Após o tratamento térmico de reutilização os dosímetros foram irradiados no acelerador com feixe de fótons de 6 MV num campo $10 \mathrm{~cm}$ x $10 \mathrm{~cm}$ e DFS de $100 \mathrm{~cm}$ na profundidade de máxima dose $(1,5 \mathrm{~cm})$ e doses que variaram de 0 a 3 Gy. $O$ passo seguinte à irradiação foi a leitura individual dos TLDs na leitora Harshaw QS 3500 que foi feito da seguinte forma: taxa de aquecimento utilizada na leitora de $12^{\circ} \mathrm{C} / \mathrm{s}$ até alcançar a temperatura de $300^{\circ} \mathrm{C}$. O pico de cada dosímetro foi selecionado no programa WinREMS como mostrado na FIG. 4.9. 
Uma curva de calibração dose $(\mathrm{Gy})$ x leitura $T L(\mathrm{nC})$ foi realizada a partir da irradiação dos TLDs com diferentes doses.

O cálculo da dose de cada TLD, irradiado em condições diversas no simulador antropomórfico para os planejamentos com IMRT, foi realizado seguindo os passos descritos a seguir.

1. Obtenção da média das leituras obtidas com o grupo de controle (que é o grupo irradiado nas condições de referência toda vez que o lote é utilizado);

2. Cálculo do fator de correção a ser aplicado no TLD irradiado com dose desconhecida através da renormalização da média das leituras obtidas no passo 1 usando o fator de calibração do grupo de controle de referência que foi de 1152 nC/Gy;

3. Aplicação do fator de correção calculado no passo 2 para a leitura do TLD irradiado com dose desconhecida;

4. Cálculo da dose dada ao TLD usando a curva da FIG. 5.10.

A espessura equivalente em água da espessura, $z$, do TLD foi determinada escalonando a espessura do TLD $(0,25 \mathrm{~mm})$ pela relação de densidades eletrônicas água/LiF, como mostrado na equação $4.3 .^{89}$ :

$$
z_{\text {agua }}=z_{T L D} \times \frac{\rho_{\text {agua }}}{\rho_{\text {TLD }}},
$$

em que $\rho_{\text {agua }}$ é $3,343 \times 10^{26} \mathrm{e} / \mathrm{kg}$ e $\rho_{T L D}$ é $2,786 \times 10^{26} \mathrm{e} / \mathrm{kg}$. Portanto para a espessura de TLD usada de $250 \mu \mathrm{m}$ o equivalente em água é aproximadamente $300 \mu \mathrm{m}$. 


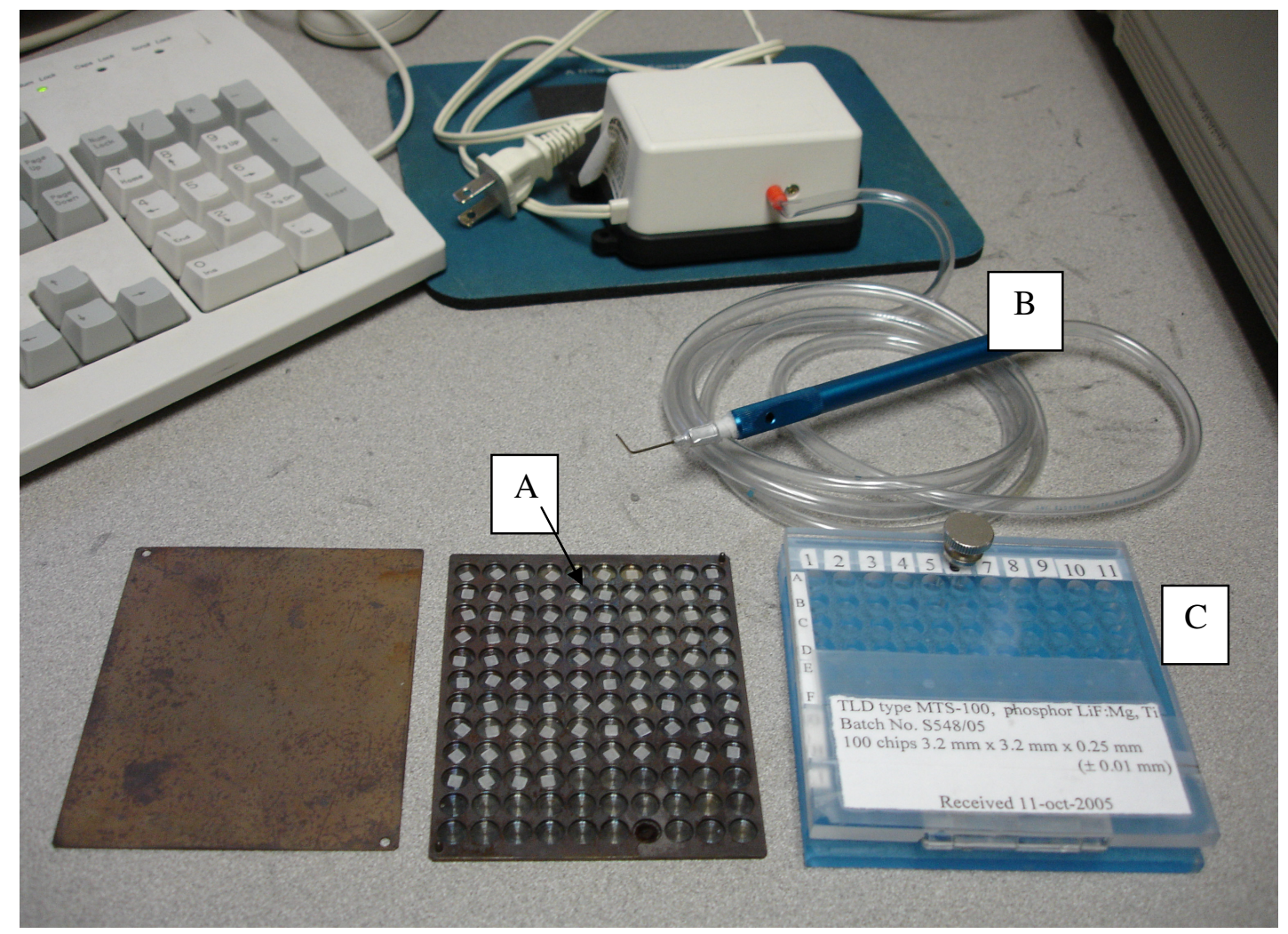

FIGURA 4.8 - A. Dosímetros termoluminescentes dispostos sobre a bandeja de cobre com cobertura, B. Pegador à vácuo para manipular os dosímetros e C. Caixa de acrílico para guardar os TLDs após o uso.

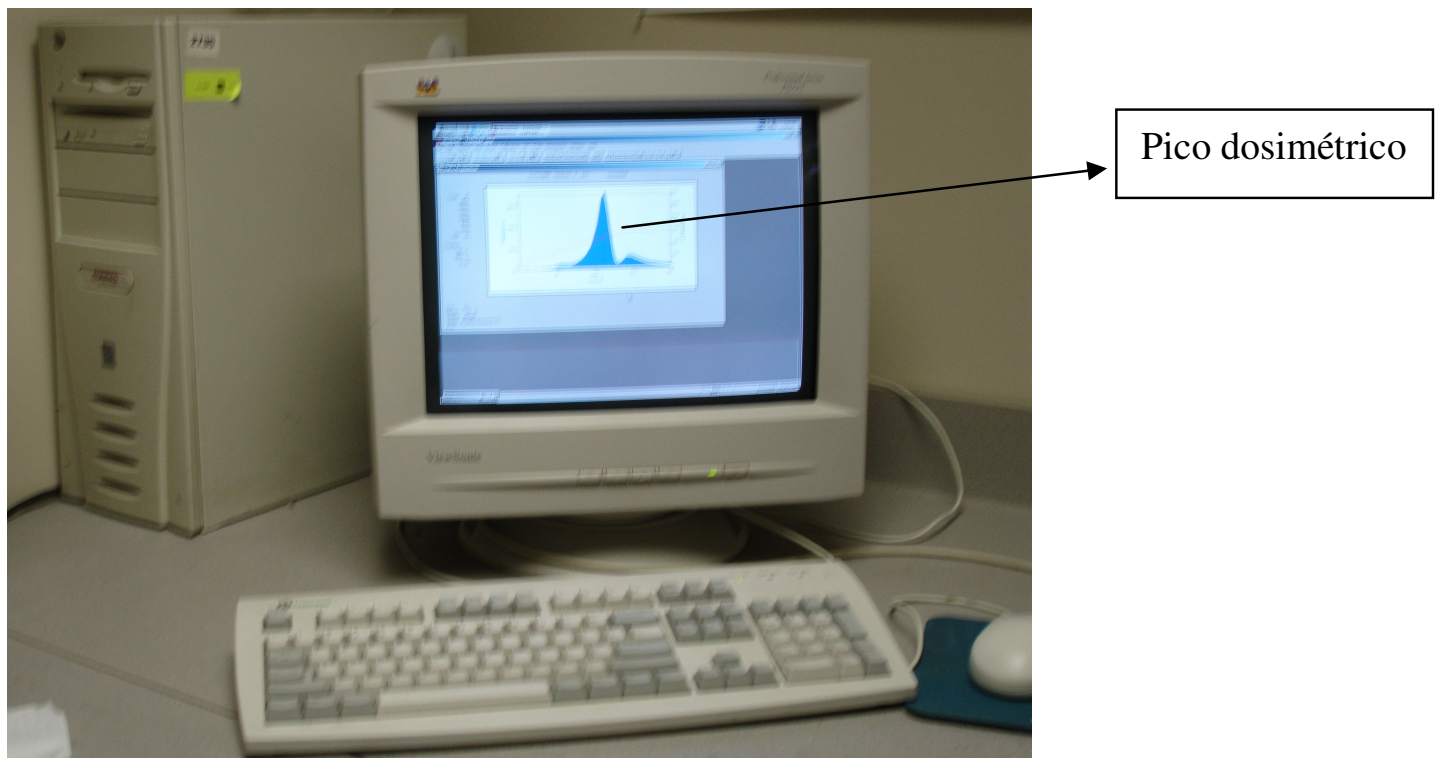

FIGURA 4.9 - Programa WinREMS que fornece a curva emissão de cada TLD onde o pico dosimétrico de cada dosímetro é selecionado individualmente. 


\subsection{TÉCNICAS EXPERIMENTAIS PARA AVALIAÇÃO DOS ERROS E INCERTEZAS ASSOCIADAS AO PTV E O SEU EFEITO NA RADIOTERAPIA}

Neste ítem, devido o simulador antropomórfico RANDO não possuir todas as estruturas: linfonodos, medula cervical, glândulas salivares, tronco cerebral, mandíbula, e os alvos, necessárias para o planejamento, optou-se por tomá-las de outro paciente e transferí-las para o RANDO por fusão. Para isso foi utilizado o sistema de planejamento AcQsim que permite fusão de imagens de estruturas.

\subsubsection{Incertezas relacionadas à localização do paciente: casos de tumor na região da cabeça e pescoço}

Os indicadores da posição vertical e horizontal da mesa de tratamento e os erros relacionados ao posicionamento do paciente, representam as situações menos favoráveis na configuração do tratamento, sendo o posicionamento do paciente, o evento mais importante nos tratamentos com modulação do feixe (IMRT) ${ }^{90-94}$. Para avaliar como a distribuição de dose é afetada devido à variações na posição do paciente, foi realizado o seguinte procedimento: 1) quatro portais de imagem eletrônica (EPI) foram tomados de 78 pacientes planejados com o TPS CORVUS, totalizando $312 \mathrm{EPI}$; 2) para cada paciente foram graficados os desvios em relação ao isocentro de tratamento planejado nas direções $X, Y, Z$. Isto pôde ser feito através da fusão da imagem digital (EPI) adquirida no acelerador linear semanalmente antes do tratamento com a imagem radiográfica digital (DRR) obtida no sistema de planejamento, FIGURAS 4.10 a), b), c). 


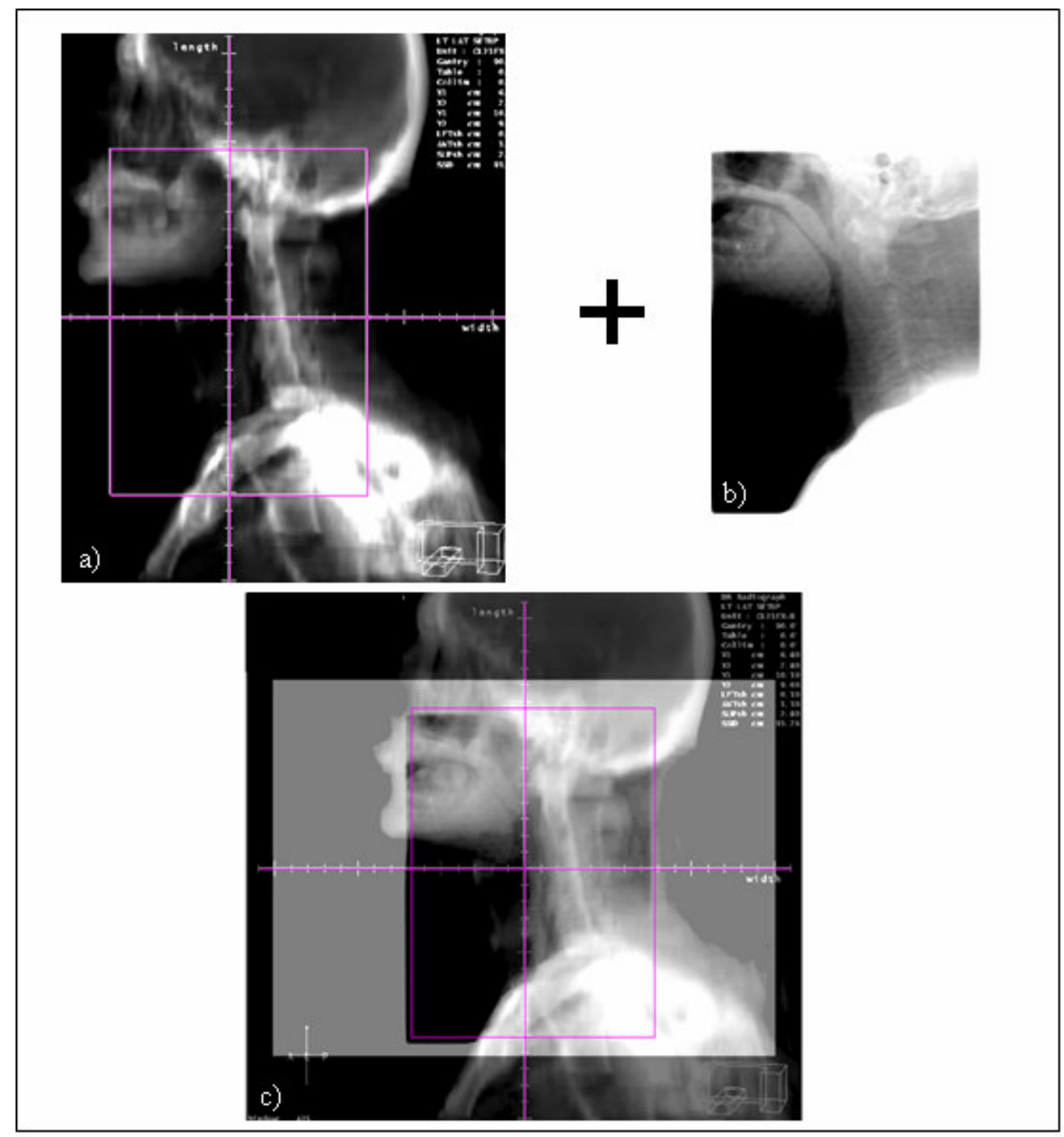

FIGURA 4.10 - a) Imagem radiográfica digital (DRR) obtida no sistema de planejamento; b) Imagem eletrônica (EPI) adquirida no acelerador linear pré-tratamento; c) Fusão do DRR com o EPI para verificação do isocentro no dia do tratamento.

\subsubsection{Efeito do deslocamento do isocentro na distribuição de dose}

Os desvios determinados no estudo anterior permitiram a simulação do que pode ocorrer com a distribuição de dose no paciente que tem seu isocentro de tratamento posicionado diferentemente do que foi planejado. Um desvio padrão para o deslocamento do isocentro avaliados no item 4.5.1, para cada direção 
$(\mathrm{x}, \mathrm{y}, \mathrm{z})$ foi aplicado no simulador antropomórfico, Rando, através do uso do planejamento no simulador híbrido.

O simulador híbrido é uma ferramenta do sistema de planejamento CORVUS que permite que o usuário recalcule o plano do paciente mudando a liberação de dose planejada para um simulador designado pelo usuário. Este procedimento é usado rotineiramente para controle de qualidade do plano de tratamento. Usando um simulador híbrido as novas coordenadas para o isocentro podem ser aplicadas nele e o plano de tratamento é recalculado sem que a otimização da fluência dos feixes, originalmente aceita no plano do paciente, seja alterada. Como para este estudo o simulador antropomórfico (Rando) foi utilizado como sendo o paciente original e também como sendo o simulador híbrido, a forma geométrica do paciente não foi alterada e assim pôde-se avaliar as variações na distribuição de dose que foram geradas somente pelo deslocamento do isocentro de tratamento. O simulador híbrido foi criado então para que os erros de posicionamento, que geraram o deslocamento do isocentro nos pacientes, fossem aplicados à ele. $O$ Rando foi planejado com dois tipos de arranjos de campos: a) plano $1 \mathrm{com} o$ gantry em 5 posições: $250^{\circ}, 325^{\circ}, 0^{\circ}, 35^{\circ}, 110^{\circ}$ e b) plano 2 com o gantry em 7 posições: $205^{\circ}, 255^{\circ}, 310^{\circ}, 0^{\circ}, 50^{\circ}, 105^{\circ}, 155^{\circ}$, que são os mais utilizados no CORVUS. Para cada planejamento o isocentro foi deslocado de $5,1 \mathrm{~mm}$ para direita do paciente, $3,7 \mathrm{~mm}$ para esquerda, $7,6 \mathrm{~mm}$ no sentido anterior, $8,8 \mathrm{~mm}$ no sentido posterior, $8,2 \mathrm{~mm}$ no sentido caudal ou inferior e $10,6 \mathrm{~mm}$ no sentido do crânio ou superior. Estes valores foram obtidos dos deslocamentos no intervalo de confiança de $95,5 \%$ obtidos das medições realizadas com os portais eletrônicos dos 78 pacientes de cabeça e pescoço planejados no CORVUS. O desvio do isocentro para cada direção foi aplicado no simulador híbrido e o recálculo do planejamento foi realizado a fim de se verificar qual das direções causa maior impacto na distribuição de dose no paciente durante as aplicações e se o número de campos usado interfere neste julgamento.

Os resultados obtidos deste estudo são apresentados no item 5.2.2 do capítulo 5 . O APÊNDICE B mostra um estudo feito para ilustrar as diferenças em termos de distribuição de dose em tecidos sadios e volumes de tratamento com os métodos de tratamento convencional, conformacional e IMRT para pacientes em tratamento de cabeça e pescoço que inclui GTV + linfonodos cervicais e supra- 
claviculares (ENT). Este estudo foi importante para mostrar porque foi decidido tratar com IMRT todos os pacientes ENT.

\subsubsection{Efeito do tamanho do PTV nas estruturas críticas vizinhas à ele}

Este estudo foi realizado para tratamentos da região de cabeça e pescoço. Através da análise retrospectiva de imagens de pacientes adquiridas com o portal eletrônico do acelerador linear, determinou-se o desvio-padrão em cada direção do sistema cartesiano, conforme ítem 4.5.2. Um CTV foi desenhado na imagem de CT do simulador antropomórfico e margens de $2 \mathrm{~mm}$ e $5 \mathrm{~mm}$ foram geradas para formar o $\mathrm{PTV}_{2}$ e $\mathrm{PTV}_{5}$, respectivamente. $\mathrm{O}$ isocentro de tratamento para estes PTVs foi então deslocado em seis direções de acordo com os desvios padrões determinados no ítem 5.2.1 do capítulo 5. A análise dos histogramas de dose-volume (DVH) realizada em relação ao CTV e às estruturas críticas possibilitou a identificação das variações de dose que ocorrem nas estruturas vizinhas ao PTV devido ao aumento da margem dada a ele. O resultado desta análise é mostrado na TABELA 5.6 do item 5.2.2 do capítulo 5 .

\subsubsection{Efeito da margem dada ao volume alvo para formar o PTV em relação à dose na superfície quando se utiliza planejamento inverso para IMRT no tratamento de câncer de cabeça e pescoço}

Esta parte do trabalho avalia a dose de superfície no paciente como uma função da proximidade do PTV a essa superfície, para os casos em que os pacientes são tratados com IMRT utilizando o planejamento inverso, e compara os resultados às medições realizadas para a técnica convencional.

Um simulador antropomórfico (RANDO) foi submetido à tomografia computadorizada (CT) na posição supino com uma máscara termoplástica padrão usada na imobilização dos pacientes ENT, que cobre toda a região da cabeça e pescoço do paciente excluindo os ombros e a região supra-clavicular. Um CTV incluindo os linfonodos cervicais e supra-claviculares com uma margem de $5 \mathrm{~mm}$ foi desenhado nas imagens de CT. Os planos foram gerados por um sistema de planejamento inverso comercialmente viável para os PTVs definidos a 0,5 , e $10 \mathrm{~mm}$ de profundidade da pele ( $\mathrm{PTV}_{\text {pele }}, \mathrm{PTV}_{5}, \mathrm{PTV}_{10}$, respectivamente) usando uma técnica de 7 campos coplanares com fótons de $6 \mathrm{MV}$. O mapa de fluência resultante da técnica de 7 campos é mostrada na FIGURA 4.11 e as 
FIGURAS $4.12 \mathrm{a}$ ), b), e c) mostram o PTV $\mathrm{Pele}_{\text {, }} \mathrm{PTV}_{5}, \mathrm{PTV}_{10}$, respectivamente. Para os experimentos de IMRT foi utilizado sistema de colimadores de multi-lâminas dinâmico (DMLC) e o método de liberação foi com a técnica de janelas deslizantes, com um total de aproximadamente 1200 UM para liberar a dose prescrita de 162 cGy ao PTV. O RANDO também foi irradiado com a técnica convencional de 3 campos, usando dois campos laterais paralelos e opostos cobrindo a região do pescoço, coincidentes com o campo direto anterior tratando a região supra-clavicular. $\mathrm{Na}$ junção dos 3 campos foram utilizados colimadores independentes fechados na metade do campo para evitar que as penumbras dos campos adjacentes se sobrepusessem. Uma dose de 200 cGy foi liberada no CTV. As medidas foram realizadas em até 4 posições ao redor do pescoço do RANDO sob a máscara termoplástica e 4 posições na região supra-clavicular na superfície do simulador. Os dosímetros utilizados foram LiF TLD-100 e MOSFET. Os dosímetros foram colocados em pedaços de água sólida, cortados nas dimensões do RANDO mas com espessuras de $5 \mathrm{~mm}$ e com cavidades de $1 \mathrm{~mm}$ de profundidade nos locais onde os dosímetros tinham que ser inseridos. Estas fatias de água sólida foram colocadas entre fatias do RANDO. Três pontos de medidas foram tomados dentro do RANDO na região do CTV, usados como referência para as medidas na superfície.

O simulador antropomórfico RANDO na posição de tratamento é ilustrado na FIGURA 4.13. A posição dos dosímetros no simulador antropomórfico RANDO é mostrada na FIGURA 4.14. 


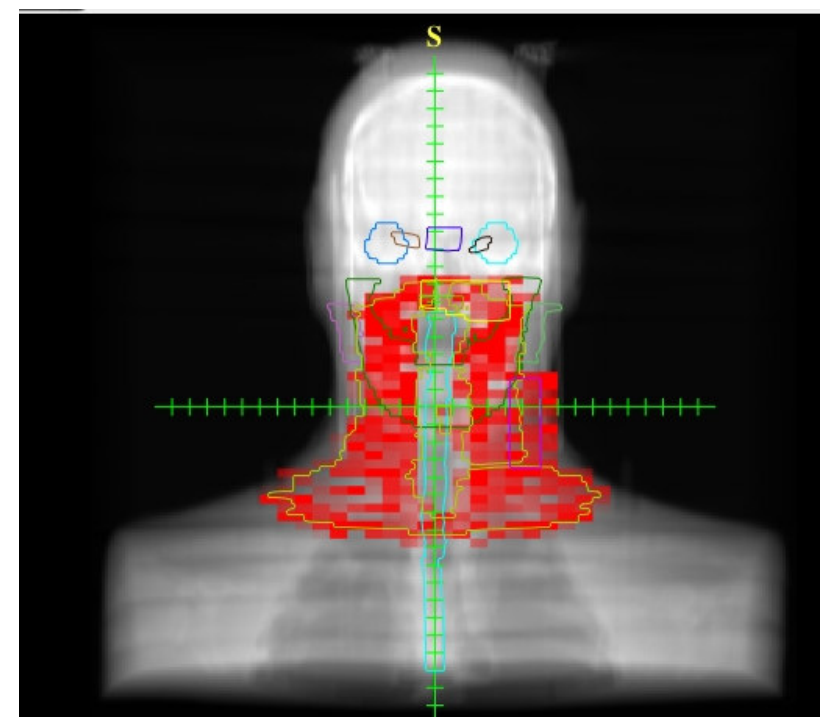

FIGURA 4.11 - Mapa de fluência resultante da técnica de 7 campos coplanares com IMRT.

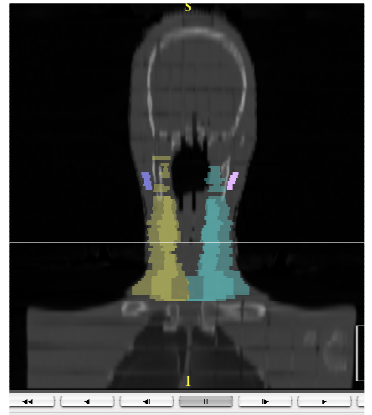

a)

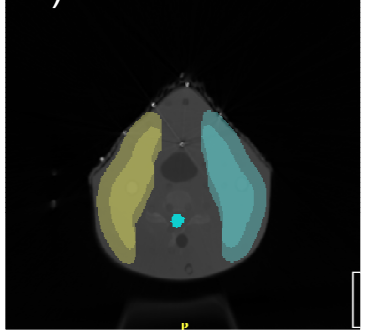

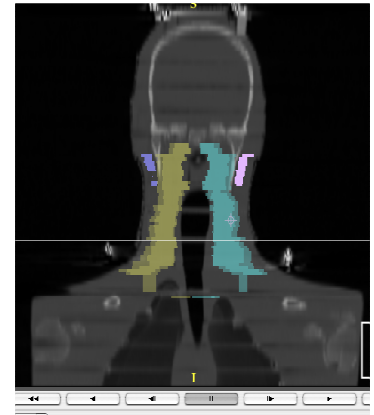

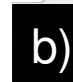

b)

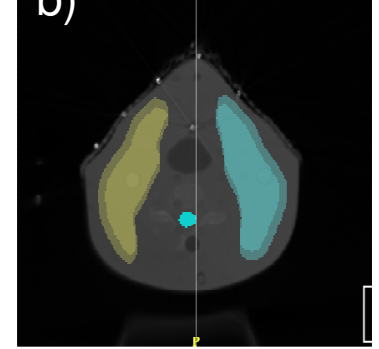

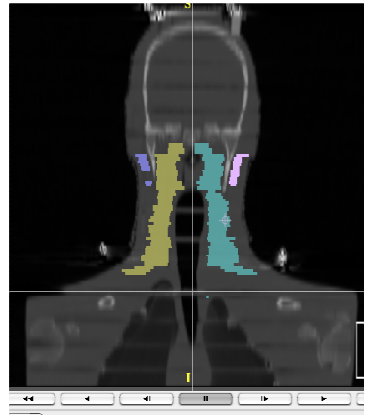

c)

FIGURA 4.12 - PTVs definidos à 0,5 , e $10 \mathrm{~mm}$ de profundidade da superfície da

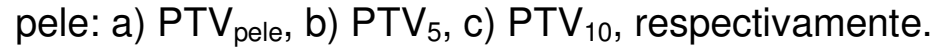




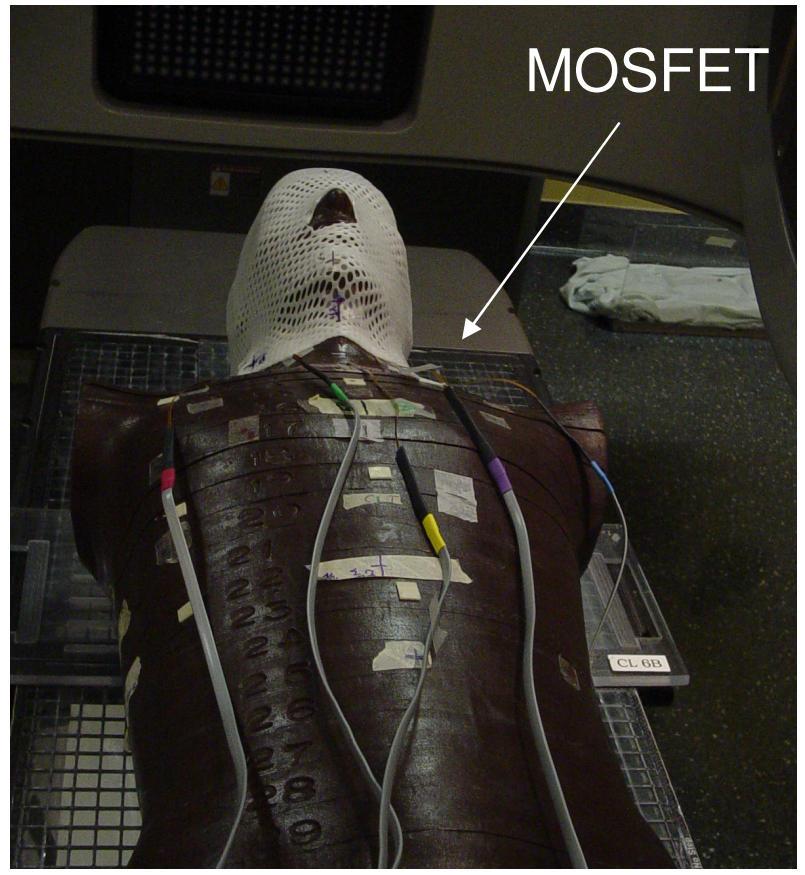

FIGURA 4.13 - Simulador antropomórfico RANDO na posição de tratamento.

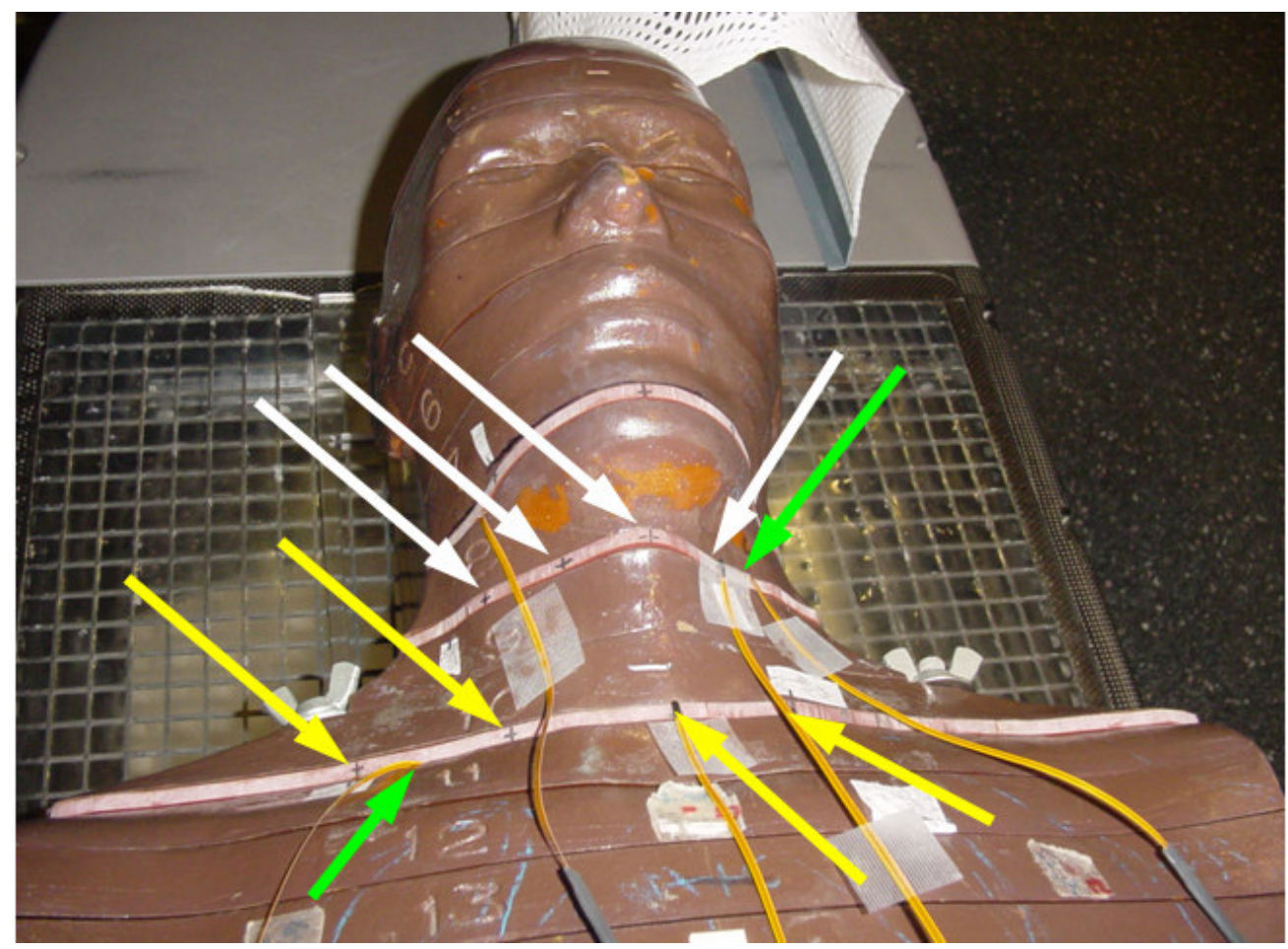

FIGURA 4.14 - A localização dos dosímetros usados para as medidas de dose na superfície é indicada pelas setas. Setas brancas indicam os dosímetros na região do pescoço, as setas amarelas na região supra-clavicular e as verdes representam as posições dos dosímetros colocados dentro do simulador RANDO. 


\subsubsection{Efeito de margens do PTV na dose periférica para tratamentos planejados com IMRT}

Para verificar se a proximidade do PTV à pele gera um aumento de dose na periferia do campo de tratamento, foram distribuídos dosímetros TL e MOSFET em diversos pontos (olhos, tórax e gônadas) do objeto simulador antropomórfico e o objeto simulador, FIG. 4.14, foi irradiado em duas situações: a primeira, usando a técnica de IMRT com planejamento inverso para o $\mathrm{PTV}_{\text {pele, }} \mathrm{PTV}_{5}$, e PTV 10 como descrito no item 4.5.4; e a segunda situação, utilizando a técnica de tratamento com arranjo convencional de feixes sendo 2 campos paralelos e opostos e 1 campo direto na região da fossa supra-clavicular. Para cada situação foram liberados 5 tratamentos e a média das leituras para cada dosímetro, TLD e MOSFET, é apresentado no item 5.2.4 do capítulo 5.

\subsubsection{Incertezas relacionadas ao movimento do órgão entre frações do tratamento: casos de tumor na próstata}

Nos itens anteriores foram estudados os desvios entre 0 isocentro de planejamento e o de tratamento, assim como a necessidade de margens de planejamento para se cobrir o volume alvo de regiões consideradas mais rígidas (cabeça e pescoço) e como essas margens podem afetar a distribuição de dose nos órgãos críticos e na periferia do campo de tratamento.

O volume alvo de planejamento (PTV) deve ter uma margem suficientemente grande ao redor do CTV para levar em consideração os erros durante o posicionamento do paciente na máquina de tratamento (setup), como visto no caso do tratamento de cabeça e pescoço, as incertezas associadas à liberação da dose e o movimento do órgão durante e entre as frações de tratamento. $O$ movimento de órgão durante o tratamento não pôde ser avaliado por falta de sistemas de aquisição de imagens quadridimensional (4-D).

O movimento do órgão entre as frações do tratamento é significativo quando a posição do alvo no dia do tratamento é diferente daquela no planejamento. Para se estudar os erros associados à esse movimento, foi utilizada a visualização da próstata de 387 pacientes tratados de câncer de próstata na McGill University Health Centre entre 2001 e 2005. Cada paciente foi submetido a uma série de localizações com ultra-som pré-tratamento durante o posicionamento diário na máquina de tratamento, como mostrado na FIGURA 3.20. 
Todos os pacientes foram submetidos à simulação com CT com bexiga cheia e nenhum procedimento específico em relação ao preenchimento retal. Os pacientes foram colocados na posição supino com um bloco de isopor quadrado colocado entre os tornozelos, FIGURA 3.7. As imagens de CT foram adquiridas conforme o protocolo padrão pélvico com $5 \mathrm{~mm}$ de espessura entre os cortes de CT. Um uretrograma foi realizado para cada paciente usando contraste de 10 a $20 \mathrm{ml}$. Três marcadores fiduciais definindo o isocentro de referência foram colocados em cada paciente. Após a CT, os pacientes foram tatuados na localização dos marcadores fiduciais e os dados foram transferidos ao sistema de planejamento de tratamento (TPS) para o desenho dos órgãos críticos e definição do alvo. O volume clínico de tratamento (CTV) foi definido como a glândula prostática como visibilizadas nas imagens da CT. O reto, bexiga, cabeças de fêmur, e bulbo peniano também foram desenhadas para cada paciente.

Os 387 pacientes receberam uma dose que variou entre 50 e 79,2 Gy com fracionamento diário convencional de 25 a 44 frações. Os pacientes foram tipicamente planejados e tratados com uma técnica conformacionada de 5 campos coplanares usando fótons de $18 \mathrm{MV}$, e as distribuições de dose foram geradas conforme as orientações dos ICRUs $50^{5}$ e $62^{6}$ para cobertura do alvo e homogeneidade de dose.

$\mathrm{O}$ isocentro de tratamento foi definido como o centro geométrico do PTV e seu sistema de coordenadas foi definido em relação ao isocentro de referência em termos de desvios nas direções antero-posterior (AP), direita-esquerda (DE), e superior-inferior $(\mathrm{SI})$. No primeiro dia de tratamento os pacientes foram posicionados com os laseres da sala de tratamento alinhados com as tatuagens definindo a posição do isocentro de referência. Os pacientes foram subsequentemente deslocados para o isocentro de tratamento como definido pelo plano de tratamento no TPS, e este passou a ser o isocentro de referência inicial para todas as frações de tratamento subsequentes.

Um sistema de ultra-som 2-D (US), disponível comercialmente, foi usado para localização diária do alvo. O sistema usa um transdutor trans-abdominal que adquire imagens únicas nos planos axial e sagital, que é capaz de rastrear a posição do transdutor em 3-D e relacionar a sua posição ao isocentro da sala de tratamento (FIGURA 4.15). Os desenhos do CTV e ógãos críticos, tipicamente bexiga e reto, préviamente desenhados no sistema de planejamento 
computadorizado tridimensional (3-DRTP) são importados para o software do US. Os contornos dos volumes de interesse nos planos axial e sagital, dos quais a posição relativa ao isocentro de tratamento é conhecida a partir do 3-DRTP, são reformatados e sobrepostos nas imagens adquiridas com o sistema US. O usuário, técnico ou médico, pode então deslocar os desenhos na tela do sistema de US até que a posição do CTV coincida com a posição da próstata como visto na imagem de ultra-som, FIGURA 4.15. Este deslocamento é realizado em ambas imagens axial e sagital, e o sistema US calcula um deslocamento em três dimensões (AP, DE, SI) pelo qual o paciente deve ser movido para alinhar o centro do alvo com o isocentro da máquina de tratamento. Uma vez que o deslocamento é realizado, a sua intensidade e direção são gravadas pelo sistema US e no sumário do tratamento.

Para os pacientes neste estudo, os desvios médios nas 3 direções e os desvios padrões foram calculados para o curso inteiro do tratamento para cada paciente. Os dados foram testados para a normalidade usando o teste Shapiro-Wilk ${ }^{95}$, que faz parte da análise estatística do programa Origin 7.0, afim de validar a correlação entre os dados das médias e dos desvios padrões, e os erros sistemáticos e randômicos respectivamente. $\mathrm{O}$ desvio médio total foi calculado através do desvio médio em cada direção para cada paciente durante todo o tratamento, e então foi realizada a média destes desvios para todos os 387 pacientes. A significância estatística dos resultados, onde parte dos dados foram comparados, foi calculado usando o teste-t de Student ${ }^{96}$ (ver APÊNDICE A).

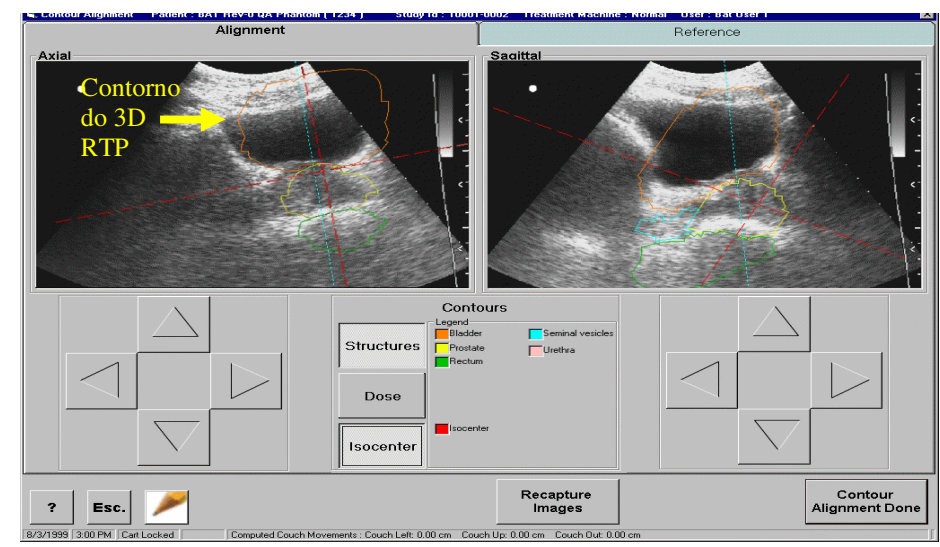

FIGURA 4.15 - Fusão das imagens axial e sagital obtidas com o ultra-som 2-D de localização pré-tratamento com os contornos gerados no TPS a partir das imagens tomográficas adquiridas para planejamento. 


\subsubsection{Modelo matemático para englobar erros sistemáticos e randômicos para definir o PTV}

Alguns autores ${ }^{91,97,98}$ sugerem uma equação para englobar os erros sistemáticos e randômicos obtidos das variações sofridas pelo alvo e órgãos sadios durante a radioterapia. A TABELA 4.2 apresenta um resumo destes trabalhos.

Estas equações foram testadas para os dados obtidos no ítem 4.5.6 e os resultados são apresentados no ítem 5.2.5.1 do capítulo 5.

TABELA 4.2 - Resumo de 3 artigos que apresentam uma equação para se determinar a margem para formar o PTV e o PORV a partir dos erros sistemáticos, $\Sigma$, e randômicos, $\sigma$, obtidos das variações de alvos e órgãos sadios.

\begin{tabular}{|c|c|c|}
\hline Autor & Margem & Objetivo \\
\hline Stroom et al. $^{97}$ & $2 \Sigma+0,7 \sigma$ & $\begin{array}{c}95 \% \text { da dose englobe } 99 \% \text { do } \\
\text { CTV }\end{array}$ \\
\hline Van Herk et al. $^{98}$ & $2,5 \Sigma+0,7 \sigma-3 \mathrm{~mm}$ & $\begin{array}{c}90 \% \text { dos pacientes receba } \\
\text { pelo menos } 98 \% \text { da dose }\end{array}$ \\
\hline McKenzie et al. $^{91}$ & $1,3 \Sigma \pm 0,5 \sigma$ & $\begin{array}{c}\text { PRV para englobar o OAR em } \\
\text { pelo menos } 90 \% \text { dos casos }\end{array}$ \\
\hline
\end{tabular}

\subsubsection{Efeito do movimento do isocentro através das novas coordenadas} geradas pela localização com ultra-som na dose no alvo

O estudo do movimento do órgão entre as frações de tratamento mostrou que é possível ter erros muito grandes no alvo, se for baseado somente na imagem inicial de planejamento do tratamento. Para melhorar a precisão do tratamento, o uso de sistema de aquisição de imagens diárias possibilitaria a localização do órgão antes de cada aplicação. Mas, como ficaria a distribuição de dose no alvo se mudássemos 0 isocentro de tratamento para as novas coordenadas dadas pelo sistema de imagem no linac? Para responder esta pergunta foi estudada a distribuição de dose no caso extremo em que a próstata foi deslocada $3 \mathrm{~cm}$ em relação à sua posição no dia do planejamento. Duas técnicas de planejamento foram usadas para verificar esse problema: técnica convencional usando 6 campos oblíquos com gantry a $225^{\circ}, 270^{\circ}, 315^{\circ}, 45^{\circ}, 90^{\circ}, 135^{\circ}$ e técnica de IMRT. 


\section{RESULTADOS E DISCUSSÕES}

Este capítulo apresenta os resultados e discussões das medições realizadas na calibração e testes de desempenho dos dosímetros, cuja metodologia foi apresentada no capítulo 4, assim como, os resultados das técnicas experimentais para avaliação dos erros e incertezas associadas ao PTV e o seu efeito na radioterapia.

\subsection{CALIBRAÇÃO E TESTES DE DESEMPENHO DOS DOSÍMETROS}

\subsubsection{Caracterização dos filmes radiográficos}

\subsubsection{Calibração dos filmes radiográficos em função da dose}

Resultados experimentais da calibração dos filmes X-Omat $V$ e EDR-2, descrito no item 4.4.1 para fótons de $6 \mathrm{MV}$. A curva de calibração relacionando densidade óptica com dose é mostrada na FIG. 5.1.

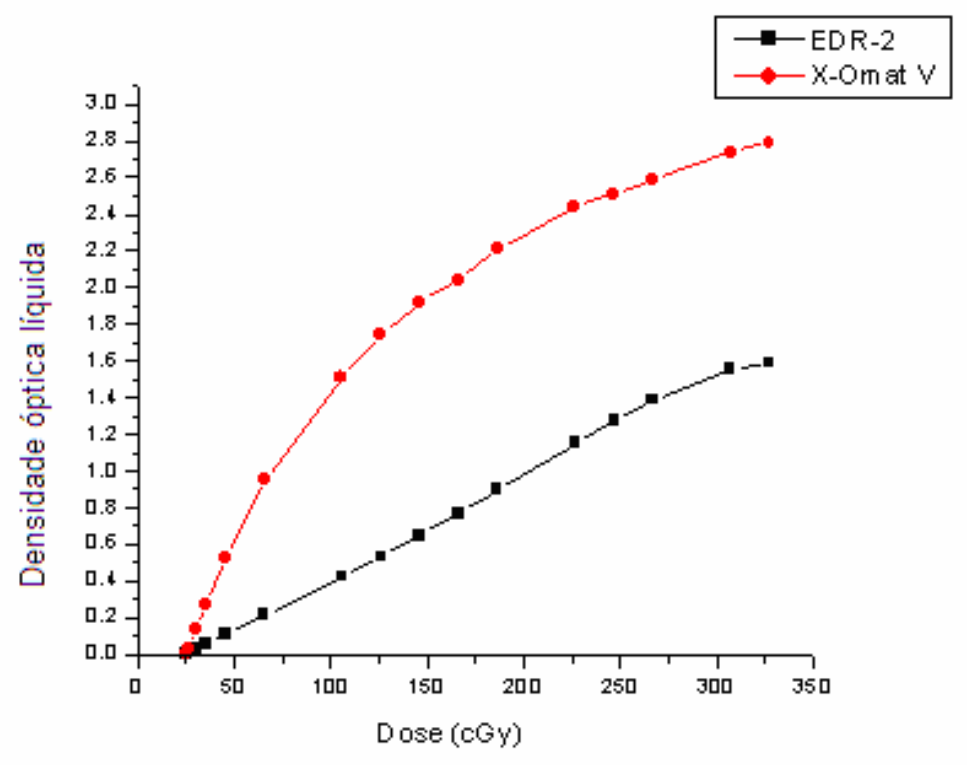

FIGURA 5.1 - Curvas de resposta em função da dose, dos filmes X-Omat V e EDR, para fótons de $6 \mathrm{MV}$.

As curvas sensitométricas para ambos os filmes são representadas através dos ajustes polinomiais apresentados nas Tabelas 5.1 e 5.2. Dependendo da faixa de dose de interesse, escolhe-se o filme X-Omat V ou EDR-2. 
TABELA 5.1 - Regressão polinomial para a curva sensitométrica do filme X-Omat V.

\begin{tabular}{|c|c|c|c|}
\hline & \\
\hline \multicolumn{3}{|c|}{$\begin{array}{l}\text { Regressão Polinomial para X-Omat V: } \\
Y=A+B 1^{*} X+B 2^{*} X^{2}+B 3^{*} X^{3}+B 4^{*} X^{4}\end{array}$} & \\
\hline Parâmetro & Valor & Erro & \\
\hline $\mathrm{A}$ & 0,00323 & 0,00868 & \\
\hline B1 & 0,02855 & $6,64 \mathrm{E}-04$ & \\
\hline B2 & $-1,54 \mathrm{E}-04$ & $1,02 \mathrm{E}-05$ & \\
\hline B3 & $4,69 \mathrm{E}-07$ & $5,28 \mathrm{E}-08$ & \\
\hline B4 & $-5,72 \mathrm{E}-10$ & $8,71 \mathrm{E}-11$ & \\
\hline \multirow{3}{*}{$\frac{\text { R-Square(COD) }}{0,99984}$} & & & \\
\hline & Desvio & $N$ & $P$ \\
\hline & 0,01522 & 16 & $<0,0001$ \\
\hline
\end{tabular}

TABELA 5.2 - Regressão polinomial para a curva sensitométrica do filme EDR-2.

\begin{tabular}{|c|c|c|c|}
\hline \\
\hline \multicolumn{4}{|c|}{$Y=A+B 1^{*} X+B 2^{\star} X^{2}+B 3^{*} X^{3}+B 4^{*} X^{4}$} \\
\hline Parâmetro & Valor & Erro & \\
\hline$A$ & 0,00177 & 0,00379 & \\
\hline B1 & 0,00568 & $3,21 \mathrm{E}-04$ & \\
\hline B2 & $-1,39 \mathrm{E}-05$ & $5,54 \mathrm{E}-06$ & \\
\hline B3 & $1,28 \mathrm{E}-07$ & $3,23 \mathrm{E}-08$ & \\
\hline B4 & $-2,85 E-10$ & $6,04 \mathrm{E}-11$ & \\
\hline R-Square(COD) & $\begin{array}{l}\text { Desvio } \\
\text { padrão }\end{array}$ & $\mathrm{N}$ & $P$ \\
\hline 0,99988 & 0,00668 & 17 & $<0,0001$ \\
\hline
\end{tabular}

A vantagem do filme EDR-2 sobre o $\mathrm{X}$-Omat $\mathrm{V}$ é que ele possui $60 \%$ mais prata ( $\mathrm{Ag}$ ), $20 \%$ mais bromo $(\mathrm{Br})$ e menor quantidade dos materiais de alto $Z$ presentes no $X$-Omat $\mathrm{V}$, o seu $Z$ efetivo é próximo ao da água. Já a vantagem do $X$-Omat $V$ é que ele não é sensível ao comprimento de onda da luz do densitômetro ${ }^{99}$.

\subsubsection{Filmes radiográficos na verificação da distribuição de dose do IMRT}

Uma distribuição de dose foi planejada aleatóriamente no TPS CORVUS utilizando IMRT para irradiar um simulador de água sólida, conforme descrito no item 4.4.1.2. Os filmes foram analisados individualmente com o software Omnipro e as curvas de isodose provenientes de cada um foram convertidas em matriz de dose. A matriz de dose de ambos foi gerada numa mesma tabela de forma a 
mostrar ambos os filmes sobrepostos e assim ser possível fazer uma intercomparação entre ambos os resultados. A visualização das isodoses provenientes dos filmes radiográficos X-Omat $V$ e EDR-2 são apresentados na FIGURA 5.2.

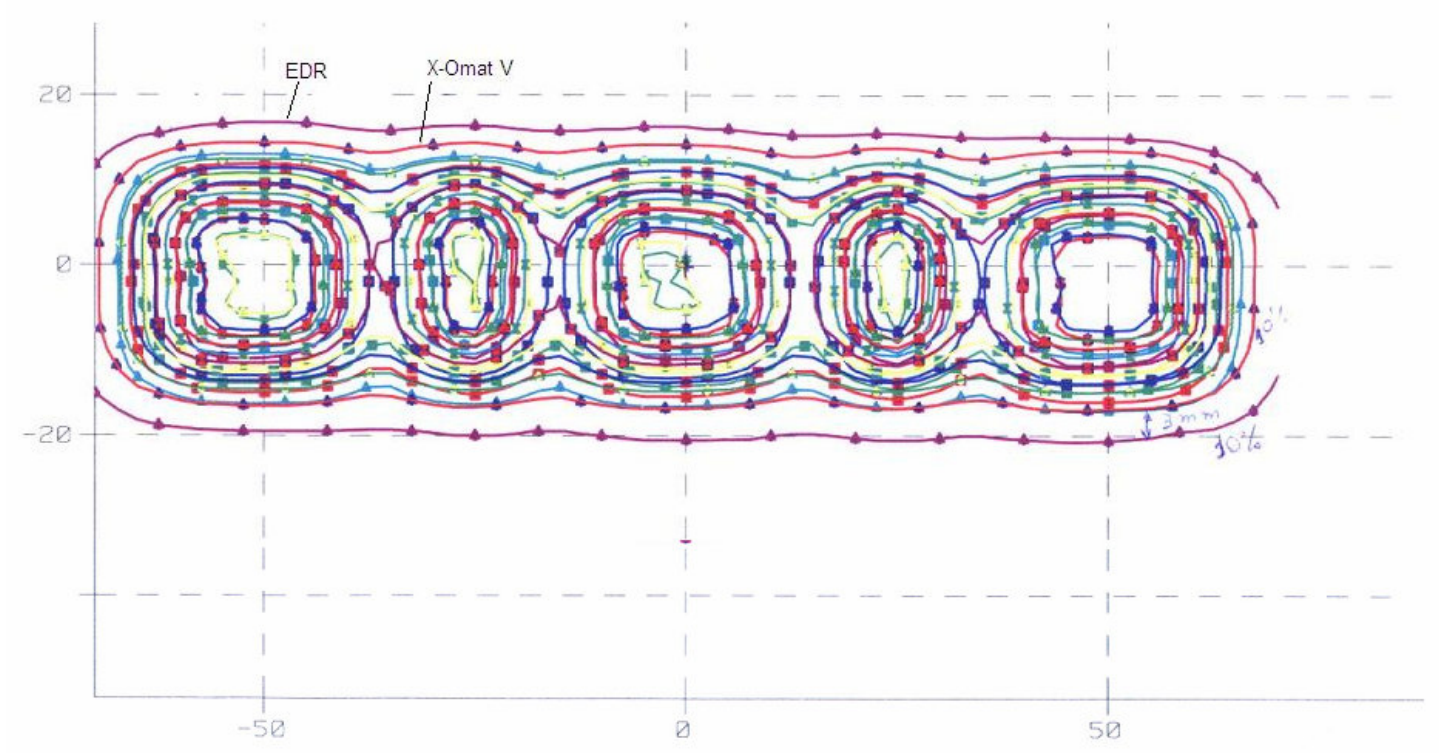

FIGURA 5.2 - Distribuição de isodose com os filmes radiográficos X-Omat V e EDR. As isodoses variam de 10 a $100 \%$, com passo de $10 \%$.

A intercomparação das distribuições de dose provenientes dos dois filmes, $\mathrm{X}$-Omat $\mathrm{V}$ e EDR-2, mostrou uma diferença significante, maior que $2 \mathrm{~mm}$, entre as isodoses menores que $20 \%$. Para as isodoses de $10 \%$ a diferença entre as distâncias foi de 3 mm, FIG. 5.2.

Para verificar qual filme mostra o valor mais correto foi realizado o mesmo experimento colocando MOSFETs (por ter melhor resolução espacial), no lugar dos filmes, nas posições correspondentes às isodoses de $100 \%$ e $10 \%$. 0 resultado é apresentado na TABELA 5.3.

TABELA 5.3 - Comparação das isodoses obtidas com filmes e as doses normalizadas para a dose máxima com os MOSFETS.

\begin{tabular}{|c|c|c|c|}
\hline Filme EDR-2 & Filme X-Omat V & MOSFET (média) & Dif. Rel. (\%) \\
\hline $100 \%$ & $100 \%$ & $100,0 \%$ & \\
\hline & $10 \%$ & $8,5 \%$ & $15 \%$ \\
\hline $10 \%$ & & $5,1 \%$ & $49 \%$ \\
\hline
\end{tabular}


De acordo com a TABELA 5.3, a maior discrepância foi para o filme EDR-2. No entanto, as diferenças encontradas entre os dosímetros na região de dose baixa foi muito alto (15\%), o que mostra a dificuldade em se ter precisão na dosimetria da região de penumbra.

\subsubsection{Caracterização do MOSFET}

\subsubsection{Teste de decaimento do sinal}

Conforme descrito no item 4.4.3.1, foi avaliado o decaimento do sinal dos MOSFETs utilizando a equação 4.1. O decaimento $\left(F_{n}\right)$ dos dosímetros 1 a 5 foram: $F_{1}$ de $0,43 \%, F_{2}$ de $0,85 \%, F_{3}$ de $0,69 \%, F_{4}$ de $0,43 \%$ e $F_{5}$ de $0,89 \%$, respectivamente.

\subsubsection{Linearidade da resposta}

O teste de linearidade foi realizado como descrito no item 4.4.3.2. A curva que relaciona dose em cGy com as respostas dos dosímetros em $\mathrm{mV}$ é mostrada na FIG. 5.3.

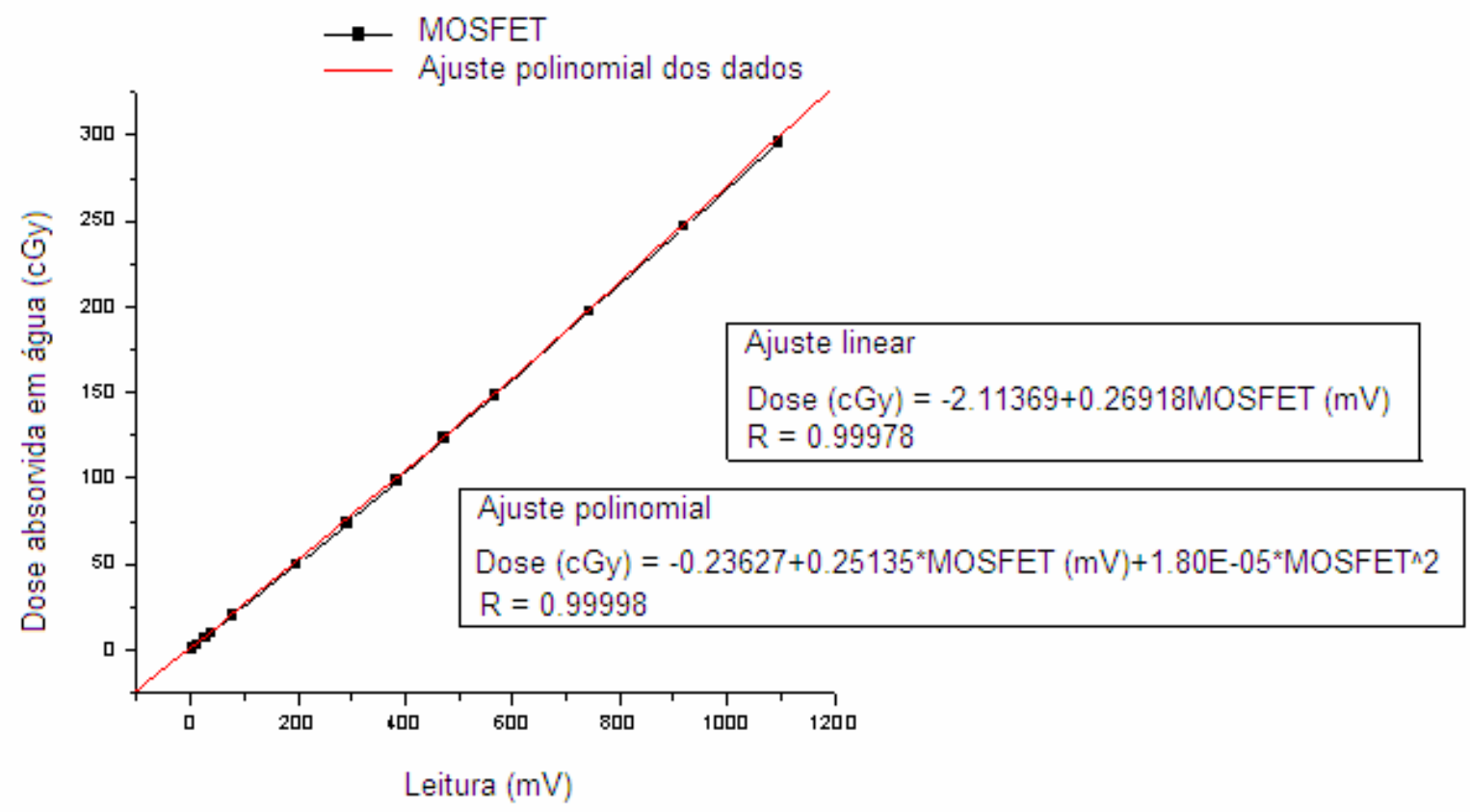

FIGURA 5.3 - Curva relacionando a leitura do MOSFET (mV) com a dose (cGy) para testar a linearidade da resposta do dosímetro. 
A diferença entre o ajuste polinomial $(R=0,99998)$ e o linear $(R=0,99978)$ não é significativa, portanto pode-se considerar que os dosímetros MOSFET apresentam resposta linear para doses até 3 Gy.

\subsubsection{Dependência com a taxa de dose}

As condições deste teste estão descritos no item 4.4.3.3. As leituras do MOSFET $(\mathrm{mV})$ em função da variação da taxa de dose (UM/min da máquina de tratamento) são apresentadas na FIG. 5.4.

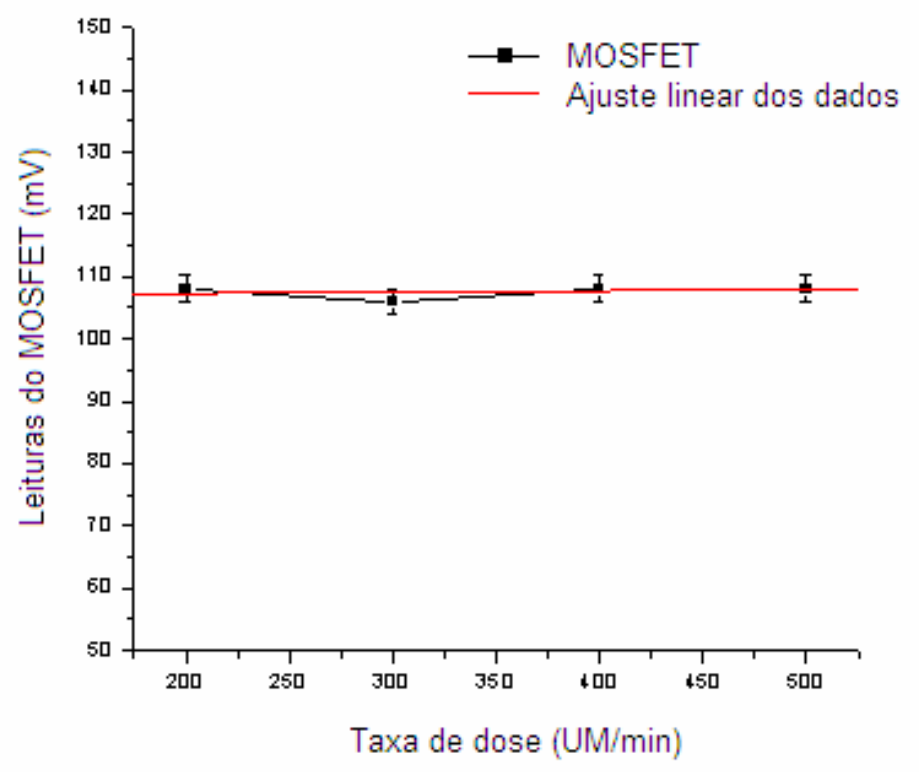

FIGURA 5.4 - Leituras dos dosímetros MOSFET (mV) em função da variação da taxa de dose (UM/min).

O desvio máximo observado é $\pm 1,0 \%$, o que significa que a resposta dos dosímetros é independente da taxa de dose.

\subsubsection{Dependência direcional}

O arranjo experimental deste teste está descrito no item 4.4.3.4. As medições foram tomadas de 2 formas: num primeiro momento girando o gantry a cada 45 graus; e depois girando o próprio dosímetro a cada 45 graus, num intervalo de 
0 a 315 graus. Os resultados da média das leituras, para 3 dosímetros, obtidas com os dois métodos, são apresentados na FIGURA 5.5.

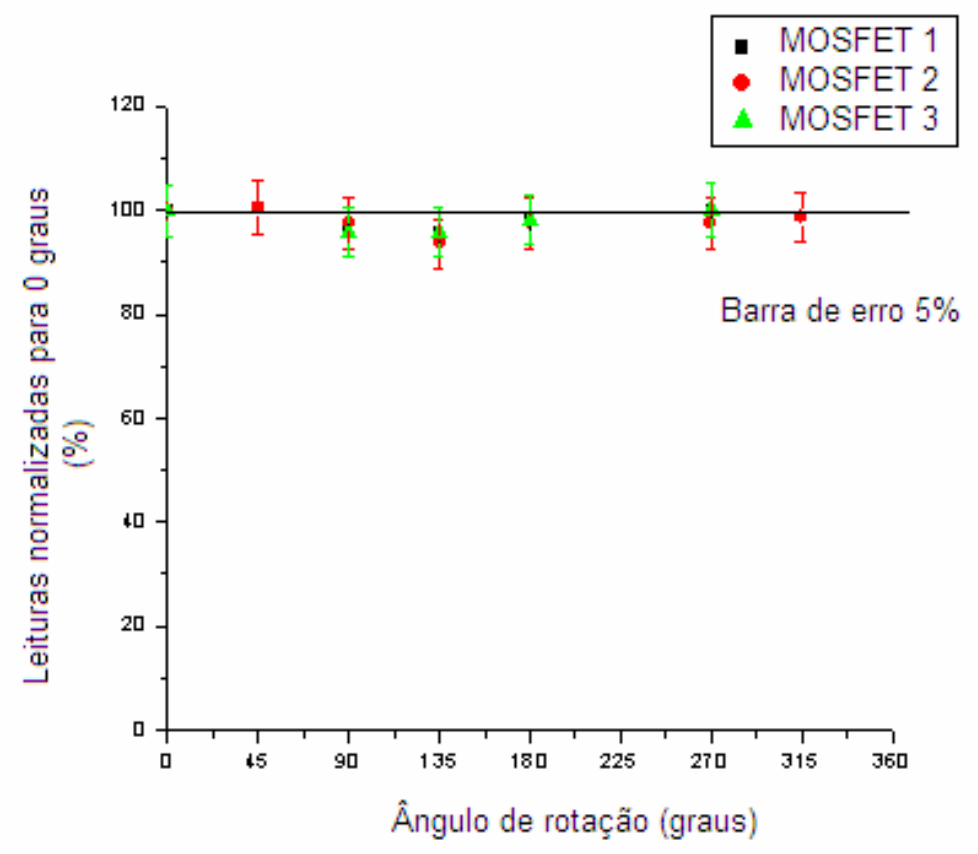

FIGURA 5.5 - Leituras médias obtidas para a mesma dose em diferentes ângulos de rotação do gantry e do dosímetro para 3 dosímetros MOSFET.

Os dosímetros MOSFETs apresentam uma certa dependência direcional quando irradiados com campos posteriores oblíquos, causando erros nas leituras de até $5 \%$, conforme apresentado na FIG. 5.5. Esta dependência é devido à diferença de material na parte posterior do MOSFET, que não é coberta por epóxi. Este efeito deve ser levado em conta quando o dosímetro for irradiado nestes ângulos.

\subsubsection{Dependência com o tamanho de campo}

Os parâmetros geométricos desta medida foram apresentados no item 4.4.3.5. Os dados resultantes deste teste para os dosímetros TL, MOSFET e câmara de ionização, irradiados com fótons de $6 \mathrm{MV}$, são apresentados na FIG. 5.6. 


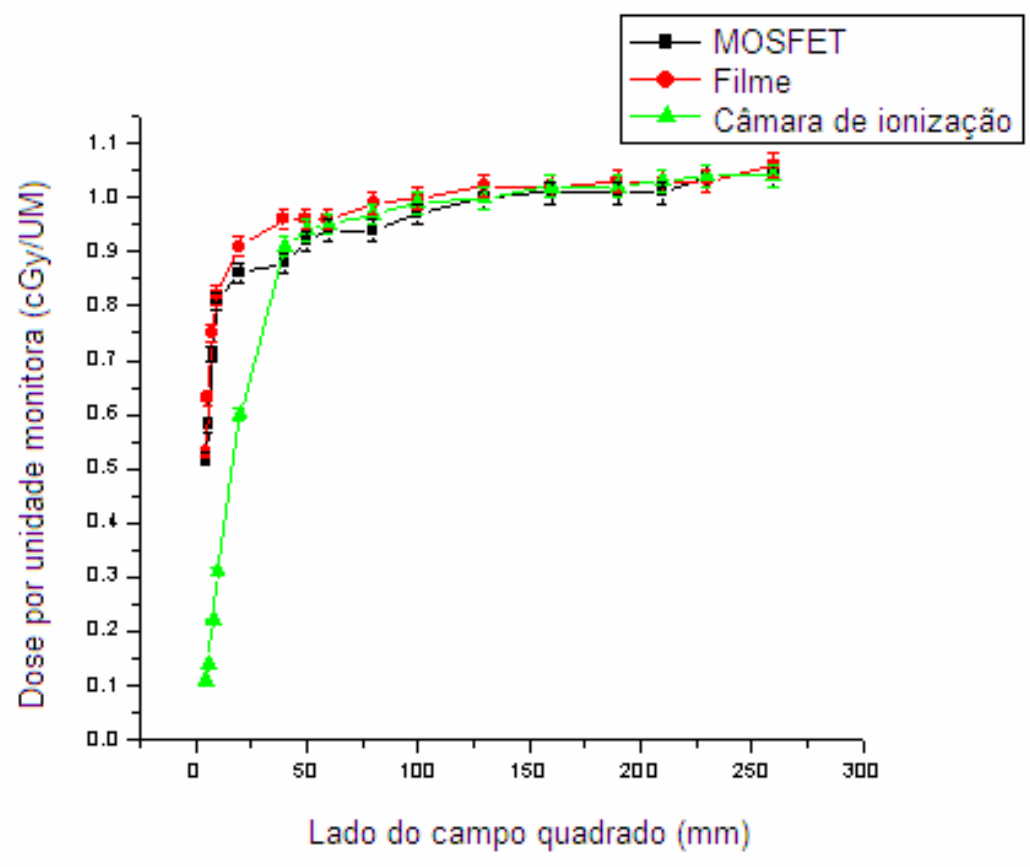

FIGURA 5.6 - Comparação entre as respostas apresentadas pelos dosímetros MOSFET, filme e câmara de ionização, normalizadas no campo $10 \mathrm{~cm} \times 10 \mathrm{~cm}$, para feixe de fótons de $6 \mathrm{MV}$.

As medidas com câmara de ionização só coincidem com as do MOSFET e filme para campos maiores ou iguais a $40 \mathrm{~mm} \times 40 \mathrm{~mm}$, isto ocorre porque o seu tamanho físico interfere na fluência do feixe.

Uma comparação usando somente MOSFET e filme é mostrado na FIG. 5.7 e uma curva de ajuste é calculada usando a exponencial de Chapman (que foi a única exponencial que se ajustou na curva experimental). Os dados das medidas com MOSFET e filme foram normalizados para o tamanho de campo de referência de $10 \mathrm{~cm} \times 10 \mathrm{~cm}$ e portanto se tornam adimensionais (fator de espalhamento de campo).

A equação 5.1 descreve a exponencial de Chapman utilizada como ajuste da curva apresentada na FIG. 5.6.

$$
y=a^{*}\left(1-e x p\left(-b^{*} x\right)\right)^{c}
$$

em que

$$
a=1,01, b=0,05, c=0,3
$$




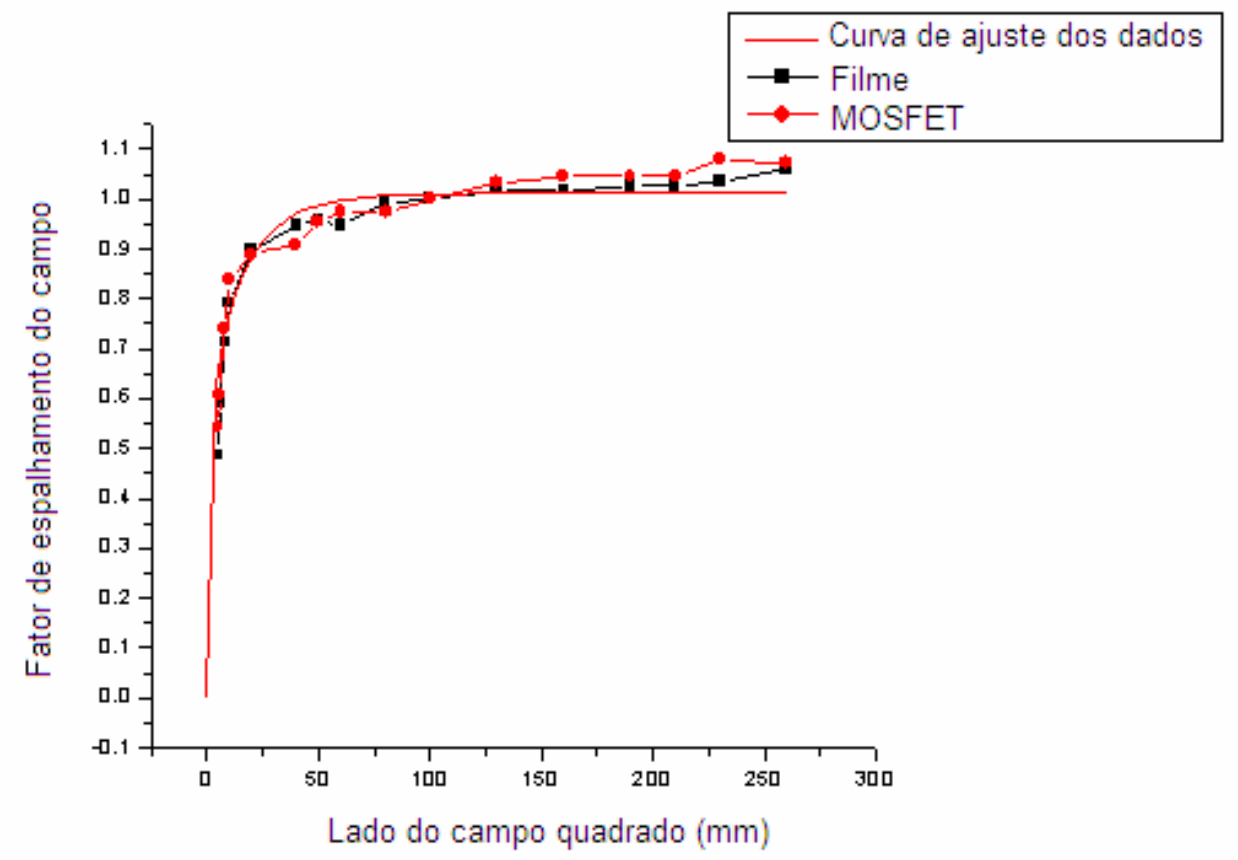

FIGURA 5.7 - Espalhamento de campo para feixe de fótons de $6 \mathrm{MV}$ avaliados com dosímetro MOSFET e filme, normalizados para o campo $10 \mathrm{~cm} \times 10 \mathrm{~cm}$. A linha contínua vermelha mostra uma curva de ajuste dos dados com exponencial de Chapman para campos menores que $10 \mathrm{~cm} \times 10 \mathrm{~cm}$.

\subsubsection{Dependência energética}

O arranjo experimental para a avaliação da dependência energética da resposta do MOSFET é mostrado na FIG. 4.7 e a descrição deste experimento apresentado no item 4.4.3.6.

Os resultados obtidos para os 3 MOSFETs e irradiados com feixe de fótons de 6 e 18 MV são apresentados na FIG. 5.8. 


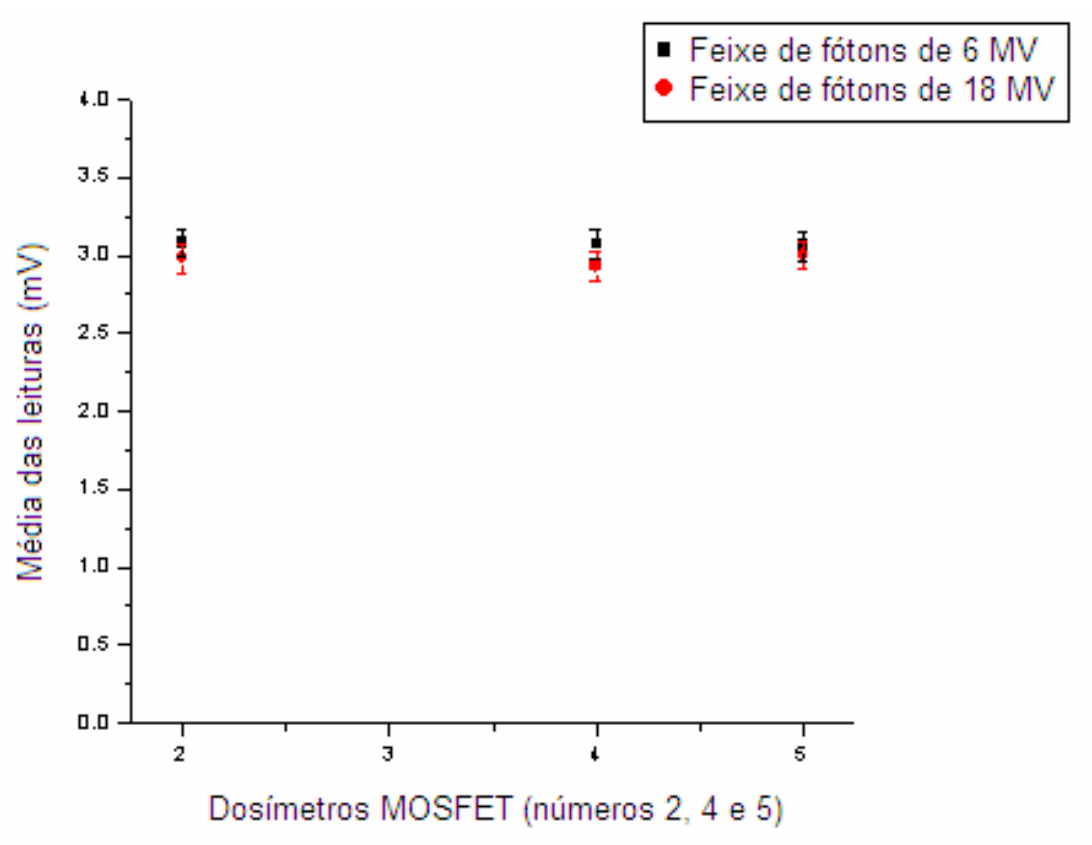

FIGURA 5.8 - Resposta dos dosímetros MOSFET número 2, 4 e 5 irradiados com os feixes de fótons de 6 e $18 \mathrm{MV}$.

A incerteza neste experimento foi aproximadamente $\pm 3 \%$ que é da ordem de grandeza encontrada entre as leituras feitas nas mesmas condições de irradiação sem mudar os feixes.

\subsubsection{Calibração em função da dose}

Os procedimentos para calibração dos dosímetros MOSFET foram apresentados no item 4.4.3.7 e através deste procedimento foram obtidos os fatores de calibração para cada um dos 4 dosímetros utilizados neste trabalho apresentados na TABELA 5.4.

TABELA 5.4 - Fatores de calibração para os MOSFET para fótons de 6 MV.

\begin{tabular}{|c|c|}
\multicolumn{1}{c|}{} & cGy/mV \\
\hline MOSFET 1 & 0,328 \\
\cline { 1 - 1 } MOSFET 2 & 0,326 \\
\cline { 1 - 1 } MOSFET 4 & 0,327 \\
\cline { 1 - 1 } MOSFET 5 & 0,328 \\
\hline
\end{tabular}


A reprodutibilidade da resposta desse conjunto de 4 dosímetros está dentro de $\pm 0,1 \%$. A vida útil do dosímetro MOSFET número 3 foi atingida por isso ele foi desconsiderado.

\subsubsection{Reprodutibilidade da resposta}

A descrição deste teste foi apresentado no item 4.4.3.8 e os resultados são apresentados na FIG. 5.9. A análise do gráfico da FIG. 5.9 resultou nos seguintes dados: uma variação média de 0,980 cGy com o desvio padrão de 0,031 cGy (e 0,062 cGy para um nível de confiança de 95\%) foi observada entre a dose do MOSFET e a dose calculada.

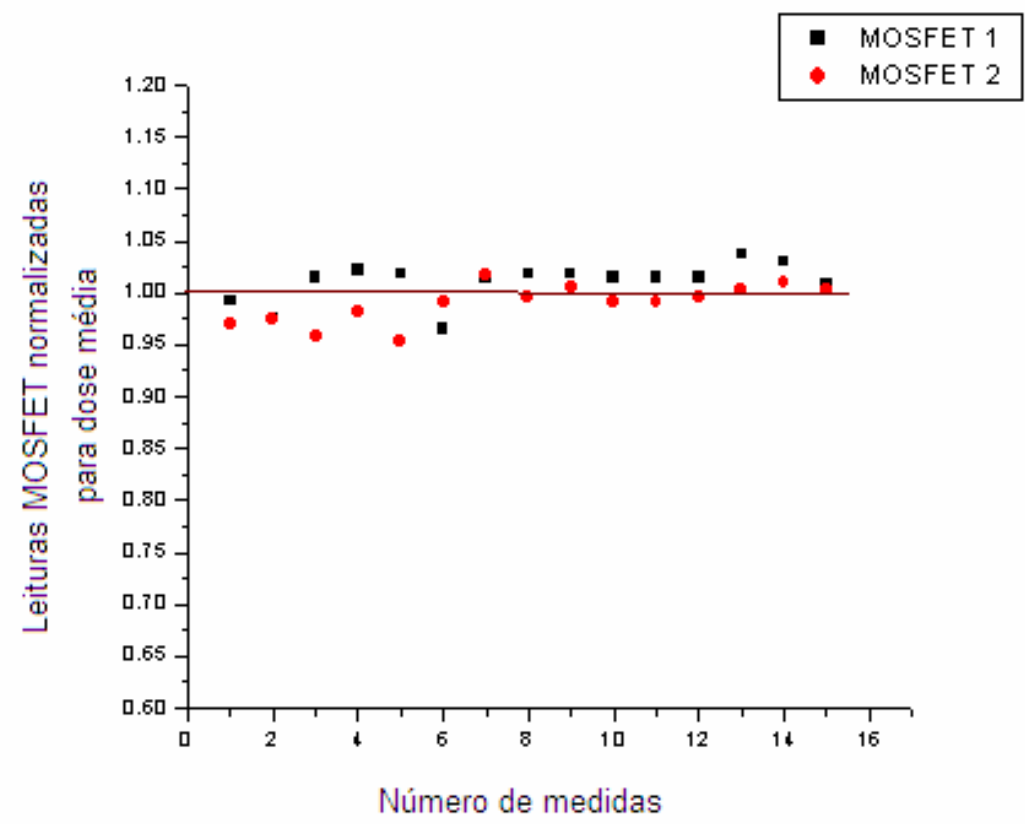

FIGURA 5.9 - Distribuição da resposta do conjunto de 15 irradiações com feixe de fótons de $6 \mathrm{MV}$ efetuados para cada MOSFET.

\subsubsection{Emprego do MOSFET na dosimetria do IMRT}

MOSFETs foram distribuídos num simulador de água sólida em alguns pontos de dose pré-calculados no TPS CORVUS usando IMRT para se avaliar a resposta do MOSFET quando irradiado com fótons $6 \mathrm{MV}$ num planejamento com modulação do feixe. O resultado é apresentado na TABELA 5.5. 
TABELA 5.5 - Comparação entre as doses obtidas com os MOSFETs e a calculada pelo sistema de planejamento CORVUS, sendo o ponto de cálculo no centro geométrico do dosímetro.

\begin{tabular}{|c|c|c|c|c|}
\hline \multirow{2}{*}{ MOSFET No. } & \multicolumn{2}{|c|}{ MOSFET } & CORVUS & \multirow{2}{*}{ Dif. Rel. (\%) } \\
\cline { 2 - 4 } & Média (cGy) & SD (cGy) & Dose (cGy) & \\
\hline 1 & 93,0 & 1,4 & 94,0 & $-1,1 \%$ \\
\hline 2 & 83,9 & 2,2 & 84,0 & $-0,2 \%$ \\
\hline 3 & 78,9 & 1,5 & 83,0 & $-5,1 \%$ \\
\hline 4 & 6,7 & 0,5 & 7,5 & $-0,1 \%$ \\
\hline 5 & 81,1 & 0,2 & 85,0 & $-4,8 \%$ \\
\hline
\end{tabular}

De um modo geral a dose obtida com os MOSFETs sub-estimaram as doses calculadas pelo TPS CORVUS. As diferenças relativas entre a dose calculada e a medida foram menores que $5 \%$. Portanto, este dosímetro pode ser usado para avaliação de dose in vivo nos tratamentos com modulação de feixe (IMRT).

\subsubsection{Caracterização do TLD}

No item 4.4.4 foi descrito o procedimento de caracterização dos TLDs. Uma curva de calibração, leitura $T L(\mathrm{nC}) \mathrm{x}$ dose (Gy), foi obtida e o resultado é mostrado na FIG. 5.10 para doses que variam de 0 a 3 Gy.

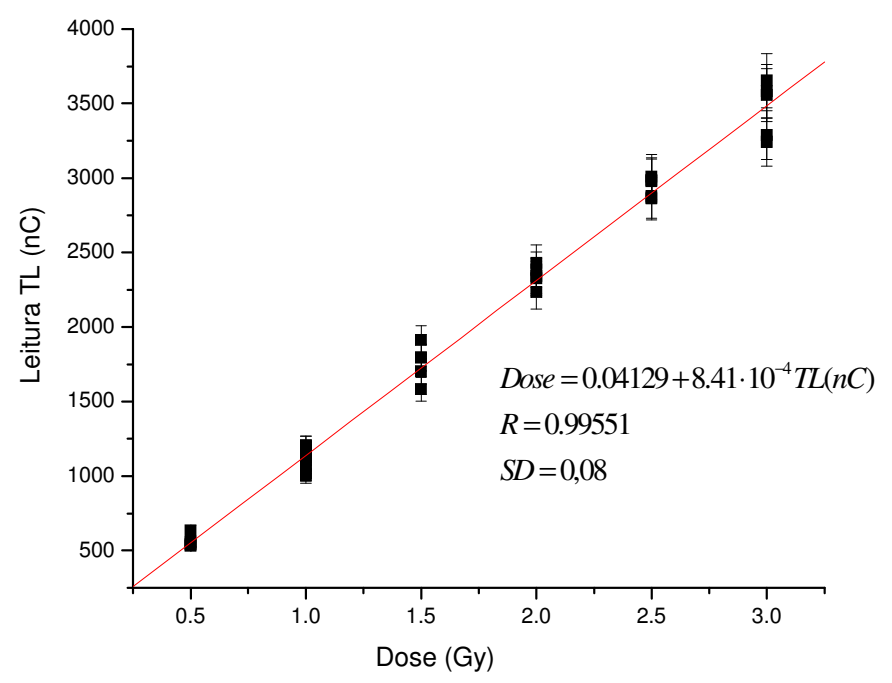

FIGURA 5.10 - Resposta TL do LiF (TLD-100) em função da dose para fótons de $6 \mathrm{MV}$. 
Como esperado para o LiF (TLD-100) a resposta TL apresenta comportamento linear no intervalo de doses estudado.

\subsection{TÉCNICAS EXPERIMENTAIS PARA AVALIAÇÃO DOS ERROS E INCERTEZAS ASSOCIADAS AO PTV E AO SEU EFEITO NA RADIOTERAPIA}

\subsubsection{Incertezas relacionadas à localização do paciente: casos ENT}

Esse estudo foi realizado através da fusão da imagem digital (EPI) adquirida no acelerador linear semanalmente antes do tratamento com a imagem radiográfica digital (DRR) realizada no sistema de planejamento, FIGURAS 4.10 a), b) e c).

Neste estudo, foram avaliados 78 pacientes. Para cada paciente foram feitos 4 conjuntos de EPI, cada conjunto consiste de uma imagem ântero-posterior e outra imagem látero-lateral, sendo que, dessas imagens foram obtidos os desvios nos sentidos $\mathrm{X}, \mathrm{Y}$ e $\mathrm{Z}$ do isocentro de tratamento. A FIGURA 5.11 é a representação gráfica dos desvios sofridos nos sentidos X1 (direita do paciente), X2 (esquerda), Y1 (inferior), Y2 (superior), Z1 (anterior) e Z2 (posterior) do isocentro no dia do tratamento em relação ao planejado para todos os 78 pacientes. A TABELA 5.6 mostra a análise estatística da FIGURA 5.11.

TABELA 5.6 - Desvio médio (Média), desvio padrão (SD), desvio mínimo (Mín) e máximo (Máx) dos isocentros de tratamento para os 78 pacientes.

\begin{tabular}{|c|c|c|c|c|}
\hline & $\begin{array}{c}\text { Média } \\
\mathbf{( c m )}\end{array}$ & $\begin{array}{c}\text { SD } \\
\mathbf{( c m})\end{array}$ & $\begin{array}{c}\text { Mín. } \\
\mathbf{( c m )}\end{array}$ & $\begin{array}{c}\text { Máx. } \\
\mathbf{( c m )}\end{array}$ \\
\hline $\mathbf{X}$ & $-0,03$ & 0,15 & $-0,52$ & 0,55 \\
\hline $\mathbf{Y}$ & 0,11 & 0,45 & $-1,10$ & 1,42 \\
\hline $\mathbf{Z}$ & 0,04 & 0,31 & $-1,20$ & 1,30 \\
\hline
\end{tabular}



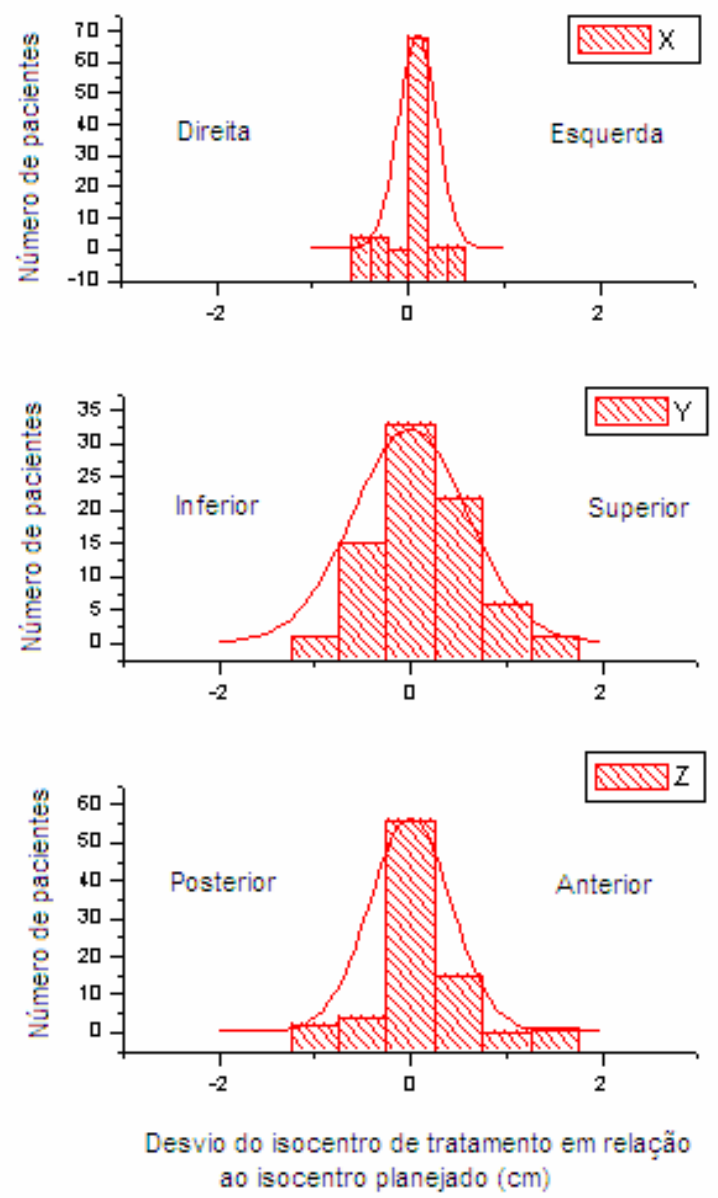

FIGURA 5.11 - Representação gráfica da distribuição dos desvios sofridos pelo isocentro de tratamento em $\mathrm{X}, \mathrm{Y}$ e $\mathrm{Z}$ nos 78 pacientes estudados.

Este resultado mostra que mesmo usando máscara termoplástica para imobilização da cabeça, $68 \%$ dos pacientes (1 SD) apresentam desvios de até $\pm 4,5 \mathrm{~mm}$ no sentido crânio-caudal ou superior-inferior. Isto ocorre devido a alguns fatores como: dificuldade de se moldar a máscara na região do crânio onde há cabelo facilitando o movimento neste sentido; erros associados ao laser de tratamento (em torno de $2 \mathrm{~mm}$ ); deformação da máscara ao longo do tratamento e rotação do crânio dentro dela. 


\subsubsection{Efeito do deslocamento do isocentro na distribuição de dose e efeito}

do tamanho do PTV nas doses geradas em suas estruturas críticas vizinhas

Este estudo mostra a análise da variação de dose que pode ocorrer nas estruturas críticas, GTV e CTVs quando o tratamento é liberado num isocentro diferente do planejado para dois tamanhos de PTV: $2 \mathrm{~mm}\left(\mathrm{PTV}_{2}\right)$ e $5 \mathrm{~mm}\left(\mathrm{PTV}_{5}\right)$. O planejamento híbrido teve seu isocentro de tratamento deslocado nos sentidos X1 (direita), X2 (esquerda), Y1 (inferior), Y2 (superior), Z1 (posterior) e Z2 (anterior) de - 3,0 mm, + 3,0 mm, - 9,0 mm, + 9,0 mm, - 6,2 mm e + 6,2 mm respectivamente, representando 2 SD ou 95,5\% dos desvios sofridos pelos 78 pacientes estudados no item a). O CTV1 inclui todos os linfonodos, CTV2 se estende à base de crânio, o GTV é o tumor visível na região cervical esquerda e as estruturas críticas analisadas foram: medula espinhal (ME), parótida direita (PD), parótida esquerda (PE) e tronco cerebral (TC). A TABELA 5.7 mostra a prescrição de dose e a porcentagem de volume permitida acima da dose prescrita para cada volume de interesse. A TABELA 5.8 mostra a análise do histograma dose-volume em relação às estruturas críticas e aos volumes alvos para $\mathrm{PTV}_{2} \mathrm{e}$ $\mathrm{PTV}_{5}$.

TABELA 5.7 - Prescrição de doses para volumes alvos e estruturas críticas no sistema de planejamento inverso para tratamento com IMRT ${ }^{53}$.

\begin{tabular}{|c|c|c|}
\hline Volume de interesse & Dose (Gy) & $\begin{array}{c}\text { Porcentagem de volume permitida acima } \\
\text { da dose prescrita (\%) }\end{array}$ \\
\hline CTV1 & 54,0 & 2 \\
\hline CTV2 & 70,0 & 2 \\
\hline GTV & 54,0 & 2 \\
\hline ME & 40,0 & 0 \\
\hline PD & 24,0 & 50 \\
\hline PE & 24,0 & 50 \\
\hline TC & 53,0 & 1 \\
\hline
\end{tabular}


TABELA 5.8 - Análise do resultado do histograma de dose-volume para os volumes de interesse da TABELA 5.7, com o planejamento híbrido deslocado em 6 direções (X1, X2, Y1, Y2, Z1 e Z2), e margem dada aos CTVs de $2 \mathrm{~mm}\left(\mathrm{PTV}_{2}\right)$ e $5 \mathrm{~mm}\left(\mathrm{PTV}_{5}\right)$. NR corresponde ao dado não relevante.

\begin{tabular}{|c|c|c|c|c|c|c|}
\hline \multicolumn{7}{|c|}{ Deslocamento no sentido da direita do paciente (X1) } \\
\hline & \multicolumn{3}{|c|}{ PTV $_{2}$} & \multicolumn{3}{|c|}{ PTV $_{5}$} \\
\hline & $\begin{array}{l}\text { Dose } \\
\text { (Gy) }\end{array}$ & $\begin{array}{l}\text { \% de volume } \\
\text { correspondente } \\
\text { a dose }\end{array}$ & $\begin{array}{l}\text { Dose em } 1 \% \\
\text { do volume } \\
\text { total (Gy) }\end{array}$ & $\begin{array}{l}\text { Dose } \\
\text { (Gy) }\end{array}$ & $\begin{array}{c}\text { \% de volume } \\
\text { correspondente } \\
\text { à dose }\end{array}$ & $\begin{array}{c}\text { Dose em 1\% } \\
\text { do volume } \\
\text { total (Gy) }\end{array}$ \\
\hline CTV1 & 54,0 & $95 \%$ & 73,0 & 54,0 & $99 \%$ & 73,2 \\
\hline CTV2 & 70,0 & $90 \%$ & 80,0 & 70,0 & $95 \%$ & 78,3 \\
\hline GTV & 54,0 & $98 \%$ & NR & 54,0 & $99 \%$ & NR \\
\hline ME & 40,0 & $6 \%$ & 51,0 & 40,0 & $8 \%$ & 60,0 \\
\hline PD & 28,0 & $50 \%$ & 53,8 & 27,1 & $50 \%$ & 56,0 \\
\hline $\mathrm{PE}$ & 17,4 & $50 \%$ & 34,0 & 18,6 & $50 \%$ & 43,8 \\
\hline TC & 49,5 & $1 \%$ & 52,0 & 53,0 & $1 \%$ & 55,5 \\
\hline \multicolumn{7}{|c|}{ Deslocamento no sentido da esquerda do paciente (X2) } \\
\hline & \multicolumn{3}{|c|}{ PTV $_{2}$} & \multicolumn{3}{|c|}{ PTV $_{5}$} \\
\hline CTV1 & 54,0 & $97 \%$ & 71,4 & 54,0 & $99 \%$ & 71,9 \\
\hline CTV2 & 70,0 & $99 \%$ & 76,7 & 70,0 & $99 \%$ & 76,4 \\
\hline GTV & 54,0 & $100 \%$ & 64,6 & 54,0 & $100 \%$ & 67,4 \\
\hline ME & 40,0 & $1 \%$ & 42,5 & 41,4 & $1 \%$ & 44,2 \\
\hline PD & 20,3 & $50 \%$ & 36,0 & 20,0 & $50 \%$ & 40,4 \\
\hline $\mathrm{PE}$ & 27,8 & $50 \%$ & 47,5 & 27,0 & $50 \%$ & 55,0 \\
\hline TC & 47,4 & $1 \%$ & 49,6 & 52,0 & $1 \%$ & 53,6 \\
\hline \multicolumn{7}{|c|}{ Deslocamento sentido inferior (Y1) } \\
\hline & \multicolumn{3}{|c|}{ PTV $_{2}$} & \multicolumn{3}{|c|}{ PTV $_{5}$} \\
\hline CTV1 & 54,0 & $89 \%$ & 72,0 & 54,0 & $98 \%$ & 72,5 \\
\hline CTV2 & 70,0 & $90 \%$ & 76,3 & 70,0 & $93 \%$ & 76,0 \\
\hline GTV & 54,0 & $71 \%$ & 62,4 & 54,0 & $93 \%$ & 65,5 \\
\hline ME & 38,1 & $1 \%$ & 40,0 & 39,6 & $1 \%$ & 42,4 \\
\hline PD & 24,6 & $50 \%$ & 45,3 & 23,3 & $50 \%$ & 52,7 \\
\hline $\mathrm{PE}$ & 25,0 & $50 \%$ & 45,0 & 29,6 & $50 \%$ & 56,0 \\
\hline TC & 45,7 & $1 \%$ & 49,0 & 53,3 & $1 \%$ & 54,8 \\
\hline \\
\hline \multicolumn{7}{|c|}{$\begin{array}{l}\text { Deslocamento no sentido superior (Y2) } \\
\text { PTV }_{2}\end{array}$} \\
\hline CTV1 & 54,0 & $83 \%$ & 72,6 & 54,0 & $94 \%$ & 77,4 \\
\hline CTV2 & 70,0 & $90 \%$ & 76,8 & 70,0 & $93 \%$ & 76,7 \\
\hline GTV & 54,0 & $69 \%$ & 64,7 & 54,0 & $96 \%$ & 68,1 \\
\hline $\mathrm{ME}$ & 38,9 & $1 \%$ & 41,3 & 40,5 & $1 \%$ & 45,9 \\
\hline PD & 22,5 & $50 \%$ & 49,6 & 25,8 & $50 \%$ & 55,9 \\
\hline $\mathrm{PE}$ & 25,7 & $50 \%$ & 75,6 & 25,6 & $50 \%$ & 75,7 \\
\hline TC & 48,2 & $1 \%$ & 49,9 & 46,0 & $1 \%$ & 47,9 \\
\hline \multicolumn{7}{|c|}{ Deslocamento no sentido posterior (Z1) } \\
\hline & \multicolumn{3}{|c|}{ PTV $_{2}$} & \multicolumn{3}{|c|}{ PTV $_{5}$} \\
\hline & $\begin{array}{c}\text { Dose } \\
\text { (Gy) }\end{array}$ & $\begin{array}{c}\text { \% de volume } \\
\text { correspondente } \\
\text { à dose }\end{array}$ & $\begin{array}{l}\text { Dose em } 1 \% \\
\text { do volume } \\
\text { total (Gy) }\end{array}$ & $\begin{array}{l}\text { Dose } \\
\text { (Gy) }\end{array}$ & $\begin{array}{l}\% \text { de volume } \\
\text { correspondent } \\
\text { e à dose }\end{array}$ & $\begin{array}{c}\text { Dose em 1\% } \\
\text { do volume } \\
\text { total (Gy) }\end{array}$ \\
\hline CTV1 & 54,0 & $91 \%$ & 71,9 & 54,0 & $98 \%$ & 72,6 \\
\hline CTV2 & 70,0 & $84 \%$ & 75,6 & 70,0 & $81 \%$ & 76,0 \\
\hline GTV & 54,0 & $97 \%$ & 66,3 & 54,0 & $100 \%$ & 68,0 \\
\hline ME & 44,6 & $1 \%$ & 46,2 & 44,1 & $1 \%$ & 49,5 \\
\hline PD & 28,0 & $50 \%$ & 61,5 & 34,3 & $50 \%$ & 59,2 \\
\hline $\mathrm{PE}$ & 29,3 & $50 \%$ & 52,9 & 30,9 & $50 \%$ & 58,1 \\
\hline TC & 38,9 & $1 \%$ & 42,1 & 47,5 & $1 \%$ & 49,9 \\
\hline
\end{tabular}




\begin{tabular}{|l|c|c|c|c|c|c|}
\hline \multicolumn{7}{|c|}{ Deslocamento no sentido anterior (Z2) $^{\text {PTV }}$. } \\
\hline \multicolumn{7}{|c|}{ PTV $_{\mathbf{5}}$} \\
\hline CTV1 & 54,0 & $93 \%$ & 73,0 & 54,0 & $98 \%$ & 73,3 \\
\hline CTV2 & 70,0 & $90 \%$ & 76,3 & 70,0 & $94 \%$ & 75,5 \\
\hline GTV & 54,0 & $95 \%$ & 62,0 & 54,0 & $100 \%$ & 63,5 \\
\hline ME & 40,0 & $1 \%$ & 45,4 & 44,2 & $1 \%$ & 47,0 \\
\hline PD & 19,9 & $50 \%$ & 36,7 & 17,9 & $50 \%$ & 33,4 \\
\hline PE & 20,6 & $50 \%$ & 37,0 & 20,7 & $50 \%$ & 37,5 \\
\hline TC & 55,6 & $1 \%$ & 56,6 & 59,3 & $1 \%$ & 60,0 \\
\hline
\end{tabular}

De acordo com a TABELA 5.8, para praticamente todos os deslocamentos estudados observa-se que os CTVs e GTVs são mais bem tratados quando é acrescentada uma margem de $5 \mathrm{~mm}$ aos CTVs (PTV 5 ). Já no caso das estruturas parótida direita, parótida esquerda e tronco cerebral não há uma diferença significativa entre as doses recebidas por esses órgãos quando se compara os planejamentos com $\mathrm{PTV}_{2}$ e $\mathrm{PTV}_{5}$. $\mathrm{O}$ único caso em que a dose limite para um órgão crítico foi ultrapassada foi com a medula espinhal (ME) para 0 deslocamento no sentido da direita do paciente (X1). Nesse caso, a dose em $1 \%$ do volume da ME recebeu doses superiores a $50 \mathrm{~Gy}$, tanto para o $\mathrm{PTV}_{2}$ como para o $\mathrm{PTV}_{5}$. Para prevenir este tipo de ocorrência seria interessante acrescentar uma margem para o órgão de risco (PORV), e assim prevenir que qualquer deslocamento sofrido pelo paciente gere um aumento de dose no órgão que se deseja poupar.

\subsubsection{Efeito da margem dada ao volume alvo para formar o PTV em relação à dose na superfície quando se utiliza planejamento inverso para IMRT no tratamento de câncer de cabeça e pescoço}

$\mathrm{O}$ aumento da margem de planejamento ao redor do CTV para garantir seu tratamento adequado faz com que o PTV se aproxime da pele. Uma das dúvidas no planejamento inverso com IMRT está em saber se essa proximidade causa um aumento de dose na pele do paciente. Para fazer essa verificação usa-se um objeto simulador antropomórfico com planejamento inverso para IMRT, usando uma técnica com IMRT de 7 campos coplanares, colimador multi-lâminas dinâmico e feixes de fótons de $6 \mathrm{MV}$. Uma dose de 162 cGy foi liberada no ponto de medição dentro do PTV. Os planos foram criados para PTVs definidos na pele (PTV pele), a $5 \mathrm{~mm}$ da superfície $\left(\mathrm{PTV}_{5}\right)$ e a $10 \mathrm{~mm}$ de distância da pele (PTV $\left.\mathrm{P}_{10}\right)$ para dentro do simulador. Dosímetros TL e MOSFET foram dispostos em várias 
regiões da superfície e internamente ao objeto simulador, nos pontos de referência, ilustrado na FIGURA 5.12, onde constam os pontos de medição indicados pelos números. A profundidade efetiva de medição $\left(\mathrm{p}_{\mathrm{ef}}\right)$ foi determinada para cada dosímetro e suas respectivas correções de PDP (relativas à $70 \mu \mathrm{m}$ ) foram aplicadas. As $p_{\text {ef }}$ para o TLD e MOSFET foram $135 \mu \mathrm{m}$ e $353 \mu \mathrm{m}$, respectivamente. As incertezas associadas aos dosímetros foram de $5 \%$.

Uma série de 6 medidas foram realizadas para se obter a média de dose, em cada ponto ilustrado pelas setas na FIGURA 5.12. A TABELA 5.9 mostra o resultado das medidas dosimétricas para os pontos avaliados.

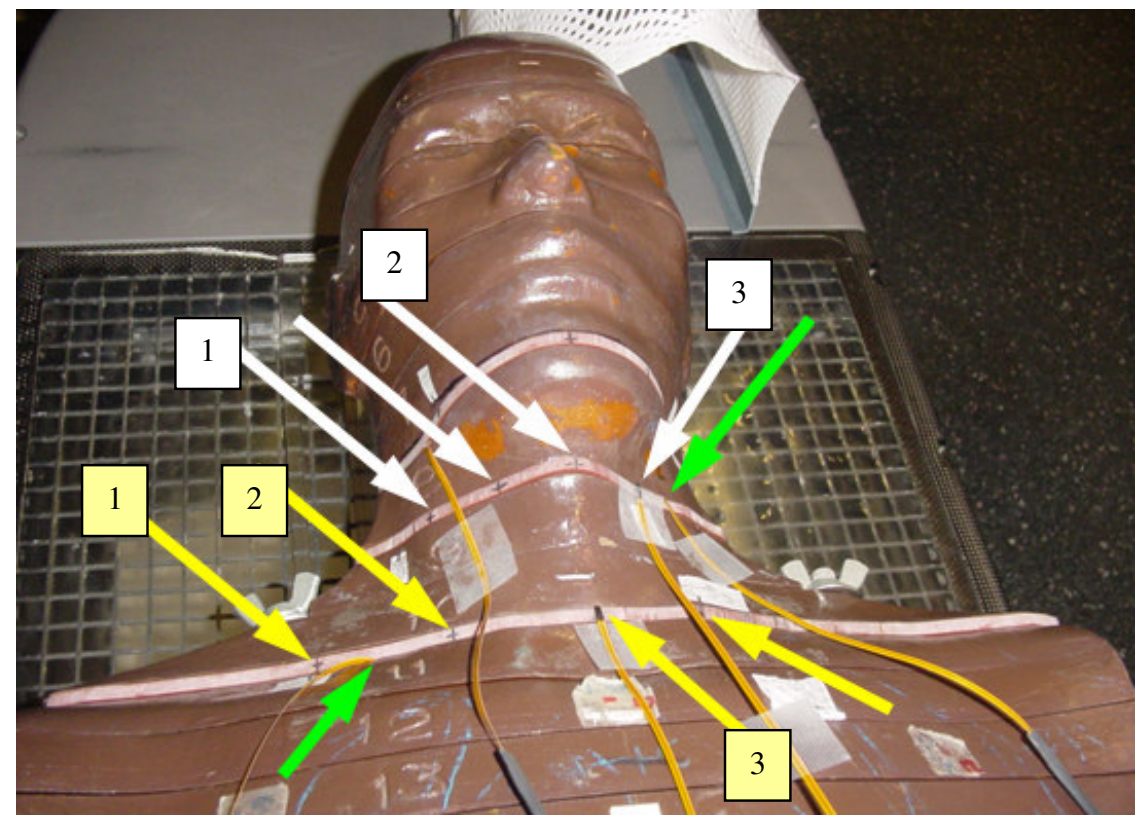

FIGURA 5.12 - FIGURA 4.14, com a indicação numérica, mostra os pontos de medição, onde se localizam os dosímetros utilizados para determinar as doses superficial e interna no simulador antropomórfico. As setas brancas indicam dosímetros na região do pescoço; as amarelas, a região supra-clavicular e as verdes, representam os pontos em que foram colocados os dosímetros dentro do objeto simulador. 
TABELA 5.9 - Medições realizadas com dosímetros TL e MOSFET para tratamentos com IMRT nos pontos identificados como 1, 2 e 3 na FIGURA 5.12. 0 desvio padrão obtido foi de $5 \%$.

\begin{tabular}{|c|c|c|c|c|c|c|c|}
\hline & & \multicolumn{2}{|c|}{ PTV 10 mm } & \multicolumn{2}{|c|}{ PTV 5 mm } & \multicolumn{2}{|c|}{ PTV na pele } \\
\hline \multicolumn{2}{|c|}{ Local de medida } & $\begin{array}{l}\text { Média } \\
\text { (cGy) }\end{array}$ & $\begin{array}{c}\text { Média } \\
(\%)\end{array}$ & $\begin{array}{l}\text { Média } \\
\text { (cGy) }\end{array}$ & $\begin{array}{c}\text { Média } \\
(\%)\end{array}$ & $\begin{array}{l}\text { Média } \\
\text { (cGy) }\end{array}$ & $\begin{array}{c}\text { Média } \\
(\%)\end{array}$ \\
\hline \multirow{4}{*}{$\begin{array}{c}\text { Pescoço } \\
\text { (sob a } \\
\text { máscara) }\end{array}$} & 1 & 100 & 70 & 146 & 88 & 155 & 94 \\
\hline & 2 & 86 & 61 & 112 & 67 & 148 & 90 \\
\hline & 3 & 100 & 70 & 123 & 74 & 149 & 90 \\
\hline & Média & 95 & 67 & 127 & 76 & 151 & 91 \\
\hline \multirow{4}{*}{$\begin{array}{c}\text { Supra- } \\
\text { Clavicular } \\
\text { (sem } \\
\text { máscara) }\end{array}$} & 1 & 77 & 54 & 101 & 61 & 130 & 79 \\
\hline & 2 & 72 & 50 & 95 & 57 & 121 & 73 \\
\hline & 3 & 76 & 53 & 78 & 47 & 109 & 66 \\
\hline & Média & 75 & 53 & 92 & 55 & 120 & 73 \\
\hline CTV & Média & 142 & 100 & 167 & 100 & 165 & 100 \\
\hline
\end{tabular}

Os resultados da TABELA 5.9 mostraram que as doses médias superficiais para os planejamentos com IMRT na região do pescoço foram: $67 \%, 76 \%$ e $91 \%$ da dose prescrita para $\mathrm{PTV}_{10}, \mathrm{PTV}_{5}$ e $\mathrm{PTV}_{\text {pele }}$ respectivamente, enquanto na região supra-clavicular foram $53 \%, 55 \%$ e $73 \%$.

Quando as medidas de dose de superfície são registradas para todos os pontos avaliados (região do pescoço e supra-clavicular), para os planos com PTV 10

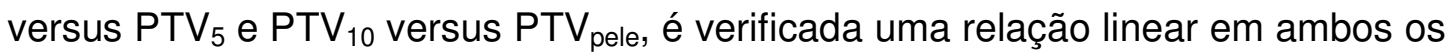
casos ( $R=0,93217, p=0,0001$ e $R=0,89191, p=0,0001$, respectivamente), como mostrado nas FIGURAS 5.13 e 5.14 respectivamente. O coeficiente angular da curva é diretamente proporcional ao aumento da dose na superfície para cada situação de PTV. Os resultados mostraram claramente que a dose superficial aumenta como uma função da proximidade do PTV à superfície da pele. As doses na região do pescoço são esperadas serem mais altas por causa do efeito "bólus" produzido pela máscara termoplástica ${ }^{100}$. 


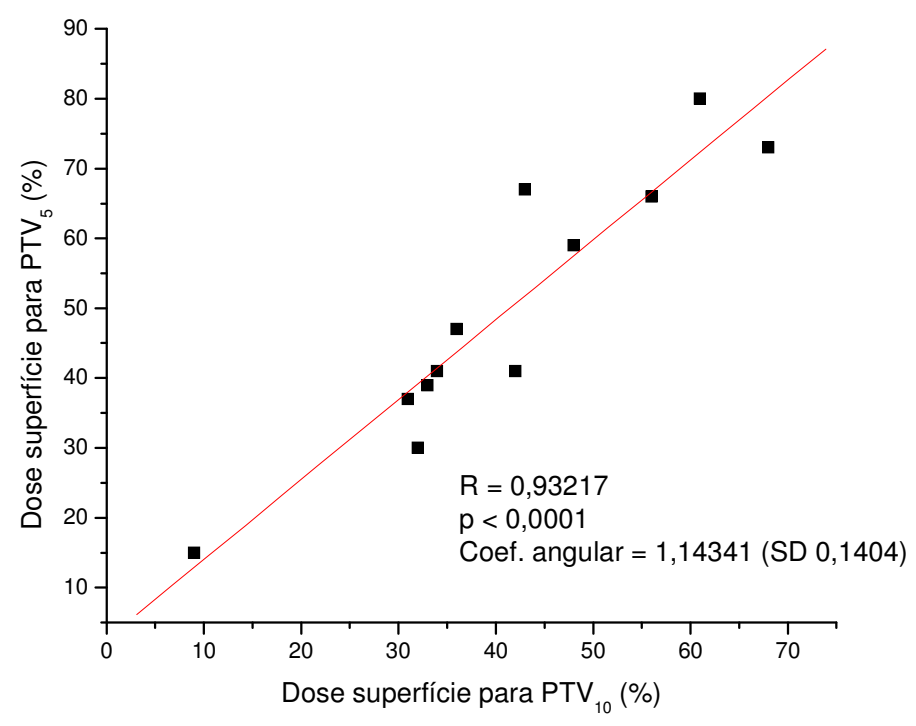

FIGURA 5.13 - Porcentagem de dose na superfície para os planos com PTV 10 e PTV 5 . Os dosímetros TLs e MOSFETs foram colocados em 12 posições diferentes na superfície do simulador Rando. A dose de superfície média para cada posição foi normalizada no ponto de prescrição localizado dentro do simulador.

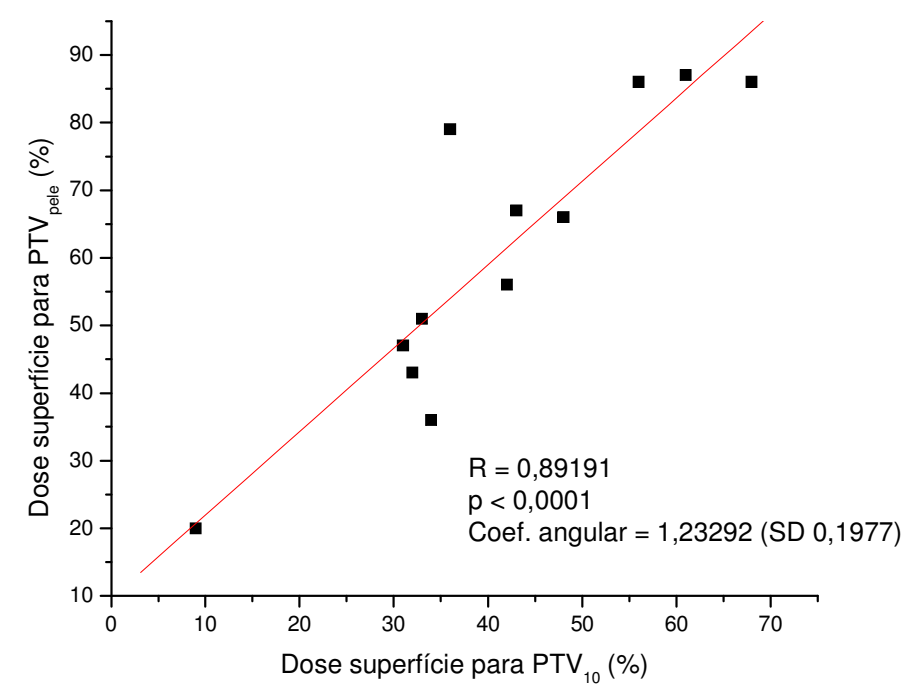

FIGURA 5.14 - Porcentagem de dose na superfície para os planos com PTV 10 e PTV $_{\text {pele. }}$ Os dosímetros TLs e MOSFETs foram colocados em 12 posições diferentes na superfície do simulador Rando. A dose de superfície média para cada posição foi normalizada no ponto de prescrição localizado dentro do simulador. 
Para verificar se o efeito de aumento de dose na pele tem relação com a técnica de tratamento escolhida, IMRT ou convencional, o objeto simulador antropomórfico foi irradiado nas mesmas condições e com os mesmos dosímetros descritos neste item, mas agora usando a técnica convencional de três campos: 2 campos paralelos e opostos na região do pescoço e 1 campo adjacente incidindo perpendicularmente à região supra-clavicular. Os resultados mostrados na TABELA 5.10 são a média das doses obtidas com TLD e MOSFET nos pontos ilustrados na FIGURA 5.12.

TABELA 5.10 - Medições de dose para geometria de feixe convencional utilizando dosímetros TL e MOSFET.

\begin{tabular}{|c|c|c|c|c|c|c|}
\hline \multicolumn{2}{|c|}{ Local de medição } & $\begin{array}{l}\text { TLD } \\
\text { (cGy) }\end{array}$ & TLD (\%) & $\begin{array}{c}\text { MOSFET } \\
\text { (cGy) }\end{array}$ & $\begin{array}{c}\text { MOSFET } \\
\text { (\%) }\end{array}$ & $\begin{array}{l}\text { Média } \\
(\%)\end{array}$ \\
\hline \multirow{5}{*}{$\begin{array}{l}\text { Pescoço } \\
\text { (sob } \\
\text { máscara) }\end{array}$} & 1 & 187 & 89 & 188 & 90 & 89 \\
\hline & 2 & 209 & 100 & 217 & 104 & 102 \\
\hline & 3 & 238 & 114 & 231 & 110 & 112 \\
\hline & 4 & 201 & 96 & 205 & 98 & 97 \\
\hline & Média & 209 & 100 & 210 & 100 & 100 \\
\hline \multirow{5}{*}{$\begin{array}{l}\text { Supra- } \\
\text { Clavicular } \\
\text { (sem } \\
\text { máscara) }\end{array}$} & 1 & 84 & 40 & 78 & 37 & 39 \\
\hline & 2 & 77 & 37 & 75 & 36 & 36 \\
\hline & 3 & 70 & 34 & 73 & 35 & 34 \\
\hline & 4 & 73 & 35 & 77 & 37 & 36 \\
\hline & Média & 76 & 36 & 76 & 36 & 36 \\
\hline \multirow{3}{*}{$\begin{array}{c}\text { CTV } \\
\text { (na prof.) }\end{array}$} & 1 & 207 & 99 & 209 & 100 & 99 \\
\hline & 2 & 210 & 100 & 204 & 97 & 99 \\
\hline & Média & 208 & 99 & 207 & 99 & 99 \\
\hline
\end{tabular}

As doses superficiais médias, para o arranjo utilizando a técnica convencional, foram $100 \%$ e $36 \%$ da dose prescrita para a região do pescoço e supra-clavicular respectivamente.

Comparando os resultados das TABELAS 5.9 e 5.10 pelas duas técnicas de tratamento (IMRT e convencional) observa-se doses superficiais mais altas na região do pescoço para técnica convencional, enquanto que para a região supraclavicular as doses mais altas foram para a técnica de IMRT, o que é esperado uma vez que na técnica convencional essa região é irradiada apenas com um campo direto não-tangencial e, portanto, a dose de entrada deve ser menor que na técnica com IMRT onde vários campos tangentes incidem na pele. Alguns autores $^{92-94}$ chegaram a resultados semelhantes com relação ao aumento de dose na pele que atribuem ao IMRT. Conforme os dados apresentados neste trabalho, 
o aumento de dose na pele não é devido somente ao IMRT, pois são observadas doses mais altas na pele na região do pescoço com a técnica convencional.

\subsubsection{Efeito de margens do PTV nas doses das regiões periféricas ao tratamento}

A proximidade do PTV à pele, como mostrado no item 5.2.3, gera um aumento de dose nela. Para verificarmos se isso também ocorre na periferia do campo de tratamento foram distribuídos dosímetros TL e MOSFET em diversos pontos (olhos, tórax e gônadas) do objeto simulador antropomórfico e irradiou-se o objeto simulador em duas situações: a primeira usando a técnica de IMRT para os PTVs: PTV $_{10}$, PTV $_{5}$, PTV $_{\text {pele }}$ e a segunda usando a técnica de tratamento com arranjo convencional de feixes. Foram liberados 5 tratamentos para cada dosímetro e 0 resultado mostrado na TABELA 5.11 é a média das doses obtidas com TLD e MOSFET.

TABELA 5.11 - Medidas de dose periféricas utilizando o objeto simulador antropomórfico para as técnicas IMRT e convencional com dosímetros TL e MOSFET. PTV $10, \mathrm{PTV}_{5}, \mathrm{PTV}_{\text {pele }}$ foram usados na técnica de IMRT. O erro associado às medidas foi de $\pm 5,0 \%$.

\begin{tabular}{|l|c|c|c|c|}
\hline \multirow{2}{*}{ Localização } & \multicolumn{3}{|c|}{ IMRT } & Convencional \\
\cline { 2 - 4 } & \multicolumn{3}{|c|}{$\begin{array}{c}\text { Dose média (cGy) } \\
\text { Dose média } \\
\text { (cGy) }\end{array}$} \\
\hline Olho direito & PTV $_{\mathbf{1 0}}$ & PTV $_{\mathbf{5}}$ & PTV $_{\text {pele }}$ & 79,8 \\
\hline Olho esquerdo & 31,5 & 39,2 & 42,7 & 74,5 \\
\hline Tórax direito & 35,0 & 42,8 & 49,2 & 14,7 \\
\hline Tórax esquerdo & 11,2 & 12,9 & 15,5 & 15,4 \\
\hline Gônada direita & 11,3 & 12,9 & 15,4 & 1,3 \\
\hline Gônada esquerda & 2,3 & 2,7 & 2,9 & 1,1 \\
\hline
\end{tabular}

$\mathrm{Na}$ região torácica, a técnica convencional é semelhante à técnica com IMRT planejada com PTV pele, em termos de dose fora do campo de tratamento (periférica). A região dos olhos parece ser mais poupada com IMRT. O resultado indica que as regiões mais afastadas do campo de tratamento recebem maior dose com a técnica de IMRT, fato que pode ser explicado pelo aumento da radiação espalhada uma vez que se utilizaram, em média, 1566 UM por plano de tratamento, enquanto que com a técnica convencional, foram utilizadas somente 406 UM para liberar a mesma dose. 


\subsubsection{Incertezas relacionadas ao movimento do órgão entre frações do tratamento: casos de tumor na próstata ${ }^{101}$}

Outra fonte de erro que faz parte da definição do volume de planejamento do tratamento (PTV) é aquela gerada pelo movimento do órgão entre as frações de tratamento. Para avaliar este erro foram estudadas as variações geométricas da próstata de 387 pacientes, diariamente, pré-tratamento, com o sistema de ultra-som 2-D (US). Dois planos, axial e sagital, foram obtidos com o US. Através da fusão das imagens do ultra-som com os contornos externos das imagens obtidas através da tomografia computadorizada de planejamento, obteve-se 0 desvio diário da próstata com relação à imagem usada no planejamento tridimensional, FIGURA 5.15. Um total de 10.327 localizações com ultra-som foram incluídas neste estudo resultando em 30.981 deslocamentos nas direções antero-posterior (AP), superior-inferior ( $\mathrm{SI}$ ) e direita-esquerda (DE) do paciente. Todos os 387 pacientes foram localizados diariamente com US em pelo menos 4 frações consecutivas do seu tratamento. Cada paciente foi submetido em média a 27 localizações (mediana $=23$ ), sendo o mínimo de 4 e o máximo de 41 . Embora tenha sido feito um esforço para prover localização pré-tratamento para todos os pacientes em todas as frações, isto não foi sempre possível por várias razões, tais como problemas mecânicos do sistema de localização ou do acelerador linear. Além disso, dependendo do esquema de tratamento, alguns pacientes receberam localização pré-tratamento somente para a fase de complementação de dose. Os resultados estatísticos provenientes de uma revisão da literatura para os movimentos da próstata com relação à sua direção são apresentados na TABELA 5.12. Para uma distribuição Normal (Gaussiana), a média pode ser considerada representativa dos erros sistemáticos e o desvio padrão (SD) representativo dos randômicos.

Os dados obtidos com este trabalho foram testados para não-normalidade usando o teste Shapiro-Wilk do programa Origin 7.0 e todos os dados se encontraram distribuídos normalmente para um nível de significância de $0,05(\mathrm{~W}=0,9881$, $p=0,8432, I C=95 \%)$. A representação gráfica destes dados através dos histogramas das médias dos desvios obtidos em todas as frações de tratamento para todos os pacientes, nos eixos X, Y e Z, é apresentada nas FIGURAS $5.16 \mathrm{a}$ ), b) e c). A estatística relacionada aos histogramas da FIGURA 5.16 é descrita na 
TABELA 5.13 e o deslocamento máximo em cada direção é descrito na TABELA 5.14.

$O$ desvio médio máximo obtido (TABELA 5.13) foi na direção $A P, 6,1 \mathrm{~mm}$ posterior, com um SD de 4,4 $\mathrm{mm}$. Um desvio médio de 2,1 $\mathrm{mm}$ com um SD de $4,5 \mathrm{~mm}$ foi encontrado no sentido superior, e ao longo do eixo lateral um desvio médio de $0,5 \mathrm{~mm}$ para a direita com um SD de $3,6 \mathrm{~mm}$ foi computado. Um gráfico da distribuição dos deslocamentos médios obtidos para cada paciente são mostrados para os planos axial, coronal e sagital na FIGURA 5.17. Para acessar qualquer tendência nos dados com relação ao tempo, os deslocamentos médios nas 3 direções assim como seus respectivos desvios padrões foram graficados como uma função do tempo (representado cronológicamente pelo número do paciente) na FIGURA 5.18.

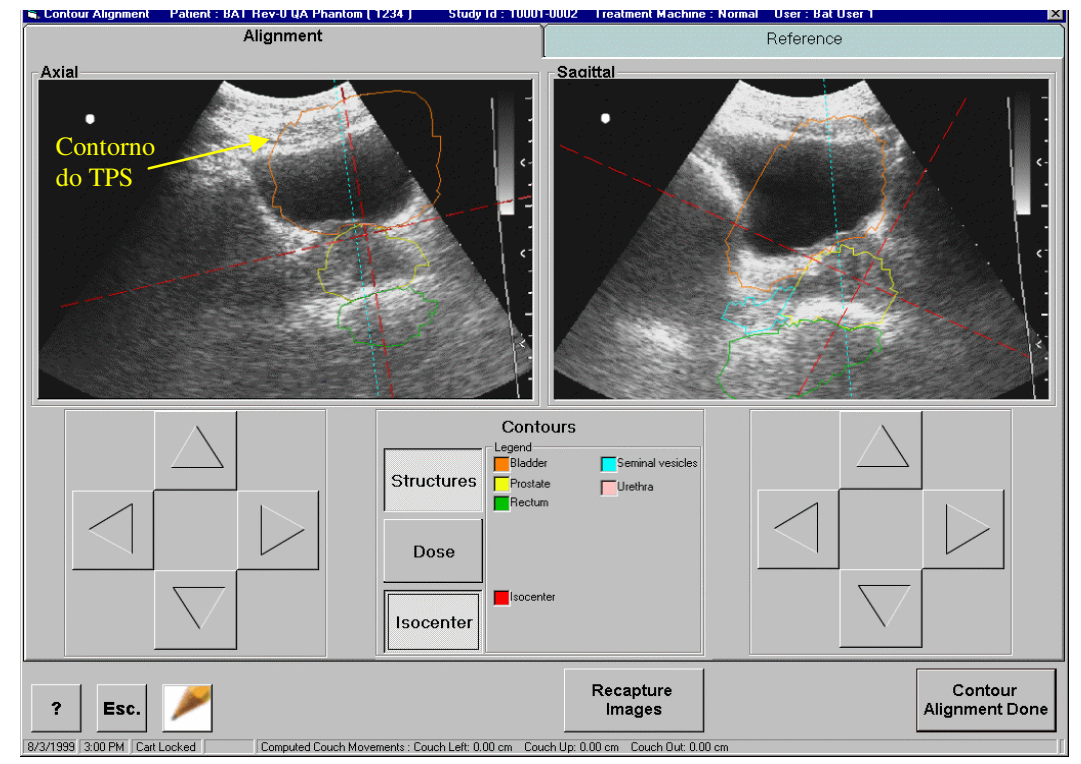

FIGURA 5.15 - Fusão das imagens axial e sagital obtidas com o ultra-som 2-D de localização pré-tratamento com os contornos gerados no sistema de planejamento tridimensional (TPS) a partir das imagens tomográficas adquiridas para planejamento. 


\section{TABELA 5.12 - Dados da literatura de análises estatísticas do movimento da próstata (1 SD) ${ }^{101}$.}

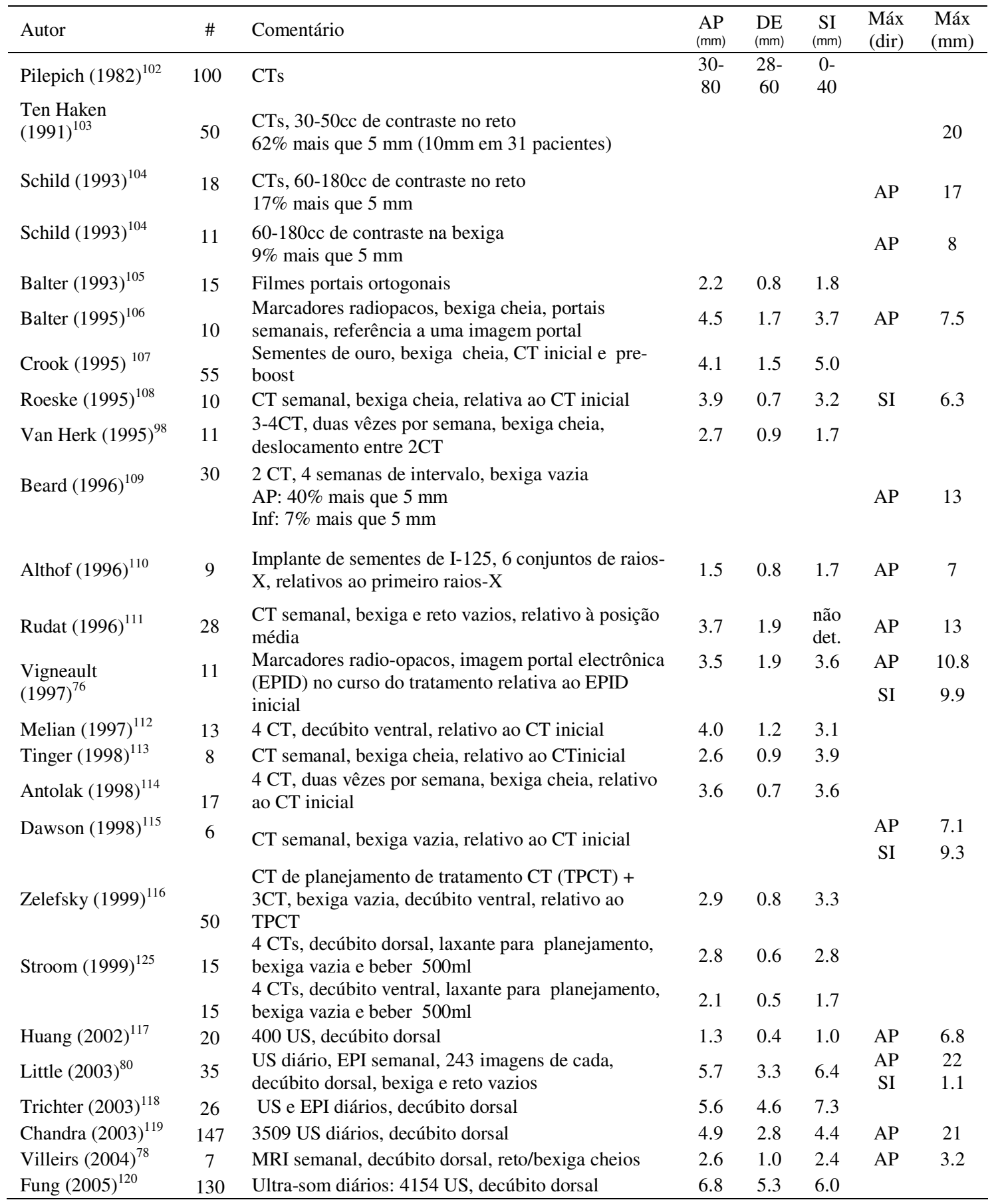



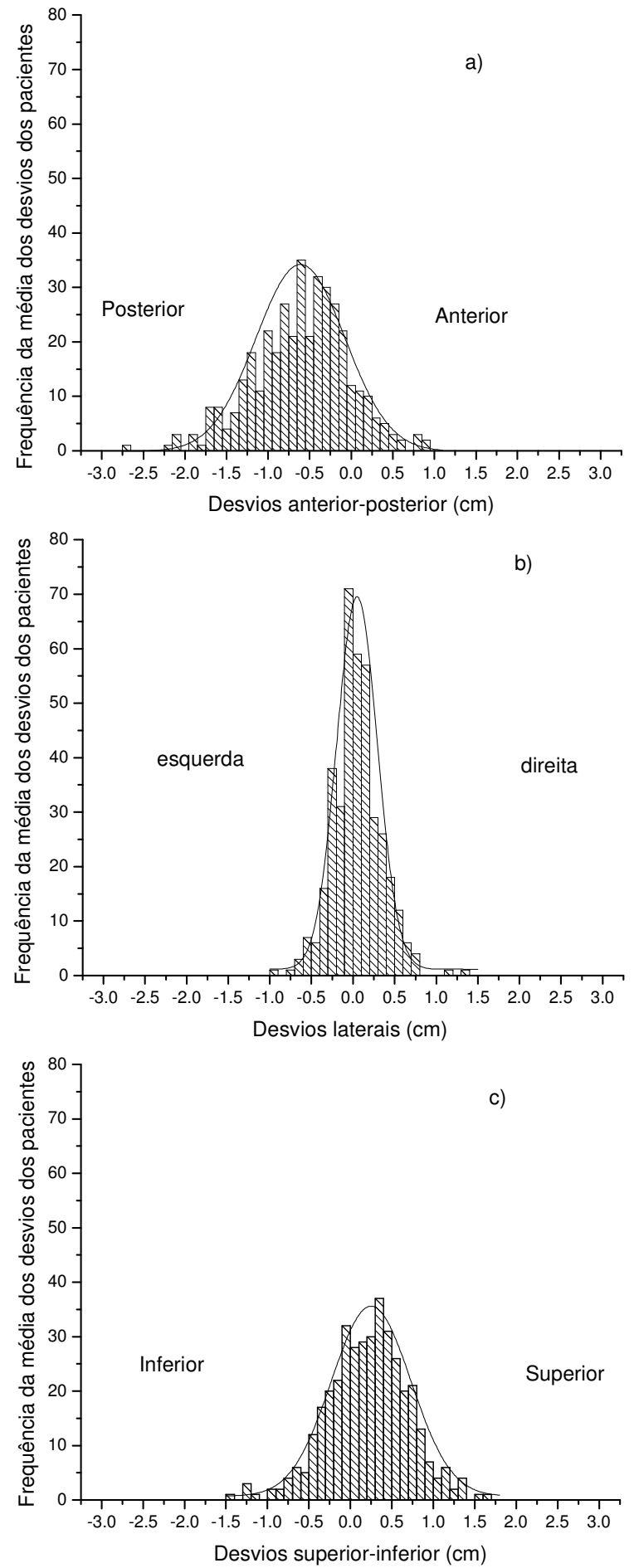

FIGURA 5.16 - Histogramas mostrando a média dos desvios sofridos em todas as frações do tratamento por todas as próstatas dos pacientes. O tamanho do intervalo usado foi de $0,1 \mathrm{~cm}$ e os histogramas foram ajustados com uma curva gaussiana. As FIGURAS 5.16 a), b) e c) representam os desvios nos sentidos anterior-posterior, látero-lateral e superior-inferior (ou crânio-caudal) respectivamente. 
TABELA 5.13 - Resultados estatísticos de 10.327 localizações com ultra-som. A direção do desvio indica a direção do deslocamento do alvo com relação ao isocentro planejado como indicado pelo software do ultra-som de localização. As distribuições foram testadas para não-normalidade usando o Teste Shapiro-Wilk.

\begin{tabular}{|c|c|c|c|c|}
\hline $\begin{array}{c}\text { Eixos de } \\
\text { medida }\end{array}$ & $\begin{array}{c}\text { Sentido do } \\
\text { desvio }\end{array}$ & $\begin{array}{c}\text { Média dos } \\
\text { desvios } \\
(\mathbf{m m})\end{array}$ & $\begin{array}{c}\text { Mediana dos } \\
\text { desvios } \\
(\mathbf{m m})\end{array}$ & $\begin{array}{c}\text { Desvio-padrão } \\
(\mathbf{\sigma}) \\
(\mathbf{m m})\end{array}$ \\
\hline AP & POSTERIOR & 6,1 & 5,7 & 4,4 \\
\hline SI & SUPERIOR & 2,1 & 2,3 & 4,5 \\
\hline DE & DIREITA & 0,5 & 0,4 & 3,6 \\
\hline
\end{tabular}

TABELA 5.14 - Resultados estatísticos de 10.327 localizações com ultra-som. A direção do desvio indica a direção do deslocamento do alvo em relação ao isocentro como indicado pelo software de localização com ultra-som. $O$ alcance é o desvio máximo sofrido pelo órgão dentre todas as localizações.

\begin{tabular}{cc}
\hline $\begin{array}{c}\text { Eixos de } \\
\text { medidas dos } \\
\text { deslocamentos }\end{array}$ & $\begin{array}{c}\text { Alcance } \\
\mathbf{( m m})\end{array}$ \\
\hline AP & 27,1 POST \\
& 9,1 ANT \\
SI & 16,7 SUP \\
& 14,7 INF \\
DE & 13,2 DIR \\
& $9,4 \mathrm{ESQ}$ \\
\hline
\end{tabular}



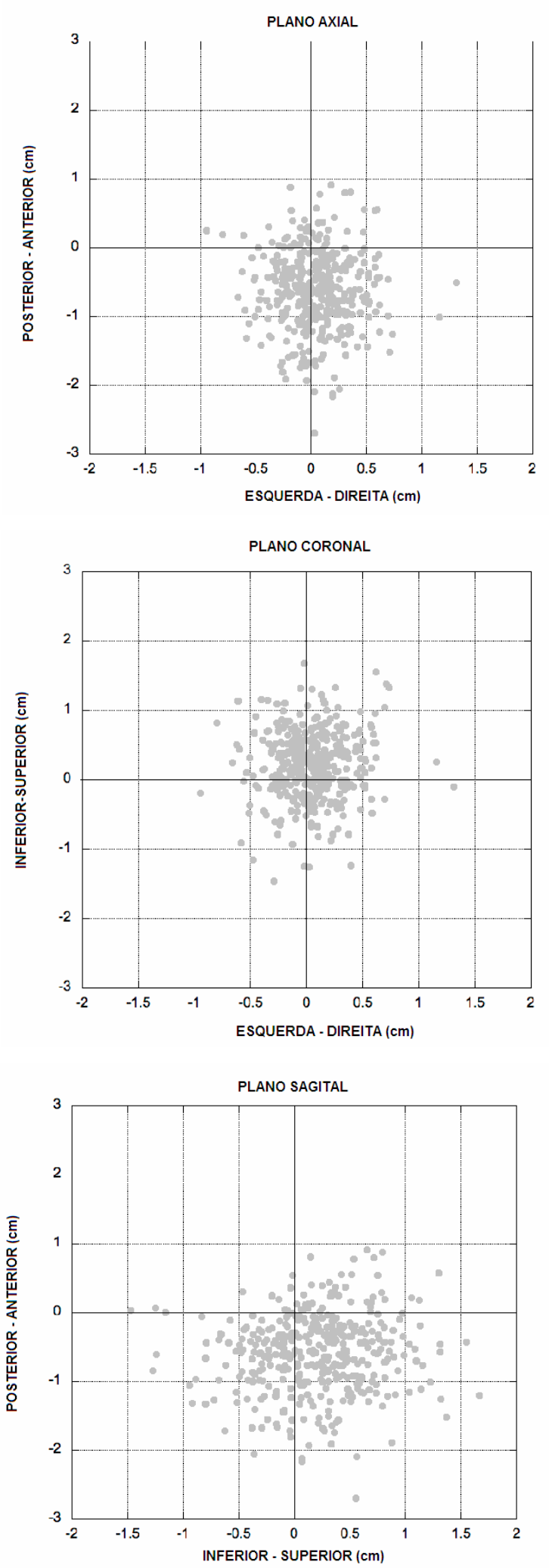

FIGURA 5.17 - Distribuição dos deslocamentos médios obtidos em relação ao isocentro $(0,0)$ para cada paciente nos planos axial, coronal e sagital. 

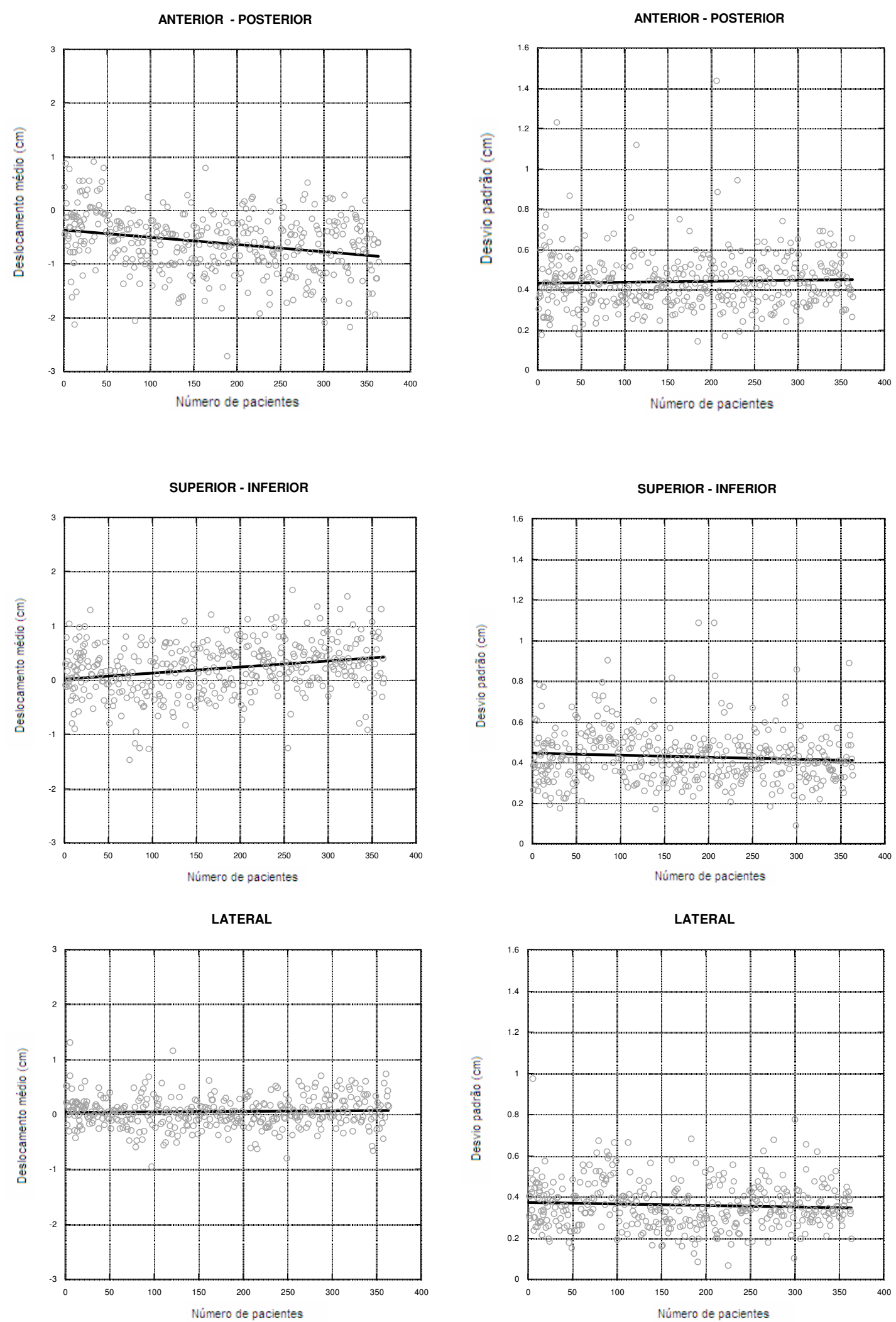

FIGURA 5.18 - Deslocamentos médio e desvio padrão dos 3 eixos principais como uma função do número de pacientes tratados desde 2001 a 2005. 
Os dados na TABELA 5.13 mostram que existe um desvio médio não desprezível em ambas as direções posterior $(6,1 \mathrm{~mm})$ e superior $(2,1 \mathrm{~mm})$. A fim de entender a origem desses desvios, um esforço foi feito para tentar identificar as principais diferenças entre os procedimentos na CT-simulador e as condições de localização com ultra-som na sala de tratamento. A primeira fonte de erro surge do fato que 0 sistema depende da comparação entre os contornos desenhados no CT e projetados junto com as informações do isocentro nas imagens de ultra-som 2-D. Não está claro se estas incertezas são de origem randômica ou sistemática (ou ambas) em natureza. Este erro pode ser minimizado através do uso de procedimentos de garantia de qualidade (QA) para assegurar a integridade dos dados durante todo o procedimento. Através de 34 procedimentos de $\mathrm{CQ}$ verificou-se que o desvio padrão médio é 1,6 mm na direção superior-inferior e que ele foi gerado devido a mudanças na localização das estruturas de referência dentro do objeto simulador. Vários autores ${ }^{75,121,122}$ têm demonstrado que a pressão causada pelo sensor do ultra-som pode produzir um deslocamento da próstata na direção posterior da ordem de alguns milímetros. Alguns autores ${ }^{123,124}$ têm mostrado que os pacientes que recebem uretrografia, como no caso dos pacientes deste estudo, para propostas de planejamento do tratamento apresentam deslocamentos sistemáticos da próstata em ambas as direções, posterior e superior, da ordem de 1 a $2 \mathrm{~mm}$, o que poderia contribuir para o erro sistemático notado em nosso estudo de 2,1 $\mathrm{mm}$ na direção superior. Uma outra fonte de erro sistemático pode ser atribuída à construção da mesa de tratamento. A mesa do scanner do CT tem uma mesa plana de grafite, que não exibe nenhuma depressão ao longo do eixo transversal em direção ao posterior. $O$ acelerador no qual os pacientes são tratados possuiu uma moldura de metal com uma "raquete de tênis" inserida no meio, para não absorver radiação, que pode causar uma depressão de 1 a $3 \mathrm{~mm}$ quando o paciente está deitado sobre ela.

Uma outra questão estudada foi com relação à mudança anatômica do paciente do dia da CT para o dia de tratamento. Para responder a esta questão foram tomados 32 pacientes, selecionados aleatoriamente do grupo estudado e comparados os desvios da próstata na direção antero-posterior das 5 frações iniciais do tratamento destes pacientes com os das 5 últimas frações. O resultado é mostrado na FIGURA 5.19 e na TABELA 5.15. Os deslocamentos médios foram calculados, na direção posterior, para a primeira semana $(6,3 \mathrm{~mm})$ e para a última 
semana $(5,3 \mathrm{~mm})$ dos tratamentos. O teste t-Student foi aplicado aos dados da FIGURA 5.19 para avaliar a significância estatística das diferenças entre as médias. O resultado mostrou que as médias não foram significativamente diferentes dentro de um intervalo de confiança de 95\% ( $\alpha=0,05, t=1,960$, $|t|=0,29279)$. Esse estudo eliminou a dúvida de que o paciente contraía a musculatura do glúteo no início do tratamento e relaxava com o decorrer dele.

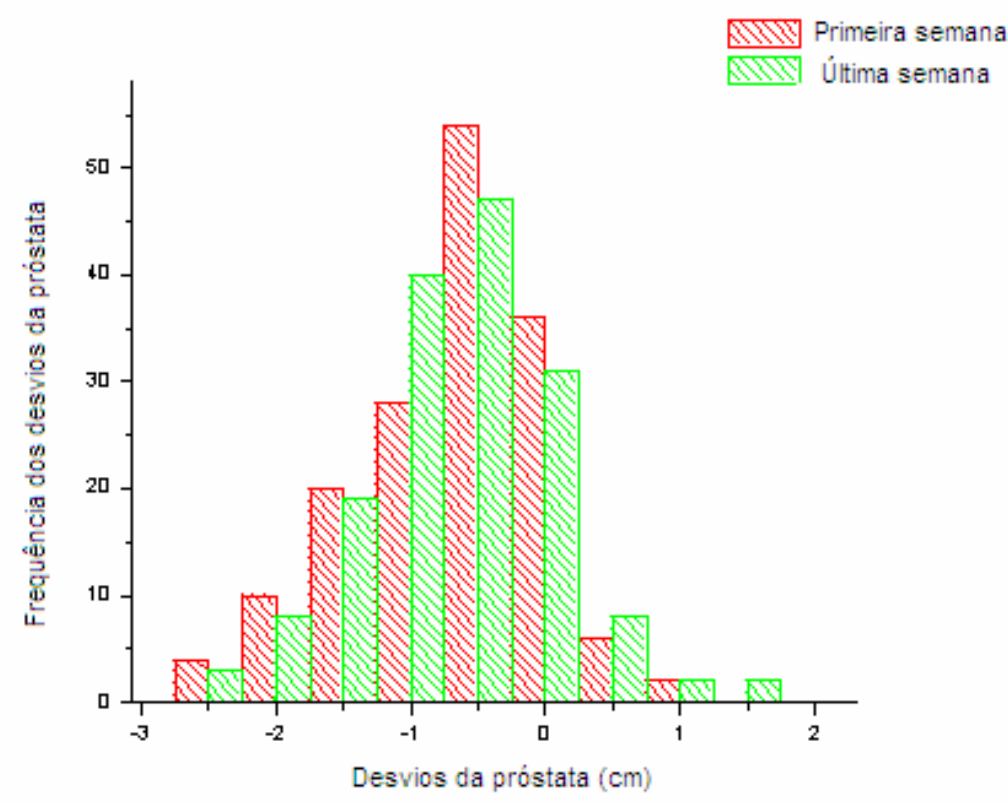

FIGURA 5.19 - Comparação entre desvios da próstata na direção antero-posterior no início (primeira semana) e no final (última semana) do tratamento.

TABELA 5.15 - Desvio padrão e média das medidas dos desvios da próstata na direção antero-posterior no início (primeira semana) e no final (última semana) do tratamento.

\begin{tabular}{|c|c|c|}
\hline & Primeira semana & Última semana \\
\hline Média (cm) & $-0,63$ & $-0,53$ \\
\hline Desvio Padrão (cm) & 0,59 & 0,63 \\
\hline
\end{tabular}

Foi realizada uma avaliação da margem necessária para englobar a próstata em 95\% dos casos se a localização por US não estivesse disponível. Os resultados são mostrados na TABELA 5.16. As dimensões da margem foram calculadas adicionando \pm 2 SD para o deslocamento médio em cada direção. 
Se os erros sistemáticos não fossem contabilizados (média igual a zero), as margens para o PTV seriam 7,2 mm, 8,8 mm e 9,0 mm DE, AP, e SI, respectivamente. Quando os deslocamentos médios são considerados, margens de 7,7 mm (direita) e 6,7 mm (esquerda), 2,7 mm (anterior) e 14,9 mm (posterior), e 11,1 mm (superior) e 6,9 mm (inferior) são requeridas para cobrir a próstata em $95 \%$ dos casos.

TABELA 5.16 - Margem necessária para que o PTV contenha os deslocamentos da próstata em $95 \%$ das localizações se o sistema de localização por ultra-som não estiver disponível. Os valores de $2 \mathrm{SD}$ na tabela representam as margens necessárias não levando em conta o erro sistemático (desvios médios).

\begin{tabular}{cccc}
\hline $\begin{array}{c}\text { Direção do } \\
\text { deslocamento }\end{array}$ & 2 SD $(\mathbf{m m})$ & Desvio médio $(\mathbf{m m})$ & $\begin{array}{c}\text { Margem de PTV } \\
\text { requerida para conter } \\
\mathbf{9 5 \%} \begin{array}{c}\text { da nossa amostra } \\
\mathbf{( m m})\end{array}\end{array}$ \\
\hline $\begin{array}{c}\text { DIREITA } \\
\text { ESQUERDA }\end{array}$ & 7,2 & 0,5 (DIREITA) & 7,7 \\
ANTERIOR & 8,8 & 6,1 (POSTERIOR) & 6,7 \\
POSTERIOR & & & 2,7 \\
SUPERIOR & 9,0 & 2,1 (SUPERIOR) & 14,9 \\
INFERIOR & & & 11,1 \\
\hline
\end{tabular}

Os dados mais relevantes da distribuição dos deslocamentos como uma função da distância em relação ao isocentro original para cada direção é apresentado na TABELA 5.17. Está descrito também o número de pacientes e a quantidade de frações nos quais ocorreu cada intervalo de deslocamento. 
TABELA 5.17 - Distribuição dos deslocamentos como uma função da distância e da direção dos deslocamentos. Intensidade negativa significa deslocamento requerido nas direções posterior, inferior e esquerda. O número de pacientes se refere ao número de pacientes para o qual o deslocamento ocorreu num dado intervalo de distância.

\begin{tabular}{cccccccc}
\hline $\begin{array}{c}\text { Intensidade } \\
\text { do desl. } \\
\text { (cm) }\end{array}$ & $\begin{array}{c}\text { \# de } \\
\text { desl. } \\
\text { DE }\end{array}$ & $\begin{array}{c}\text { \# de } \\
\text { pacientes } \\
\text { DE }\end{array}$ & $\begin{array}{c}\text { \# de desl. } \\
\text { AP }\end{array}$ & $\begin{array}{c}\text { \# de } \\
\text { pacientes } \\
\text { AP }\end{array}$ & $\begin{array}{c}\text { \# de desl. } \\
\text { SI }\end{array}$ & $\begin{array}{c}\text { \# de } \\
\text { pacientes } \\
\text { SI }\end{array}$ & $\begin{array}{c}\text { \# total } \\
\text { de desl. }\end{array}$ \\
\hline$>-3,9$ & 0 & 0 & 0 & 0 & 1 & 1 & 1 \\
$-3,9$ to -3 & 0 & 0 & 6 & 4 & 0 & 0 & 6 \\
$-2,9$ to -2 & 4 & 3 & 313 & 73 & 26 & 14 & 343 \\
$-1,9$ to -1 & 180 & 79 & 2521 & 286 & 348 & 106 & 3049 \\
$-0,9$ to 0 & 5699 & 382 & 5956 & 375 & 4081 & 358 & 15736 \\
0 to 0,9 & 4139 & 374 & 1382 & 243 & 4798 & 368 & 10319 \\
1 to 1.9 & 294 & 128 & 139 & 53 & 1043 & 196 & 1476 \\
2 to 2,9 & 10 & 3 & 10 & 8 & 27 & 18 & 47 \\
3 to 3,9 & 1 & 1 & 0 & 0 & 3 & 2 & 4 \\
$>3,9$ & 0 & 0 & 0 & 0 & 0 & 0 & 0 \\
\hline Total & 10.327 & & 10.327 & & 10.327 & & 30.981 \\
\hline
\end{tabular}

Uma análise posterior foi realizada detalhando o número de vezes em que a próstata deveria estar contida dentro de um PTV com dimensões especificadas se - sistema de localização US não estivesse disponível. Os resultados são mostrados na TABELA 5.18. Uma margem de $5 \mathrm{~mm}$ só conteria a próstata 93, 51 e $71 \%$ do tempo nas direções DE, AP, e SI, respectivamente. A cobertura do alvo aumenta com o aumento da margem do PTV, e para um PTV de $15 \mathrm{~mm}$ de margem, a próstata deveria estar contida nele 100, 95 e 100\% do tempo nas direções DE, AP, e SI, respectivamente. 
TABELA 5.18 - Porcentagem do total de desvios em cada eixo do deslocamento (10.327) em que a próstata deveria permanecer dentro de uma margem uniforme especificada (PTV) se o US de localização diário pré-tratamento não fosse utilizado.

\begin{tabular}{cccc}
\hline $\begin{array}{c}\text { Tamanho da margem } \\
\text { uniforme para PTV } \\
(\mathbf{m m})\end{array}$ & \multicolumn{3}{c}{$\%$ deslocamentos da próstata dentro do PTV } \\
\hline 5 & DE (\%) & AP (\%) & SI (\%) \\
\hline 7 & 93,2 & 51,4 & 71,0 \\
10 & 98,6 & 66,4 & 84,7 \\
12 & 99,5 & 81,0 & 95,0 \\
15 & 99,7 & 88,0 & 98,0 \\
\hline
\end{tabular}

\subsubsection{Modelo matemático para englobar erros sistemáticos e randômicos para definir PTV}

Os erros randômicos podem ser acessados a partir dos desvios padrões (SD) obtidos das medidas dos deslocamentos dos órgãos. Eles são uma manifestação de erros de localização, inconsistências no sistema de calibração do ultra-som ( $\pm 2 \mathrm{~mm}$ ), e mudanças randômicas na anatomia do paciente. Esta última pode ser função do enchimento do reto e/ou bexiga, assim como posição do paciente. $O$ conhecimento destas incertezas é importante uma vez que elas ajudam a definir as dimensões do volume de planejamento do alvo (PTV), se um sistema de localização diária não for disponível no Serviço de Radioterapia. Os SDs encontrados foram 4,4 mm, 4,5 mm e 3,6 mm nas direções AP, SI e DE respectivamente. $\mathrm{Na}$ ausência de erros sistemáticos, uma margem para formar o PTV de 8,8 mm AP, $9 \mathrm{~mm}$ SI e 7,2 mm DE, equivalente a $2 \mathrm{SD}$, deveriam conter a próstata $95,5 \%$ das frações de tratamento se não houvesse um sistema de localização diária. Estes resultados são muito próximos dos obtidos por Fung et al. ${ }^{120}$ que sugerem margens de $10 \mathrm{~mm}$ na direção AP, $9 \mathrm{~mm}$ na SI, e $8 \mathrm{~mm}$ na DE. Na situação deste trabalho em particular, com erros sistemáticos representados por valores diferentes de zero na distribuição dos deslocamentos, 
margens maiores deveriam ser aplicadas para englobar a próstata se não fosse usado nenhum sistema de localização diário do órgão. A margem não-uniforme nos eixos principais para formar o PTV requerida para conter a próstata 95,5\% do tempo seria então de 2,7 mm e 14,9 mm dependendo da direção em que ela for aplicada. É importante notar que a maior margem requerida se extenderia $14,9 \mathrm{~mm}$ posteriormente na direção do reto que é a estrutura crítica de maior relevância num plano de tratamento típico da próstata.

A TABELA 5.18 confirma os dados encontrados na TABELA 5.16, indicando que uma margem uniforme de $15 \mathrm{~mm}$ engloba o alvo em pelo menos $95 \%$ do tempo.

Considerando-se que, os erros sistemáticos e randômicos que ocorrem diariamente num tratamento de um paciente estão distribuídos numa gaussiana então pode ser calculado o erro total a partir do erro sistemático $\Sigma$ (mudanças no contorno do paciente, calibração dos equipamentos) e do erro randômico $\sigma$ (movimento do alvo, variação diária do posicionamento do paciente) obtidos de uma curva gaussiana como mostrado na FIGURA 5.20.

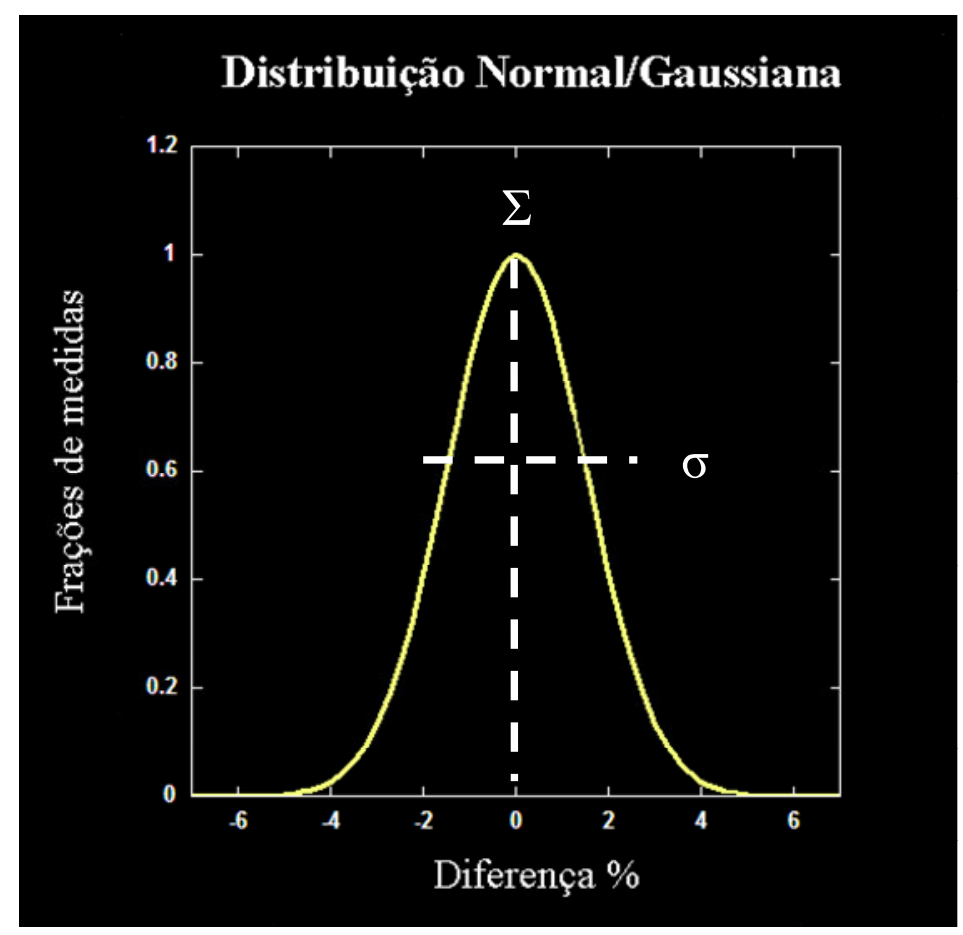

FIGURA 5.20 - Representação gráfica de uma distribuição normal ou gaussiana onde $\Sigma$ representa os erros sistemáticos e pode ser quantificado através do valor médio da distribuição. Os erros randômicos, $\sigma$, é o desvio padrão da distribuição. Numa distribuição normal a média das medidas deve coincidir com a mediana e a moda. 
Alguns trabalhos ${ }^{91,98,125}$ tentam equacionar esses erros para avaliar a margem que deve ser atribuída ao CTV para que ele seja tratado com a dose prescrita.

Como nesta parte deste trabalho foi identificada a margem total necessária para englobar um CTV dentro do PTV em 95\% do tempo de tratamento, pode ser aplicado o deslocamento médio e o desvio padrão encontrado em cada direção na equação proposta por Stroom et al. ${ }^{125}$ da TABELA 4.2, onde a margem total $\left(M_{\mathrm{t}}\right)$ é a soma dos erros sistemáticos $(\Sigma)$ e randômicos $(\sigma)$ segundo a equação:

$$
M_{t}=2 \Sigma+0,7 \sigma \text {. }
$$

Segundo Stroom et al. ${ }^{125}$ esta seria a margem para que $95 \%$ da dose englobe 99\% do CTV.

Considerando $\boldsymbol{\Sigma}$ igual a $0,5 \mathrm{~mm}, 6,1 \mathrm{~mm}$, e $2,1 \mathrm{~mm}$ e o $\boldsymbol{\sigma}$ igual a $3,6 \mathrm{~mm}, 4,4 \mathrm{~mm}$ e $4,5 \mathrm{~mm}$ para as direções DE, AP e SI respectivamente. Substituindo esses valores de $\Sigma$ e $\sigma$, provenientes da TABELA 5.13, na equação 5.1 sugerida por Stroom et al. tem-se que a margem total para cada direção é: $3,5 \mathrm{~mm}$ para $\mathrm{DE}$; $15,3 \mathrm{~mm}$ para AP e 7,3 mm para SI. Estes valores são próximos aos obtidos neste trabalho apresentados na TABELA 5.16.

Estas margens mostram a importância de um sistema de localização diária. Com o sistema de localização de ultra-som diário somente seria necessário levar em conta os erros devido ao sistema de localização $( \pm 2 \mathrm{~mm})$ e os relacionados ao movimento do órgão durante o tratamento ${ }^{121}$.

\subsubsection{Efeito na dose devido ao movimento do isocentro através das novas coordenadas geradas pela localização do alvo com ultra-som}

O estudo do movimento do órgão entre as frações de tratamento mostrou que é possível ter erros muito grandes no alvo se for somente baseado na imagem inicial de planejamento do tratamento. Este estudo mostra a distribuição de dose no caso extremo em que a próstata foi deslocada $3 \mathrm{~cm}$ no sentido anterior e $3 \mathrm{~cm}$ no superior em relação a sua posição no dia do planejamento, TABELA 5.19. 
TABELA 5.19 - Dados do histograma dose-volume para o CTV (próstata) com e sem deslocamento (s/desl.) da próstata em relação às coordenadas do planejamento. A diferença relativa entre as doses é apresentada na coluna \% Rel. Dif. para as técnicas convencional e IMRT.

\begin{tabular}{|c|c|c|c|c|c|c|c|c|c|c|}
\hline & \multicolumn{5}{|c|}{ Convencional } & \multicolumn{5}{|c|}{ IMRT } \\
\hline & s/desl. & $\begin{array}{l}3 \mathrm{~cm} \\
\text { ANT }\end{array}$ & $\begin{array}{c}\text { \% Dif. } \\
\text { Rel. }\end{array}$ & $\begin{array}{l}3 \mathrm{~cm} \\
\text { SUP }\end{array}$ & $\begin{array}{c}\% \text { Dif. } \\
\text { Rel. }\end{array}$ & s/desl. & $\begin{array}{l}3 \mathrm{~cm} \\
\text { ANT }\end{array}$ & $\begin{array}{c}\% \text { Dif. } \\
\text { Rel. }\end{array}$ & $\begin{array}{l}3 \mathrm{~cm} \\
\text { SUP }\end{array}$ & $\begin{array}{c}\% \\
\text { Dif. } \\
\text { Rel. }\end{array}$ \\
\hline $\begin{array}{c}\text { Volume } \\
\left(\mathrm{cm}^{3}\right)\end{array}$ & 33,5 & 34,2 & 1,9 & 33,5 & 0,0 & 37,0 & 37,0 & $-0,1$ & 37,0 & 0,0 \\
\hline Dose & & & & & & & & & & \\
\hline $\begin{array}{c}\text { Mín } \\
\text { (cGy) }\end{array}$ & 7024,0 & 7087,0 & 0,9 & 6935,0 & $-1,3$ & 66,9 & 67,1 & 0,3 & 65,7 & $-1,9$ \\
\hline Dose & & & & & & & & & & \\
\hline $\begin{array}{l}\text { Máx } \\
\text { (cGy) }\end{array}$ & 7376,0 & 7553,0 & 2,3 & 7302,0 & $-1,0$ & 75,3 & 77,3 & 2,5 & 74,9 & $-0,6$ \\
\hline $\begin{array}{l}\text { Dose } \\
\text { Média } \\
\text { (cGv) }\end{array}$ & 7284,0 & 7427,0 & 1,9 & 7214,0 & $-1,0$ & 71,7 & 72,3 & 0,9 & 70,8 & $-1,3$ \\
\hline SD (\%) & 0,8 & 1,0 & & 0,8 & & 0,9 & 1,6 & & 0,9 & \\
\hline
\end{tabular}

Os dados da TABELA 5.19 mostram que a diferença máxima na dose recebida pelo CTV após o reposicionamento na mesa de tratamento foi de $2,5 \%$ que é muito pequeno se comparado com o quanto de dose poderia ter sido perdido pelo alvo se ele não tivesse sido localizado (praticamente $100 \%$ do alvo, para um volume de próstata de $36 \mathrm{~cm}^{3}$, estaria fora do campo de tratamento se o isocentro de planejamento tivesse sido mantido).

\subsubsection{Guia prático: como eleger o paciente à certas restrições de dose}

Uma das grandes dificuldades ao se planejar com técnicas conformadas é obedecer aos limites de dose para estruturas críticas propostos por grupos de estudos internacionais de Radioterapia como o Radiation Therapy Oncology Group (RTOG) ${ }^{126}$, mostrado na TABELA 5.20, e/ou artigos que relatam as doses que podem gerar complicações nestas estruturas quando seus limites são ultrapassados $^{16}$. O uso da margem de planejamento para definir o PTV faz com que o cumprimento desses limites de dose fique ainda mais difícil. Para ilustrar como o aumento do PTV influência no aumento do volume de tecido sadio na região de prescrição de dose, foram desenhados PTVs com 5, 10 e $15 \mathrm{~mm}$ de margem a partir de um CTV e o aumento do reto no PTV pode ser visualizado na FIGURA 5.21. 
Para exemplificar como pode ser verificado na prática, antes do início do planejamento do paciente, se ele é ou não elegível a certas restrições de dose, pode ser usado o operador booleano para verificar a quantidade de PTV coincidente com o volume referente à estrutura crítica que se quer poupar. $A$ TABELA 5.21 mostra um exemplo de verificação do volume de reto coincidente com o PTV para o tratamento da próstata (CTV).

TABELA 5.20 - Restrições de dose de acordo com o RTOG estudo $01-26^{126}$ para tratamento da próstata com radioterapia conformacionada e dose de prescrição de 79,2 Gy.

\begin{tabular}{|c|c|c|}
\hline Limite de órgão normal & $\begin{array}{c}\text { Não mais que 15\% do } \\
\text { volume recebe dose } \\
\text { que exceda }\end{array}$ & $\begin{array}{c}\text { Não mais que 25\% do } \\
\text { volume receba dose } \\
\text { que exceda }\end{array}$ \\
\hline $\begin{array}{c}\text { Restrição de dose para } \\
\text { bexiga }\end{array}$ & $80 \mathrm{~Gy}$ & $75 \mathrm{~Gy}$ \\
\hline $\begin{array}{c}\text { Restrição de dose para } \\
\text { reto }\end{array}$ & $75 \mathrm{~Gy}$ & $70 \mathrm{~Gy}$ \\
\hline
\end{tabular}




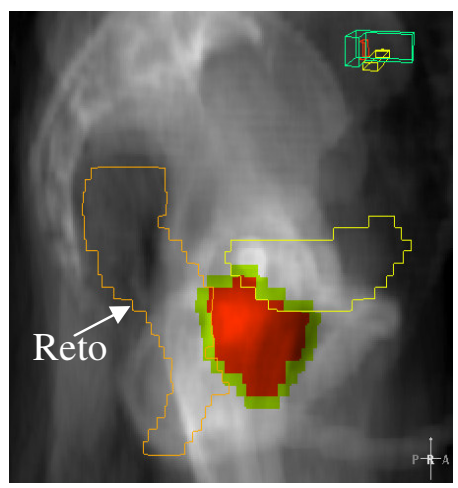

5 mm PTV

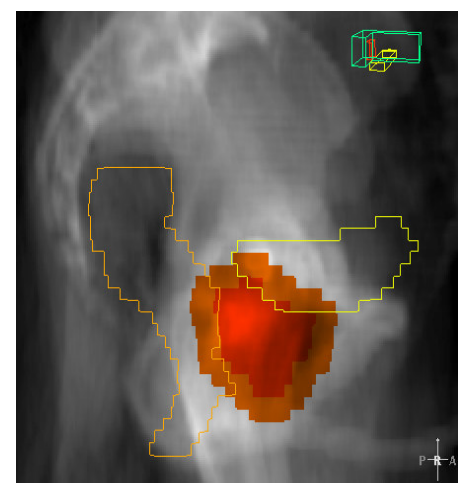

$10 \mathrm{~mm}$ PTV

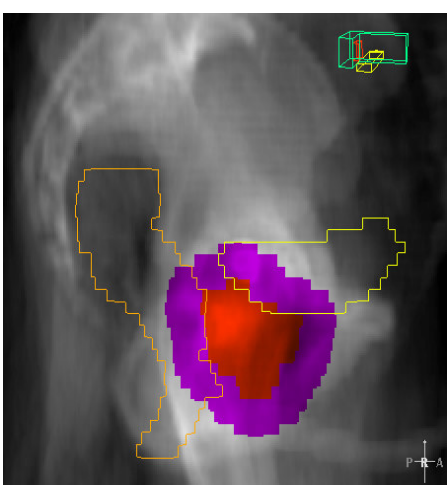

$15 \mathrm{~mm}$ PTV

FIGURA 5.21 - Aumento do PTV influencia no aumento do volume de tecido sadio na região de prescrição de dose para tratamento do alvo. Os PTVs 5, 10 e $15 \mathrm{~mm}$ estão representados pelas cores verde, laranja e roxa respectivamente.

TABELA 5.21 - Dados referentes à fração do volume de reto que foi englobado pelo PTV (volume de intersecção entre o reto e o PTV) para 10 pacientes em tratamento da próstata.

\begin{tabular}{|c|c|c|c|}
\hline \multicolumn{4}{|c|}{ \% Volume de reto no PTV } \\
\hline No paciente & PTV 5 $\mathbf{~ m m}$ & PTV 7 $\mathbf{~ m m}$ & PTV 10 $\mathbf{~ m m}$ \\
\hline 1 & 0,5 & 6,8 & 25,8 \\
\hline 2 & 5,6 & 9,5 & 19,0 \\
\hline 3 & 1,4 & 4,6 & 11,1 \\
\hline 4 & 3,8 & 8,2 & 16,2 \\
\hline 5 & 3,0 & 6,2 & 16,4 \\
\hline 6 & 4,3 & 8,8 & 20,7 \\
\hline 7 & 7,7 & 13,7 & 23,6 \\
\hline 8 & 8,6 & 14,0 & 24,9 \\
\hline 9 & 4,8 & 8,9 & 13,6 \\
\hline 10 & 1,6 & 3,8 & 9,9 \\
\hline
\end{tabular}

Os dados da TABELA 5.21 mostram que se for usado um PTV formado com $10 \mathrm{~mm}$ de margem do CTV, somente 3 pacientes poderiam ser tratados com dose de 79,2 Gy e ainda obedecer às restrições de dose sugeridas pelo RTOG 01-26 $6^{126}$ apresentados na TABELA 5.20 onde nenhum volume de reto superior a $15 \%$ do seu volume total pode receber dose superior a 75 Gy. 


\subsubsection{Resumo dos procedimentos para definição do PTV}

Resumidamente, os aspectos mais importantes na determinação de margens para definir volumes de planejamento de tratamento (PTV) baseado nos estudos deste trabalho podem ser descritos como: a) variações fisiológicas (movimentos e variações dos órgãos contidos no CTV) entre e durante as frações do tratamento; b) imprecisões e perda de reprodutibilidade no posicionamento do paciente e alinhamento do feixe durante o planejamento do tratamento e das sessões de radioterapia (erro de posicionamento).

\section{a) Variações fisiológicas}

\section{- Movimento entre-frações do tratamento}

Para quantificar essas variações foi usado um sistema de localização por imagem, ultra-som 2-D, que permitiu a localização do alvo de tratamento diariamente.

Para cada tipo de órgão deverá ser escolhido o sistema que melhor reproduz a posição deste. No caso da região do pulmão, por exemplo, o melhor seria um sistema de imagem que seguisse a freqüência da respiração para localizar o alvo em cada fase da respiração e assim sincronizar a posição no momento da aquisição da imagem para planejamento com o momento da aplicação; seguindo assim o alvo no espaço e no tempo. Um resumo da literatura para o movimento de vários órgãos durante o tratamento é mostrado no item 1.1.2.

- Movimento durante a fração de tratamento

Para quantificar essas variações deveria ser usado um equipamento que registrasse a posição do alvo em vários momentos durante o tempo de tratamento, ou seja, adquirisse imagens do alvo durante os segundos de tratamento. No caso da próstata foi utilizada informação fornecida por alguns estudos $^{127,128}$ que determinaram essa quantidade através da marcação da próstata com sementes de ouro e adquiriram imagens eletrônicas digitais durante o tratamento e outros que utilizaram imagens de ressonância magnética realizadas seguidamente durante alguns minutos para determinar qual a mobilidade do órgão. 


\section{b) Erro de posicionamento ou setup é a combinação de vários fatores como:}

- Incertezas mecânicas: estativa rotatória, colimadores, mesa e lasers. Pode ser estimado durante os testes de garantia de qualidade realizados no acelerador;

- Incertezas dosimétricas também podem ser estimadas durante os testes de garantia de qualidade do equipamento (calibração) e do planejamento (no caso do IMRT a verificação da dose liberada é realizada por paciente);

- $\quad$ Erro na transferência de dados do CT e simulador à unidade de tratamento: a verificação é realizada utilizando um objeto simulador com estruturas geométricas de densidades eletrônicas diferentes; ele é então submetido à tomografia computadorizada, desenho de suas estruturas (contornos) na estação de planejamento e transferência das imagens radiográficas digitais obtidas neste para o sistema de tratamento e/ou para o sistema de localização diária (ex: ultra-som). A partir das imagens transferidas verifica-se o volume e a posição das estruturas correspondem às reais especificadas no objeto simulador. No nosso caso essas variações podem gerar erros de 2 a $5 \mathrm{~mm}$, dependendo da espessura do corte usada para aquisição das imagens tomográficas (quanto menor maior a precisão);

- Variações no posicionamento do paciente dependem do tipo de imobilizador e fatores humanos. Sua natureza pode ser de origem sistemática e/ou randômica.

Todas essas variações geométricas possíveis que acontecem no decorrer da radioterapia, ao serem analisadas em conjunto, como mostra a FIGURA 5.16, se distribuem normalmente e, portanto, podem ser divididas em 2 grupos: randômicas e sistemáticas.

> Variações randômicas: movimento e/ou deformação de estruturas do paciente (enchimento da bexiga, gás no intestino, variações nos pulmões devido à respiração e deslocamento do diafragma), movimento do paciente e localização diária (setup);

Variações sistemáticas: mudanças na posição do tratamento, erro na técnica, redução do tumor, perda ou ganho de peso do paciente. 
Portanto, ao se obter uma distribuição gaussiana dos desvios sofridos por um órgão, seja ele o alvo ou a estrutura de risco, pode-se identificar essas variações e conhecer melhor a sua origem.

Após a determinação da margem para gerar o PTV baseado nas variações geométricas descritas, foram avaliados os efeitos possíveis que ela pode causar na distribuição de dose, verificando os seguintes aspectos:

$>\quad$ Se a margem é adequada para cobrir o volume clínico com a dose prescrita;

> Se a proximidade dela à superfície da pele gera variação de dose em estruturas críticas vizinhas;

> Se a proximidade do PTV à pele gera um aumento de dose e se a variação de dose depende da técnica de tratamento utilizada (IMRT ou convencional);

$>\quad$ Se o aumento de margem dada ao CTV produz um aumento da dose periférica no paciente quando se usa técnica conformacionada com modulação de feixe (IMRT) e técnica convencional (3 campos);

$>$ Se o deslocamento do isocentro de tratamento, através do reposicionamento diário do sistema de coordenadas no órgão com ultra-som 2-D, altera a distribuição de dose;

> E, por fim, sempre que possível, verificar antes de iniciar o planejamento, a possibilidade de seguir restrições de dose nos órgãos de risco, adjacentes ao volume alvo, verificando se o volume de estrutura crítica, coincidente com o PTV, não ultrapassa a restrição de dose. 


\section{CONCLUSÕES}

- O filme X-Omat $\mathrm{V}$ apresentou resposta em termos de dose, na dosimetria para IMRT, mais acurada que o EDR-2 com uma incerteza máxima de 15\% e 49\% nas regiões de doses baixas respectivamente.

- O MOSFET é um dosímetro pequeno e fácil de ser utilizado, especialmente quando empregado na dosimetria in vivo, sendo sua maior vantagem apresentar resposta logo após o término da irradiação. Este dosímetro também se mostrou bastante útil e confiável para verificação de tratamentos com IMRT.

- O estudo das incertezas com relação à localização diária de pacientes que utilizam máscaras termoplásticas como imobilizadores da região da cabeça e pescoço mostrou variações na posição do isocentro de tratamento de $\pm 4,5 \mathrm{~mm}$ no sentido crânio-caudal (ou superior-inferior), que é bem maior (quase o dobro) do encontrado por Gross et al. ${ }^{44}(2,69 \mathrm{~mm})$ com técnica estereotáxica.

- O estudo do efeito do deslocamento do isocentro mostrou a importância do acréscimo de margem no CTV para garantir o tratamento adequado do alvo, e também mostrou como a variação diária no isocentro de tratamento, ao posicionar o paciente na máquina de tratamento, pode causar um aumento de dose maior que o nível de tolerância dos órgãos sadios, como visto no caso da medula espinhal.

- Para os planos realizados com IMRT e planejamento inverso, a dose na superfície da pele do paciente aumentou em função da proximidade do PTV a esta superfície. A relação linear entre as medidas da dose na superfície para planos com PTV 10 versus PTV 5 e PTV pele é um indicativo que o aumento da dose na superfície não é uma função da localização da medida ou forma do PTV, mas somente uma função da profundidade do PTV em relação à pele.

- Ao contrário do que sugere Lee et al. ${ }^{129}$, este trabalho mostrou que o aumento de toxicidade na pele pode ser devido à proximidade do PTV à ela, fazendo com que o algorítmo de otimização ao cobrir o PTV com a dose prescrita, faça com 
que a pele também receba uma dose alta, que está de acordo com o estudo de Thomas et al. ${ }^{130}$.

- As doses na periferia do campo de tratamento, principalmente nas regiões mais distantes como as gônadas, foi bem maior (praticamente o dobro) quando se utilizou a técnica de IMRT, o que pode ser explicado pelo aumento da radiação de fuga da máquina de tratamento na sala, já que o tempo de radiação no caso de tratamento da cabeça e pescoço com IMRT ( 1566 UM ou 4,9 min) é muito maior que o tempo de radiação utilizando técnica 3-D convencional ( 1,3 min).

- Só foi possível avaliar o movimento do órgão entre as frações de tratamento para o caso da próstata, pois era o único tratamento realizado no MUHC onde se empregava a radioterapia guiada por imagem (IGRT) através do uso do ultra-som (BAT) acoplado na máquina de tratamento para localização diária do alvo. Portanto, quando um sistema para fazer IGRT não for empregado, há necessidade de se gerar um PTV com margem uniforme de $15 \mathrm{~mm}$ para que 0 alvo (CTV) seja englobado em pelo menos 95\% das frações de tratamento. Isto mostra a importância de se localizar o alvo diariamente (IGRT).

- Ao se utilizar os valores obtidos do estudo de próstata para os erros sistemáticos, $\Sigma$, e randômicos, $\sigma$, na equação proposta por Stroom et al. ${ }^{97}$ chegase a resultados muito próximos aos obtidos da margem total de PTV requerida para conter $95 \%$ da nossa amostra, o que torna esta equação útil para ser empregada na prática clínica para determinação de margem para o PTV nos casos de próstata.

- Ao realizar a simulação de um deslocamento exagerado do isocentro de tratamento para reposicionar um paciente, cujo alvo se encontra deslocado $3 \mathrm{~cm}$ do isocentro planejado, pôde-se verificar uma variação máxima de dose de 2,5\%, que é aceitável para a liberação do tratamento. Portanto, o IGRT com ultra-som se mostrou perfeitamente viável e o alvo foi aceitávelmente coberto pela dose prescrita, mesmo em casos de reposicionamento do paciente. 
- Em suma, definir uma margem adequada para o PTV é essencial para garantir a cobertura do alvo durante toda a radioterapia conformada, mas devem ser tomados alguns cuidados como a verificação do efeito da margem na dose para o paciente, que é tão relevante quanto a própria definição do PTV, uma vez que a localização ou o tamanho da margem podem gerar doses maiores que a de tolerância dos órgãos sadios, que se localizam próximo ou distantes ao campo de tratamento. Também, se deve levar em conta na definição do PTV a técnica de tratamento escolhida, pois como visto há diferenças de doses para mesmos PTVs e diferentes técnicas.

Este trabalho identificou diversos aspectos que precisam ser analisados ao se acrescentar margens de planejamento ao CTV; alguns estão relacionados ao Serviço de Radioterapia como: o erro de posicionamento ou localização que está relacionado ao tipo de imobilização usada no paciente, posicionamento do paciente no equipamento de tratamento e fatores humanos. Outros aspectos que precisam ser analisados estão relacionados ao movimento de órgãos durante 0 tratamento, que podem ser extraídos da literatura, quando o estudo em questão mostrar uma distribuição estatística normal. Nosso objetivo, além de tentar descrever um método para a quantificação dessas margens, foi o de abranger as implicações que existem, em termos de variações na distribuição de dose próxima ao alvo e na periferia, ao se colocar margens de planejamento de tratamento. Essas margens devem garantir que a dose prescrita atinja adequadamente 0 CTV, mas ao mesmo tempo deve haver um comprometimento em se avaliar o aumento de dose em tecidos sadios com a técnica utilizada.

Como atividades futuras propõem-se estudar: o PTV para a região do pulmão, que não pôde ser concluída neste trabalho pois há necessidade de um grande número de pacientes; estudar o TCP e NTCP para os sítios de tratamento avaliados neste trabalho e em outros em que a incerteza na localização seja grande; avaliar as diferenças entre as otimizações em diferentes TPS com planejamento inverso. Assim como Stroom et al. ${ }^{146}$ tem mostrado as limitações do PORV na prática clínica, um estudo importante é avaliar as implicações em se usar o PORV e PTV nos tratamentos com planejamento inverso e modulação de feixe. 


\section{APÊNDICE A - DEFINIÇÕES DE TERMOS ESTATÍTICOS E ANÁLISE ESTATÍSTICA PARA DOSÍMETROS E DADOS DE IMAGEM ${ }^{3,95,96,131}$}

\section{A-1- Precisão, exatidão e erro}

A precisão de medidas dosimétricas específica a reprodutibilidade das medidas sob condições similares e pode ser estimada dos dados obtidos em medidas repetidas.

A exatidão de medidas dosimétricas é a proximidade do valor esperado ao "valor verdadeiro" da grandeza medida. Os resultados de medidas não podem ser absolutamente exatos e a inexatidão do resultado medido é caracterizado como incerteza. A incerteza é um parâmetro que descreve a dispersão dos valores medidos de uma grandeza; ela é avaliada por métodos estatísticos (tipo A) ou por outros métodos (tipo B), não tem sinal e geralmente é assumida como simétrica.

$O$ erro de medidas é a diferença entre os valores medidos de uma grandeza e o valor verdadeiro desta grandeza. Um erro tem valor numérico e um sinal. Tipicamente, os erros medidos não são conhecidos exatamente, mas eles são estimados da melhor forma possível e quando for viável, correções de compensação são introduzidas. Após a aplicação de todas as correções conhecidas, o valor esperado para os erros deveriam ser zero e as únicas grandezas de relevância são as incertezas ${ }^{3}$.

\section{A-2- Incerteza padrão tipo A}

Se uma medida de uma grandeza dosimétrica $x$ é repetida $\mathrm{N}$ vezes, então a melhor estimativa para $x$ é $\bar{x}$, o valor médio aritmético de todas as medidas $x_{i}$ :

$$
\bar{x}=\frac{1}{N} \sum_{i=1}^{N} x_{i}
$$

O desvio padrão $\sigma_{x}$ caracteriza a incerteza média para um resultado individual $x_{i}$ e é dado por:

$$
\sigma_{x}=\sqrt{\frac{1}{N-1} \sum_{i=1}^{N}\left(x_{i}-\bar{x}\right)^{2}}
$$

O desvio padrão do valor médio é dado por:

$$
\sigma_{\bar{x}}=\frac{1}{\sqrt{N}} \sigma_{x}=\sqrt{\frac{1}{N(N-1)} \sum_{i=1}^{N}\left(x_{i}-\bar{x}\right)^{2}}
$$


A incerteza do tipo $\mathrm{A}$, denominada $u_{A}$, é definida como o desvio padrão do valor médio, $u_{A}=\sigma_{\bar{x}}$. Ela é obtida através de repetidas medidas e em princípio poderia ser reduzida através do aumento do número de medidas.

\section{A-3- Incerteza padrão tipo B}

As incertezas padrão tipo $\mathrm{B} u_{B}$ não podem ser estimadas através da repetição de medidas. Elas são suposições inteligentes ou julgamentos científicos de incertezas não estatísticas associadas a uma medida. Elas incluem influências no processo de medida, aplicação de fatores de correção ou dados físicos provenientes da literatura.

Geralmente se assume que as incertezas do tipo B possuem uma distribuição de probabilidade tal como uma normal (Gaussiana) ou uma distribuição retangular (probabilidade igual em qualquer lugar dentro de dados limites). Elas podem ser derivadas através da estimativa do limite além do qual o valor do fator não irá permanecer, e uma fração deste limite é tomado como c. A fração é escolhida de acordo com a distribuição assumida.

\section{A-4- Incerteza combinada e expandida}

A equação que determina uma grandeza dosimétrica $Q$ num ponto $\mathrm{P}$ é do tipo:

$$
Q_{P}=M \prod_{i=1}^{N} F_{i}
$$

em que $M$ é a leitura proveniente do sistema dosimétrico e $F_{i}$ é o coeficiente de correção ou conversão.

A incerteza padrão combinada $u_{C}$ associada com a grandeza $Q$ é a soma quadrática das incertezas do tipo $\mathrm{A}\left(u_{A}\right)$ e do tipo $\mathrm{B}\left(u_{A}\right)$ :

$$
u_{C}=\sqrt{u_{A}^{2}+u_{B}^{2}}
$$

A incerteza combinada é assumida exibir uma distribuição normal e é multiplicada por um fator de cobertura, $k$, para se obter a incerteza expandida $U=k u_{C}$. $\mathrm{O}$ resultado da grandeza $Q$ é então expressa por:

$$
Q=Q_{P} \pm U
$$


A incerteza expandida $U$ com um fator de cobertura $k=2$, corresponde a $95 \%$ do nível de confiança e é frequentemente usada para representar uma incerteza total que está relacionada a acurácia da medida da grandeza $Q$.

\section{A-5- Histograma de Frequências}

O histograma é formado por um conjunto de retângulos justapostos cujas bases se localizam sobre o eixo horizontal (x), onde são representados os intervalos de classe numa escala contínua. As frequências são representadas no eixo vertical (y) começando de zero. As alturas dos retângulos devem ser proporcionais às frequências, absoluta ou relativa, das classes. Num histograma, a sua área é proporcional à soma das frequências ${ }^{96}$.

\section{A-6- Histogramas de dose-volume (DVH)}

Um plano de tratamento 3-D consiste de informação da distribuição de dose sobre uma matriz de pontos sobre a anatomia do paciente. Os DVHs resumem a informação contida na distribuição de dose 3-D e são uma ferramenta extremamente importante para a avaliação quantitativa dos planos de tratamento. O DVH representa uma distribuição de frequência de valores de dose dentro de um volume definido que poderá ser o PTV ou um órgão específico ao seu redor. Ao invés de mostrar a frequência, os DVHs são geralmente apresentados na forma de porcentagem de volume do volume total, disposto na ordenada, e a dose, na abscissa ${ }^{3}$.

Normalmente são utilizadas dois tipos de DVH: a) DVH direto ou diferencial; b) DVH cumulativo ou integral.

\section{A-6-1- Histograma de dose-volume direto ou diferencial}

Para criar um DVH direto, o computador soma o número de voxels com uma dose média dentro de um dado limite e mostra o volume resultante (ou a porcentagem do volume de órgão total) como uma função da dose. Um exemplo de um DVH direto para um volume alvo é mostrado na FIGURA A.1a. Um DVH ideal para um dado volume alvo deveria ser uma única coluna indicando que $100 \%$ do volume recebeu a dose prescrita. Para uma estrutura crítica, o DVH deve conter vários picos, indicando que partes diferentes do órgão receberam diferentes doses. Um 
exemplo de um DVH para o reto no tratamento da próstata, usando a técnica de quatro campos, é mostrado na FIGURA A.1b.

(a)

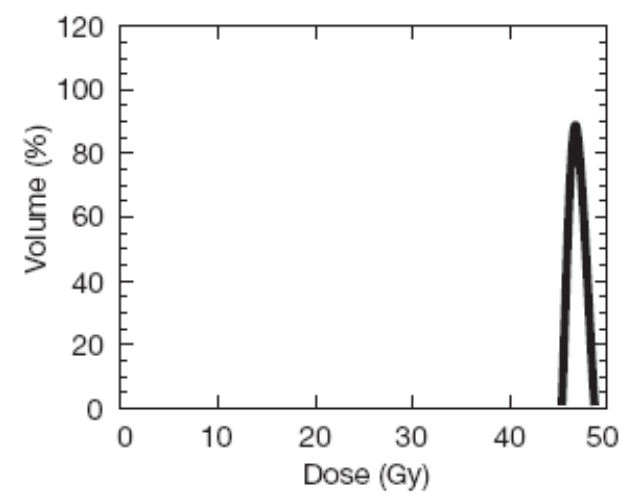

(b)

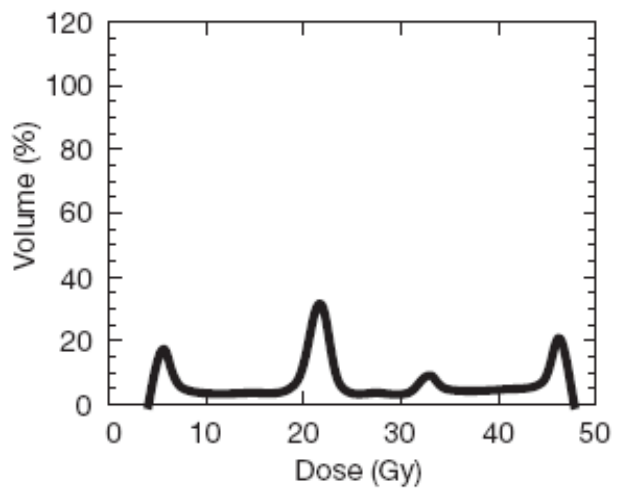

FIGURA A.1 - DVHs diferencial para um plano de tratamento da próstata com quatro campos para (a) o volume alvo e (b) o reto. O DVH diferencial ideal deveria ser picos infinitamente estreitos na dose alvo para o PTV e a 0 Gy para a estrutura crítica ${ }^{3}$.

\section{A-6-2- Histograma de dose-volume cumulativo}

Para responder questões como: "Que parte do alvo é englobado pela isodose de 95\%?" que são igualmente relevantes na interpretação de um planejamento de tratamento 3-D, será necessário determinar a área sob a curva para todos os níveis de dose. Por esta razão o DVH cumulativo é mais popular que o diferencial. O computador calcula o volume do alvo (ou estrutura crítica) que recebe no mínimo a dose dada e mostra este volume (ou porcentagem do volume) versus a dose. Todo DVH cumulativo inicia no $100 \%$ do volume para 0 Gy, uma vez que todo o volume recebe no mínimo nenhuma dose.

Para os mesmos órgãos indicados na FIGURA A.1a e A.1b, a FIGURA A.2a mostra o correspondente DVH cumulativo (ambas estruturas são mostradas agora no mesmo gráfico). 
(a)

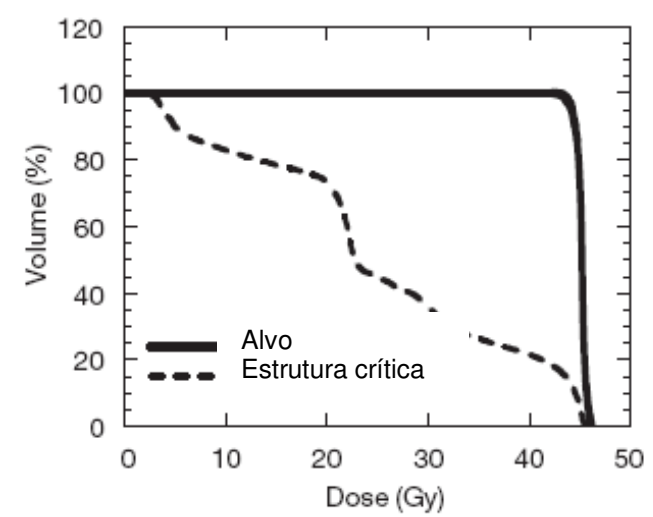

(b)

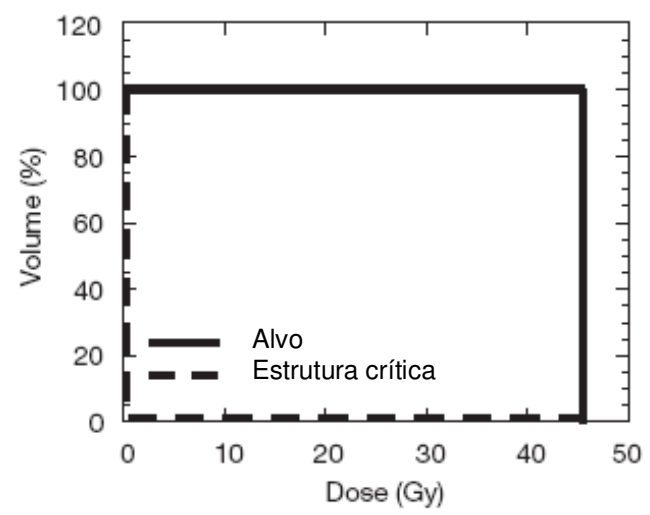

FIGURA A.2 - (a) DVHs cumulativo para o mesmo plano de tratamento da próstata com quatro campos usado na FIGURA A.1. Os DVHs cumulativo ideal são mostrados em (b) ${ }^{3}$.

\section{A-7- Estatística descritiva}

As medidas de posição, também conhecidas como medidas de tendência central, indicam os valores em torno dos quais ocorre a maior concentração do fenômeno quantitativo em estudo. A média aritmética, a moda e a mediana são as três medidas de tendência central.

\section{A-7-1- Média aritmética}

A média da amostra é representada pelo símbolo $\bar{x}, \mathrm{x}$ é o valor de cada ítem do grupo e $\mathrm{n}$ é a grandeza de ítens. Calcula-se segundo a equação 7.

$$
\bar{x}=\frac{\sum x}{n}
$$

\section{A-7-2- Mediana}

A mediana é o valor que ocupa a posição central quando todos os ítens do grupo estão dispostos, em termos de valor, em orgem crescente ou decrescente de magnitude. Para os valores: $76,78,82,84,86,90,90,90,98$ a mediana é 86 . 


\section{A-7-3- Moda}

A moda é o valor que ocorre com maior frequência em um conjunto de valores. É uma medida de dominância. Para os valores: 76, 78, 82, 84, 86, 90, 90, 90, 98 a moda é 90.

\section{A-7-4- Dispersão em variáveis quantitativas}

As medidas de dispersão indicam o grau de afastamento de um conjunto de números em relação à sua média.

\section{A-7-5- Variância}

As medidas de tendência central são insuficientes para descrever uma amostra adequadamente. É necessário também descrever em que medida os dados de observações estão agrupados ao redor da média. A variância mede a dispersão dos dados de observações de uma amostra em relação à respectiva média.

A variância amostral, simbolizada por $s^{2}$, é calculada pela fórmula:

$$
s^{2}=\frac{\sum(x-\bar{x})^{2}}{n-1}
$$

em que x são as observações da amostra, e n, o número total de observações. A variância é a soma dos quadrados dos desvios em relação à média dividida pelo número de observações da amostra menos uma.

\section{A-7-8- Desvio-padrão}

O desvio-padrão é a mais importante medida de dispersão dos valores individuais ao redor da média. Apresenta a vantagem sobre a variância de utilizar a mesma unidade de medida de dados que as empregadas na tomada das observações. É representado por s ou SD e calculado por:

$$
\begin{aligned}
& s=\sqrt{\frac{\sum(x-\bar{x})^{2}}{n-1}} \text { ou } \\
& s=\sqrt{\frac{\sum x^{2}-\frac{\left(\sum x\right)^{2}}{n}}{n-1}}
\end{aligned}
$$

O desvio-padrão é, portanto, a raiz quadrada da variância. Para os dados de medição, especialmente em grandes amostras, o desvio-padrão indica os limites 
prováveis dentro dos quais se situam certas proporções das observações. Assim, verifica-se que cerca de $68 \%$ das observações da amostra estarão entre os limites $\bar{x} \pm s ; 95 \%$ das observações, entre $\bar{x} \pm 2 s$; e $99 \%$ das observações, entre $\bar{x} \pm 3 s$.

\section{A-7-9- Coeficiente de variação}

O coeficiente de variação (CV) é a magnitude relativa do desvio-padrão expresso em porcentagem da média.

$$
C V=\frac{s \times 100}{\bar{x}}
$$

\section{A-8 Distribuição Normal}

Diversas variáveis contínuas seguem um padrão em suas distribuições de frequência que pode ser descrito como a distribuição normal de probabilidade. Sob o ponto de vista gráfico, a distribuição normal de probabilidade é descrita como uma curva em forma de sino, simétrica em relação ao ponto de frequência máxima (média). É também chamada curva de distribuição normal ou de Gauss e representa a distribuição de frequências da população. A curva normal é considerada a forma limite do histograma da distribuição de frequências da amostra. Muitos fenômenos naturais se apresentam distribuídos, aproximadamente, segundo o modelo da curva normal.

A distribuição normal é descrita por dois parâmetros: $\mu$ e $\sigma$, onde $\mu$ representa a média da população e $\sigma$ é o desvio-padrão da população. A curva normal apresenta as seguintes características: a média, a mediana e a moda coincidem; a curva é simétrica ao redor da média; as extremidades da curva, em ambos os lados da média se extendem cada vez mais próximas da linha da base (abscissa) sem jamais tocá-la.

Em estatística, o termo probabilidade é uma outra expressão para frequência relativa. Diz-se que uma observação, tirada ao acaso de uma população normal, tem uma probabilidade igual a 0,95 de estar contida num intervalo $\mu \pm 2 \sigma$, ou, que tem uma probabilidade igual a 0,05 de que seu valor esteja fora desse intervalo. A partir dessas considerações, são obtidas as seguintes informações: $68,26 \%$ das medidas em uma população normal estão no intervalo de $\mu \pm \sigma ; 95,44 \%$ das medidas em uma população normal estão no intervalo de $\mu \pm 2 \sigma ; 99,74 \%$ das 
medidas em uma população normal estão no intervalo de $\mu \pm 3 \sigma$; ilustrado na FIGURA A.3.

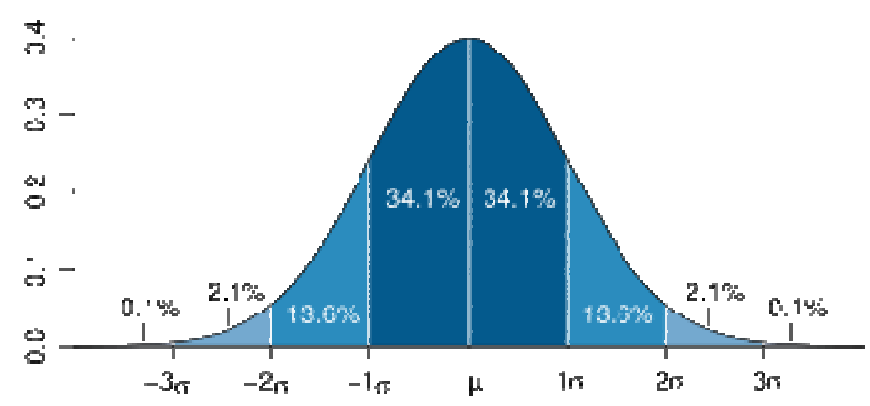

FIGURA A.3 - Curva normal. As percentagens são as áreas sob a curva descritas pelo múltiplos dos desvios-padrão.

\section{A-8-1- Teste de Normalidade (Shapiro-Wilk) ${ }^{95}$}

O teste Shapiro-Wilk testa a hipótese nula que uma amostra $x_{1}, \ldots, x_{n}$ vem de uma população distribuída normalmente. O teste estatístico é:

$$
W=\frac{\left(\sum_{i=1}^{n} a_{i} x_{(i)}\right)^{2}}{\sum_{i=1}^{n}\left(x_{i}-\bar{x}\right)^{2}}
$$

em que

$\mathrm{x}_{(\mathrm{i})}$ é o i de estatística ordem (menor número na amostra);

$\bar{x}=\left(x_{1}+\ldots .+x_{n}\right) / n$ é a média da amostra;

as contantes $a_{i}$ são dadas por

$$
\left(a_{1}, \ldots, a_{n}\right)=\frac{m^{T} V^{-1}}{\left(m^{T} V^{-1} V^{-1} m\right)^{1 / 2}}
$$

em que

$m=\left(m_{1}, \ldots, m_{n}\right)^{\top}$ e $m_{1}, \ldots, m_{n}$ são os valores esperados de uma amostra de uma distribuição normal padrão, e $\mathrm{V}$ é a matriz de covariância. $\mathrm{O}$ teste rejeita a hipótese nula se $\mathrm{W}$ for muito pequeno.

\section{A-9- Distribuição t de Student}

É uma distribuição teórica de probabilidades, especificamente direcionada para trabalhar com médias de amostras pequenas quando se desconhece $\sigma$. 
O valor de t é a medida do desvio entre a média $\bar{x}$, estimada a partir de uma amostra aleatória de tamanho $\mathrm{n}$, e a média $\mu$ da população, usando o erropadrão (EP) como unidade de medida:

$$
t=\frac{\bar{x}-\mu}{s / \sqrt{n}},
$$

em que $E P=s / \sqrt{n}$.

A distribuição de $t$ tem como principais aplicações: a comparação entre duas médias pelo teste $\mathrm{t}$; e estimação dos intervalos de confiança para a média da população.

\section{A-10- Intervalo de Confiança para a média populacional}

O intervalo de confiança (IC) é delimitado por dois limites numéricos, entre os quais se situa o valor verdadeiro do parâmetro, com um nível de confiança (NC) especificado, em geral fixado em $95 \%$.

O intervalo de confiança associado a um determinado nível de confiança, para a média populacional $\mu$, quando o desvio-padrão, $\sigma$, é conhecido, é calculado por:

$$
\mathrm{IC}_{\mathrm{NC}} \text { para } \mu=\bar{x} \pm z_{N C} \cdot \frac{\sigma}{\sqrt{n}}
$$

O intervalo de confiança de $95 \%$ para $\mu$, é dado por:

$$
\mathrm{IC}_{95 \%} \text { para } \mu=\bar{x} \pm 1,96 \cdot \frac{\sigma}{\sqrt{n}}
$$

O valor de 1,96 foi obtido a partir da tabela de z para $95 \%$ (47,5\% de cada lado da curva, a partir do centro).

Para um intervalo de confiança de $99 \%$ :

$$
\text { IC }_{99 \%} \text { para } \mu=\bar{x} \pm 2,58 \cdot \frac{\sigma}{\sqrt{n}}
$$

O valor de 2,58 foi obtido a partir da tabela de z para 99\% (49,5\% de cada lado da curva, a partir do centro).

\section{A-11- Correlação e coeficiente de correlação}

A correlação é uma medida do grau de dependência linear entre duas variáveis ou entre uma medida da intensidade da associação dessas variáveis. O coeficiente 
linear de Pearson ( $r$ ) é a medida mais conhecida para o estudo da correlação entre duas variáveis quantitativas e é obtido por:

$$
r=\frac{\sum x_{i} y_{i}-\frac{\sum x_{i} \sum y_{i}}{n}}{\sqrt{\left[\sum x_{i}^{2}-\frac{\left(\sum x_{i}\right)^{2}}{n}\right]}\left[\sum y_{i}^{2}-\frac{\left(\sum y_{i}\right)^{2}}{n}\right]}
$$

O coeficiente de correlação $r$ é um número absoluto, independente das unidades usadas para medir as variáveis $\mathrm{x}$ e y. Ele pode variar de $-1 \mathrm{a}+1$. A sua correta interpretação envolve a consideração dos seguintes fatores:

- o valor da probabilidade (P). Toda correlação apresenta uma probabilidade de ter ocorrido devido ao acaso. Quando $\mathrm{P}<0,05$, considera-se que a correlação é estatisticamente significativa. Caso contrário é como se não houvesse correlação; - o sinal da correlação. Uma correlação positiva indica que as duas variáveis tendem a aumentar ou diminuir concomitantemente. Uma correlação negativa diz que, quando uma variável tende a aumentar de valor, a outra tende a diminuir;

- o valor absoluto da correlação (r). Mostra a intensidade da relação linear entre as duas variáveis. $O$ valor 0 indica total ausência de relação linear, enquanto que o valor 1 indica uma relação linear perfeita.

\section{A-12- Coeficiente de determinação}

Representa a fração da variabilidade que é compartilhada entre as duas variáveis, ou seja é a percentagem de variação explicada por uma das variáveis em relação a outra. É dado pelo valor de r elevado ao quadrado $\left(r^{2}\right)$. $O$ valor de $r^{2}$ varia de 0 a 1. Quanto maior for o valor de $r^{2}$ melhor será o ajuste da reta aos dados.

\section{A-13- Propagação de erros}

\section{A-13-1- Variáveis correlacionadas}

lei geral

$$
\begin{array}{ll}
\text { Função: } & \mathrm{u}\left(\mathrm{x}_{1}, \mathrm{x}_{2}, \ldots, \mathrm{x}_{\mathrm{n}}\right) \\
\text { Variáveis: } & \mathrm{x}_{1}, \mathrm{x}_{2}, \ldots, \mathrm{x}_{\mathrm{n}} \\
\text { Desvios Padrões: } & \sigma_{1}, \sigma_{2}, \ldots, \sigma_{\mathrm{n}}
\end{array}
$$


Variância : $\quad \operatorname{var}\left(\mathrm{x}_{\mathrm{i}}\right)=\sigma_{\mathrm{i}}^{2}$,

Covariância entre as variáveis $i$ e $j: \operatorname{cov}\left(x_{i} x_{j}\right)$,

$$
\sigma_{u}^{2}=\sum_{i, j}^{n}\left(\frac{\partial u}{\partial x_{i}}\right)\left(\frac{\partial u}{\partial x_{j}}\right) \operatorname{cov}\left(x_{i} x_{j}\right)
$$

onde

$$
\begin{aligned}
& \operatorname{cov}\left(x_{i} x_{j}\right)=\lim _{N \rightarrow \infty} \frac{1}{N} \sum_{k=1}^{N}\left[\left(x_{i}-\overline{x_{i}}\right)\left(x_{j}-\overline{x_{j}}\right)\right]_{k} \\
& \sigma_{x_{i}}^{2}=\operatorname{var}\left(x_{i}\right)=\operatorname{cov}\left(x_{i} x_{i}\right)=\lim _{N \rightarrow \infty} \frac{1}{N} \sum_{k=1}^{N}\left[\left(x_{i}-\overline{x_{i}}\right)^{2}\right]_{k}
\end{aligned}
$$

\section{Caso 1: soma entre variáveis}

$$
\begin{gathered}
u=x_{1}+x_{2} \\
\sigma_{u}=\sqrt{\sigma_{1}^{2}+\sigma_{2}^{2}+2 \operatorname{cov}\left(x_{1} x_{2}\right)}
\end{gathered}
$$

Caso 2: diferença entre variáveis

$$
\begin{gathered}
u=x_{1}-x_{2} \\
\sigma_{u}=\sqrt{\sigma_{1}^{2}+\sigma_{2}^{2}-2 \operatorname{cov}\left(x_{1} x_{2}\right)}
\end{gathered}
$$

Caso 3: multiplicação entre variáveis

$$
\begin{gathered}
u=x_{1} x_{2} \\
\frac{\sigma_{u}}{u}=\sqrt{\left(\frac{\sigma_{1}}{x_{1}}\right)^{2}+\left(\frac{\sigma_{2}}{x_{2}}\right)^{2}+2 \frac{\operatorname{cov}\left(x_{1} x_{2}\right)}{x_{1} x_{2}}}
\end{gathered}
$$


Caso 4: divisão entre variáveis

$$
\begin{gathered}
u=x_{1} / x_{2} \\
\frac{\sigma_{u}}{u}=\sqrt{\left(\frac{\sigma_{1}}{x_{1}}\right)^{2}+\left(\frac{\sigma_{2}}{x_{2}}\right)^{2}-2 \frac{\operatorname{cov}\left(x_{1} x_{2}\right)}{x_{1} x_{2}}}
\end{gathered}
$$

\section{C-13-2- Variáveis independentes (não-correlacionadas)}

lei geral

$$
\begin{array}{ll}
\text { Função: } & \mathrm{u}\left(\mathrm{x}_{1}, \mathrm{x}_{2}, \ldots, \mathrm{x}_{\mathrm{n}}\right) \\
\text { Variáveis: } & \mathrm{x}_{1}, \mathrm{x}_{2}, \ldots, \mathrm{x}_{\mathrm{n}} \\
\text { Desvios Padrões: } & \sigma_{1}, \sigma_{2}, \ldots, \sigma_{\mathrm{n}} \\
\sigma_{u}{ }^{2}=\sum_{i=1}^{n}\left(\frac{\partial u}{\partial x_{i}}\right)^{2} \sigma_{i}^{2} &
\end{array}
$$

Caso 1: somas ou diferenças

$$
\begin{gathered}
u=x_{1}+x_{2} \text { ou } u=x_{1}-x_{2} \\
\sigma_{u}=\sqrt{\sigma_{1}^{2}+\sigma_{2}^{2}}
\end{gathered}
$$

Caso 2: multiplicação por uma constante

$$
\sigma_{u}=A \sigma_{x} \quad u=A x
$$

Caso 3: multiplicação ou divisão entre variáveis

$$
\begin{aligned}
& u=x_{1} x_{2} \quad \text { ou } \quad u=x_{1} / x_{2} \\
& \frac{\sigma_{u}}{u}=\sqrt{\left(\frac{\sigma_{1}}{x_{1}}\right)^{2}+\left(\frac{\sigma_{2}}{x_{2}}\right)^{2}}
\end{aligned}
$$




\section{APÊNDICE B - Estudo da distribuição de dose nas técnicas convencional, conformacional e IMRT com planejamento inverso para os casos de cabeça e pescoço}

Este estudo ilustra as diferenças em termos de distribuição de dose nos tecidos sadios e nos volumes de tratamento empregando as técnicas de tratamento convencional, conformacional e IMRT com planejamento inverso para pacientes em tratamento de cabeça e pescoço (ENT), onde são incluídos o GTV, os linfonodos cervicais e os supra-claviculares (CTV). Este estudo foi importante para mostrar porque foi decidido tratar com IMRT todos os pacientes ENT.

Os planejamentos com as técnicas de tratamento convencional e conformacional foram realizadas com o sistema de planejamento tridimensional (TPS) Eclipse e os planejamentos em que foram empregados a técnica de tratamento IMRT foi realizada no sistema de planejamento tridimensional CORVUS.

O simulador antropomórfico RANDO foi mapeado por um tomógrafo computadorizado de simulação e sua imagem foi enviada para o sistema de planejamento AcQsim, onde foram realizados os desenhos dos volumes de interesse, GTV e CTV, e estruturas críticas como medula e parótidas, para ambos sistemas de planejamento, Eclipse e CORVUS.

No CORVUS foram realizados 2 planos de tratamento: 1) técnica IMRT com planejamento inverso com cinco campos oblíquos e coplanares (gantry a $250^{\circ}$, $\left.325^{\circ}, 0^{\circ}, 35^{\circ}, 110^{\circ}\right)$; 2) técnica IMRT com planejamento inverso com sete campos oblíquos e coplanares (gantry a $205^{\circ}, 255^{\circ}, 310^{\circ}, 0^{\circ}, 105^{\circ}, 155^{\circ}$ ).

No Eclipse foram realizados 3 planos de tratamento: 1) técnica convencional com dois campos paralelos e opostos para irradiar todos os alvos, GTV e CTV e depois 3 campos oblíquos para complementar dose no GTV (boost); 2) técnica conformacional utilizando cinco campos coplanares com colimador multi-lâminas (gantry $250^{\circ}, 325^{\circ}, 0^{\circ}, 35^{\circ}, 110^{\circ}$ ), e 3 campos oblíquos para complementar a dose no GTV; 3) técnica conformacional utilizando cinco campos oblíquos e coplanares (gantry $250^{\circ}, 325^{\circ}, 0^{\circ}, 35^{\circ}, 110^{\circ}$ ) e 3 campos oblíquos para complementar a dose no GTV, todos os campos utilizando blocos de proteção de cerrobend ao invés do MLC para proteger tecido sadio.

As doses prescritas foram 50 Gy para o CTV e 60 Gy para o GTV e foi usado feixe de fótons de $6 \mathrm{MV}$ para todos os planos. 
Os histogramas de dose-volume (DVH) para dose mínima, máxima e média recebida pelos volumes de interesse estudados são apresentados nas FIGURAS B.1, B.2 e B.3 respectivamente. As estruturas críticas estudadas foram tecido sadio total no paciente (Tecido), lente ocular esquerda (LE), lente ocular direita (LD), quiasma óptico (QO), nervo óptico esquerdo (NOE), nervo óptico direito (NOD), medula espinhal (ME), parótida esquerda (PE) e parótida direita (PD).

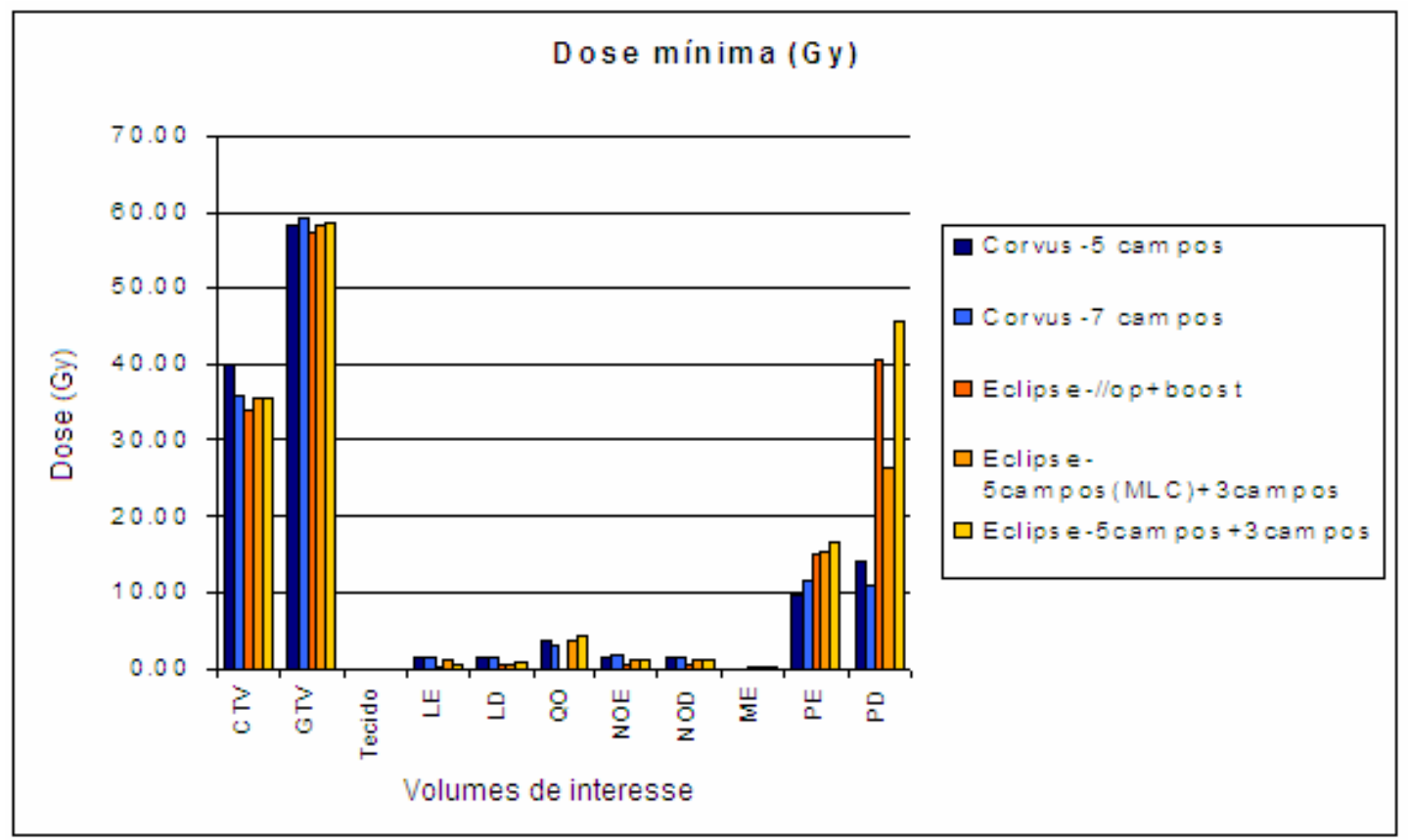

FIGURA B.1 - Comparação entre DVHs de planejamentos de tratamentos feitos com técnicas convencional, conformacional (Eclipse) e IMRT (CORVUS), aplicadas no RANDO, em termos de dose absoluta mínima recebida pelo alvo e estruturas críticas. 


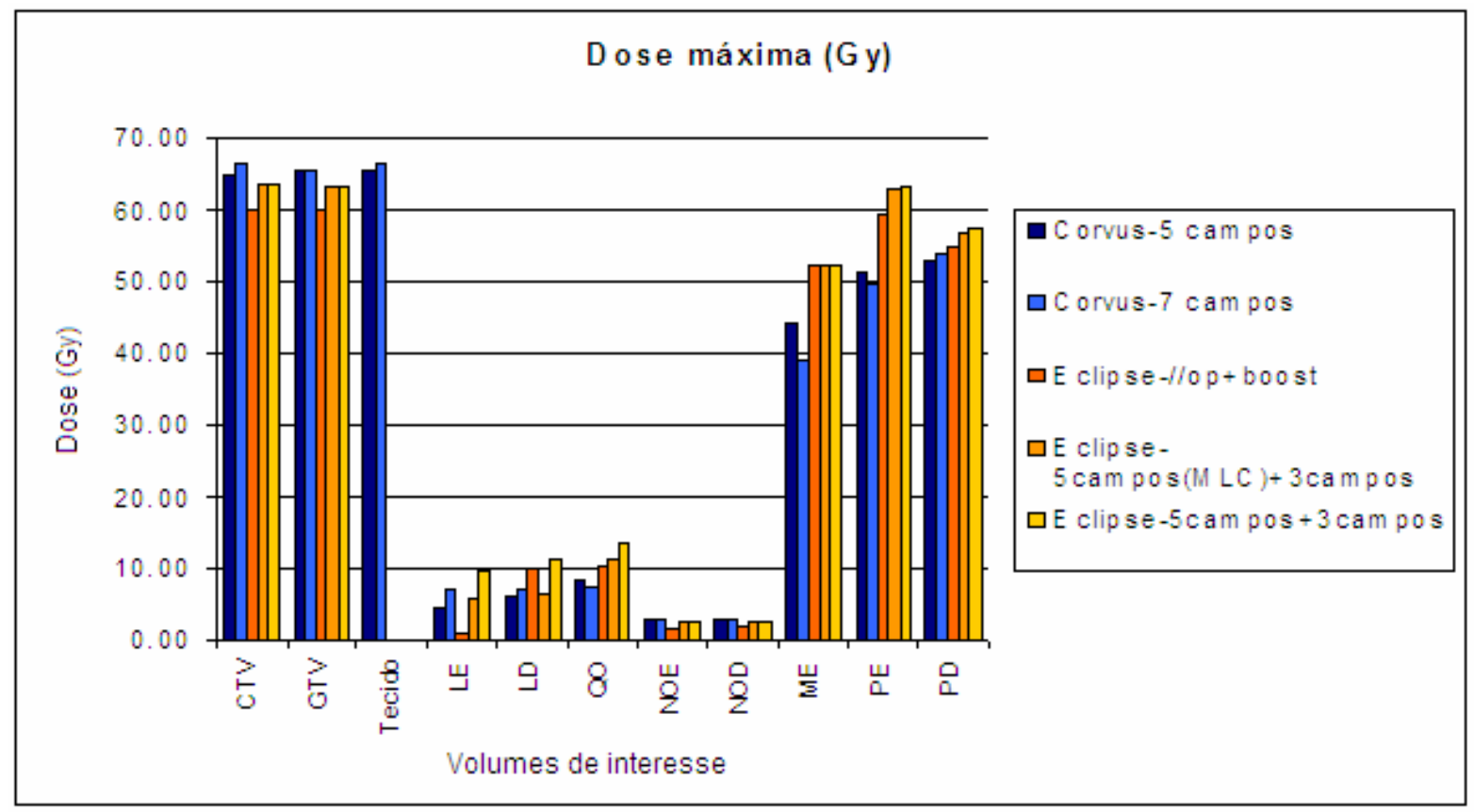

FIGURA B.2 - Comparação entre DVHs de planejamentos de tratamentos feitos com técnicas convencional, conformacional (Eclipse) e IMRT (CORVUS), aplicadas no RANDO, em termos de dose absoluta máxima recebida pelo alvo e estruturas críticas. 


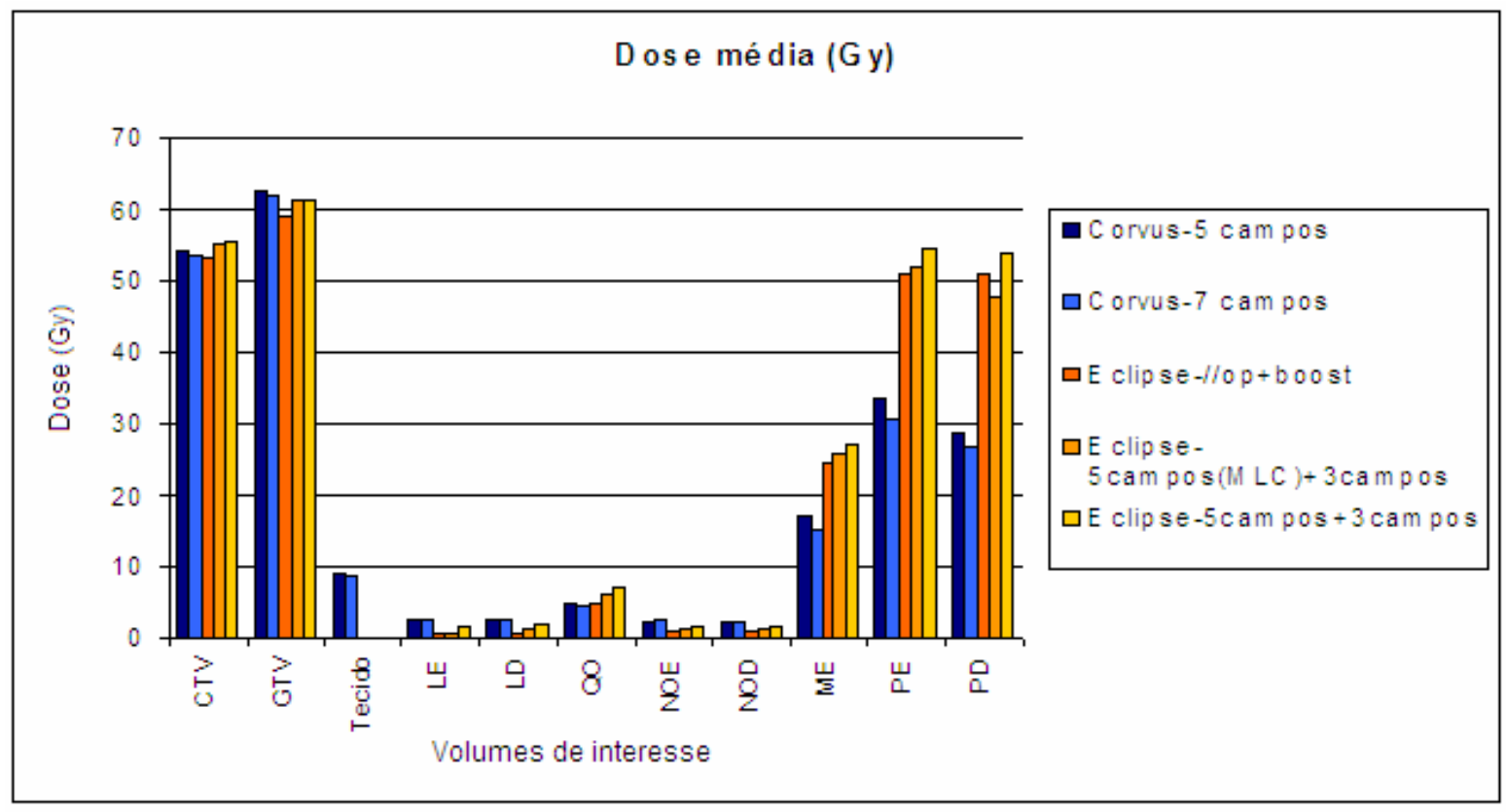

FIGURA B.3 - Comparação entre DVHs de planejamentos de tratamentos feitos com técnicas convencional, conformacional (Eclipse) e IMRT (CORVUS), aplicadas no RANDO, em termos de dose absoluta média recebida pelo alvo e estruturas críticas.

Como ilustrado nas FIGURAS B.1, B.2 e B.3, os alvos podem ser cobertos adequadamente pela dose prescrita com todas as técnicas de tratamento: convencional, conformacional e IMRT. Já as estruturas críticas recebem menos dose de uma forma geral com as técnicas de IMRT, especialmente as parótidas. Diminuir a dose nas parótidas é a maior vantagem em se usar modulação de feixe (IMRT) nos casos de câncer na região de cabeça e pescoço pois assim pode-se evitar que ocorra xerostomia (conhecido como secura da boca que ocorre devido a uma disfunção das glândulas salivares) nos pacientes submetidos à radioterapia. 


\section{APÊNDICE C - FÍSICA DOS DOSÍMETROS E DETECTORES}

\section{C-1- Câmara de ionização ${ }^{51,132-138}$}

As câmaras de ionização são os equipamentos dosimétricos mais comuns na radioterapia. Elas são simples e eficazes quando calibradas. Mas para se obter medidas precisas e acuradas é necessário uma preparação cuidadosa do posicionamento. As câmaras tipo dedal com geometria cilíndrica são as mais usadas na radioterapia.

Em geral, as câmaras de ionização dedal consistem de um isolador de ar nãocondutivo e três eletrodos (FIGURA C.1). A parede do eletrodo externo com formato cilíndrico é aterrada. O eixo central do eletrodo interno é o eletrodo de polarização e coleção. O eletrodo de guarda minimiza a carga de fuga através de sua conexão ao eletrodo de coleção, e ajuda a delimitar eficazmente o volume sensível e eliminar regiões de campo com baixa intensidade onde pode ocorrer recombinação de íons. Uma alta tensão é aplicada entre os eletrodos internos e externos, e um eletrômetro mede o sinal (proveniente da corrente), que é por sua vez dependente da direção e intensidade do campo elétrico gerado.

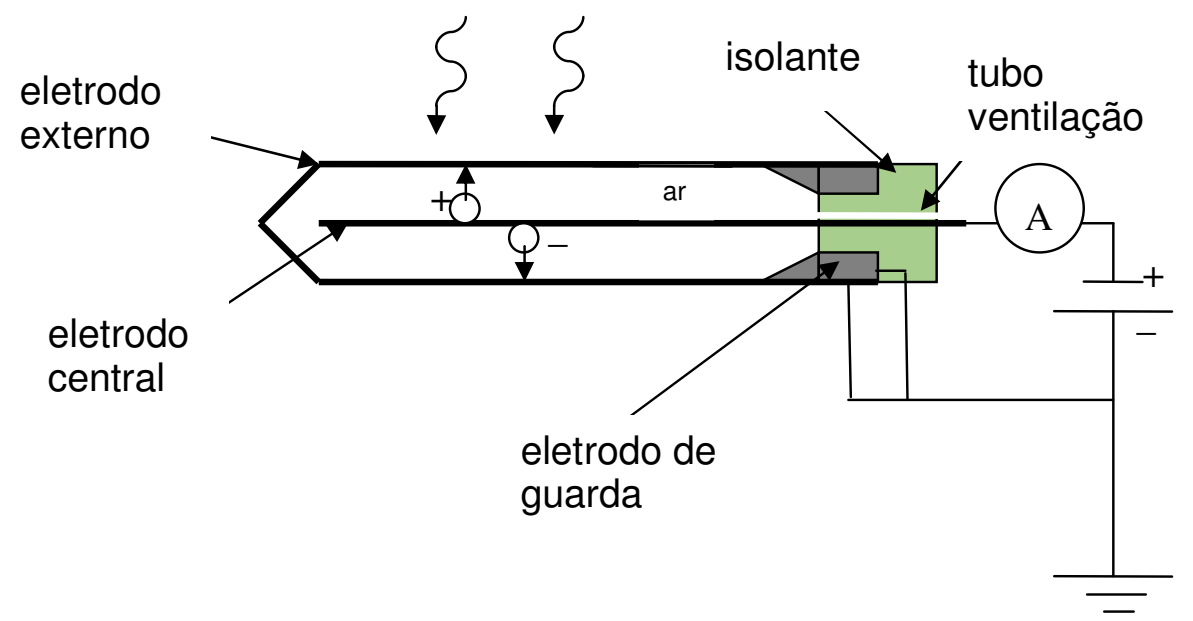

FIGURA C.1 - Diagrama esquemático de uma câmara de ionização cilíndrica tipo Farmer. 
A carga coletada nos eletrodos está na forma de íons produzidos na cavidade de ar. O ar da cavidade sofre as mudanças de temperatura e pressão de acordo com as condições do meio ambiente, pois a câmara de ionização possui um orifício para este fim.

$\mathrm{Na}$ presença de radiação ionizante a fluência do elétron primário, gerado no material ao redor e no meio da cavidade, interage com moléculas de ar formando íons positivos e elétrons de baixa energia que subsequentemente se juntam às moléculas de oxigênio $\left(\mathrm{O}_{2}\right.$ é uma molécula eletronegativa). Os íons são atraídos para os eletrodos carregados com sinal oposto. Uma câmara de ionização é essencialmente um capacitor que é carregado quando um campo elétrico é aplicado entre os eletrodos, e descarregado quando os pares de íons são atraídos para os eletrodos opostos.

A intensidade da carga e os sinais gerados são proporcionais ao número de ionizações na cavidade de ar. A dose na cavidade é a quantidade de energia usada para ionizar as molécular de ar por unidade de massa de ar. Quanto maior o volume da cavidade da câmara maior a quantidade de sinais produzidos nela. Portanto, para a mesma dose, cavidades com volumes maiores produzirão mais sinais, contudo a energia liberada na cavidade é distribuída sobre uma massa de ar maior. A dose na cavidade é relacionada ao número de cargas de íons de um mesmo sinal liberadas no ar seco $M$, a massa de ar na cavidade do volume $m_{\text {air }}$, e a energia média gasta para produzir um par de íon por unidade de carga $\left(\bar{W}_{\text {air }} / e\right)$,

$$
D_{\text {cav }}=\left(\frac{\bar{W}_{\text {air }}}{e}\right) \frac{M}{m_{\text {air }}} k_{h} P_{T, p} P_{\text {pol }} P_{\text {ion }} P_{\text {elec }}
$$

em que $k_{h} P_{T, p} P_{p o l} P_{\text {ion }} P_{\text {elec }}$ são uma série de fatores de correções que levam em conta a umidade do ambiente, temperatura e pressão, e imprecisão na coleção de carga.

A International Atomic Energy Agency, IAEA (2001) ${ }^{51}$, aceita que o valor de $\left(\bar{W}_{\text {air }} /\right.$ e) seja $33,97 \pm 0,5 \% \mathrm{eV} /$ par de íon, ou J/C, em condição ambiental padrão de $20^{\circ} \mathrm{C}, 760 \mathrm{~mm} \mathrm{Hg}$, e ar seco. 


\section{C-2- FILMES RADIOGRÁFICOS $3,45,99$}

A radiação ionizante ou a luz visível têm a propriedade de afetar um filme. $\mathrm{O}$ filme radiográfico consiste de uma base de filme transparente (acetato de celulose ou resina de poliester) coberta com uma emulsão contendo cristais muito pequenos de brometo de prata. Quando a radiação interage com estes cristais, eles se tornam mais suscetíveis à mudança química e formam o que é chamado de imagem latente. Quando o filme é revelado, os cristais afetados pela radiação são reduzidos a pequenos grãos de prata metálica. O filme é então fixado; quando o brometo de prata não afetado é desativado, deixando o filme limpo em seu lugar. A prata metálica, que não é afetada pelo fixador, causa o enegrecimento do filme nas áreas que foram expostas à radiação. Então, o grau de enegrecimento de uma área do filme depende da quantidade de prata livre depositada e, consequentemente, da energia absorvida da radiação.

A concentração de grãos de prata metálica é medida pela determinação da densidade óptica do filme, usando um densitômetro.

\section{C-2-1- Densitômetro}

O densitômetro é formado por uma lâmpada e um medidor de intensidade de luz. A amostra a ser estudada á colocada entre estes componentes, de forma que o medidor possa avaliar sua densidade óptica. Na prática, um sistema óptico concentra a luz da lâmpada num espaço de cerca de $2 \mathrm{~mm}$. O medidor utilizado é um tubo fotomultiplicador, munido de um ampliador. Este faz funcionar um amperímetro, cuja leitura indica a intensidade de luz recebida pelo fotomultiplicador.

A luz da fonte passa através de uma tela difusora e incide sobre uma pequena abertura localizada logo abaixo do filme em teste. A luz transmitida através do filme $\left(\mathrm{I}_{\mathrm{t}}\right)$ é medida por uma fotocélula colocada sobre o filme. Este detector é colocado de forma a coletar toda a luz que vem da pequena abertura. A leitura desta luz é comparada com o valor obtido da quantidade de luz coletada sem o filme $\left(\mathrm{I}_{0}\right)$ e a densidade óptica, DO, é calculada do $\log \left(\mathrm{I}_{0} / \mathrm{I}_{\mathrm{t}}\right)$ usando a equação

$$
D O=\log \left(I_{0} / I_{t}\right)
$$

Em dosimetria, a grandeza de interesse é geralmente a densidade óptica líquida, que é obtida pela subtração da leitura da base fog ou background (densidade 
óptica do filme processado não exposto à radiação) da densidade óptica medida do filme exposto à radiação.

Um registro da densidade óptica líquida como função da exposição de radiação ou dose é chamada curva sensitométrica. Se um filme é exposto na região não linear, devem ser feitas correções para converter densidade óptica em dose.

O filme é bem estabelecido como método de medida de distribuição de feixes de elétrons, mas seu uso para dosimetria de fótons é relativamente limitado. Por causa do efeito fotoelétrico depender do número atômico ao cubo, a prata $(Z=45)$ na emulsão do filme absorve radiações abaixo de $150 \mathrm{keV}$ fortemente por este processo. Como a maioria dos feixes clínicos contém um componente espalhador de fótons de baixa energia, a correlação entre DO e dose se torna tênue. Além disso, o filme sofre vários erros potenciais tais como mudanças nas condições de processamento, diferenças nas emulsões interfilmes e artefatos causados por ar junto ao filme embalado. Por estas razões, a dosimetria absoluta com filme é impraticável, no entanto, ele é muito usado para observar campos de radiação, coincidência de campo radioativo com luminoso, planura de campo e simetria e, também, para obtenção rápida de dados sobre a distribuição da radiação.

\section{C-3- MOSFET ${ }^{74,86,87,139-141}$}

O princípio básico do transistor de efeito de campo meta-óxido-semicondutor, MOSFET, ou simplesmente MOS, foi proposto e patenteado por em 1928 por Lilienfeld. A realização física do transistor MOS não foi possível na época devido a limitação tecnológica. A limitação tecnológica da época refere-se a falta de controle e alta densidade de estados e cargas de superfície do semicondutor. Esta alta densidade de estados de superfície produzia uma blindagem do semicondutor, impedindo assim uma modulação da densidade de portadores, portanto, da condutância entre os contatos de fonte e dreno, pela tensão de porta. Apenas em 1960 obteve-se sucesso na fabricação do transistor MOS, na Bell Labs por D. Hahng e M. Atalla. O desenho esquemático do transistor MOS tipo nMOS (substrato p) é mostrado na FIG. C.2. O transistor MOS é um dispositivo de 4 terminais, sendo estes: fonte, dreno, porta e substrato. $O$ transistor pMOS é complementar ao nMOS, ou seja é formado por substrato tipo $\mathrm{n}$ e regiões de fonte e dreno tipo $p$. 

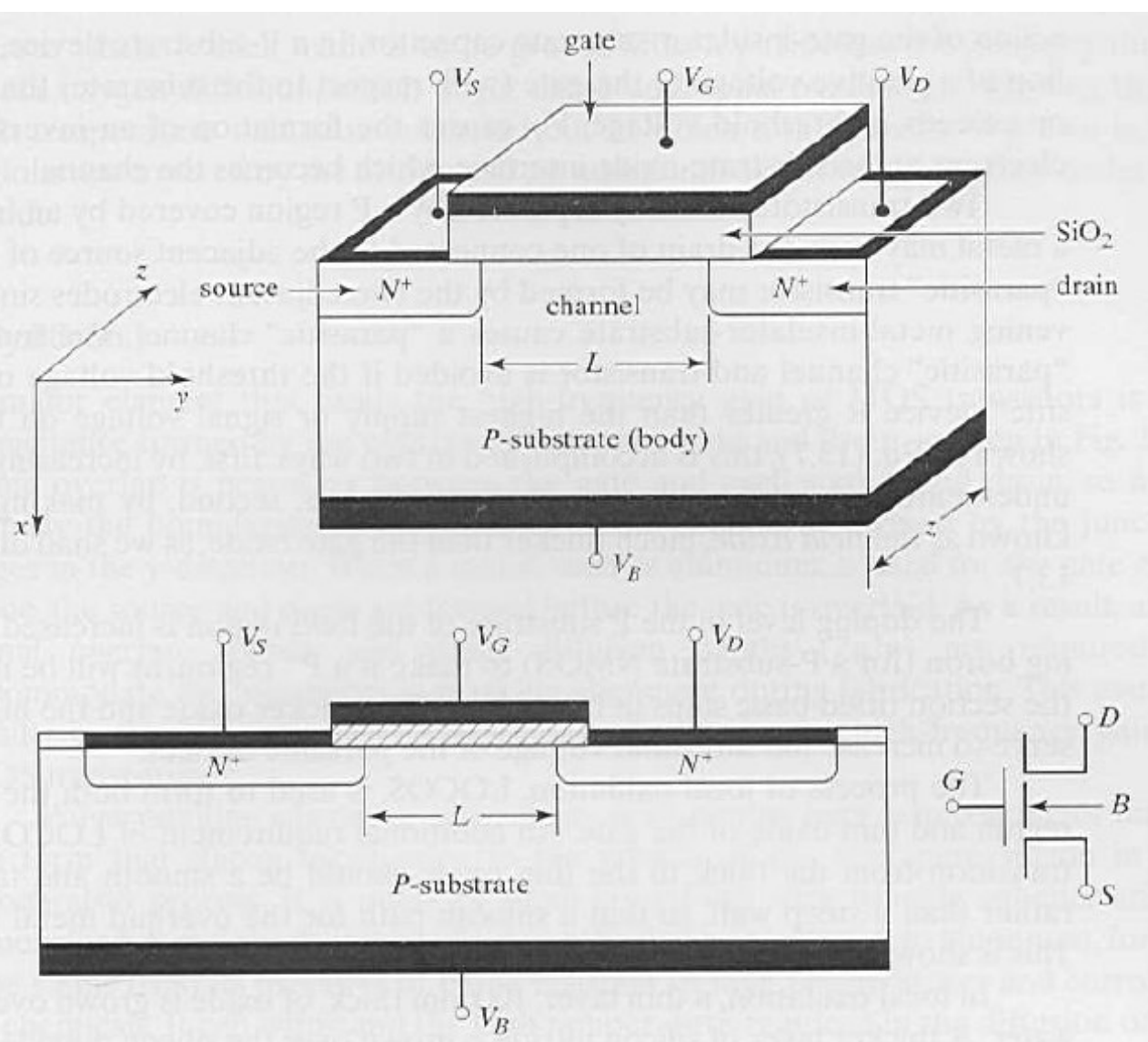

FIGURA C.2 - Esquema da estrutura moderna do transistor MOSFET em perspectiva, corte em secção transversal e o símbolo do transistor nMOS ${ }^{141}$.

Variando a tensão $V_{G}$ (porta), variam os diagramas de banda, de densidades de cargas, de campo elétrico e de potencial elétrico num eixo perpendicular à superfície, isto é o efeito do campo elétrico ou da tensão aplicada a uma porta de um capacitor MOS. A análise deste fenômeno resultou na determinação da tensão limiar clássica da estrutura MOS definida como a condição onde o potencial de superfície, $\Phi_{\mathrm{S}}$, torna-se de valor igual a duas vezes o potencial de Fermi, $\Phi_{\mathrm{F}}$, ou seja, considerando substrato tipo $p$ temos ${ }^{141}$ :

$$
\begin{aligned}
& \phi_{S}=2 \phi_{F} \\
& \text { em que } \phi_{F}=\frac{k T}{q} \ln \left(\frac{N_{A}}{n_{i}}\right) \\
& V_{T}=V_{F B}+2 \phi_{F}+\frac{1}{C_{o}} \sqrt{2 q \varepsilon_{S i} N_{A} 2 \phi_{F}}
\end{aligned}
$$

onde 
kT/q é a tensão térmica; q é a carga no semicondutor; $N_{A}$ é a concentração de dopantes (lado p); $n_{i}$ é a concentração de elétrons na superfície;

$V_{T}$ é a tensão de limiar de inversão forte;

$V_{F B}$ é a tensão de porta (do inglês flat band);

$$
V_{F B}=-\frac{Q_{o}}{C_{O}}+\Phi_{M S}
$$

$Q_{o}=$ carga efetiva de interface $\mathrm{SiO}_{2}-\mathrm{Si}$, por unidade de área.

$\Phi_{M S}=$ diferença de função trabalho entre o metal e o semicondutor.

$C_{O}=\frac{\varepsilon_{o x}}{t}=$ capacitância de placas paralelas do dielétrico de porta por unidade de área.

Estes conceitos constituem os fundamentos para o entendimento do transistor MOSFET.

Um diagrama esquemático de um detector MOSFET atual, com suas dimensões, é mostrado na FIG. C.3.

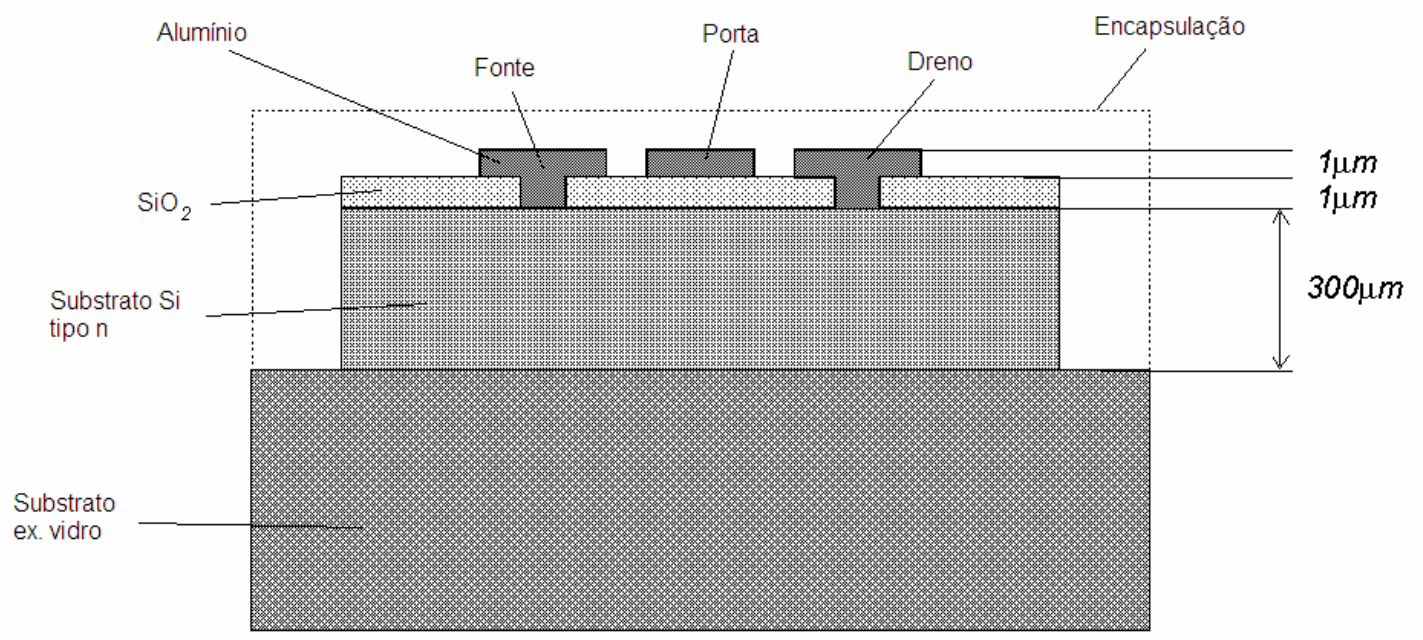

FIGURA C.3 - Diagrama esquemático de um MOSFET. O sinal de tensão é medido entre o substrato $\mathrm{Si}$ e a porta ${ }^{74}$.

De um modo simplificado o MOSFET mostrado na FIG. C.3 é um MOSFET canal $\mathrm{P}$ que é construído sobre um silício (tipo-n) dopado negativamente. Quando uma tensão negativa suficientemente grande é aplicada na porta de polisilício um número significante de buracos (carregadores minoritários) serão atraídos para a superfície de óxido/silício de ambas regiões: substrato de silício, fonte e dreno. 
Um canal de condução é formado quando uma concentração suficiente de buracos se acumularam nestas regiões, permitindo que uma corrente flua entre a fonte e o dreno $\left(\mathrm{I}_{\mathrm{ds}}\right)$. A tensão necessária para iniciar o fluxo de corrente é conhecida como a tensão de limiar do equipamento $\left(\mathrm{V}_{T H}\right)$.

Quando um detector MOSFET é irradiado, pares elétrons-buracos são gerados dentro do dióxido de silício $\left(\mathrm{SiO}_{2}\right)$ pela radiação incidente. Elétrons, cuja mobilidade no $\mathrm{SiO}_{2}$ à temperatura ambiente é aproximadamente 4 vezes maior que a dos buracos, se movem rapidamente para fora do eletrodo porta enquanto os buracos se movem estocasticamente na direção da interface $\mathrm{Si} / \mathrm{SiO}_{2}$ onde eles ficam armadilhados por longos períodos causando uma mudança na tensão limiar negativa $\left(D V_{T H}\right)$ que pode persistir por anos. A diferença de mudança na tensão antes e depois da exposição pode ser medida e é proporcional à dose.

Na FIG. C.4 está representado o MOSFET após ser submetido à irradiação com os buracos armadilhados no substrato de $\mathrm{Si}$ e a formação da corrente entre a fonte e o dreno.

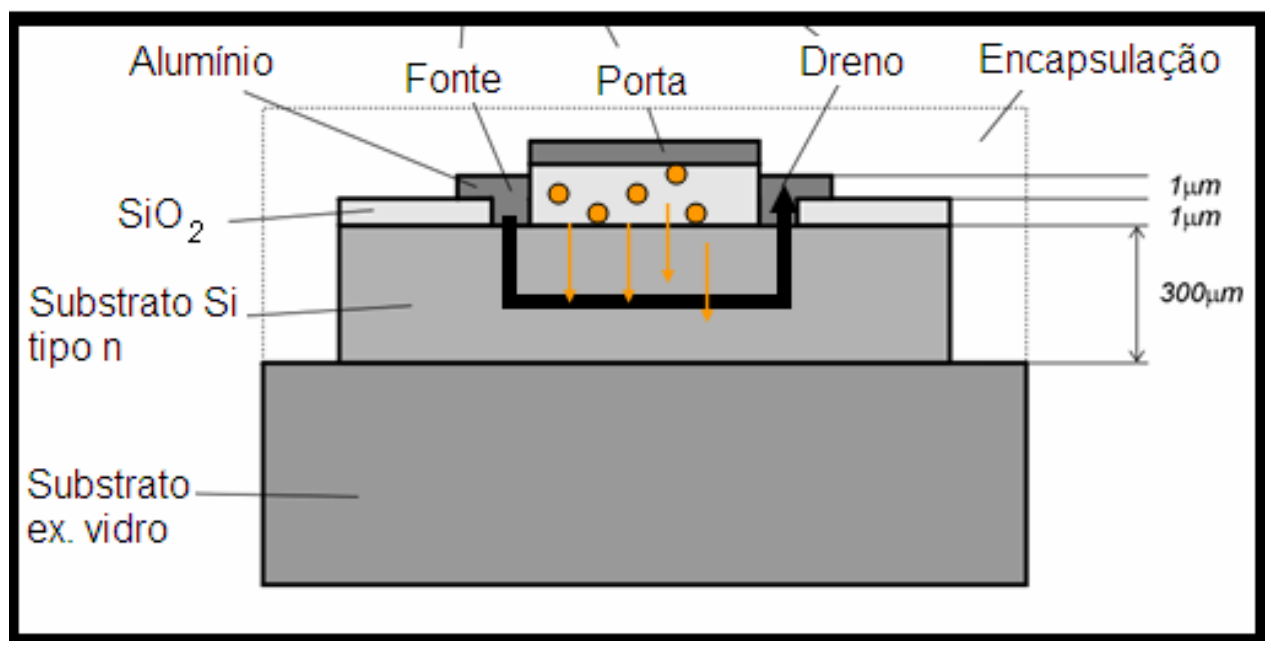

FIGURA C.4 - Secção transversal do MOSFET com os buracos (em laranja) armadilhados no substrato de Si e a formação da corrente entre a fonte e o dreno representado pela seta em preto.

O porta bias durante a irradiação determina a sensitividade do detector e após a irradiação ela é necessária para manter a corrente constante. O porta bias e a leitora do MOSFET são mostrados na FIGURA C.5. 


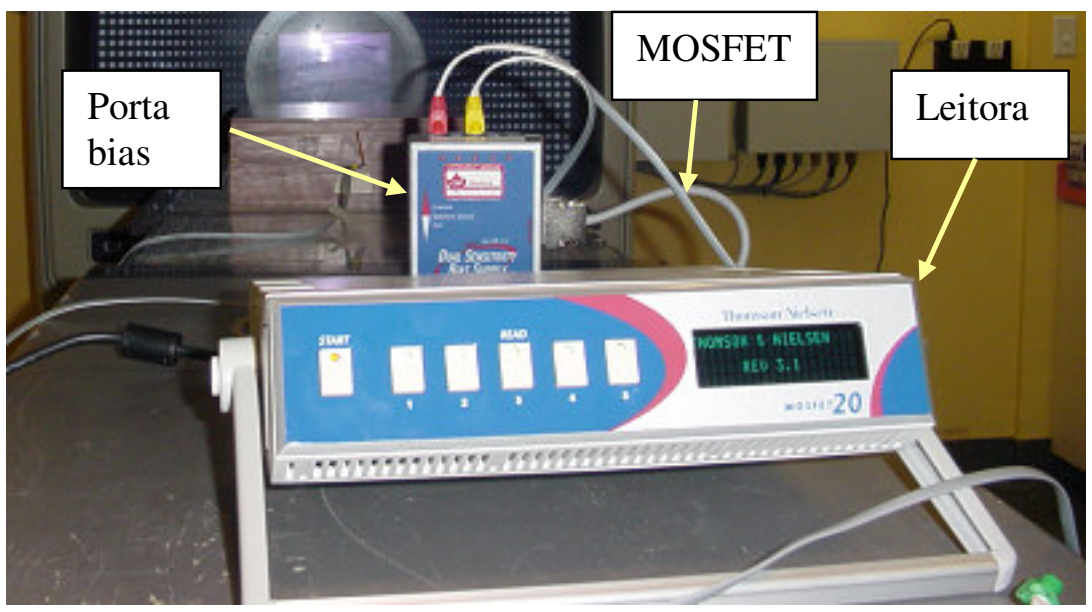

FIGURA C.5 - Leitora e porta bias de um conjunto de 5 detectores tipo MOSFET.

Em termos dosimétricos, os transistores de efeito de campo metal-óxidosemicondutor ou MOSFET são os mais recentes dosímetros desenvolvidos para dosimetria in-vivo. Eles têm sido incluídos na prática clínica há uns seis anos. Eles são uma substituição eletrônica para os TLDs, com tamanhos semelhantes e a vantagem de ter menos correções que os diodos. O dosímetro é composto por silício geralmente no tamanho $1 \mathrm{~mm} \times 1 \mathrm{~mm}$ com uma área ativa de 0,2 $\mathrm{mm} \times$ $0,2 \mathrm{~mm}$. A radiação absorvida por um MOSFET resulta uma mudança permanente na tensão de limiar devido a carga gerada pela radiação armadilhada no óxido de porta. Esta mudança na tensão é proporcional a dose absorvida. É um dosímetro de integração verdadeiro. Na prática, o instrumento de leitura eletrônico mede a tensão de limiar do MOSFET antes e depois da irradiação e a variação é calculada pelo instrumento e mostrado em cGy. O MOSFET é independente da DFS, ângulo de incidência da radiação e energia, por isso sua vantagem sobre o diodo.

\section{C-4- DOSÍMETROS TERMOLUMINESCENTES ${ }^{142-146}$}

\section{C-4-1- O processo de termoluminescência - TL}

Os materiais inorgânicos cintiladores quando expostos à radiação ionizante emitem luz na forma de fluorescência instantânea. Os fótons de cintilação são emitidos quando os pares de elétron-lacuna, que foram criados pela radiação incidente, se recombinam no local ativador. Estes materiais são mantidos 
propositalmente livres de outras impurezas e defeitos para maximizar o rendimento de emissão instantânea de luz de cintilação.

Uma classe diferente de cristais inorgânicos, conhecida como dosímetros termoluminescentes (TLDs), é baseada em um processo oposto. Em vez de promover a recombinação rápida de pares de elétron-lacuna, são usados materiais com altas concentrações de armadilhas dentro do banda proibida. Como ilustrado na FIG. C.6, o processo desejado é tal que os elétrons são elevados da banda de valência para a de condução pela radiação incidente, mas são então capturados em uma das armadilhas. Se a distância entre o nível de energia da armadilha e a banda de condução for suficientemente grande, há apenas uma pequena probabilidade por unidade de tempo, em temperaturas normais, que o elétron escape da armadilha, sendo excitado térmicamente à banda de condução. Então, a exposição de um material à uma fonte contínua de radiação, embora não resultando em um rendimento significante de luz de cintilação, conduz à um aumento progressiva de elétrons aprisionados.

As lacunas também podem ser aprisionadas em um processo análogo. Uma lacuna original criada pela radiação incidente, pode migrar pelo cristal até alcançar uma armadilha de lacuna com uma energia um pouco maior que a do limite da banda de valência. Se esta diferença de energia for suficientemente grande, a lacuna não migrará mais adiante e é então presa em uma determinada posição, a menos que seja adicionada energia térmica ao cristal. Uma amostra de material TL funcionará então como um detector integrativo, no qual o número de elétrons e lacunas aprisionados é uma medida do número de pares de elétronlacuna formados pela exposição à radiação.

Depois do período de exposição, as armadilhas podem ser medidas também pelo processo ilustrado na FIG. C.6. A amostra de material TL é colocada em uma base aquecida, ou então a própria amostra é aquecida, e sua temperatura é elevada gradualmente. Em uma temperatura que é determinada pelo nível de energia da armadilha, os elétrons aprisionados podem absorver energia térmica suficiente, de forma que eles são re-excitados de volta à banda de condução. Assumindo que esta temperatura seja mais baixa que a necessária para as lacunas aprisionadas, os elétron liberados migram então para próximo às lacunas aprisionadas onde eles podem se recombinar com a emissão de um fóton. Alternativamente, se as lacunas são libertadas a uma temperatura mais 
baixa, elas podem migrar para um elétron aprisionado e a recombinação deles também resulta em um fóton emitido. Em ambos os casos, se a diferença de energia for aproximadamente 3 ou $4 \mathrm{eV}$, os fótons emitidos estão na região visível e são a base do sinal TL. Idealmente, um fóton é emitido por armadilha. Então, o número total de fótons emitidos pode ser usado como uma indicação do número original de pares de elétron-lacuna criados pela radiação.
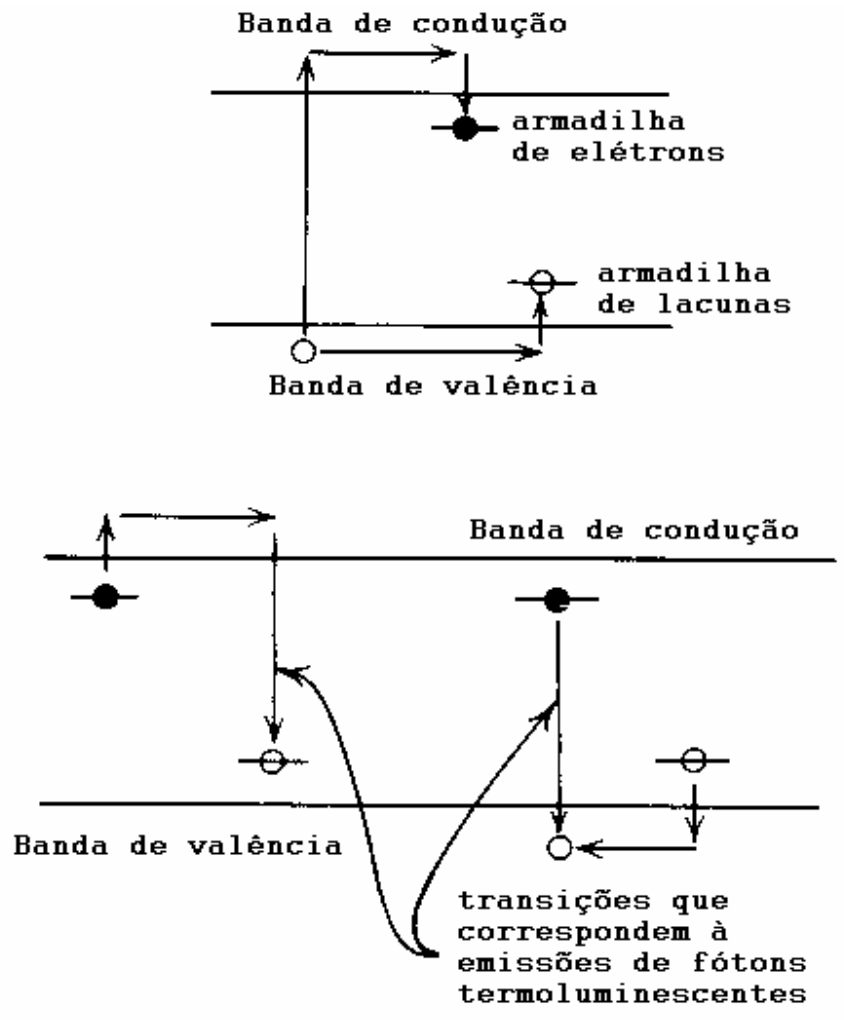

FIGURA C.6 - O diagrama superior representa a formação de um par de elétronlacuna em um material TL, conduzindo a uma população de armadilhas de lacuna e de elétrons. O diagrama inferior ilustra os dois modos possíveis de recombinação quando a temperatura é elevada, conduzindo à emissão de um fóton de termoluminescência ${ }^{143}$.

O sinal TL é obtido usando um sistema aquecedor no qual a amostra pode ser aquecida até temperaturas da ordem de 300 a $400^{\circ} \mathrm{C}$, a quantidade de luz emitida é captada por um tubo fotomultiplicador. O rendimento fotônico é 
registrado como uma função da temperatura da amostra em uma curva de intensidade do tipo mostrada na FIG. C.7. O sinal básico relacionado à exposição de radiação é o número total de fótons emitidos, ou a área abaixo da curva de intensidade. Se a amostra é aquecida a uma temperatura relativamente alta, todas as armadilhas são esvaziadas e a exposição registrada na amostra é igual a zero. Os materiais TL têm uma vantagem prática de reciclabilidade, e uma única amostra pode ser usada muitas vezes.

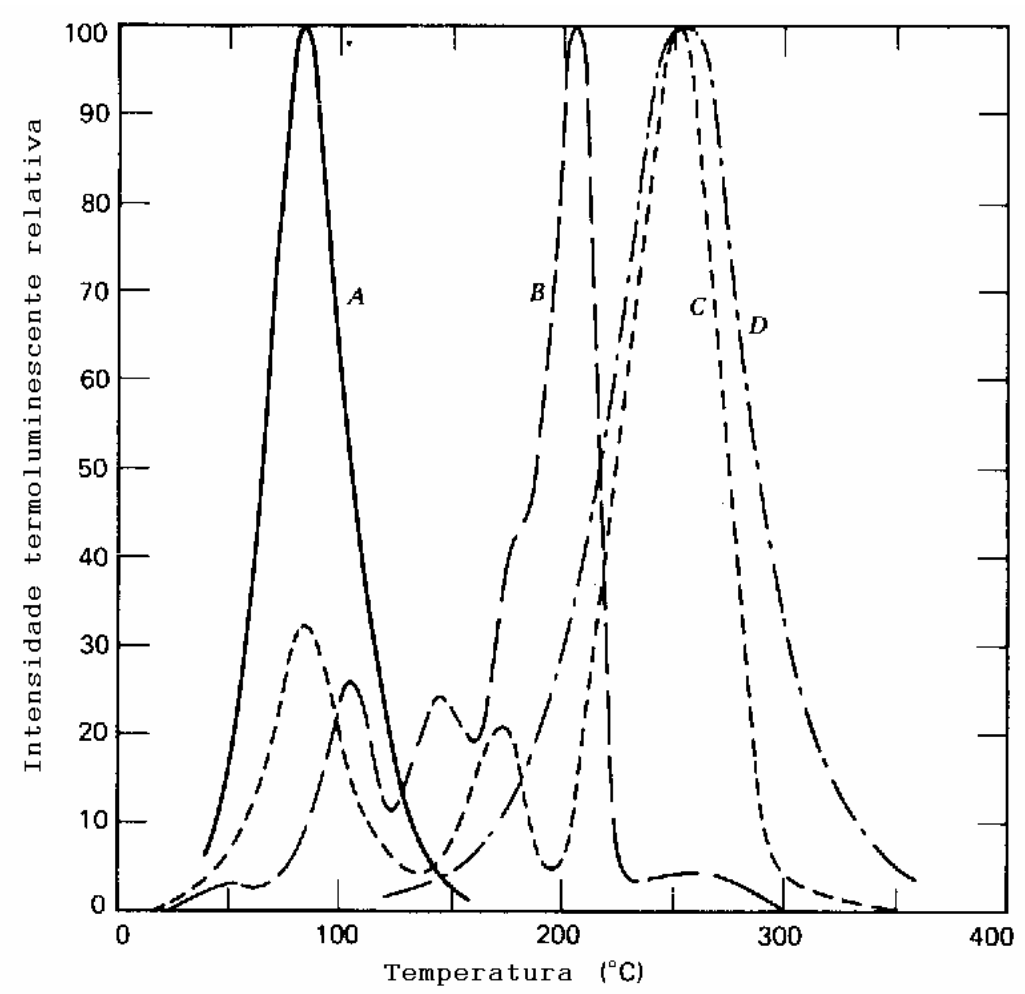

FIGURA C.7 - Curvas típicas de intensidade de termoluminescência normalizadas à mesma intensidade máxima. Os materiais são A- $\mathrm{CaSO}_{4}: \mathrm{Mn}$; B- $\mathrm{LiF}$; C- $\mathrm{CaF}_{2}$; e D- $\mathrm{CaF}_{2}: \mathrm{Mn}$. As características destas curvas dependerão dos procedimentos de tratamento térmico, nível de exposição de radiação, taxa de aquecimento durante o estágio de leitura ${ }^{144}$.

\section{C-4-2- Materiais Termoluminescentes}

Alguns materiais populares consistem de cristais aos quais uma concentração pequena de impureza foi acrescentada como um ativador (por exemplo, $\mathrm{CaSO}_{4}: \mathrm{Mn}$, onde Manganês é o ativador). Outros não requerem a 
adição de um ativador, onde as armadilhas são criadas pelas impurezas inerentes e defeitos no cristal. Na escolha de materiais TL tem que se levar em conta a profundidade da armadilha e número atômico do material. Se a energia que nivela as armadilhas é muito próxima do limite do banda proibida (como no $\mathrm{CaSO}_{4}: \mathrm{Mn}$ ), o número de armadilhas por unidade de exposição pode ser muito grande. Então, este material pode ser fabricado com uma tal sensibilidade de exposição tão baixa quanto $0,2 \mu \mathrm{Gy}$. As armadilhas rasas são até mesmo um pouco instáveis à temperaturas ambientes e, então, o material mostrará um decaimento térmico do sinal considerável, podendo perder até $85 \%$ das cargas armadilhadas ao longo de alguns dias. Entretanto, outros materiais como CaF $: M n$, LiF:Mg,Ti e $\mathrm{CaSO}_{4}: \mathrm{Dy}$ com armadilhas um pouco mais profundas, são mais indicados para exposições a longo prazo, embora a sensibilidade deles seja várias ordens de magnitude menor. A curva de emissão de diferentes materiais é mostrado na FIG. C.7.

De todos os materiais TL, o LiF:Mg,Ti (TLD-100) se tornou o mais popular devido ao seu decaimento térmico quase desprezível à temperatura ambiente e seu número atômico efetivo baixo, que não difere muito do ar ou do tecido humano. A energia depositada no LiF é, portanto, comparável a uma exposição de raios gama ou de dose equivalente sobre uma grande variedade de energia dos gamas. Para materiais TL com número atômico mais alto, as probabilidades de interação fotoelétricas intrínsecas ampliam a resposta para raios- $x$ de baixa energia, ou raios gama.

Na FIG. C.8, a resposta relativa para $2,58 \times 10^{-4} \mathrm{C} / \mathrm{kg}$ de exposição de radiação gama é registrada para vários materiais TL diferentes. Só a curva para 0 LiF permanece razoavelmente constante sobre a variação de energia dos fótons. Pastilhas pequenas de LiF entraram assim em uso popular como dosímetros pessoais. Estes tipos de TLD estão substituindo crachás de filmes fotográficos gradualmente em muitas situações, porque as exposições podem ser medidas diretamente pelo usuário sem a necessidade de revelação fotográfica do filme, e os dosímetros podem ser usados de novo muitas vezes quando tratados à temperaturas adequadas.

Devido à grande variedade entre amostras e métodos de aquecimento, os valores absolutos da dose de radiação, normalmente, são determinados 
submetendo uma amostra a uma exposição de raios gama conhecida. O limite mínimo de detecção do LiF (TLD-100) é aproximadamente $100 \mu \mathrm{Gy}$, e os sinais permanescem lineares com a dose até aproximadamente 10 Gy. Para doses mais altas, o material apresenta um aumento da não-linearidade da resposta por unidade de exposição, um comportamento conhecido como supralinearidade.

Devido ao fato de que o Lítio natural contém $7,4 \%{ }^{6} \mathrm{Li}$, detectores TL feitos de LiF serão também sensíveis a nêutrons lentos através da reação $(\boldsymbol{n}, \boldsymbol{\alpha})$. Esta resposta pode ser aumentada usando Lítio enriquecido em ${ }^{6} L i$, ou suprimida usando Lítio que consiste completamente do isótopo ${ }^{7} L i$. Detectores TL sensíveis a nêutrons rápidos também foram fabricados cobrindo as amostras com um material como $\mathrm{Al}_{2} \mathrm{O}_{3}$ com polietileno.

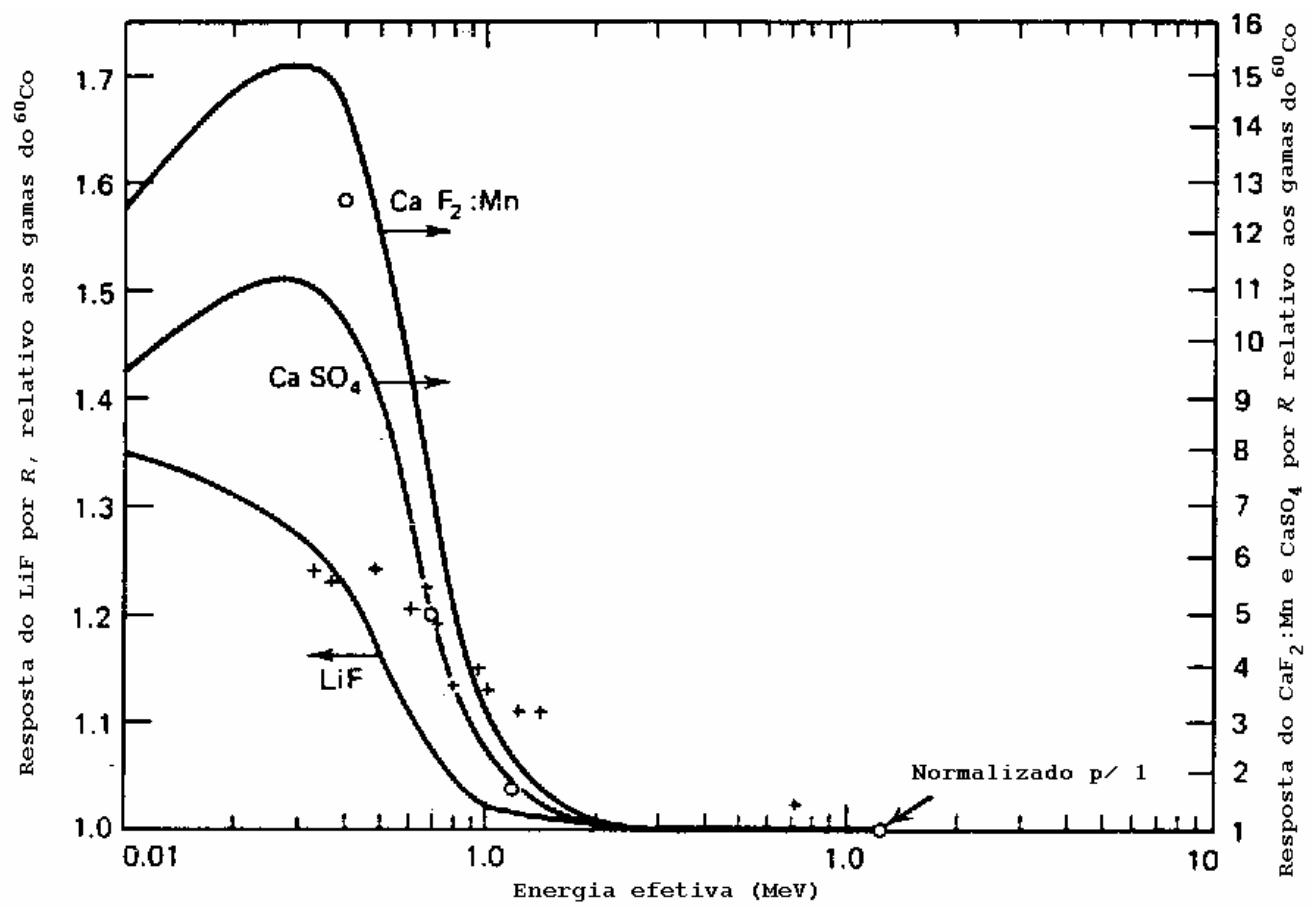

FIGURA C.8 - Variação da resposta TL do LiF em função da energia da radiação gama por $2,58 \times 10^{-4} \mathrm{C} / \mathrm{kg}$. As curvas são calculadas apartir da probabilidade de interação do raio gama, assumindo uma resposta constante por unidade de dose absorvida no material TL. (o) são medidas experimentais para $\mathrm{CaF}_{2}: \mathrm{Mn},(+)$ são medidas para $L i F^{145}$. 


\section{C-4-3- Leitores termoluminescentes}

A FIG. C.9 ilustra esquematicamente a instrumentação de leitora de TLD, geralmente utilizada em medidas para fins de pesquisa ${ }^{145}$. O material termoluminescente é colocado numa prancheta ou placa que é aquecida intensamente. Em alguns casos, o aquecimento é à gás ou radiofrequência.

Os dosímetros termoluminescentes são normalmente aquecidos em uma atmosfera de gás $N_{2}$ inerte durante a leitura. A temperatura da prancheta é controlada através de um termostato em contato com a sua superfície. A luz emitida pelo fósforo atravessa um sistema óptico que é constituído de lentes coletoras e um filtro infra-vermelho que focaliza a luz no fotocatodo de uma fotomultiplicadora.

$\mathrm{Na}$ técnica de contagem dos fótons, o pulso da fotomultiplicadora (devido a interação única do fóton emitido pelo TLD com o fotocatodo) é amplificado uma vez mais e é conduzido ao discriminador (para eliminar pulsos devido ao ruído) antes de ser analizado por um analizador multicanal. A curva de emissão (contagem do número de fótons do TLD em função do tempo) é transferida para um contador para sua análise. Na técnica mais comum (integração de carga) a corrente de saída da fotomultiplicadora (proporcional a quantidade de luz que atinge o fotocatodo) é amplificada, conduzida a um integrador e registrada. 


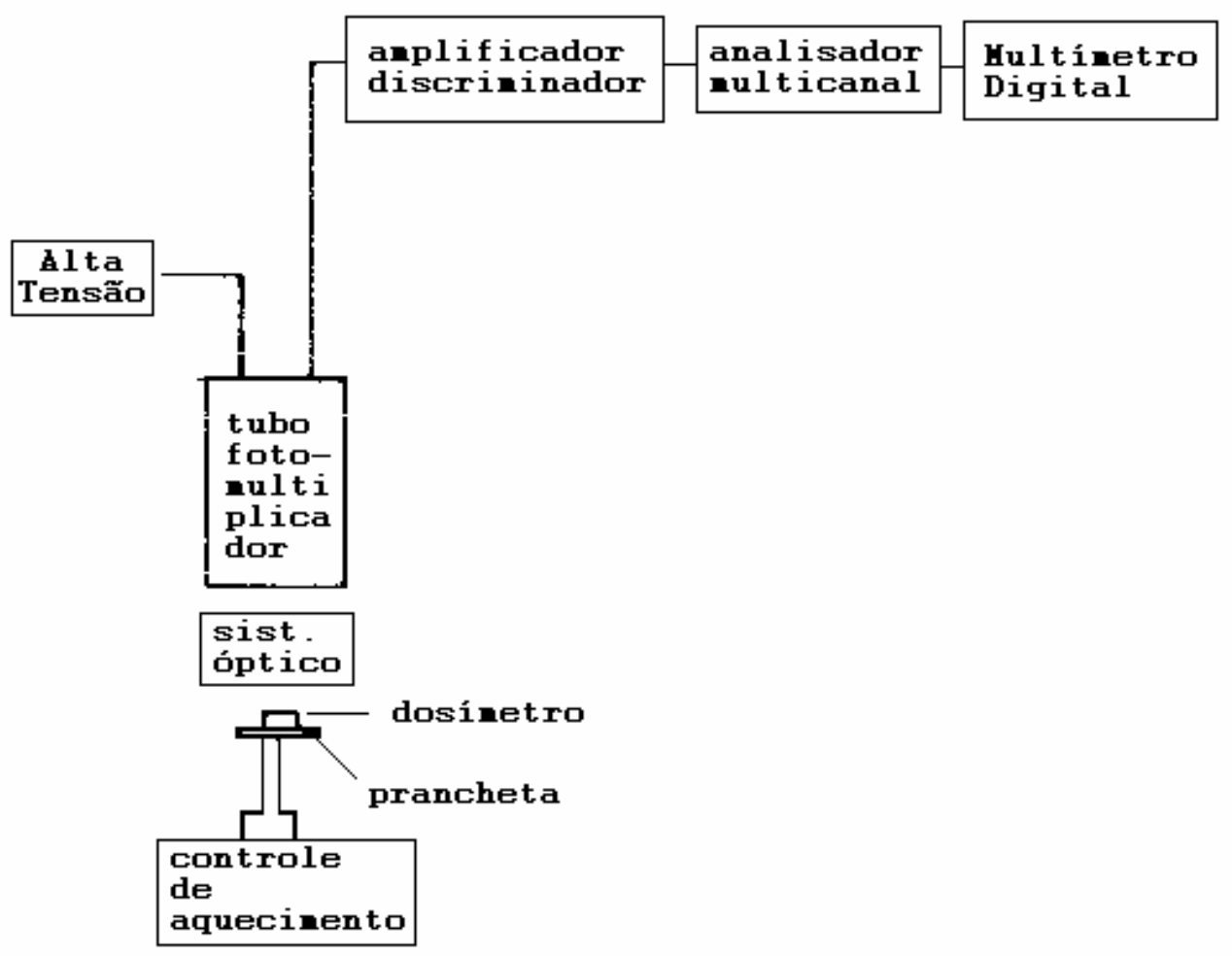

FIGURA C.9 - Esquema de uma leitora de TLDs ${ }^{136}$. 


\section{referências bibliográficas}

1. Cameron, J. R. Acronyms. Madison, WI: Medical Physics Publishing, 2005.

2. Van Dyk, J. (Ed.). The modern technology of radiation oncology. Madison, WI: Medical Physics Publishing, 2. ed., 2005.

3. Podgorsak, E. B. (Ed.). Radiation Oncology Physics: A Handbook for Teachers and Students. Vienna: International Atomic Energy Agency, p.657, 2005.

4. Bucci, M. K.; A. Bevan; et al. Advances in Radiation Therapy: Conventional to 3D, to IMRT, to 4D, and beyond. CA Cancer J. Clin., v.55, p.117-134, 2007.

5. ICRU. Report 50: International Commission on Radiation Units and Measurements ICRU Report 50. Prescribing, recording, and reporting photon beam therapy. Bethesda, MD, 1993.

6. ICRU. Report 62: Prescribing, recording and reporting photon beam therapy (supplement to ICRU report 50). Bethesda: International Commission on Radiation Units and Measurements. Bethesda, MD, 1999.

7. Clarkson, J.R. A note on depth doses in fields of irregular shapes. Br.J.Radiol. v. 14, p. 265, 1941.

8. Sharpe, M. B.; Batista, J.J. Dose calculation using convolution and superposition principles: The orientation of dose spread kernel in divergent x-ray beams. Med. Phys., v. 20, n. 6, p. 1685-1694, 1993.

9. Bourland, J. D.; Chaney, E. L. A finite-size pencil beam model for photon dose calculations in three dimensions. Med. Phys., v.19, n.6, p.1401-1412, 1992.

10. CWG. Intensity Modulated Radiation Therapy Collaborative Working Group. Intensity-modulated radiotherapy: current status and issues of interest. Int. J. Radiat. Oncol. Biol. Phys., v. 51, n. 4, p. 880-914, 2001.

11. Xuepeng S.; Xia P.; Yu N. Effects of the intensity levels and beam map resolutions on static IMRT plans. Med. Phys., v.31, n.9, p.2402-2411, 2004.

12. Venencia C.D.; Besa P. Commissioning and quality assurance for intensity modulated radiotherapy with dynamic multileaf collimator: Experience of the Pontificia Universidade Catolica de Chile. Journal of Applied Clinical Medical Physics, v.5, n.3, p.37-54, 2004.

13. Nomos. CORVUS 5.0 User Manual. Sewickley, PA: NOMOS Corporation, 2002. 
14. Nomos. Corvus Beam Utilities 6.0 User Manual. Cranberry, PA: NOMOS Corporation, 2004.

15. Ezzell, G. A.; Galvin, J. M.; et al. Guidance document on delivery, treatment planning, and clinical implementation of IMRT: report of the IMRT Subcommittee of the AAPM Radiation Therapy Committee. Med. Phys., v.30, n.8, p.2089-2115, 2003.

16. Emami, B.; Lyman, J.; et al. Tolerance of normal tissue to therapeutic irradiation. Int. J. Radiat. Oncol. Biol. Phys., v.21, n.1, p.109-122, 1991.

17. Kutcher, G. J. Quantitative plan evaluation: TCP/NTCP models. Front. Radiat. Ther. Oncol., v.29, p.67-80, 1996.

18. Fowler, J. F. The linear-quadratic formula and progress in fractionated radiotherapy. Br. J. Radiol., v.62, n.740, p.679-694, 1989.

19. Niemierko, A. Reporting and analyzing dose distributions: a concept of equivalent uniform dose. Med. Phys., v.24, n.1, p.103-110, 1997.

20. Kessler, M. L. Multimodality Imaging for Radiotherapy. Disponível em: $<$ http://149.142.114.117/aapmscc/2006 Midwinter PDFs/Marc\%20Kessler Multimodality\%20Imaging\%20for\%20Radiotherapy.pdf>. AAPM Winter School, 2006. Acesso em: dez. 2006.

21. Leter, E. M. ; Cademartiri, F.; et al. Four-dimensional multislice computed tomography for determination of respiratory lung tumor motion in conformal radiotherapy. Int. J. Radiat. Oncol. Biol. Phys., v.62, n.3, p.888-892, 2005.

22. Hoisak, J. D.; Sixel, K. E; et al. Correlation of lung tumor motion with external surrogate indicators of respiration. Int. J. Radiat. Oncol. Biol. Phys., v.60, n.4, p.1298-1306, 2004.

23. Plathow, C.; Ley, S.; et al. Analysis of intrathoracic tumor mobility during whole breathing cycle by dynamic MRI. Int. J. Radiat. Oncol. Biol. Phys., v.59, n.4, p.952-959, 2004.

24. Allen, A. M.; Siracuse, K. M.; et al. Evaluation of the influence of breathing on the movement and modeling of lung tumors. Int. J. Radiat. Oncol. Biol. Phys., v.58, n.4, p.1251-1257, 2004.

25. Hof, H.; Herfarth, K. K.; et al. The use of the multislice CT for the determination of respiratory lung tumor movement in stereotactic singledose irradiation. Strahlenther. Onkol., v.179, n.8, p.542-547, 2003.

26. Erridge, S. C.; Seppenwoolde, Y.; et al. Portal imaging to assess set-up errors, tumor motion and tumor shrinkage during conformal radiotherapy of non-small cell lung cancer. Radiother. Oncol., v.66, n.1, p.75-85, 2003. 
27. Remouchamps, V. M.; Letts, N.; et al. Initial clinical experience with moderate deep-inspiration breath hold using an active breathing control device in the treatment of patients with left-sided breast cancer using external beam radiation therapy. Int. J. Radiat. Oncol. Biol. Phys., v.56, n.3, p.704-715, 2003.

28. Cheung, P. C.; Sixel, K. E.; et al. Reproducibility of lung tumor position and reduction of lung mass within the planning target volume using active breathing control (ABC). Int. J. Radiat. Oncol. Biol. Phys., v.57, n.5, p.1437-1442, 2003.

29. Onishi, H., Kuriyama, K.; et al. A new irradiation system for lung cancer combining linear accelerator, computed tomography, patient self-breathholding, and patient-directed beam-control without respiratory monitoring devices. Int. J. Radiat. Oncol. Biol. Phys., v.56, n.1, p.14-20, 2003.

30. Giraud, P.; De Rycke, Y.; et al. Conformal radiotherapy (CRT) planning for lung cancer: analysis of intrathoracic organ motion during extreme phases of breathing. Int. J. Radiat. Oncol. Biol. Phys., v.51, n.4, p.1081-1092, 2001.

31. Shirato, H.; Shimizu, S.; et al. Physical aspects of a real-time tumor-tracking system for gated radiotherapy. Int. J. Radiat. Oncol. Biol. Phys., v.48, n.4, p.1187-1195, 2000.

32. Mah, D.; Hanley, J.; et al. Technical aspects of the deep inspiration breathhold technique in the treatment of thoracic cancer. Int. J. Radiat. Oncol. Biol. Phys., v.48, n.4, p.1175-1185, 2000.

33. Wong, J. W.; Sharpe, M. B.; et al. The use of active breathing control (ABC) to reduce margin for breathing motion. Int. J. Radiat. Oncol. Biol. Phys., v.44, n.4, p.911-919, 1999.

34. Hanley, J.; Debois, M. M.; et al. Deep inspiration breath-hold technique for lung tumors: the potential value of target immobilization and reduced lung density in dose escalation. Int. J. Radiat. Oncol. Biol. Phys., v.45, n.3, p.603-611, 1999.

35. Van Sornsen De Koste, J. R.; Lagerwaard, F. J.; et al. Tumor location cannot predict the mobility of lung tumors: a 3D analysis of data generated from multiple CT scans. Int. J. Radiat. Oncol. Biol. Phys., v.56, n.2, p.348-354, 2003.

36. Lee, S.; Yang, D. S.; et al. Development of respiratory motion reduction device system (RMRDs) for radiotherapy in moving tumors. Jpn J Clin Oncol, v.34, n.11, p.686-691, 2004. 
37. Kimura, T.; Hirokawa, Y.; et al. Reproducibility of organ position using voluntary breath-hold method with spirometer for extracranial stereotactic radiotherapy. Int. J. Radiat. Oncol. Biol. Phys., v.60, n.4, p.1307-1313, 2004.

38. Wagman, R.; Yorke, E.; et al. Respiratory gating for liver tumors: use in dose escalation. Int. J. Radiat. Oncol. Biol. Phys., v.55, n.3, p.659-668, 2003.

39. Ford, E. C.; Mageras, G. S.; et al. Evaluation of respiratory movement during gated radiotherapy using film and electronic portal imaging. Int. J. Radiat. Oncol. Biol. Phys., v.52, n.2, p.522-53, 2002.

40. Dawson, L. A.; Brock, K. K.; et al. The reproducibility of organ position using active breathing control ( $\mathrm{ABC}$ ) during liver radiotherapy. Int. J. Radiat. Oncol. Biol. Phys., v.51, n.5, p.1410-1421, 2001.

41. Mageras, G. S.; Yorke, E.; et al. Fluoroscopic evaluation of diaphragmatic motion reduction with a respiratory gated radiotherapy system. J. Appl. Clin. Med. Phys., v.2, n.4, p.191-200, 2001.

42. Kim, D. J.; Murray, B. R.; et al. Held-breath self-gating technique for radiotherapy of non-small-cell lung cancer: a feasibility study. Int. J. Radiat. Oncol. Biol. Phys., v.49, n.1, p.43-49, 2001.

43. Barker, J. L.; Garden Jr., A. S.; et al. Quantification of volumetric and geometric changes occurring during fractionated radiotherapy for head-andneck cancer using an integrated CT/linear accelerator system. Int $\boldsymbol{J}$ Radiat Oncol Biol Phys, v.59, n.4, p.960-970, 2004.

44. Gross, M. W.; Spahn, U.; et al. Assessment of the accuracy of a conventional simulation for radiotherapy of head and skull base tumors. Technol. Cancer Res. Treat., v.2, n.4, p.345-351, 2003.

45. Attix, F. H. Introduction to radiological physics and radiation dosimetry. New York, NY: John Wiley \& Sons, 1986.

46. ICRU. Report 37: International Commission on Radiation Units and Measurements ICRU Report 37. Stopping powers for electrons and positrons. Bethesda, MD, 1984.

47. Nahum, A. E. Water/air mass stopping power ratios for megavoltage photon and electron beams. Phys. Med. Biol., v.23, n.1, p.24-38, 1978.

48. IAEA. Absorbed Dose Determination in Photon and Electron Beams: An International Code of Practice. Technical Report Series TRS-277. Vienna, 1987.

49. Khan, F.M. The physics of radiation therapy. Baltimore, MD: Williams \& Wilkins, 1994. 
50. AAPM. American Association of Physicists in Medicine. A Protocol for clinical reference dosimetry of high energy photon and electron beams. AAPM TG-51. Med. Phys., v.26, p.1847-1870, 1999.

51. IAEA. Absorbed dose determination in external beam radiotherapy: An international code of practice for dosimetry based on standards of absorbed dose to water. Technical Report Series IAEA TRS-398. Vienna, 2001.

52. West, J.; Fitzpatrick, J. M.; et al. Comparison and evaluation of retrospective intermodality brain image registration techniques. J. Comput. Assist. Tomogr., v.21, n.4, p.554-566, 1997.

53. Radiation Therapy Oncology Group. RTOG 0225: A phase II study of intensity modulated radiation therapy (IMRT) \pm chemotherapy for nasopharyngeal cancer. Criado em: 21 mar. 2002. Disponível em: <http://www.rtog.org/>. Acesso em: abril 2005.

54. Castiglia, M. M. DICOM. Universidade Federal de São Paulo (UNIFESP), 1999. Disponível em: <http://www.virtual.epm.br/material/tis/currmed/temas/med5/med5t21999/dicom/dicom2.htm>. Acesso em: $15 \mathrm{dez}$. 2005.

55. Leybovich L.B.; Sethi A.; Dogan N. Comparison of ionization chambers of various volumes for IMRT absolute dose verification. Med. Phys., v.30, n.2, p.119-123, 2003.

56. Verhaegen, F.; Das, I. J.; et al. Monte Carlo dosimetry study of a $6 \mathrm{MV}$ stereotactic radiosurgery unit. Phys. Med. Biol., v.43, n.10, p.2755-2768, 1998.

57. Mohan, R.; Chui, C.; et al. Differential pencil beam dose computation model for photons. Med. Phys., v.13, n.1, p.64-73, 1986.

58. Bortfeld, T. Optimized planning using physical objectives and constraints. Semin. Radiat. Oncol., v.9, n.1, p.20-34, 1999.

59. Mageras, G. S.; Mohan, R. Application of fast simulated annealing to optimization of conformal radiation treatments. Med. Phys., v.20, n.3, p.639-647, 1993.

60. Mohan, R.; Mageras, G. S.; Baldwin B.; et al. Clinically relevant optimization of 3-D conformal treatments. Med. Phys., v.19, p.933-944, 1992.

61. Arfken, G. B.; Weber, H. J. The Method of Steepest Descents. Mathematical Methods for Physicists, 4. ed. San Diego, CA: Academic Press, p. 446-456, 1995.

62. Deasy, J. O. Multiple local minima in radiotherapy optimization problems with dose-volume constraints. Med. Phys., v.24, n.7, p.1157-1161, 1997. 
63. Kirkpatrick, S.; Gelatt, Jr. C. D.; Vecchi, M. P. Optimization by simulated annealing. Science, v.220, n.4598, p.671-680, 1983.

64. Metropolis, N.; Rosenbluth, A.; Rosenbluth, M.; Teller, A.; Teller, E. Equation of State Calculations by Fast Computing Machines. J. Chem. Phys., v.21, n.6, p. 1087-1092, 1953.

65. Aarts, E.H.; Korst, J.; Van Laarhoven, P.J. Simulated Annealing. E.H. Aarts, and J. K. Lenstra ed., Local Search in Combinatorial Optimization, chapter 4. John Wiley \& Sons, 1997.

66. Rosen, L; Lam, K. S.; et al. Comparison of simulated annealing algorithms for conformal therapy treatment planning. Int. J. Radiat. Oncol. Biol. Phys., v.33, n.5, p.1091-1099, 1995.

67. Hearn, S. D. O.; Kusalik, A. J.; et al. MolCom: a method to compare protein molecules based on 3-D structural and chemical similarity. Protein Engineering, v.16, n.2, p.169-178, 2003.

68. Solberg, T. D. Notas de aula: Treatment delivery systems 2 - Field shaping; design characteristics and dosimetry issues. UCLA. Medical Physics Division. 44 ${ }^{\text {th }}$ AAPM Annual Meeting Montreal, 2002.

69. Hammoud, R. On-board imaging system: Implementation and Quality assurance procedures. AAPM Summer School, 20006. Disponível em: <http://www.aapm.org/meetings/06SS/documents/HammoudQA.pdf>. Acesso em: 10 jan. 2007.

70. LoSasso, T. J. Quality Assurance of IMRT. In a practical guide to intensity-modulated radiation therapy. Madison, WI: Medical Physics publishing. p.147-167, 2003.

71. LoSasso, T.; Chui, C. S.; et al. Comprehensive quality assurance for the delivery of intensity modulated radiotherapy with a multileaf collimator used in the dynamic mode. Med. Phys., v.28, n.11, p.2209-2219, 2001.

72. Suchowerska, N.; Hoban, P.; Butson, M.; Davison, A.; Metcalfe, P. Directional dependence in film dosimetry: radiographic and radiochromic film. Phys. Med. Biol., v.46, p. 1391-1397, 2001.

73. Childress, N. L.; Rosen, I. I. Effect of processing time delay on the dose response of Kodak EDR 2 film. Med. Phys., v.31, n.8, p.2284-2288, 2004.

74. Butson, M. J.; Rozenfeld, A.; et al. A new radiotherapy surface dose detector:the MOSFET. Med Phys, v.23, n.5, p.655-658, 1996. 
75. Artignan, X.; Smitsmans, M. H.; et al. Online ultrasound image guidance for radiotherapy of prostate cancer: impact of image acquisition on prostate displacement. Int. J. Radiat. Oncol. Biol. Phys., v.59, n.2, p.595-601, 2004.

76. Vigneault, E.; Pouliot, J.; et al. Electronic portal imaging device detection of radiopaque markers for the evaluation of prostate position during megavoltage irradiation: a clinical study. Int $\boldsymbol{J}$ Radiat Oncol Biol Phys, v.37, n.1, p.205-212, 1997.

77. Guan, H.; Yin, F. F.; et al. Accuracy of inhomogeneity correction in photon radiotherapy from CT scans with different settings. Phys Med Biol, v.47, n.17, p.N223-231, 2002.

78. Villeirs, G. M.; De Meerleer, G. O.; et al. Magnetic resonance assessment of prostate localization variability in intensity-modulated radiotherapy for prostate cancer. Int. J. Radiat. Oncol. Biol. Phys., v.60, n.5, p.1611-1621, 2004.

79. Wolthaus, J. W.; Van Herk, M.; et al. Fusion of respiration-correlated PET and CT scans: correlated lung tumour motion in anatomical and functional scans. Phys. Med. Biol., v.50, n.7, p.1569-1583, 2005.

80. Little, D. J.; Dong, L.; et al. Use of portal images and BAT ultrasonography to measure setup error and organ motion for prostate IMRT: implications for treatment margins. Int. J. Radiat. Oncol. Biol. Phys., v.56, n.5, p.12181224, 2003.

81. Bouza, A. A. Desenvolvimento de uma técnica para fusão de imagens como complemento ao planejamento cirúrgico em condições estereotáxicas. 1999. Tese (Mestrado). Neurociências, Universidade Federal de São Paulo, São Paulo.

82. Maes, F. ; Collignon, A. ; et al. Multimodality image registration by maximization of mutual information. IEEE Trans. Med. Imaging, v.16, n.2, p.187-198, 1997.

83. Van Den Elsen, P. A.; Maintz, J. B.; et al. Geometry driven multimodality matching of brain images. Brain Topogr., v.5, n.2, p.153-157, 1992.

84. Varian Medical Systems. Clinac linear accelerators. Disponível em: $<$ http://www.varian.com/orad/index.html>. Palo Alto, CA. Acesso em: jun. 2005.

85. ICRP. International Commission on Radiological Protection series. ICRP publication 23. Reference man: anatomical, physiological and metabolic characteristics. Annals of ICRP, series 23, 1975. 
86. Ramaseshan, R.; Kohli, K. S.; Zhang, T. J.; et al. Performance characteristics of a microMOSFET as an in vivo dosimeter in radiation therapy. Phys. Med. Biol., v.49, n.17, p. 4031-4048, 2004.

87. Benson, C.; Price, R. A.; et al. Radiation-induced statistical uncertainty in the threshold voltage measurement of MOSFET dosimeters. Phys. Med. Biol., v.49, n. 14, p.3145-3159, 2004.

88. McKinley, A.F. Thermoluminescence Dosimetry. Medical Physics Handbook 5. Heyden \& Son Inc., London/Philadelphia/Rheine, 1981.

89. Abdel-Rahman, W.; Seuntjens, J. P.; Verhaegen, F.; Deblois, F.; Podgorsak, E. B. Validation of Monte Carlo calculated surface doses for megavoltage photon beams. Med. Phys., v. 32, n.1, p.286-298, 2005.

90. Astreinidou, E.; Bel, A.; et al. Adequate margins for random setup uncertainties in head-and-neck IMRT. Int. J. Radiat. Oncol. Biol. Phys., v.61, n.3, p.938-944, 2005.

91. McKenzie, A.; Mijnheer, B.; Herk, M. Margins for geometric uncertainty around organs at risk in radiotherapy. Radiotherapy and Oncology; v.62, p.299-307, 2002.

92. Xing, L.; Lin, Z.; et al. Dosimetric effects of patient displacement and collimator and gantry angle misalignment on intensity modulated radiation therapy. Radiotherapy and Oncology, v.56, p.97-108, 2000.

93. Manning, M.; Wu, Q.; Cardinale, R.; et al. The effect of setup uncertainty on normal tissue sparing with IMRT for head-and-neck cancer. Int. J. Radiat. Oncol. Biol. Phys., v.51, n.5, p.1400-1409, 2001.

94. Samuelsson, A.; Mercke, C.; Johansson, K. Systematic setup errors for IMRT in the head and neck region: effect on dose distribution. Radiotherapy and Oncology, v.66, p.303-311, 2003.

95. Shapiro, S. S.; Wilk, M. B. An Analysis of Variance Test for Normality. Biometrika, v.52, n.3/4, p.591-611, 1965.

96. Motta, V.; Wagner, M. Bioestatística. EDUCS, São Paulo, SP: Robe Editorial, 2003. (Estatística)

97. Stroom, J. C.; Heijmen, B. J. Geometrical uncertainties, radiotherapy planning margins, and the ICRU-62 report. Radiother Oncol, v.64, n.1, p.75-83, 2002.

98. Van Herk, M.; Bruce, A.; et al. Quantification of organ motion during conformal radiotherapy of the prostate by three dimensional image registration. Int. J. Radiat. Oncol. Biol. Phys., v.33, n.5, p.1311-1320, 1995. 
99. Cheung, T.; Butson, M. J.; et al. Visible dye light absorption properties of processed radiographic film. Phys. Med. Biol., v.46, n.8, p.N197-201, 2001.

100. Hadley, S. W.; Kelly, R.; Lam, K. Effects of immobilization mask material on surface dose. J. Appl. Clin. Med. Phys., v.6, n.1, p.1-7, 2005.

101. Poli, M. E.; Parker, W.; et al. An Assessment of PTV Margin Definitions for Patients Undergoing Conformal 3D External Beam Radiation Therapy for Prostate Cancer Based on an Analysis of 10,327 Pretreatment Daily Ultrasound Localizations. Int. J. Radiat. Oncol. Biol. Phys., v.67, n.5, p.1430-1437, 2007.

102. Pilepich, M. V.; Prasad, S. C.; et al. Computed tomography in definitive radiotherapy of prostatic carcinoma, part 2: definition of target volume. Int. J. Radiat. Oncol. Biol. Phys., v.8, n.2, p.235-239, 1982.

103. Ten Haken, R. K.; Forman, J. D.; et al. Treatment planning issues related to prostate movement in response to differential filling of the rectum and bladder. Int. J. Radiat. Oncol. Biol. Phys., v.20, n.6, p.1317-1324, 1991.

104. Schild, S. E.; Casale, H. E.; et al. Movements of the prostate due to rectal and bladder distension: implications for radiotherapy. Med. Dosim., v.18, n.1, p.13-15, 1993.

105. Balter, J. M.; Chen, G. T.; et al. Online repositioning during treatment of the prostate: a study of potential limits and gains. Int. J. Radiat. Oncol. Biol. Phys., v.27, n.1, p.137-143, 1993.

106. Balter, J. M.; Sandler, H. M.; et al. Measurement of prostate movement over the course of routine radiotherapy using implanted markers. Int. J. Radiat. Oncol. Biol. Phys., v.31, n.1, p.113-118, 1995.

107. Crook, J. M.; Raymond, Y.; et al. Prostate motion during standard radiotherapy as assessed by fiducial markers. Radiother. Oncol., v.37, n.1, p.35-42, 1995.

108. Roeske, J. C.; Forman, J. D.; et al. Evaluation of changes in the size and location of the prostate, seminal vesicles, bladder, and rectum during a course of external beam radiation therapy. Int. J. Radiat. Oncol. Biol. Phys., v.33, n.5, p.1321-1329, 1995.

109. Beard, C. J., P. Kijewski, et al. Analysis of prostate and seminal vesicle motion: implications for treatment planning. Int $\boldsymbol{J}$ Radiat Oncol Biol Phys, v.34, n.2, Jan 15, p.451-8. 1996.

110. Althof, V. G.; Hoekstra, C. J.; et al. Variation in prostate position relative to adjacent bony anatomy. Int. J. Radiat. Oncol. Biol. Phys., v.34, n.3, p.709-715, 1996. 
111. Rudat, V.; Schraube, P.; et al. Combined error of patient positioning variability and prostate motion uncertainty in 3D conformal radiotherapy of localized prostate cancer. Int. J. Radiat. Oncol. Biol. Phys., v.35, n.5, p.1027-1034, 1996.

112. Melian, E.; Mageras, G. S.; et al. Variation in prostate position quantitation and implications for three-dimensional conformal treatment planning. Int. J. Radiat. Oncol. Biol. Phys., v.38, n.1, p.73-81, 1997.

113. Tinger, A.; Michalski, J. M.; et al. A critical evaluation of the planning target volume for 3-D conformal radiotherapy of prostate cancer. Int. J. Radiat. Oncol. Biol. Phys., v.42, n.1, p.213-221, 1998.

114. Antolak, J. A.; Rosen, L; et al. Prostate target volume variations during a course of radiotherapy. Int. J. Radiat. Oncol. Biol. Phys., v.42, n.3, p.661672, 1998.

115. Dawson, L. A.; Mah, K.; et al. Target position variability throughout prostate radiotherapy. Int. J. Radiat. Oncol. Biol. Phys., v.42, n.5, p.1155-1161, 1998.

116. Zelefsky, M. J.; Crean, D.; et al. Quantification and predictors of prostate position variability in 50 patients evaluated with multiple CT scans during conformal radiotherapy. Radiother. Oncol., v.50, n.2, p.225-234, 1999.

117. Huang, E.; Dong, L.; et al. Intrafraction prostate motion during IMRT for prostate cancer. Int. J. Radiat. Oncol. Biol. Phys., v.53, n.2, p.261-268, 2002.

118. Trichter, F.; Ennis, R. D. Prostate localization using transabdominal ultrasound imaging. Int. J. Radiat. Oncol. Biol. Phys., v.56, n.5, p.12251233, 2003.

119. Chandra, A.; Dong, L.; et al. Experience of ultrasound-based daily prostate localization. Int. J. Radiat. Oncol. Biol. Phys., v.56, n.2, p.436-447, 2003.

120. Fung, A. Y.; Enke, C. A.; et al. Prostate motion and isocenter adjustment from ultrasound-based localization during delivery of radiation therapy. Int. J. Radiat. Oncol. Biol. Phys., v.61, n.4, p.984-992, 2005.

121. Madsen, B. L.; Hsi, R. A.; et al. Intrafractional stability of the prostate using a stereotactic radiotherapy technique Int. J. Radiat. Oncol. Biol. Phys., v.57, n.5, p.1285-1291, 2003.

122. Molloy, J. A.; Srivastava, S.; et al. A method to compare supra-pubic ultrasound and CT images of the prostate: technique and early clinical results. Med. Phys., v.31, n.3, p.433-442, 2004. 
123. Liu, Y. M.; Ling, S.; et al. Prostate movement during simulation resulting from retrograde urethrogram compared with "natural" prostate movement. Int. J. Radiat. Oncol. Biol. Phys., v.60, n.2, p.470-475, 2004.

124. Roberge, D.; Corns, R.; et al. Prostate and seminal vesicle displacement following urethrography: a computed tomography-based study. Cancer Radiother., v.9, n.3, p.148-151, 2005.

125. Stroom, J. C.; Koper, P. C.; et al. Internal organ motion in prostate cancer patients treated in prone and supine treatment position. Radiother. Oncol., v.51, n.3, p.237-248, 1999.

126. Radiation Therapy Oncology Group. RTOG 01-26: A phase III randomized study of high dose 3D-CRT versus standard dose 3D-CRT in patients treated for localized prostate cancer. Disponível em: $<$ http://www.rtog.org/members/protocols/0126/p0126.pdf $>$. Criado em: 21 mar. 2002. Acesso em: 20 out. 2004.

127. Kitamura, K.; Shirato, $\mathrm{H}$.; et al. Three-dimensional intrafractional movement of prostate measured during real-time tumor-tracking radiotherapy in supine and prone treatment positions. Int. J. Radiat. Oncol. Biol. Phys., v.53, n.5, p.1117-1123, 2002.

128. Nederveen, A. J.; Van Der Heide, U. A.; et al. Measurements and clinical consequences of prostate motion during a radiotherapy fraction. Int. J. Radiat. Oncol. Biol. Phys., v.53, n.1, p.206-214, 2002.

129. Lee, N.; Chuang, C.; et al. Skin toxicity due to intensity-modulated radiotherapy for head-and-neck carcinoma. Int. J. Radiat. Oncol. Biol. Phys., v.53, n.3, p.630-637, 2002.

130. Thomas, S. J.; Hoole, A. C. The effect of optimization on surface dose in intensity modulated radiotherapy (IMRT). Phys Med Biol, v.49, n.21, Nov 7, p.4919-4928, 2004.

131. Rabinovich, S. Measurements errors: theory and practice. New York, N.Y.: American Institute of Physics, 1993.

132. Alexander Volya, H. E. Dynamic polarization effects in Coulomb excitation. J. Opt. B.: Quantum Semiclass, Oct 5, p.S407-S412, 2003.

133. Fano, U. Note on the Bragg-Gray cavity principle for measuring energy dissipation. Radiat. Res., v.1, n.3, p.237-240, 1954.

134. Havercroft, J. M.; Klevenhagen, S. C. Ion recombination corrections for plane-parallel and thimble chambers in electron and photon radiation. Phys. Med. Biol., v.38, n.1, p.25-38, 1993. 
135. Palm, A.; Mattsson, O. Experimental study on the influence of the central electrode in Farmer-type ionization chambers. Phys. Med. Biol., v.44, n.5, p.1299-1308, 1999.

136. Spencer, L. V.; Attix, F. H. A cavity ionization theory including the effects of energetic secondary electrons. Radiology, v.64, n.1, p.113, 1955.

137. Spencer, L. V.; Attix, F. H. A theory of cavity ionization. Radiat. Res., v.3, n.3, p.239-254, 1955.

138. Sanchez-Doblado, F.; Andreo, P.; et al. Ionization chamber dosimetry of small photon fields: a Monte Carlo study on stopping-power ratios for radiosurgery and IMRT beams. Phys Med Biol, v.48, n.14, Jul 21, p.20812099, 2003.

139. Rosenfeld, A.; Carolan, M. G.; et al. MOSFET dosimeters: The role of encapsulation on dosimetric characteristics in mixed gamma-neutron and megavoltage $x$-ray fields. IEEE Transactions on Nuclear Science, v.42, n.6, p.1870-1877, 1995.

140. Soubra, M.; Cygler, J.; et al. Evaluation of a dual bias metal-oxide-silicon semiconductor field effect transistor detector as a radiation dosimeter. Med. Phys., v.21, n.4, p.567-572, 1994.

141. Swart, J. W. Aula 5: Potenciais de Contato e Introdução ao MOSFET. Unicamp. Disponível em:

$<$ http://www.ccs.unicamp.br/cursos/ie733/aula5 contatos MOSFET.ppt\#25 6,1,IE733>. Acesso em: Jan. 2006.

142. Karzmark, C. J.; Fowler, J. F.; et al. Problems of reader design and measurement error in lithium fluoride thermoluminescent dosimetry. Int. J. Appl. Radiat. Isot., v.17, n.3, p.161-173, 1966.

143. Knoll, G. F. Radiation Detection and Measurement. 2. ed. New York, N.Y.: John Wiley \& Sons, 1989.

144. Fowler, J. F.; ATTIX, F. H. Radiation Dosimetry, v. 2, 2. ed. New York, N.Y.: Academic Press, 1966.

145. Horowitz, Y. S. Thermoluminescence and Thermoluminescent Dosimetry, v. 1, Boca Raton, FL: CRC Press, 1984.

146. Stroom, J. C.; Heijmen, B. J. Limitations of the planning organ at risk volume (PRV) concept. Int. J. Radiat. Oncol. Biol. Phys., v.66, n.1, p.279-286, 2006. 